\title{
EMBRACING THE BLOCK
}

Adapting European Perimeter-Block Housing for use in New Zealand's Cities

BY

DANIEL WEZEL

\begin{abstract}
A Thesis
Submitted to the Victoria University of Wellington in partial fulfilment of the requirements for the degree of

Master of Architecture (Professional).
\end{abstract}

Victoria University of Wellington

2020 


\section{ACKNOWLEDGEMENTS}

I'd like to thank my supervisor, Chris

Macdonald, for his unfaltering support, advise and feedback. His advanced knowledge in the field of urban design has been incredibly beneficial to the research topic and it's subsequent studies.

I'd also like to thank my parents, Caron and Carl, who's moral and financial support over the five-or-more years of study cannot go unrecognised and will forever be held over me. 


\section{ABSTRACT}

With an estimated housing shortage of 150,000 homes in 2020, New Zealand is in urgent need of a new housing solution to keep up with demand. Given that families make up $70 \%$ of New Zealand households, attracting families towards inner-city living is the key to decreasing housing shortage and managing urban growth. The research investigates a housing model that is underutilised in New Zealand, but has the potential to accommodate families in high-density central city developments.

The European Perimeter Block (EPB) is a housing model prevalent in Europe's largest cities, providing highly liveable urban housing at relatively high densities. Analysis of traditional
EPB literature, contemporary EPB precedents and best-practice apartment design is combined with analysis of the New Zealand context to develop an extensive list of design strategies and criteria. This list provides a framework for the design of EPB housing in New Zealand cities. A subsequent design case study tests the applicability of the design strategies and criteria on a successful high-density housing development in Auckland's CBD, with a focus on providing an attractive inner-city lifestyle for New Zealand families. The resulting outcome is a concise set of design criteria and a repertoire of strategies to usefully inform the design of an attractive EPB housing development in New Zealand cities. 


\section{TABLE OF CONTENTS}

\section{CHAPTER ONE}

02 Introduction

$04 \quad$ Research Methodology

$06 \quad$ Perimeter-Blocks in New Zealand?

\section{CHAPTER TWO}

10 European Perimeter Block Housing

$21 \quad$ New Zealand Urban Living

\section{CHAPTER THREE}

30 Contemporary EPB Body of Work

56 Apartment Design Attribute Studies

\section{CHAPTER FOUR}

72 Urban Residential Best-Practice

$80 \quad$ Availability of Sites in New Zealand

\section{CHAPTER FIVE}

100 Adapted Design Strategies \& Criteria

108 Site Selection \& Master-plan

\section{CHAPTER SIX}

122 Design Case Study
154 Design Evaluation

\section{CHAPTER SEVEN}

170 Conclusions 


\section{CHAPTER ONE}

Thesis Introduction, Methodology, and Feasibility of Research Question 


\section{RESEARCH QUESTION}

How can European Perimeter-Block housing be adapted to provide an attractive housing choice for NZ cities?

\section{OPPORTUNITY}

The European Perimeter-Block (EPB) is a housing typology prominent in most of Europe's largest cities.

It was formalized during the 19th century, mostly due to new urban planning legislation and provides highly liveable urban housing at a relatively high density. Traditional EPB housing is identified by a continuous row of low-to-mid-rise buildings along the perimeter of an urban block, defining the street edge and consequently forming a private courtyard in the centre of the block.

In most cases, the central courtyard provides the block's residents with a communal green-space to be used for active recreation and as a pleasant, verdant outlook from their apartments. The nature of its design means that each apartment receives sufficient natural light and exhibits a distinct separation between public, private, and communal space. The ground floor is typically allocated to commercial establishments, which improves street appeal and removes the potential privacy issues associated with ground floor living.

\section{APPLICATION}

European Perimeter-block housing is poorly represented in NZ cities, and current high-density housing options are deterring families from living in dense urban areas. Families make up 70\% of New Zealand households and are the most demanding occupants of high-density housing options. With New Zealand's housing shortage estimated to be around 150,000 homes in the middle of 2020, the need for higher-density homes is greater than ever. Providing a highdensity housing option which appeals to NZ families is key to meeting or exceeding housing demand and managing urban growth.

One of the greatest complaints against higher-density housing in New Zealand is the inability of the outdoor spaces to meet 
the needs of its residents. EPB housing provides the opportunity for coordinated outdoor green spaces in large-scale planned developments, with a density that rivals, and even exceeds, that of current mediumto-high density developments. This paves the way for urban housing that not only increases urban density, but appeals to the lifestyles of New Zealand families.

The ideal locations for EPB housing developments are Brownfield land in close proximity to the urban core. This eliminates the possibility of replicating traditional EPB housing with their beautifully consistent street frontages and orthogonal grid layout within close proximity to the urban core. Therefore, to maintain a connection with the inner-city, EPB housing in New Zealand must be provided as standalone developments.

Contemporary examples of EPB housing are much more relevant precedents to a New Zealand application because they are predominantly standalone designs and are designed in response to modern expectations and technology. These examples of contemporary EPB developments are analysed, assessed and adapted to best suit the New Zealand context.

\section{INTENTION}

An investigation, through design, is carried out to determine how the EPB might be adapted to provide an attractive urban housing alternative for New Zealand families. Attractiveness is assessed against a range of criteria which have been established through literature review and analysis of existing precedents.

The design case study tests the applicability of selected traditional and contemporary European Perimeter-block housing characteristics in the New Zealand context.

The outcome of this thesis is a set of design criteria and a repertoire of strategies that usefully inform EPB housing development in New Zealand. 


\section{RESEARCH METHODOLOGY}

The Thesis applies an established European housing model to a New Zealand context. To do this effectively, the model and the context are analysed individual and subsequently the model is adapted for NZ conditions.

A step-by-step methodology is used to combine the knowledge from both the EPB model and the NZ context to identify and test a set of design criteria and strategies.

\section{STEP ONE}

Develops a list of design principles, strategies and criteria for the design of European perimeter-block housing based on a review of relevant literature and analysis of a contemporary body of work.

\section{STEP TWO}

Develops a list of design opportunities, constraints and criteria for the design of urban housing within a New Zealand context, based on a review of relevant literature, best-practice residential design and an aerial survey of available sites.

\section{STEP THREE}

Compares and contrasts the outcomes from the previous two steps to establish a refined list of adapted strategies and criteria which provide a baseline framework to take forward to the design phase of the thesis.

\section{STEP FOUR}

Tests the adapted design strategies and criteria within a design case study. The design process is iterative with each iteration critiqued and evaluated against the strategies and criteria while continuous reflection governs the development of one iteration to the next.

\section{STEP FIVE}

Indicates the culmination of the design phase, in which an evaluation of the design outcome(s) refines and finalises the list of design strategies and criteria. A final discussion then reflects on the successes, failures and points of interest that have emerged from the design development. To conclude, the research questions are answered, followed by the key findings, limitations, implications and finally a closing statement. 


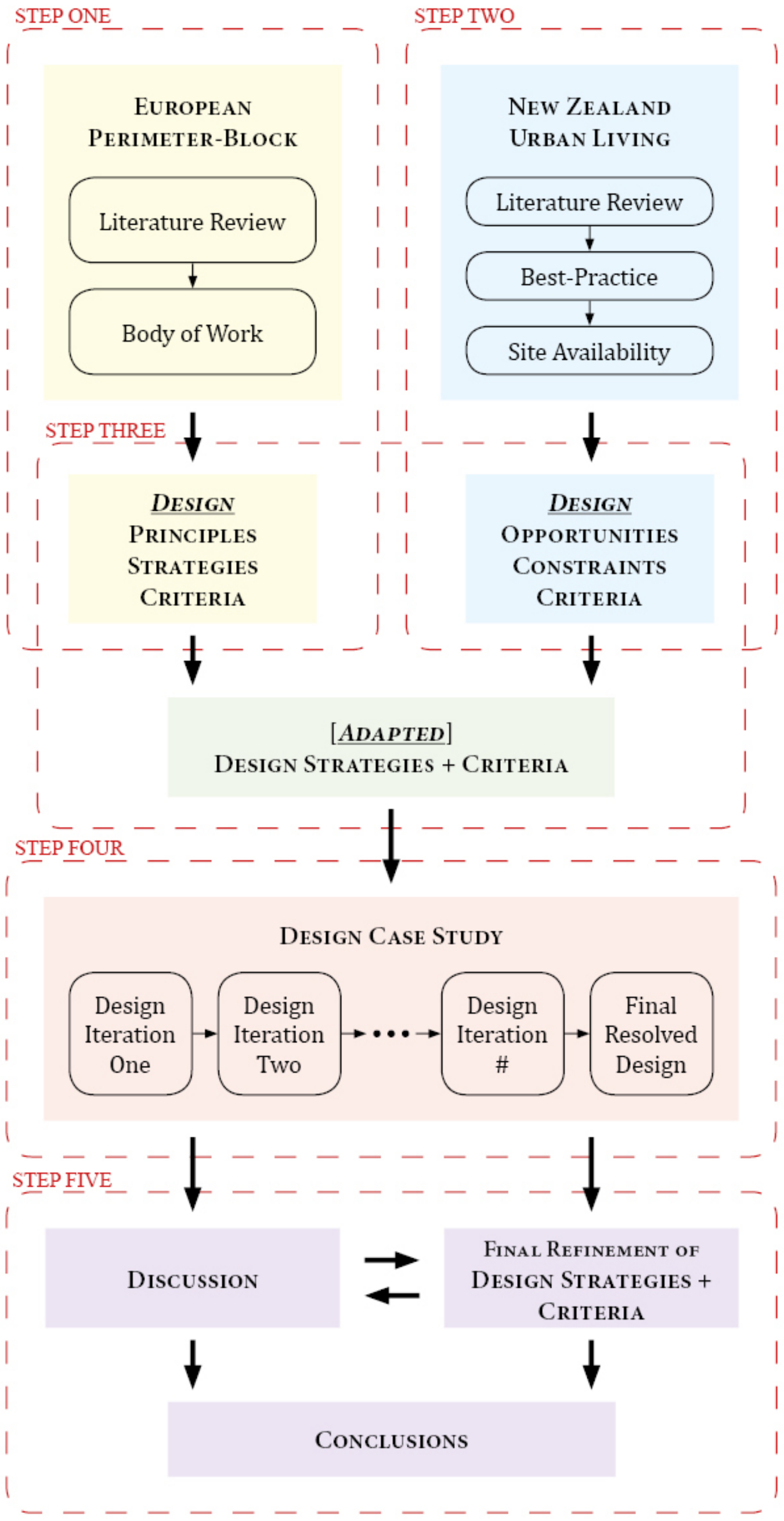




\section{EPB HOUSING IN NEW ZEALAND}

To ensure that this research is worthwhile and the outcome plausible, I first needed to confirm that the European PerimeterBlock housing model did not already exist in New Zealand. A desktop survey of aerial photography for New Zealand's three main cities uncovered the following buildings or developments. On first inspection, these findings do resemble the EPB housing model. This is particularly evident in the shape of their floor plan with central open space. However, after further analysis, each image shows only an approximation of EPB housing with different building types and functional programmes. Many of these approximations are made up of multiple separate buildings with gaps between, forming only a superficial resemblance to the perimeter-block form.
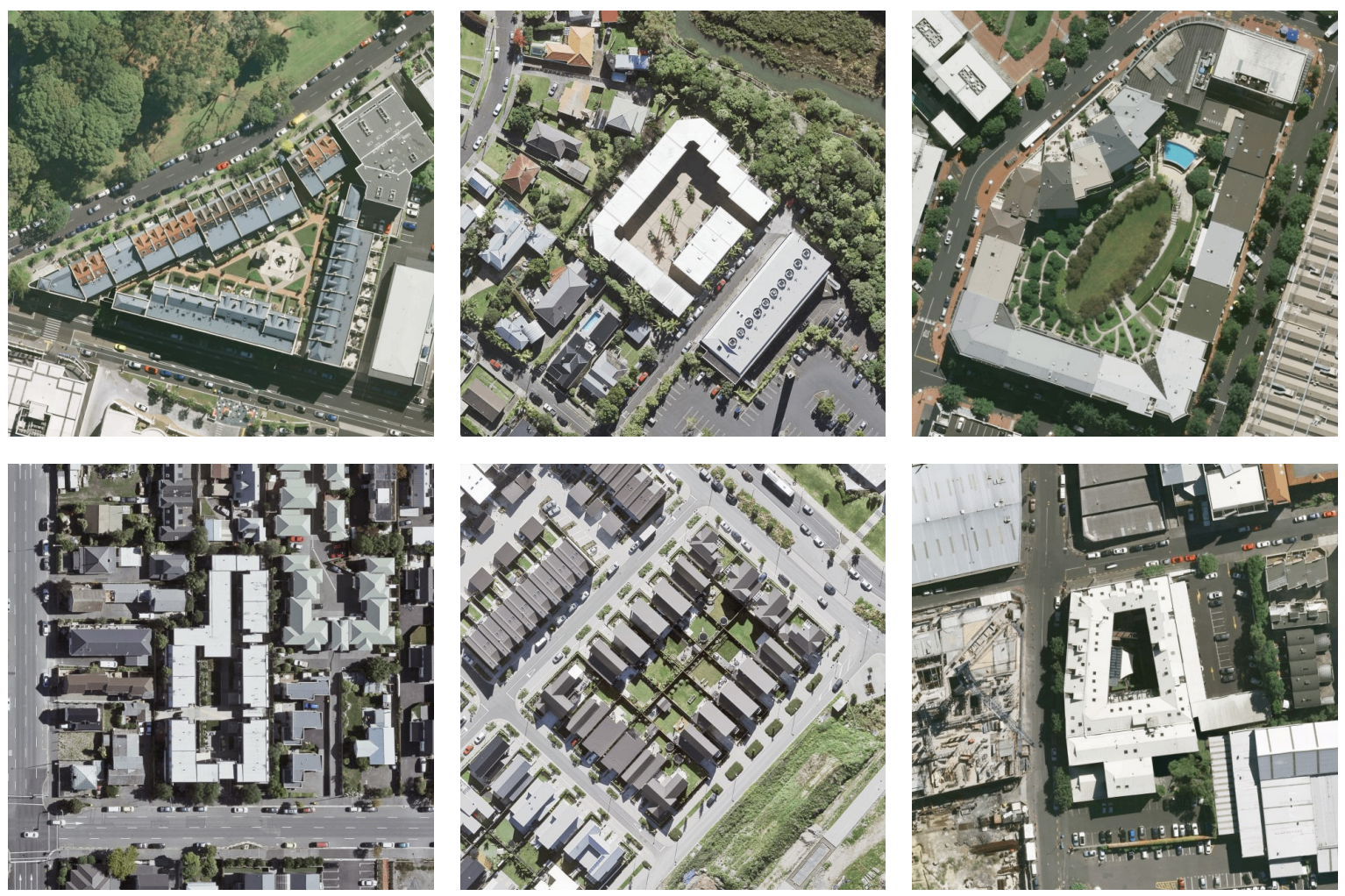

Figure 1.02 - Aerial images of NZ buildings that resemble EPB's 

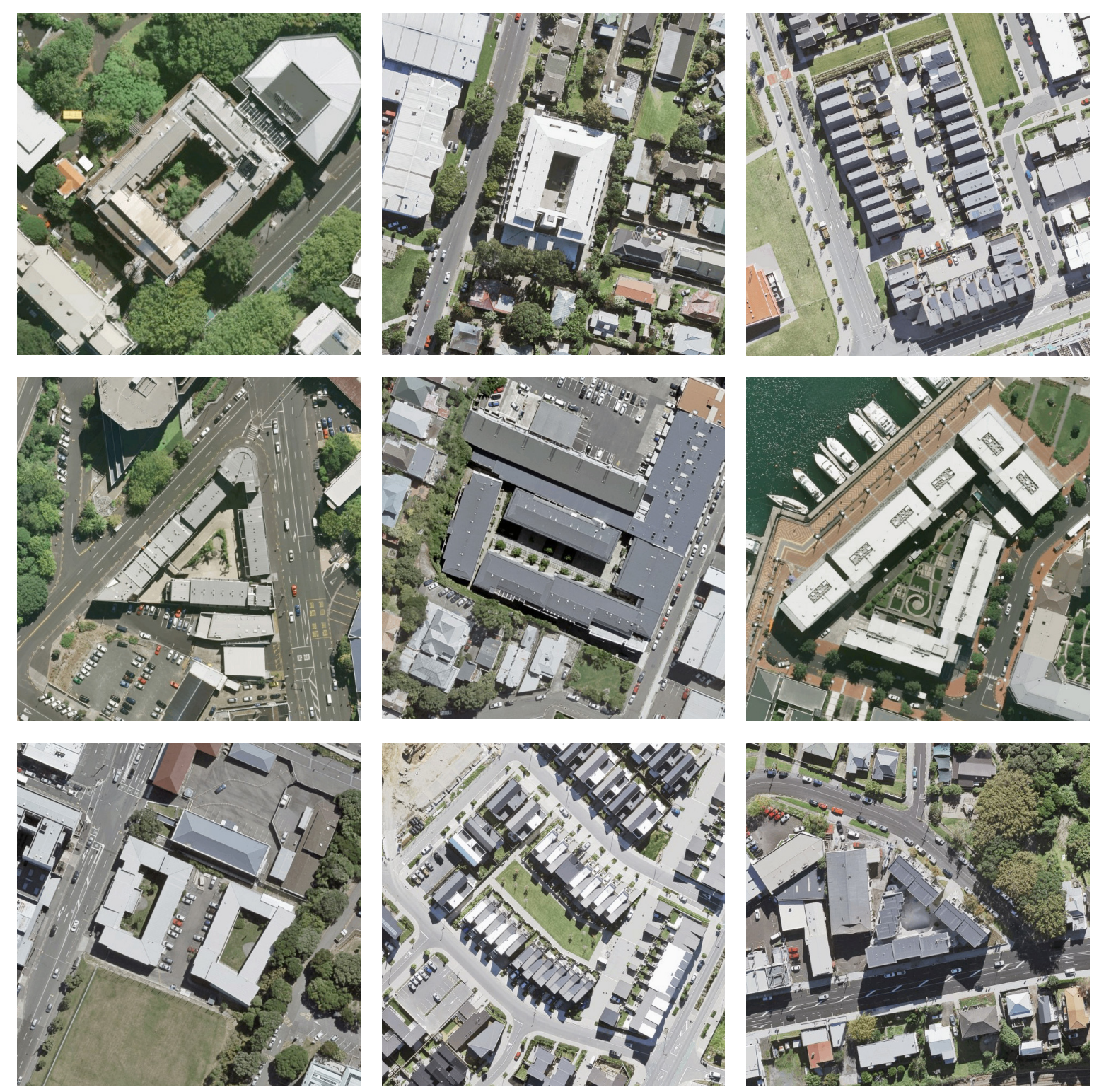

Figure 1.03 - Aerial images of NZ buildings that resemble EPB's 


\section{I.}

\section{ar.}

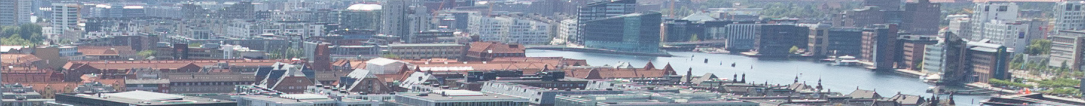

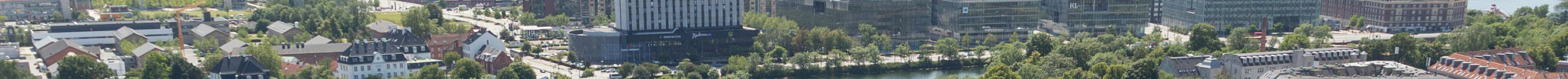

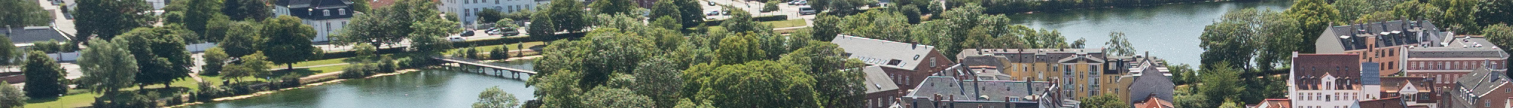

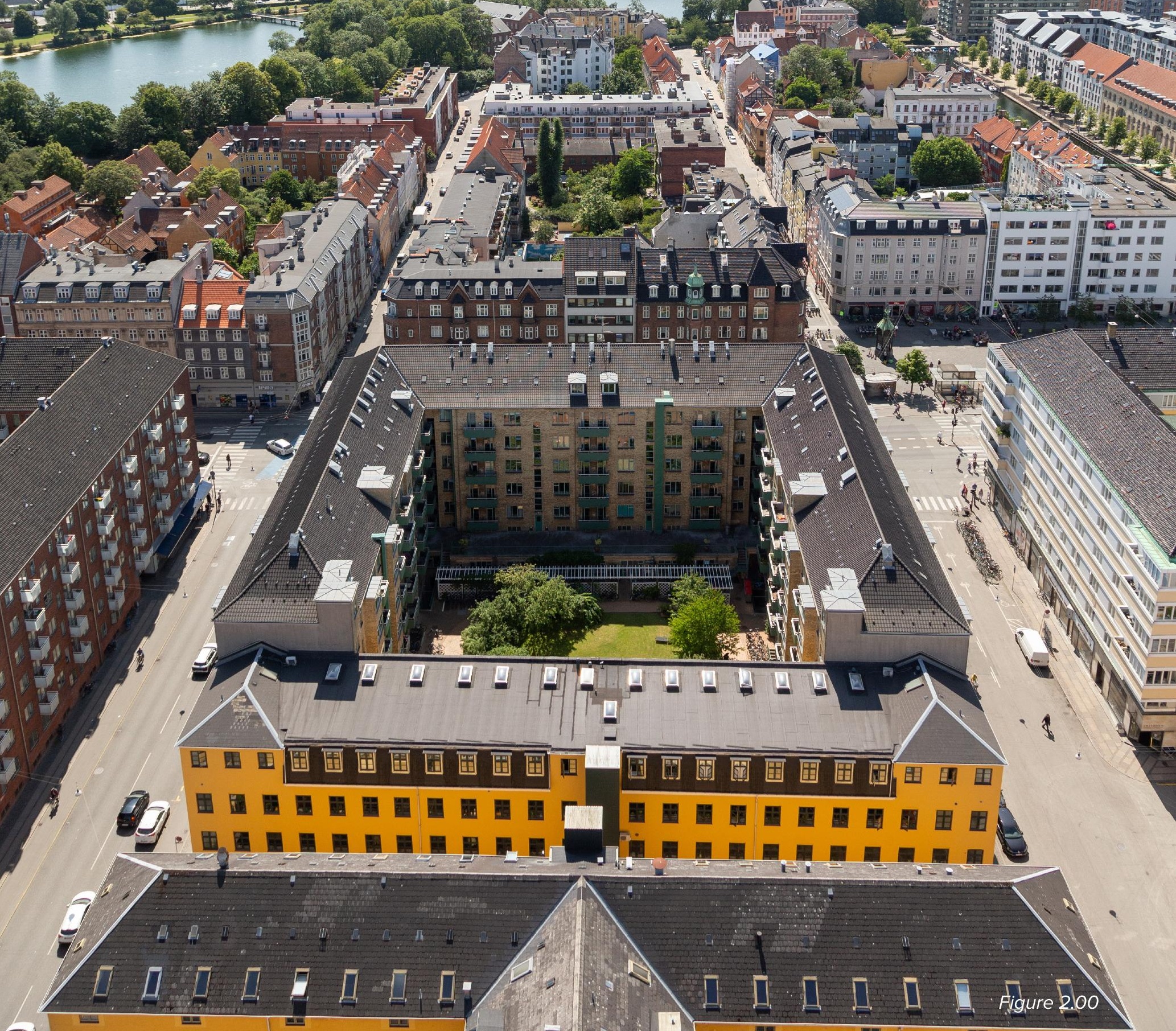


CHAPTER TWO

Background Information on Perimeter-Blocks and New Zealand Urban Living 
European Perimeter-Block:

\section{LITERATURE REVIEW / BACKGROUND}

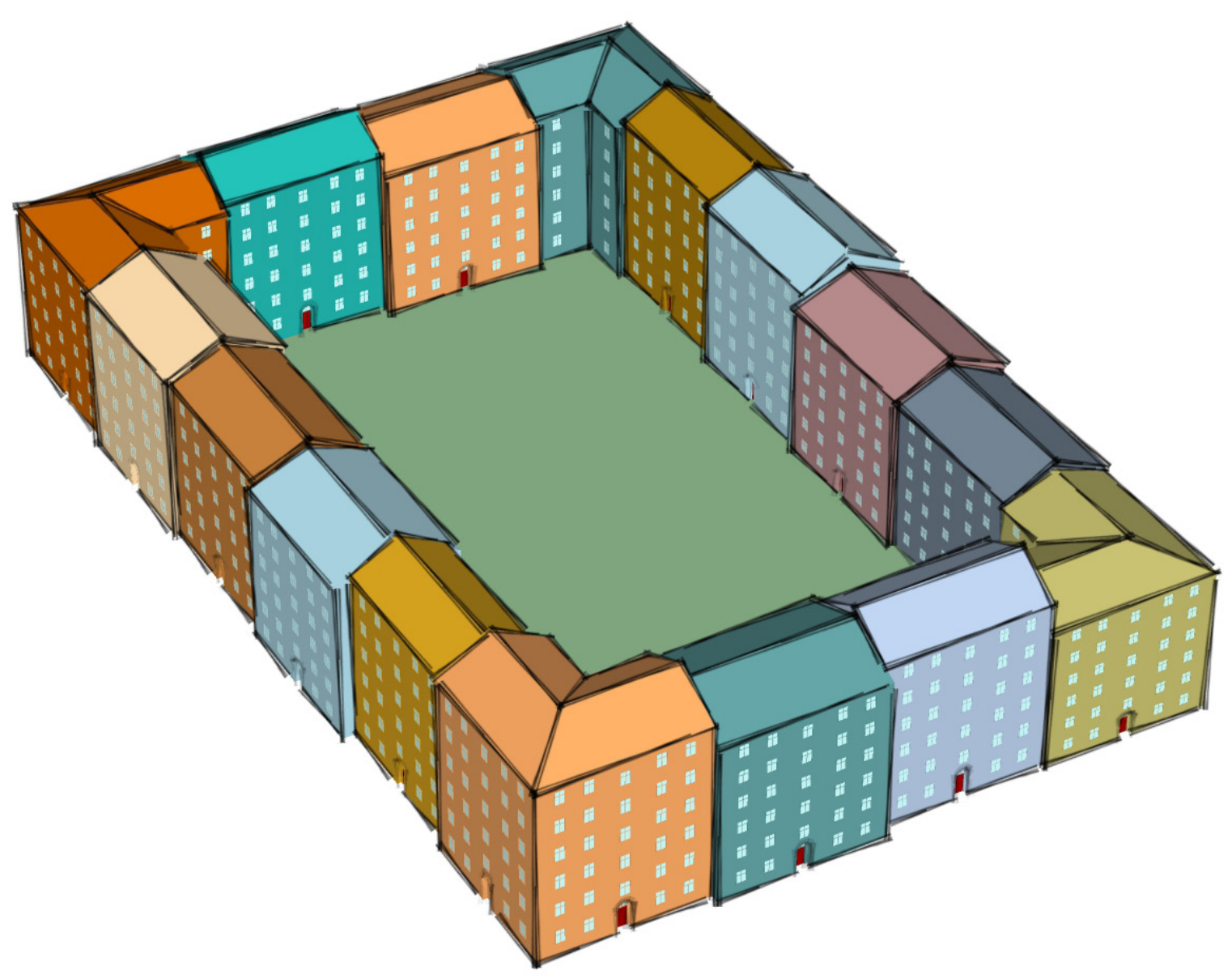

Figure 2.01 - Indicative isometric of tenement style EPB housing 
The European Perimeter-Block (EPB) is an urban housing model prevalent throughout Europe and is often considered the defining characteristic of the classic European City. While many variations exist, the predominant identifier of the EPB is a linked row of buildings lining the entire edge of a city block, defining the street and forming a perimeter around a central courtyard. Originally, the perimeter was made up of linked terrace housing, however in later years this was substituted for tenement housing, ultimately increasing the number of dwellings per block. (Leupen, 2011)

While Perimeter-Block-style urban housing models did exist during the Middle Ages and through the renaissance, the EPB as it is known today was mostly formalised during the 19th century in response to inadequate urban living conditions. A spike in European city population caused an increase in housing density and the infill of existing open space, resulting in compact urbanliving conditions which lacked adequate ventilation and natural light. This facilitated the spread of diseases, increased fire risk and minimised accessibility. In a bid to improve the living conditions within urban Europe, the governing bodies established city planning regulations, which were predominantly absent until this point, to widen the streets and introduce perimeterblock developments to urban Europe (Edwards, 2006).

The EPB model was a result of "climatic influence, of social structure and an effective union between land utilization and wider cultural values". (Edwards, 2006, Pg. 187). Dimensions were adjusted to maximise natural ventilation and sunlight; the height of the perimeter in relation to the courtyard was crucially managed to provide the perfect balance between favourable living conditions and housing density. Orientation and building design was also adjusted to balance light and airflow. Orienting the block parallel to the prevailing winds improved ventilation. Orienting parallel to the north/south axis improved sunlight penetration and also provided equal amounts of sunshine to the east and west facades of the block (Edwards, 2006). 


\section{CHARACTERISTICS}

\section{LOW-RISE HIGH DENSITY}

The EPB model is a very efficient method for providing similar density to other housing models at a much friendlier urban scale. Used well, it results in a better connection to the urban context. Heath (2010) discusses how two sites of identical plot-ratios could accommodate either a 10 -storey tower block in the middle of the site with open space amenity surrounding it, or a 3-storey perimeter block with open space in the centre of the block. Both options provide the same housing density and similar green-space amenity. However, Heath claims the quality of life is better for those living in the low-rise EPB option.

\section{EXPLICIT PUBLIC/PRIVATE DISTINCTION}

In all forms of urban housing, developments typically benefit from orienting their front and back in relation to external public and private spaces. Forming a connection with the public realm while maintaining an acceptable level of privacy is key to urban living. EPB housing is recognised as a reliable method for providing an explicit distinction between public and private space. (Heath, 2010). In a city of countless adjacent EPB developments, this distinction is seamless and consistent. Fronts are oriented towards the public street and other housing fronts. Backs are oriented towards a semi-private courtyard and other housing backs. Putting the semi-private spaces at the back gives the occupants greater control over their environments, without compromising the connection to the public realm at the front of the building. (Bentley, 1985).

\section{SEMI-PRIVATE GREEN SPACE AMENITY}

The central courtyard, which is arguably the primary identifying feature of the EPB model, forms a relatively large open space within the confines of a single EPB development. Varying uses for the courtyard existed, from large semi-private communal gardens with playgrounds, to private single plots dividing up the courtyard, separated by walls or fences (Diehl, 1981). The most 
desirable form of EPB central courtyard was one that was fully enclosed, shielded from the activity of the surrounding streets, with communal open green space in the centre, providing fresh air and sunlight to the adjacent dwellings (Nußbaum, 1904). In this case, the space was often used by the residents of the development for active recreation, gardens, and mostly just a pleasant verdant outlook from the units.

\section{DOUBLE-ASPECT APARTMENT OUTLOOK}

A fortunate outcome of most EPB housing designs is that each dwelling faces both into the courtyard and out to the street simultaneously. This isn't always the case, but it is a popular and advantageous variation of EPB housing. The benefits of this in regard to public and private space has already been covered, however the benefits not yet mentioned include sufficient cross-ventilation and access to natural light. Having two external walls, as opposed to just one, allows better access to external windows, which is particularly helpful for providing highly liveable bedrooms and living spaces within an efficient floor plan. Double-aspect apartments are also more forgiving when used in a perimeter block because regardless of the position within the block, at least one façade will receive some sun and sufficient natural light (Lewis, 2005).

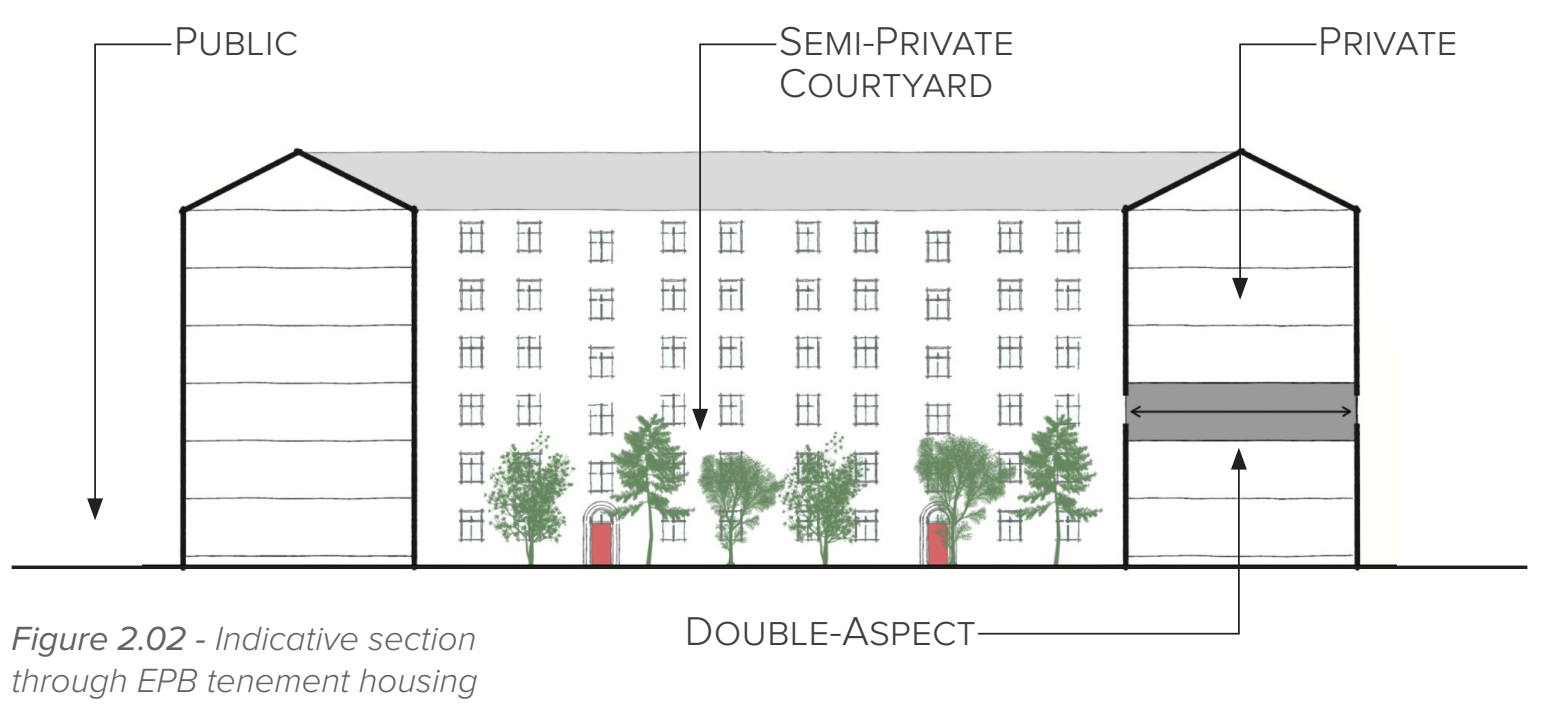




\section{FLEXIBILITY OF DESIGN AND USE}

EPB housing provides a flexibility not seen in other residential building types.

The nature of its design means that it can accommodate various housing types, uses and tenures. EPB developments, as mentioned, are typically made up of multiple terrace or tenement buildings. So the integration of multiple housing types and commercial uses within a single development is not difficult or uncommon. And various housing tenures are more easily achievable due to the building divisions throughout the block. (Lewis, 2005).

In addition to flexible building function, variation in EPB density can be controlled by simple dimensional changes. (Lewis, 2005). Increasing the building height or decreasing the width of the entire block can have a large impact on density, at the expense of courtyard size and sunlightpenetration. The ground floor of EPB buildings were often rezoned for retail use to activate the street-front and eliminate the potential privacy issues for the ground floor dwellings.
EPB developments are readily adapted to urban context. This is because they are typically the result of street-based planning, which helped to regulate the form, size and hierarchy of urban buildings (Edwards, 2006). In other words, a continuous street wall is one of the defining characteristics of the building type. Also, given that the first EPB developments were just reformed row or tenement housing, it is no surprise that EPB housing shares similar sizes and designs. This also contributes to visual cohesion at an urban scale

\section{ACCESSIBILITY TO APARTMENTS AND AMENITY}

Access to the individual units of an EPB development differed based on the housing type. However, there were typically multiple entrances along the public facades of the block, accessed directly from the street. In low-rise terrace-style houses, the entrance to each dwelling was located at ground floor, directly off the street with a back door to access the central courtyard. Diehl (1981) and Bentley (1985) both mention examples of medium-rise tenement-style 
EPB developments. Arguably, their shared stairwells constitute the ideal form of vertical circulation. A central staircase accessed from the street served two units per floor, maintaining the double-aspect outlook of the apartments and providing access to between six and ten dwellings, within an acceptable number of floors.

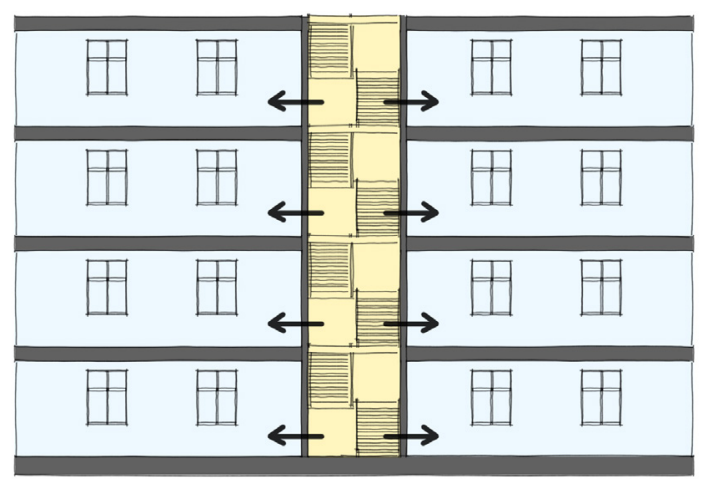

Figure 2.03 - Access to apartments via semi-private shared stairwell

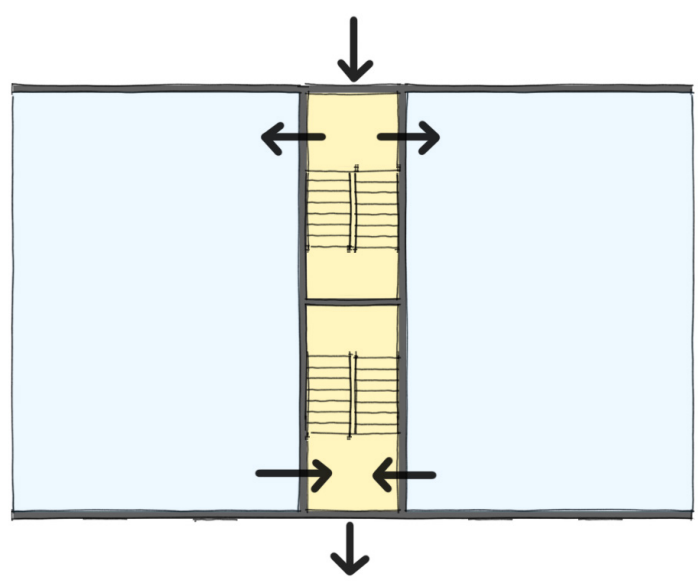

Figure 2.04 - Indicative access to and from apartments (Plan View)
This resulted in a far more intimate relationship between the individual dwellings and their respective access from the street. Particularly when compared to tenement buildings that feature doubleloaded internal corridors. Access to the courtyards was offered by either multiple back-doors corresponding to each semiprivate staircase, or monumental archways which penetrate the perimeter (Sonne, 2009). This multi-core tenement-style EPB provides the definitive model for this research.

\section{ISSUES WITH THE EPB}

As with all urban housing models, EPB housing did have its downfalls, predominantly relating to orientation and aspect. Due to the nature of its layout, not all units within a Perimeter-Block receive equal sun exposure and effective crossventilation, particularly in the corners. The corner dwellings had little-to-no connection with the internal courtyard, and the units to the north or south of the block had one facade which received little-to-no sunlight. 
However, the presence of the sun-facing façade on the opposite side of the units can be seen as adequate compensation. (Leupen, 2011).

Early modernist architects criticised the EPB. Walter Gropius (1956), emphasises the problems with the EPB model, especially with the corner apartments. $\mathrm{He}$ states that ventilation is inadequate when compared to parallel rows of apartments due to the transverse blocks at each end of the perimeter blocking air-flow, plus the apartments with "unfavourable orientation" have the unavoidable away-from-sun aspect. Another defect identified by Gropius is the self-shading which can be caused by the apartments closest to the sun creating shadows for the apartments adjacent or behind.

Lack of privacy is another issue with EPB developments, caused by overlooking. Particularly at internal corners, it can be difficult to manage overlooking from adjacent dwellings. Bentley (1985) states that this can be solved by leaving a gap in the corners. However, blocks must be kept relatively large to decrease the effect that the gaps have on consistent street enclosure (This strategy is explored further by David Baker Architects. See chapter Three).

\section{FUTURE DEVELOPMENTS}

There have always been different formats for EPB developments. Even the most popular variants changed following their inception. One major change to the EPB housing model was the opening of the perimeter. Ideally, the courtyard is fully enclosed by the perimeter of buildings, however it is not uncommon for breaks in the block to occur. This may allow easier access into the courtyard for the residents or for means of maintenance. It also deals with difficult internal corners and can accommodate the seismic separation that is crucial for New Zealand buildings with irregular plans. However, this openness can have large implications on the privacy and safety that is typically favoured.

When a single city block is the product of many independent buildings forming EPB 
developments, the resulting streetscape can appear disorderly. Sonne (2009) describes "the ideal perimeter block" from Scandinavia, in which the entire EPB is built all at once with a single cohesive treatment. This defines the street-edge with a precision not seen in other types. Long façades with repeating windows and expressed corners perfectly framed the streets, which at the time was particularly desirable. Such a result could now be considered monotonous. Contemporary Architects deliberately introduce variation to EPB design, seemingly to avoid this degree of uniformity.

A popular development of the central courtyard, also synonymous with the Scandinavian EPB developments, was hierarchical space division. The area still provided a large planted courtyard with a communal green space in the very centre. However, smaller private gardens were also located around the periphery, adjacent to their corresponding dwellings. This division of green space is well suited to the opening of the perimeter and is still a popular method for the EPB courtyard. It satisfied the needs of large open space while also providing private gardens. The main issue was that the private gardens could only be allocated to the dwellings on the lower floors. So upperfloor dwellings had to make do with private balconies and a communal green-space at ground level.

\section{CONCLUSIONS}

The Traditional European Perimeter Block is a long-running housing model which was formed in an effort to improve living conditions in dense urban environments. Much of its design focuses on providing sufficient natural light, fresh air and greater access to dwellings and amenity. Housing units were easily accessible from the street and provided access to shared amenities, such as the central courtyard. Accessibility to places frequently visited such as work and shops is provided by the central city location of these developments. The added benefit of street-edge definition and façade activation creates a pleasant street-scape which ultimately improves the urban context in which it is situated. 
The definitive EPB housing model for this research is medium-rise multi-core tenement housing. Its flexible number of floors and double-aspect layout provide desirable living conditions at a density appropriate to modern city housing. It is best suited to developments which are designed and built as one entity, which allows greater coherence and integration of amenities. The multi-core circulation emphasises the public/private distinction of EPB's with a more intimate method for accessing each apartment, provided by multiple shared stairwells accessed from the street.

The only downsides of the EPB model identified in the literature concern the corners, and to some degree the dwellings located within the northern and southern components of the building. This is mostly due to reduced sunlight and outlook concerns. These few issues are insignificant when compared to the numerous advantages already mentioned, and various strategies exist to dampen their effects. Similar issues arise with other medium-to-high density housing models.
Much like the variation in EPB buildings, the central courtyard has no single definitive model. A large range of options exist, each with varying desirability based on the culture and social expectations of its location in Europe. The main concern regarding these options is the balance between opening up the courtyard to the public or achieving containment for the purpose of safety and privacy. Opening such a space to the public can activate the space, often allowing for a pleasant pathway through the site, however it is arguably more useful to keep this space as a private 'haven' used only by the residents of the building surrounding it.

EPB housing may help to resolve the issues associated with urban New Zealand housing (see NZ Urban Housing Background), but there is no certainty that this model will be readily accepted. The attributes which popularise EPB are still very attractive today, as evidenced by the number of EPB developments still occupied throughout Europe, new and old. Despite this, there is an uncertainty attached to a New Zealand application of the EPB model. This is 
because EPB design is poorly represented in New Zealand, so New Zealanders have had little experience with such a housing model.

Particular uncertainty applies to the role of the central courtyard. Without an in-depth study into New Zealanders' social and cultural responsiveness to such a space, it is difficult to ascertain how successful this central space would be. This said, the increasing diversity of New Zealand society, (particularly in Auckland) suggests that socio-cultural norms are broadening with a consequent increase in receptiveness to denser living environments with greater emphasis on communal space.

In traditional EPB developments, and even more prevalent in contemporary examples (see Chapter Three), a wide range of activities and landscape treatments are assigned to the central courtyard. This flexibility suggests that the central space is capable of being adapted to fit different social and cultural circumstances. This includes the particular tastes and needs of New Zealanders in an urban context.
New Zealanders' receptiveness to communal living space is a fitting research subject in its own right. However, in the first instance, this work needs to be undertaken with input from social scientists and others skilled in observing and understanding human behaviour. This thesis focuses on an architectural question, primarily of the practical and aesthetic considerations associated with the EPB building type. The central courtyard is an intrinsic feature of EPB housing, but it is only one component of the development type.

Additional concern applies to the potential sites for EPB developments in New Zealand. Available sites within New Zealand's cities are mostly small and relatively scarce (see chapter Four) so only single, standalone developments are viable options for integration. This eliminates the possibility of replicating traditional EPB housing with their beautifully consistent street frontages and often orthogonal grid layout within close proximity to the urban core. However, since EPB developments occupy a full city block, the street frontages on each side of the block 
can be consistent or express a relationship not possible with typical block subdivision. The building will also be viewed as a unified whole, allowing it to have a unique identity within its context without disrupting the character of surrounding developments.

\section{DESIGN PRINCIPLES, STRATEGIES AND CRITERIA}

\section{PRINCIPLES:}

$\rightarrow \quad$ Favourable Living Conditions

$\rightarrow \quad$ Comprehensive Accessibility

\section{STRATEGIES:}

$\rightarrow \quad$ Linked perimeter of buildings

$\rightarrow \quad$ Communal central courtyard

$\rightarrow \quad$ Double-Aspect Apartments

$\rightarrow \quad$ Multi-core access to units

$\rightarrow \quad$ Semi-private shared staircases

$\rightarrow \quad$ Mixed-use development

\section{CRITERIA:}

$\rightarrow \quad$ Low-Rise High-Density

$\rightarrow \quad$ Explicit Distinction between Public and Private

$\rightarrow \quad$ Semi-Private Green Space Amenity

$\rightarrow \quad$ Variable design and function

$\rightarrow \quad$ Abundant sunlight and ventilation

$\rightarrow \quad$ Defined, active street edge

$\rightarrow \quad$ Coherent urban form

$\rightarrow \quad$ Conforms to contextual parameters 
New Zealand Urban Living:

\section{LITERATURE REVIEW / BACKGROUND}
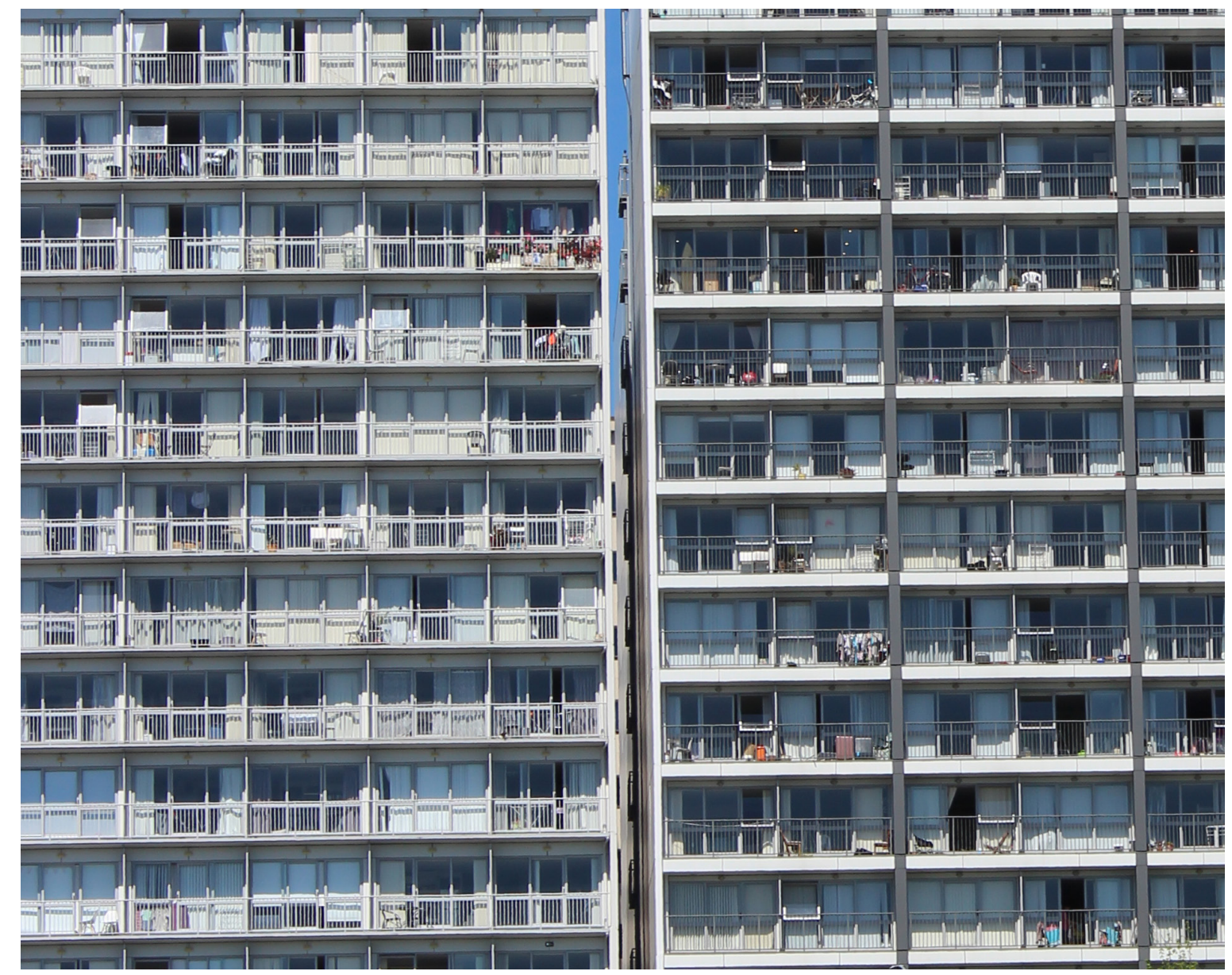

Figure 2.05 - High-Density apartment building in Auckland NZ 


\section{PREFACE}

This Thesis does not aim to solve the New Zealand housing crisis, it merely sets out to discover whether a European housing model could be adapted to work within a New Zealand urban context. The aim of the following literature review is to summarise the issues that exist in the current NZ urban housing market, and provide a context for the subsequent investigation of contemporary European Perimeter Block housing and its applicability to New Zealand.

\section{THE NEED FOR GREATER DENSITY}

There is no doubt that kiwis prefer to live in the family-oriented suburbs on the periphery of New Zealand's cities. However, higherdensity living is inevitable and stand-alone dwellings are going to become increasingly unaffordable.

A study conducted by Kiwibank (2019) economists' estimates the New Zealand housing shortage in the middle of 2019 to be around 130,000 homes nationwide. Despite an increase in the construction of homes, the rate at which houses are being built is not keeping up with the demand. If things continue at the same rate, the shortage will increase to 150,000 homes by mid-2020.

Trying to keep up with or exceed housing demand with low-density housing is bound to be a near-impossible task. The February 2018 report of New Zealand's Housing Stocktake (NZ Government, 2018) underlines that the key to providing more houses is integrating urban planning, which allows an increase in higher-density, highquality houses to be built. This also means that land will be more efficiently used and distributed. The result is more houses per unit of land, built at a faster rate.

Statistics New Zealand estimates that almost $70 \%$ of households are currently occupied by families and this percentage will remain for the next 20 years as the population increases.

\section{NEW ZEALAND URBAN HOUSING}

Most New Zealanders want the best of both worlds; stand-alone houses with plenty of 
space in suburbia, and short travel times to work, schools and local shops. While this demand is not uncommon in some of New Zealand's small towns, it is increasingly difficult to satisfy in dense urban environments.

New Zealanders' preference for stand-alone housing is associated with an affinity for private open space and the environmental benefits that accompany this. A 2017 survey and literature review conducted by BRANZ (Bryson, 2017) confirmed that New Zealanders have a "long-standing preference for stand-alone housing", with attitudes towards other typologies relating directly to the density of the housing type. Lowerdensity housing scored better across the board, with linear decrease in scores relative to density increase.
While it was discovered that those who had previously lived in higher-density housing did have a more positive response to this housing type, they still opted for stand-alone houses as their main preference.

These findings are backed up by Carroll et al. (2011) who identified that families living in high-density inner-city housing in Auckland fail to make a lasting commitment to compact multi-unit living despite benefits regarding convenience and affordability. Most families living in central city apartments are content 'for now' but plan to move back to suburbia in the future. They are motivated by perceived inadequate space indoors and outdoors as well as privacy and safety concerns, particularly for children.

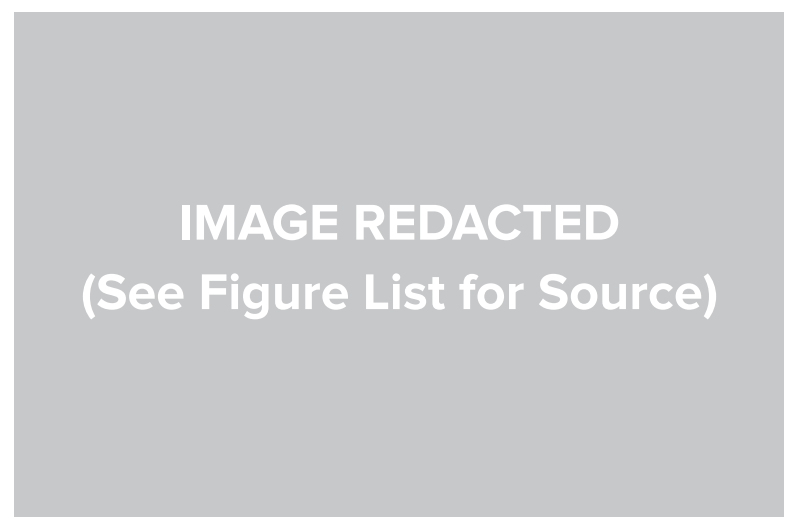

Figure 2.06 BRANZ survey data on "Willingness to live in housing types in the future" 
Privacy concerns related to balconies, which were also considered a safety risk with children. Safety issues were also raised by children having to go elsewhere to play, crossing dangerous roads and being exposed to unpleasant people. A dedicated, safe area for children was considered an important selling point when it came to family housing. Despite increasing travel times and overall cost, the benefits of the stand-alone suburban home still outweighed those of inner-city living.

The lack of adequate outdoor space is seen as a huge downside when it comes to higher-density living. This formed the basis for Ashworth's (2018) thesis called "Where the heck do I put the BBQ?" in which he aimed to provide a design for high-rise New Zealand apartments with a diverse range of outdoor space amenity. During his research he discovered two major flaws with current New Zealand high-rise apartments. Firstly, there is a significant lack in private and shared outdoor space. Secondly, a large percentage of floor space is taken up by circulation (up to 20\%). Ashworth claims that without addressing these issues and ultimately improving high-density housing design in New Zealand, it is unlikely that market resistance towards it will subside.

\section{CONCLUSIONS}

New Zealand needs a high-density housing model that not only allows efficient urban living, but also improves the perception of lifestyles in the centre of New Zealand's cities. Without people wanting to live in higher densities, the housing shortage is unlikely to disappear. To convince the country that urban living is the way forward we need "fewer disasters and more successful examples". (Witten, 2011).
A high-density housing model with high amenity is the key solution to this problem. It has been made evident that higher-density urban housing in New Zealand has a few issues that are deterring New Zealand families. Considering that families make up $70 \%$ of New Zealand households, resolving these issues will pave the way for increased inner-city living. Among others, these key issues include: 
$\rightarrow \quad$ Safety risks for children

$\rightarrow \quad$ Lack of privacy for occupants

$\rightarrow \quad$ Insufficient indoor space

$\rightarrow \quad$ Inadequate provision of outdoor space

$\rightarrow \quad$ Inefficient building circulation

Considering the findings of traditional EPB developments, and comparing these to the issues surrounding New Zealand urban housing, it appears that the EPB model may deliver a suitable basis for resolving such issues.

The obvious characteristic of EPB housing which is likely to improve high-density urban housing in New Zealand is the central courtyard. Provision of outdoor space is more than catered for with the open green space provided by a central courtyard. While many variations exist, a fully enclosed courtyard with space for children and families to play would be the desired option. The nature of EPB housing design means that not only is the courtyard shielded from the public streets, but it also has all-day surveillance from the surrounding dwellings. The convenience and safety provided by such an amenity is sure to be regarded as an acceptable alternative to public parks or private backyards in the suburbs.

It is important to recognise that while a central courtyard may replace some important aspects of public parks or backyards, it is not necessarily a substitute for private outdoor space. This poses the question regarding the value of such a space as a substitute for more traditional private outdoor space in suburban New Zealand.

As mentioned in the EPB background conclusions, it is difficult to ascertain how successful this central space will be, particularly when comparing it to what New Zealanders currently experience in lowdensity suburban living environments. New Zealand's ever-increasing receptiveness to high-density living and greater emphasis on communal space suggests a shift in sociocultural norms. The flexibility of the central courtyard suggests EPB housing can be readily adapted to fit shifting expectations in a changing New Zealand cultural context. New Zealanders' acceptance of such a 
space is a research topic in its own right and largely outside the scope of this thesis. This development.

thesis focuses primarily on the practical and aesthetic considerations associated with the EPB building type.

This distinction between public and private space, as evident in the central courtyard, is further emphasised by multiple circulation cores. EPB's have more ground floor entrances to their dwellings than a typical apartment building, each accompanied by a set of stairs and a lift (modern examples).

This means that while access to each apartment is still shared, it is shared by fewer people, providing a semi-private threshold between the public street and the private dwelling. This also reduces the unpleasant crowding that occurs in an apartment building's main lobby.

While having multiple cores is not a particularly cost-effective option, it can result in a more efficient circulation system if implemented correctly. This ultimately increases the amount of available floor area to be used as living space, thereby increasing the net-to-gross floor area ratio for the 


\section{DESIGN OPPORTUNITIES, CONSTRAINTS AND CRITERIA}

\section{OPPORTUNITIES:}

$\rightarrow \quad$ Opportunity for integration of shared open space

$\rightarrow \quad$ Opportunity for improved perception of living area sizes

$\rightarrow \quad$ Opportunity for improved private outdoor space area

$\rightarrow \quad$ Opportunity to decrease horizontal circulation

CONSTRAINTS:

$\rightarrow \quad$ Must provide shared open space

$\rightarrow \quad$ Must provide high level of safety for shared open space

$\rightarrow \quad$ Must improve privacy and safety for private outdoor areas

$\rightarrow \quad$ Must provide for families

\section{CRITERIA:}

$\rightarrow \quad$ High level of amenity provision

$\rightarrow \quad$ Efficient circulation system

$\rightarrow \quad$ Diverse provision of apartments

$\rightarrow \quad$ Public, private and semi-private separation

$\rightarrow \quad$ Improved perception of safety and spaciousness 

CHAPTER THREE

Contemporary EPB Body of Work Study

+ Apartment Attribute Studies 
European Perimeter-Block:

CONTEMPORARY BODY OF WORK

\section{IMAGE REDACTED \\ (See Figure List for Source)}

Figure 3.01 - Image of contemporary EPB: 79\& Park by BIG 
Contemporary examples of EPB's are

relatively new forms of urban housing which are based on the fundamental characteristics of the traditional model. They are much more relevant to New Zealand because they are predominantly stand-alone developments and are designed in response to modern technology and lifestyles. No two designs are the same because all the precedents respond to their own specific requirements and context.

Traditional EPB housing is well documented due to its lengthy history and prevalence throughout Europe. As a result, traditional models can be understood by referring to an extensive collection of literature. Contemporary examples of EPB housing, on the other hand, are less well documented. Few scholarly or professional studies have been made of this housing type in the context of present day. As a consequence, this research includes a systematic examination of precedents with the aim to identify the formal and spatial characteristics that are most prevalent, unique, or attractive for a New Zealand application.
To discover what I can about contemporary EPB's, an assortment of examples from around the globe have been analysed spatially and formally. The chosen examples include a wide range of heights, sizes, shapes and materials. While all contemporary EPB's are primarily for residential use, the clients vary, resulting in a multitude of different housing types within the block. Each design also resolves unique climatic issues associated with their specific locations around the world. The differences and similarities will form a strong basis for adaptation of EPB's for use in New Zealand.

Particular attention was given to six examples from the Bjarke Ingels Group (BIG) worldwide architecture practice. BIG are one of the only firms which feature more than a few examples of contemporary EPB housing designs. They are also renowned for pushing the boundaries on architectural design and formal composition with over 100 large-scale projects. The six examples of EPB developments are unique because while they appear to follow the fundamental traits of EPB housing, each design is distinctive. 
For every contemporary EPB example, a typical floor-plan was drawn to better understand the apartment layout, aspect, circulation system and location of vertical cores. This consistent representation of each example's floor plan also allows for easy comparison, to best extract the spatial characteristics of each design. Images of each of the examples were used to ascertain the prominent and unique formal characteristics and compare these to the spatial characteristic to better understand why certain design choices were made. The BIG examples received special treatment. For each of these, a simplified 3D isometric was redrawn to further understand the formal characteristics for each.

Each precedent was analysed formally and spatially, with specific details listed alongside the redrawn floor-plan and images for each. The characteristics of each example were comprehensively summarised in a list of the prevalent and interesting characteristics. These are listed following the examples, divided into formal and spatial characteristics.

\section{PRECEDENT DISCLAIMER}

Apart from the BIG examples which are all drawn at the same scale, the redrawn floorplans are depicted at different sizes and orientations. Direct size comparisons cannot be made in the current format.

\section{FLOOR-PLAN KEY:}

- Apartments

- Horizontal circulation

- Staircases

- Elevators

- Staircase \& Elevator

- Internal Private Stairs 


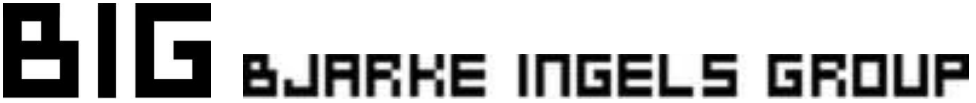

B1 Name: 8 House (Tallet House)

Location: Copenhagen, Denmark

Year: Floor Count: 11 Apartments: 475

2009 Density: $220 \mathrm{dpH}$ Site Area: $2.16 \mathrm{Ha}$

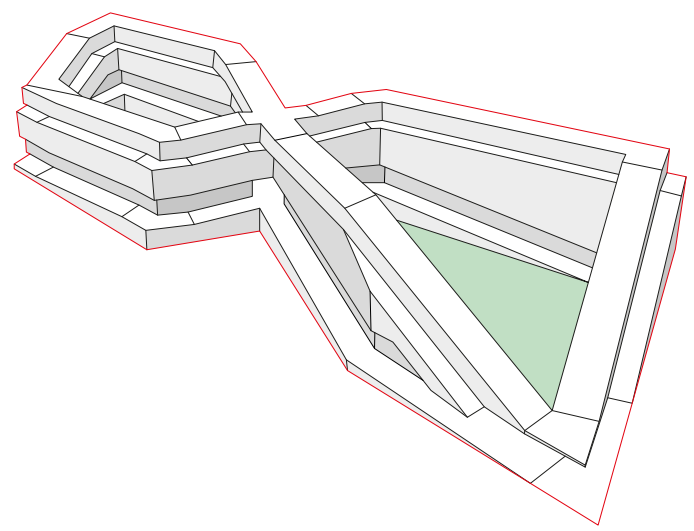

Figure $3.02 a$

$\rightarrow \quad$ Duplex Apartments

$\rightarrow \quad$ Sloped/Tiered Roof-line

$\rightarrow \quad$ Varied Building Heights

$\rightarrow \quad$ Rooftop Terraces

$\rightarrow \quad$ Strip Balcony

$\rightarrow \quad$ Dedicated Communal Areas

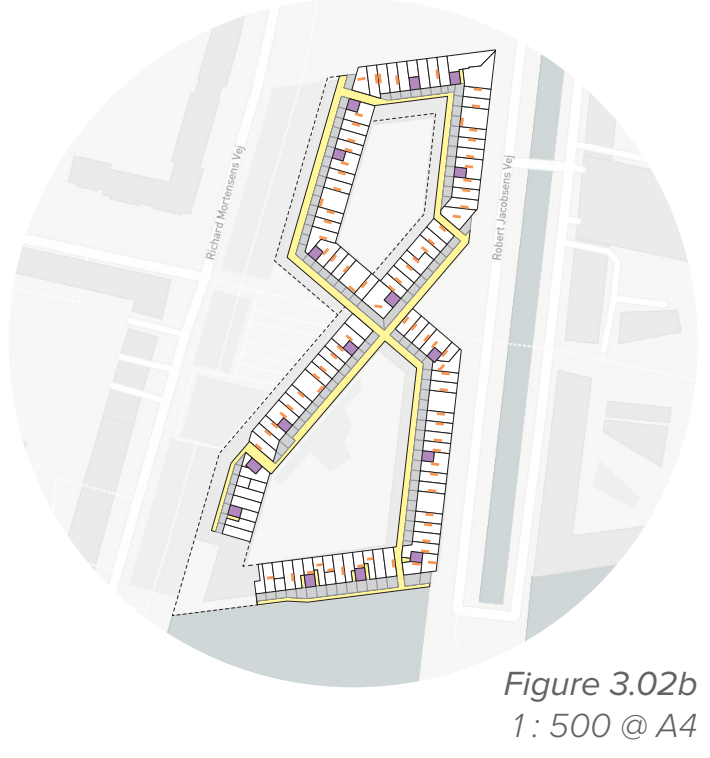

Figure $3.02 b$ 1:500@A4
Name : VIA 57 West

Location: New York, USA

Year: Floor Count: 34 Apartments: 709

2016 Density: $800 \mathrm{dpH}$ Site Area: $0.89 \mathrm{Ha}$

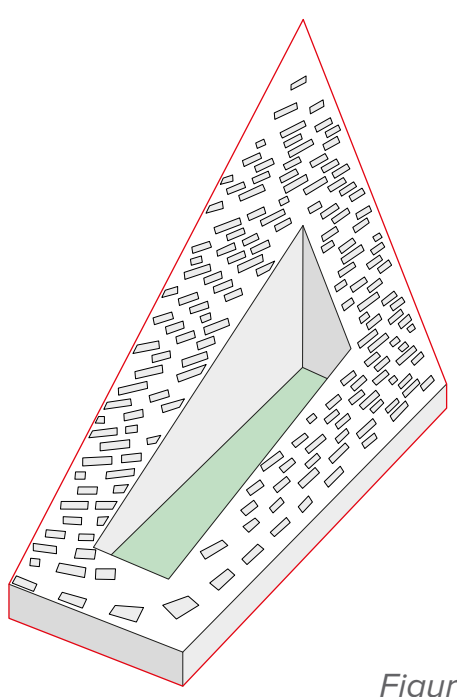

Figure $3.03 a$

$\rightarrow \quad$ Sloped/Tiered Roof-line

$\rightarrow \quad$ Saw-Tooth Façade

$\rightarrow \quad$ Semi-Enclosed Balcony

$\rightarrow \quad$ Elevated Courtyard

$\rightarrow \quad$ Vertical Cores in Corners

$\rightarrow \quad$ Rooftop Terraces

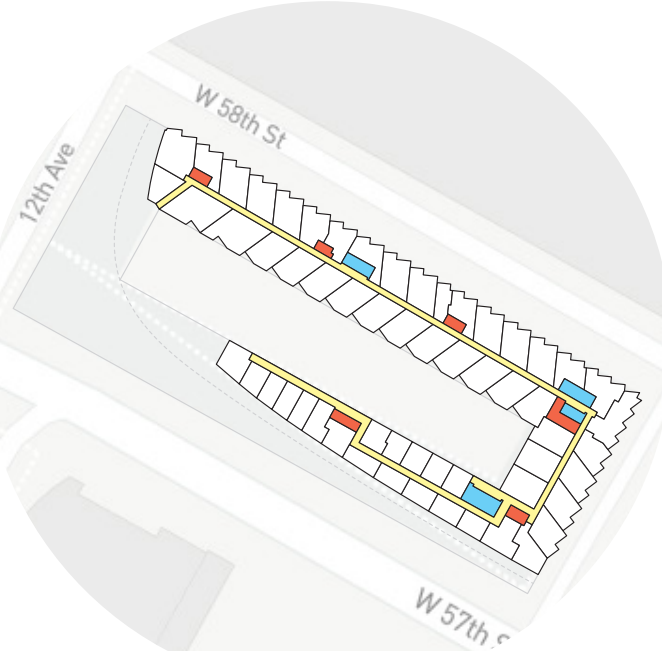

Figure $3.03 b$

1:300@A4 


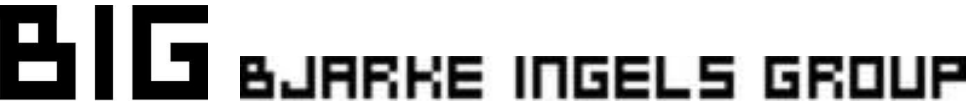

B3 Name : Lock House (Sluishuis)

Location: Amsterdam, The Netherlands

Year: Floor Count: $10 \quad$ Apartments: 380

2016 Density: $490 \mathrm{dpH}$ Site Area: $0.77 \mathrm{Ha}$

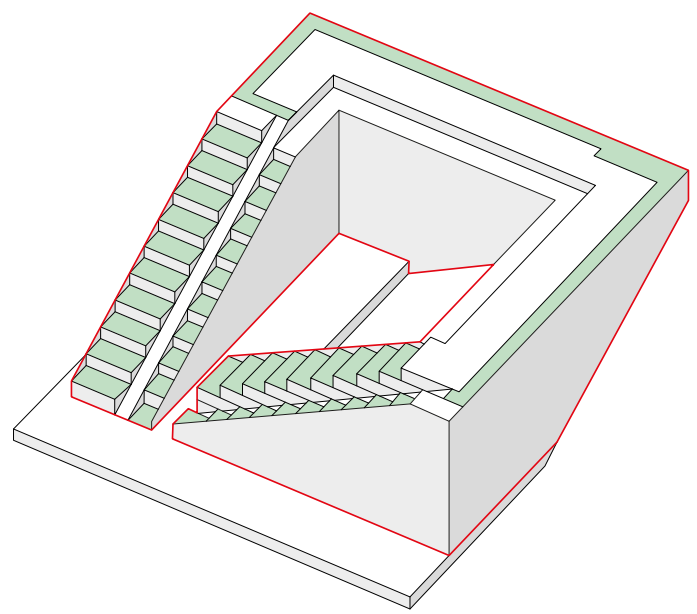

Figure $3.04 a$

$\rightarrow \quad$ Sloped/Tiered Roof-line

$\rightarrow \quad$ Rooftop Terraces

$\rightarrow \quad$ Vertical Cores in Corners

$\rightarrow \quad$ Protruding Balcony

$\rightarrow \quad$ Opening in Block Perimeter

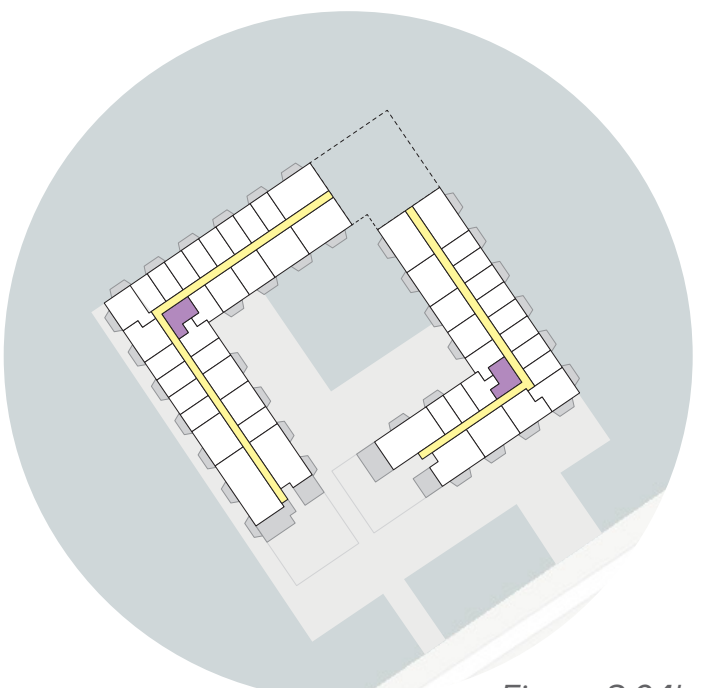

Figure $3.04 b$

1:300@A4
Location: Aarhus, Denmark

Year: Floor Count: 20 Apartments: 255

2016 Density: $410 \mathrm{dpH}$ Site Area: $0.62 \mathrm{Ha}$

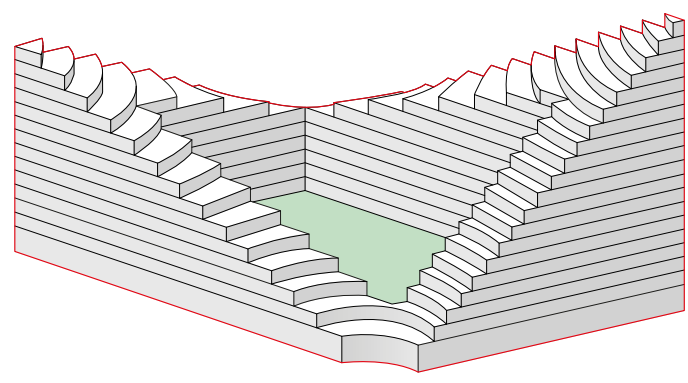

Figure $3.05 a$
$\rightarrow \quad$ Clustered Apartments
$\rightarrow \quad$ Rooftop Terraces
$\rightarrow \quad$ Vertical Cores in Corners
$\rightarrow \quad$ Strip Balcony
$\rightarrow \quad$ Elevated Courtyard 


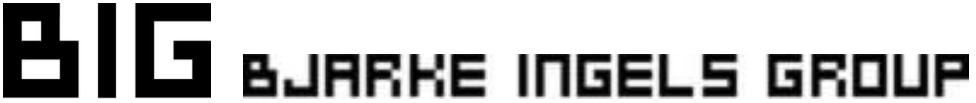

B5 Name : 79\& park

Location: Stockholm, Sweden

Year: Floor Count: 9 Apartments: 169

2008 Density: $300 \mathrm{dpH}$ Site Area: $0.57 \mathrm{Ha}$

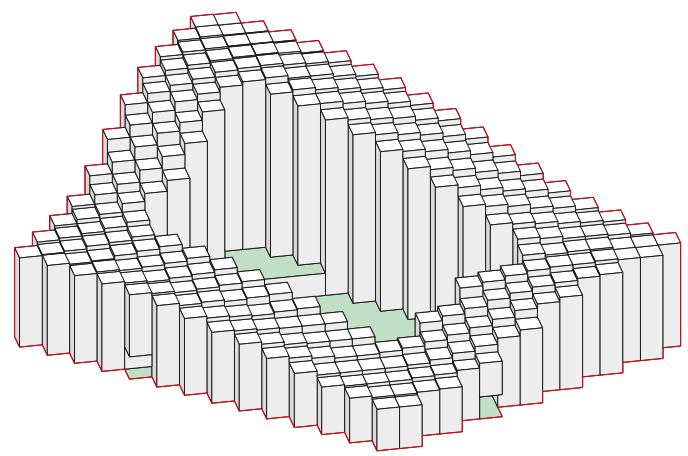

Figure $3.06 a$

$\rightarrow \quad$ Modular Pixel Form

$\rightarrow \quad$ Sloped/Tiered Roof-line

$\rightarrow \quad$ Clustered Apartments

$\rightarrow \quad$ Semi-Enclosed Balcony

$\rightarrow \quad$ Rooftop Terraces
Location: Toronto, Canada

Year: Floor Count: 16 Apartments: 516

2016 Density: $550 \mathrm{dpH}$ Site Area: $0.94 \mathrm{Ha}$

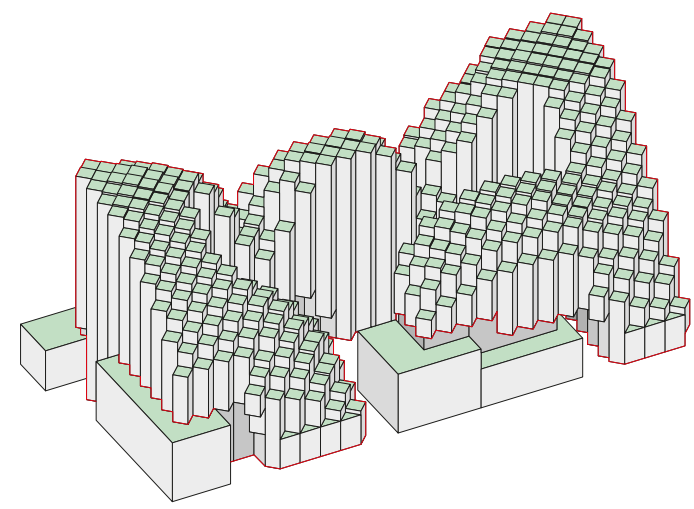

Figure $3.07 a$

$\rightarrow \quad$ Modular Pixel Form

$\rightarrow \quad$ Varied Building Heights

$\rightarrow \quad$ Vertical Cores in Corners

$\rightarrow \quad$ Semi-Enclosed Balcony

$\rightarrow \quad$ Opening in Block Perimeter

$\rightarrow \quad$ Rooftop Terraces 

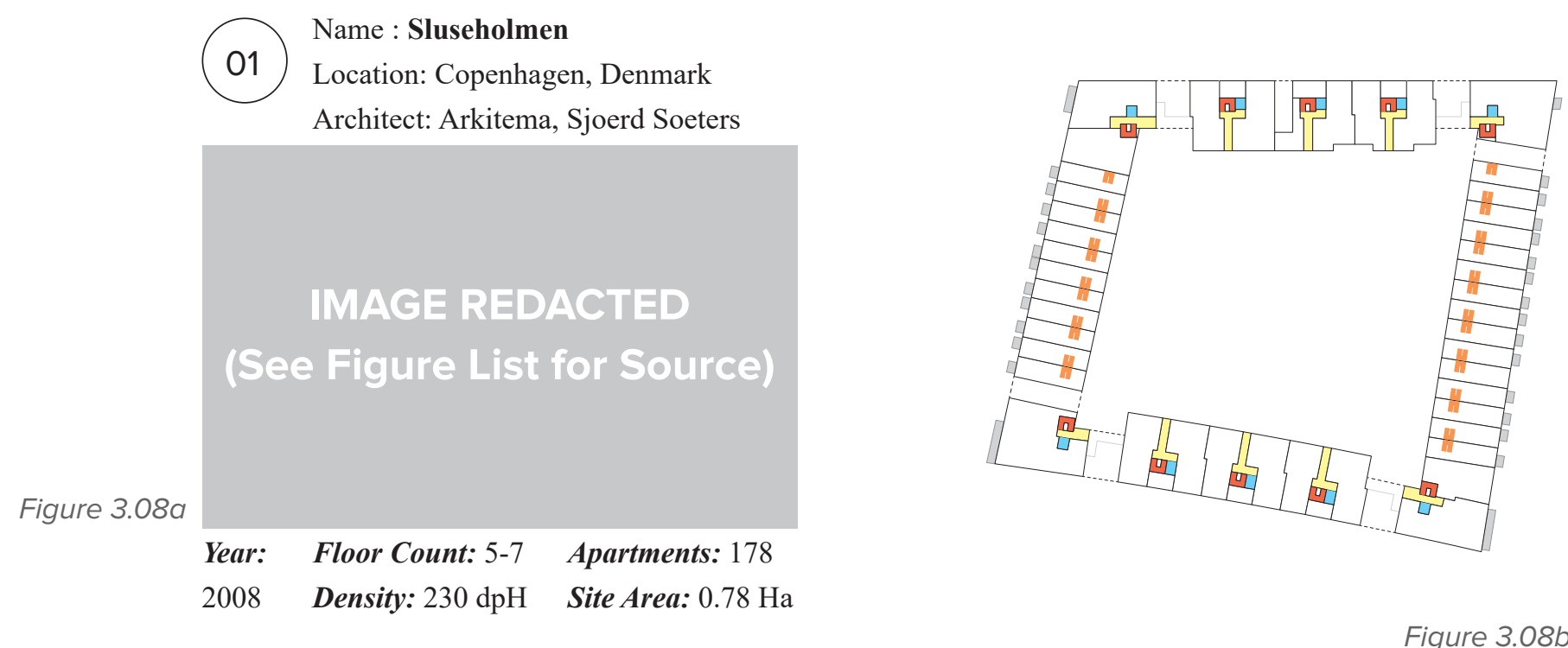

Figure $3.08 b$
(02 Name : Vivazz, Mieres Social Housing
02 Location: Astuias, Spain
Architect: Zigzag Arquitectura
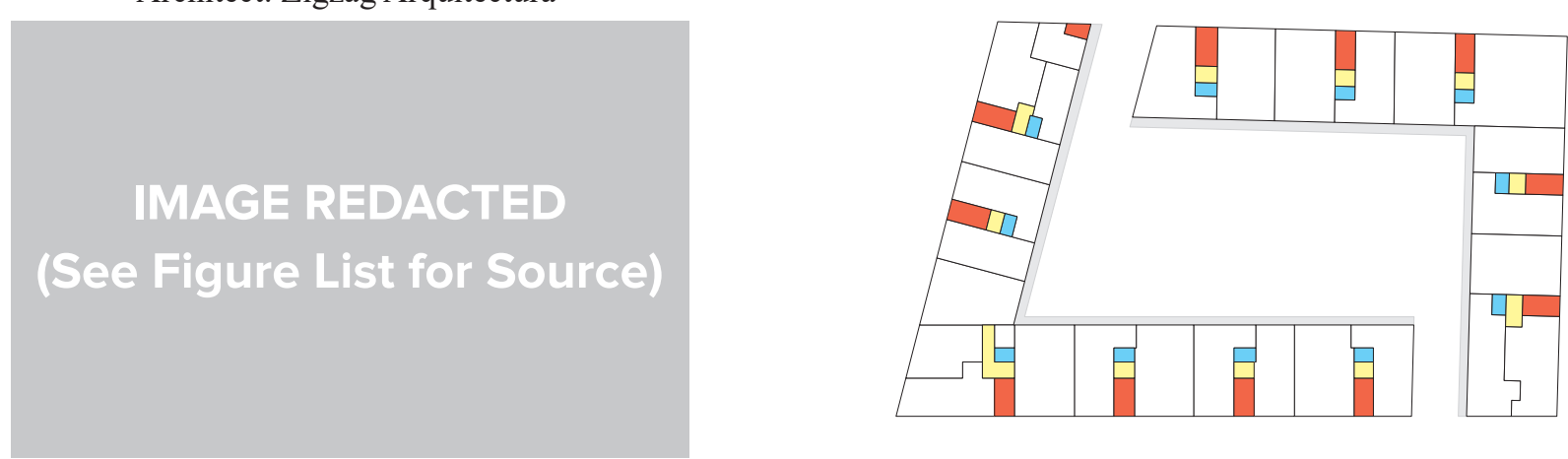

Figure $3.09 a$

Year: Floor Count: 3-7 Apartments: 131

2010 Density: $320 \mathrm{dpH}$ Site Area: $0.41 \mathrm{Ha}$

Figure $3.09 b$
03
Name : Tietgen Dormitory
03 Location: Copenhagen, Denmark

Architect: Lundgaard \& Tranberg

Figure $3.10 a$

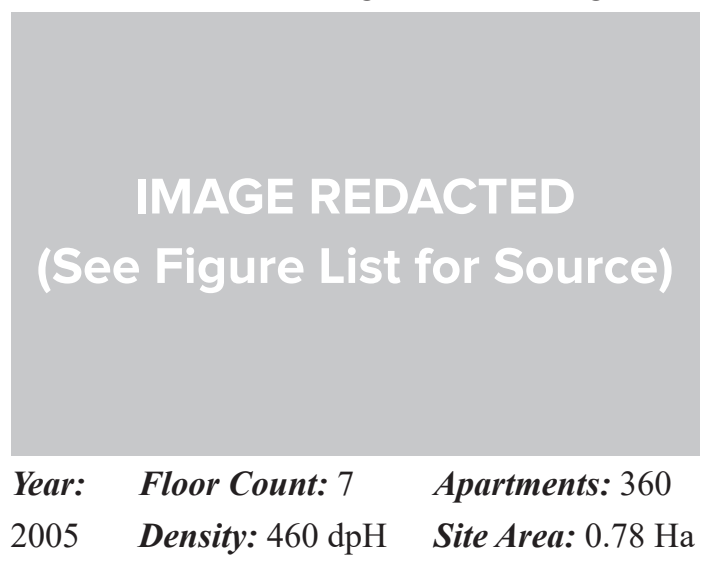

Figure $3.10 b$ 


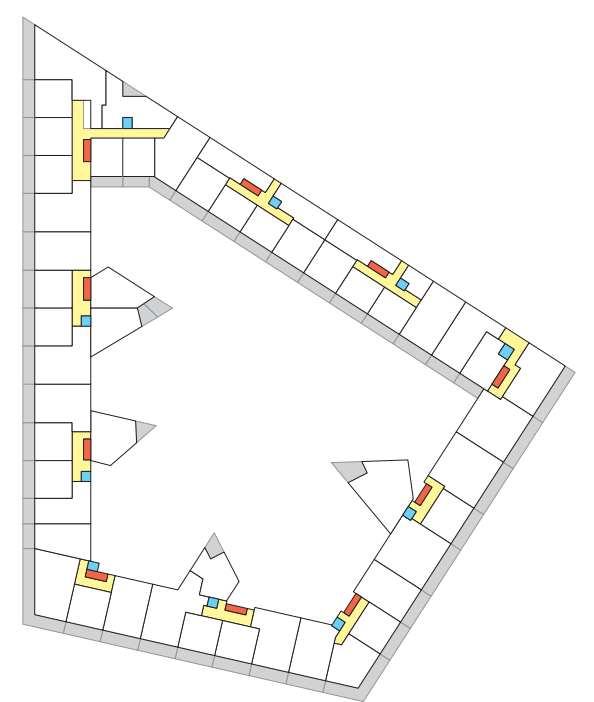

Figure $3.11 b$

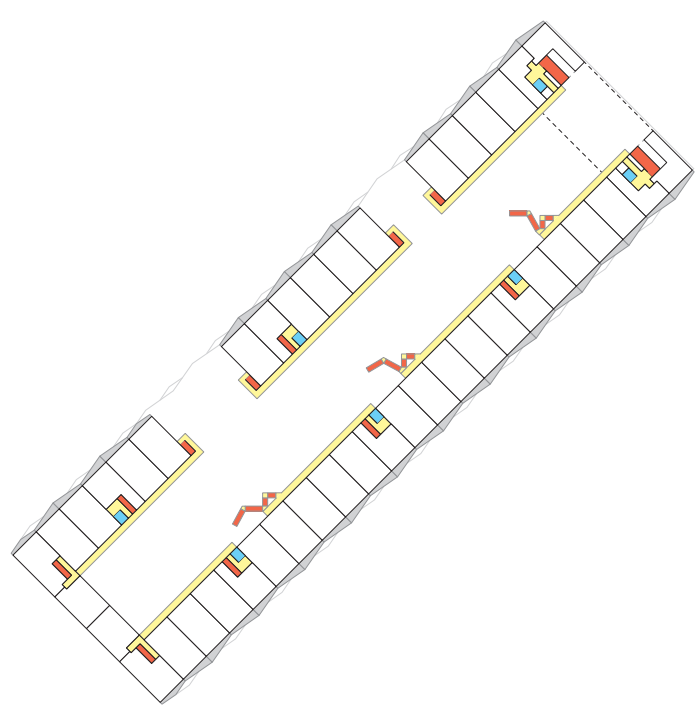

Figure $3.12 b$

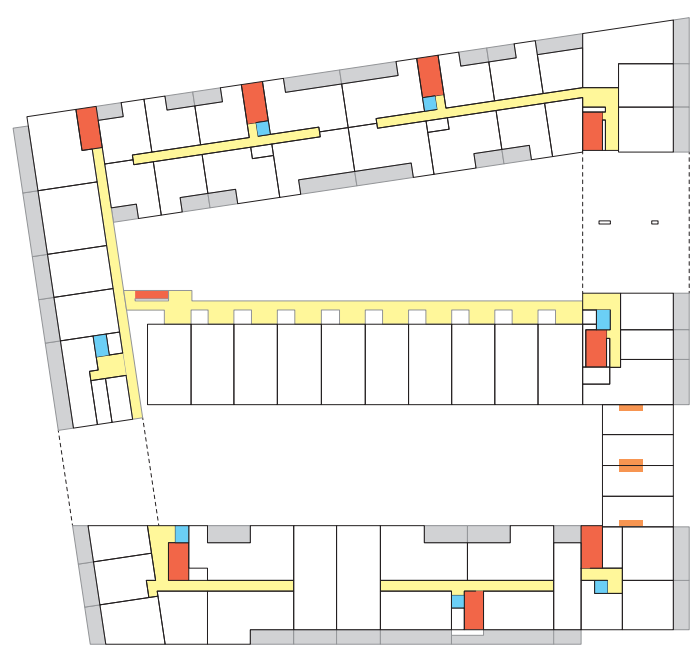

Figure $3.13 b$
04 Name : Harjunkulma Housing Block Location: Jyvaskyla, Finland Architect: Kirsti Siven \& Asko Takala

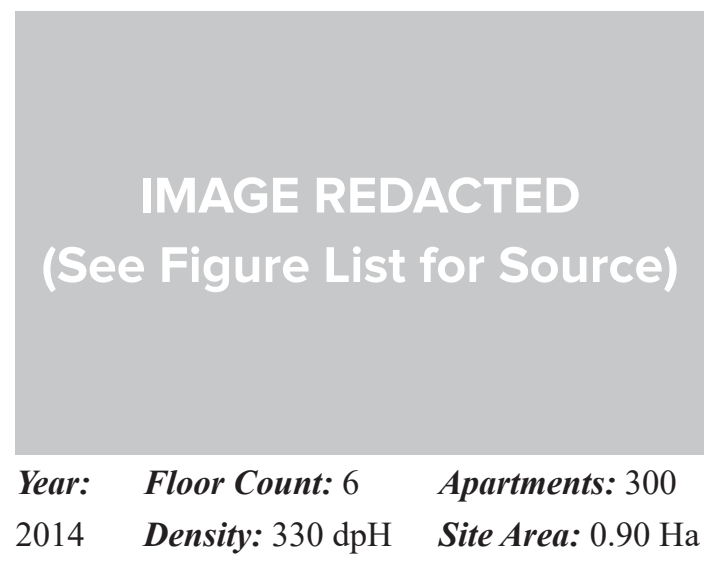

Figure 3.11a
Year: Floor Count: 4-10 Apartments: 226

2012 Density: $240 \mathrm{dpH}$ Site Area: $0.93 \mathrm{Ha}$

05 Location: Bijlmermeer, Netherlands Architect: NL Architects

IMAGE REDACTED (See Figure List for Source) Name : Bayonne Marinadour Location: Bayonne, France Architect: Mateo Arquitectura

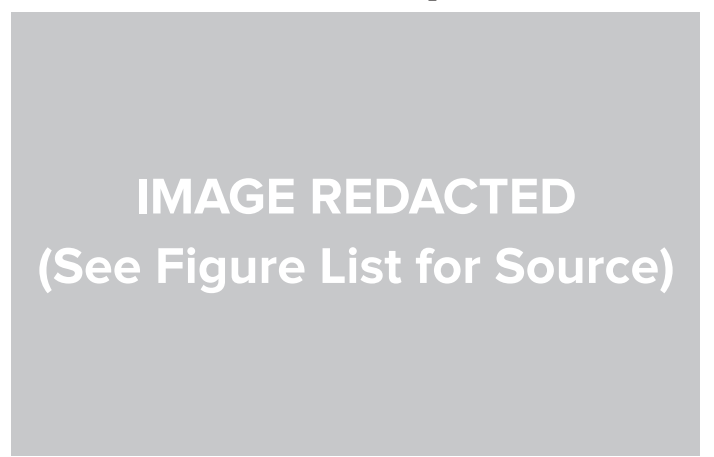

Figure $3.13 a$

Year: $\quad$ Floor Count: 4-8 Apartments:--2015 Density: --- dpH Site Area: $0.72 \mathrm{Ha}$ 
(07) Name : Heliopolis Social Housing

Architect: Biselli Katchborian

IMAGE REDACTED

(See Figure List for Source)

Figure 3.14a

Year: Floor Count: 8 Apartments: 420

2014 Density: $480 \mathrm{dpH}$ Site Area: $0.87 \mathrm{Ha}$

Name : Block 64

08 Location: Amsterdam, The Netherlands Architect: Loos Architects

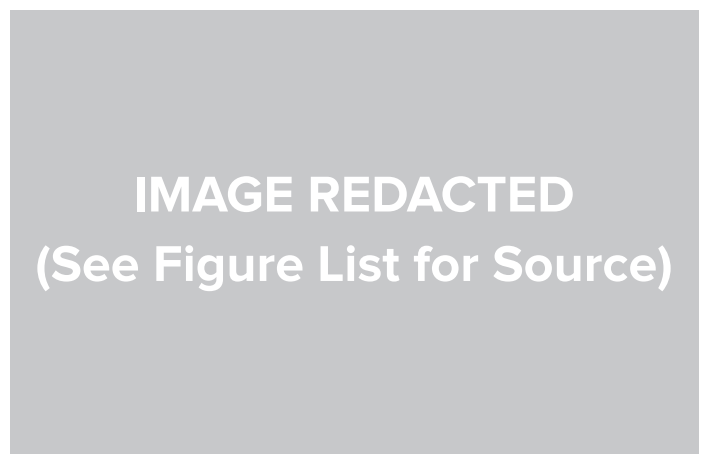

Year: Floor Count: 3-5 Apartments: 45

2011 Density: $120 \mathrm{dpH}$ Site Area: $0.37 \mathrm{Ha}$
09

Name : Sorenga Block 6

Location: Oslo, Norway

Architect: MAD Arkitekter

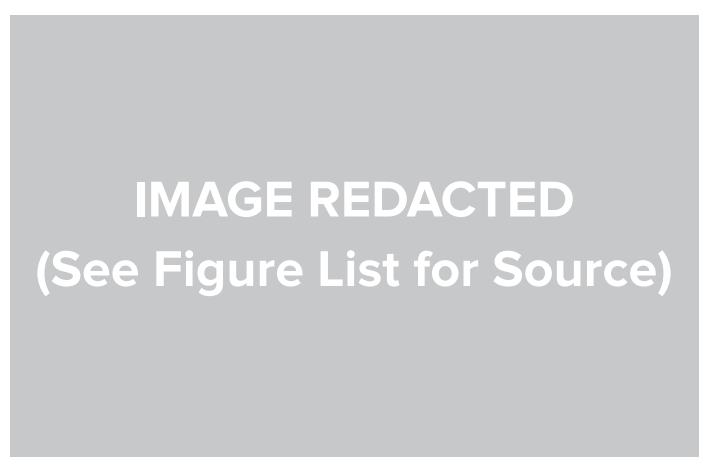

Year: Floor Count: 1-7 Apartments: 110

2015 Density: $310 \mathrm{dpH}$ Site Area: $0.35 \mathrm{Ha}$

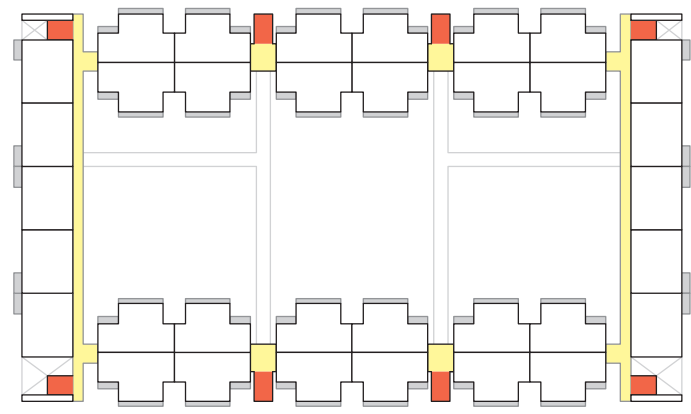

Figure 3.14b

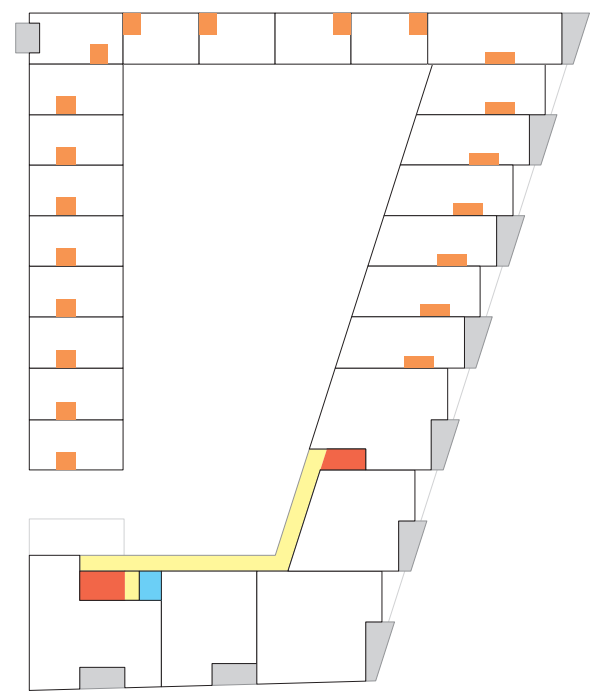

Figure $3.15 b$

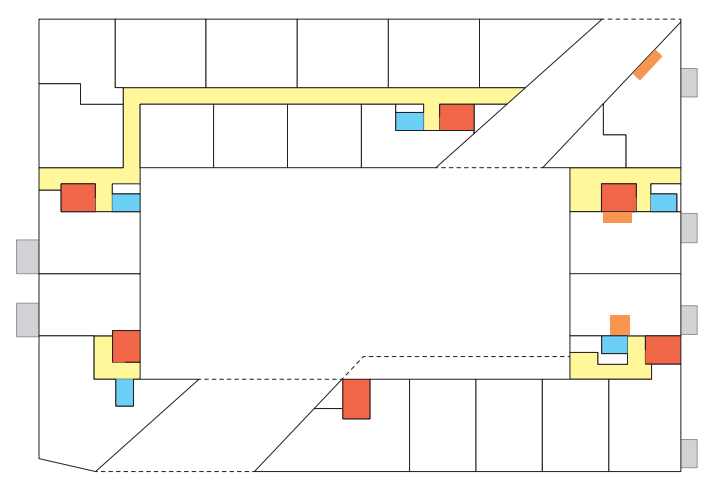

Figure 3.16a

Figure $3.16 b$ 


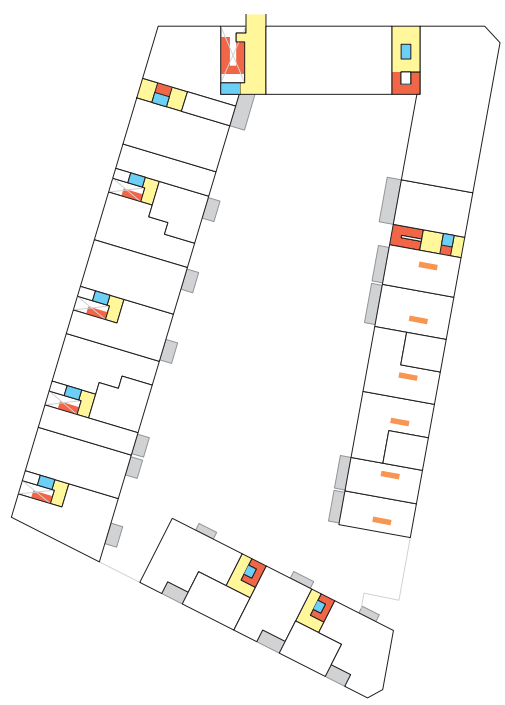

Figure $3.17 b$

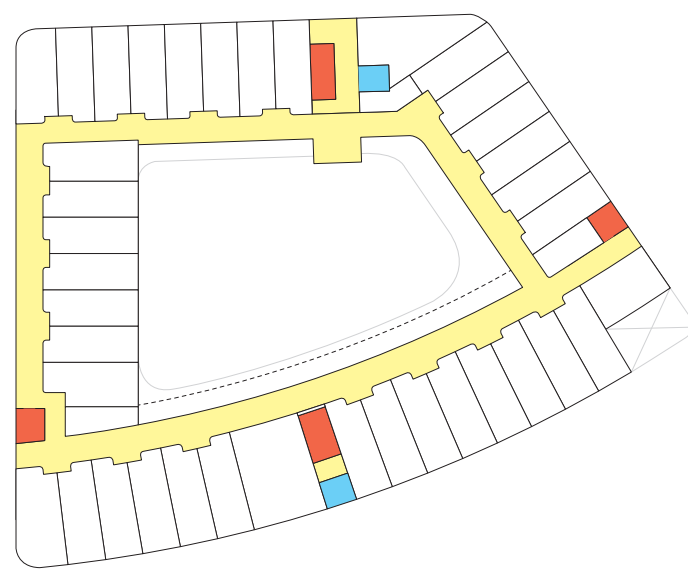

Figure $3.18 b$

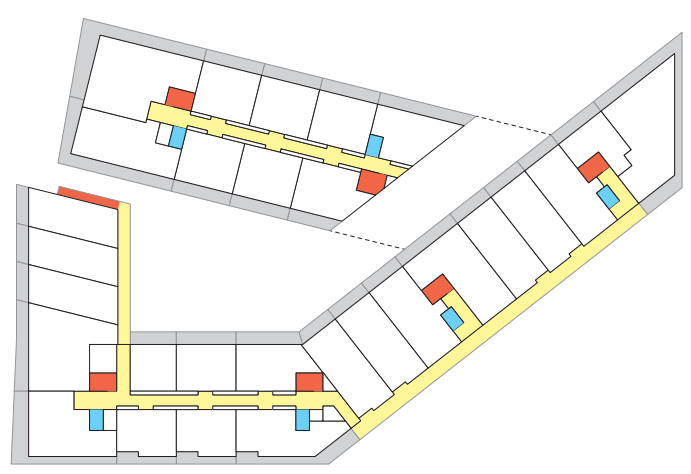

Figure $3.19 b$

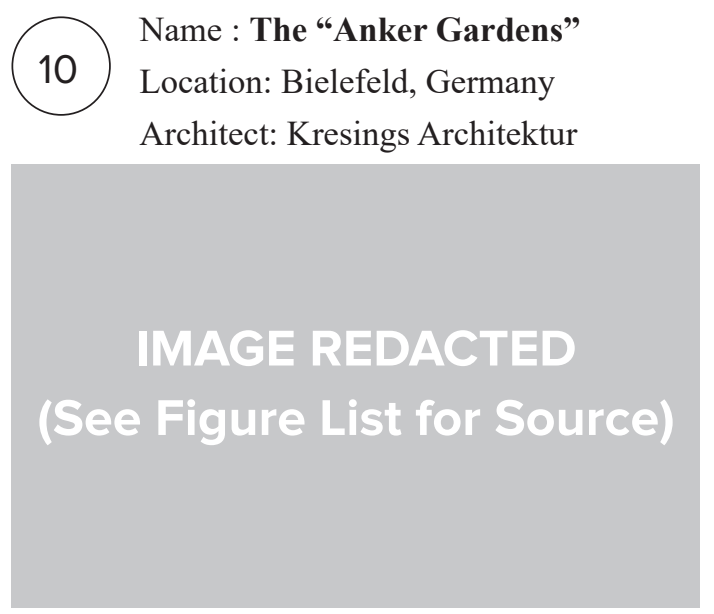

Figure $3.17 a$

Year: Floor Count: 3-4 Apartments: 102

2017 Density: $150 \mathrm{dpH}$ Site Area: $0.70 \mathrm{Ha}$

(11) Location: Utrecht, The Netherlands Architect: LEVS Architecten

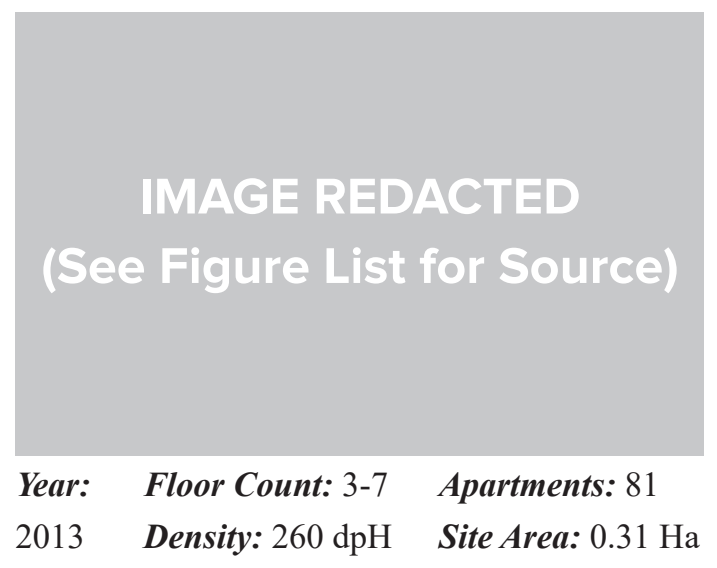

Figure $3.18 a$

Year: Floor Count: 3-10 Apartments: 225

2016 Density: $590 \mathrm{dpH}$ Site Area: $0.38 \mathrm{Ha}$

12 Name : Rosteriet

Location: Stockholm Sweden Architect: Kod Arkitekter

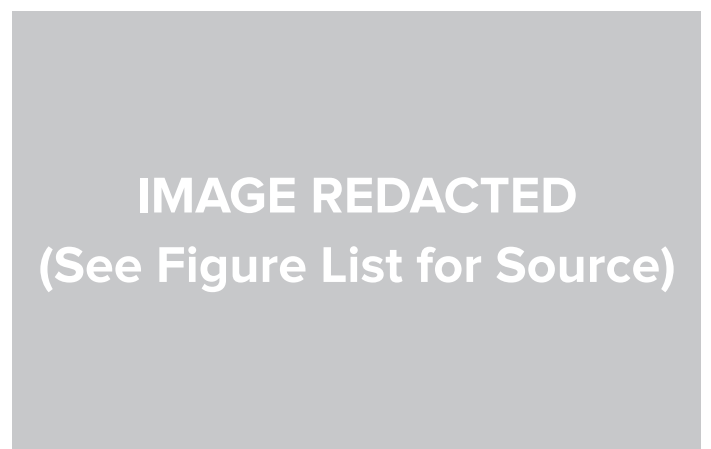


13

Name : Lange Eng Collective Living

Location: Albertslund, Denmark

Architect: Dorte Mandrup Arkitekter

IMAGE REDACTED

(See Figure List for Source)

Figure 3.20a

Year: Floor Count: 2-3 Apartments: 71

2012 Density: $90 \mathrm{dpH}$ Site Area: $0.80 \mathrm{Ha}$

Figure $3.20 b$

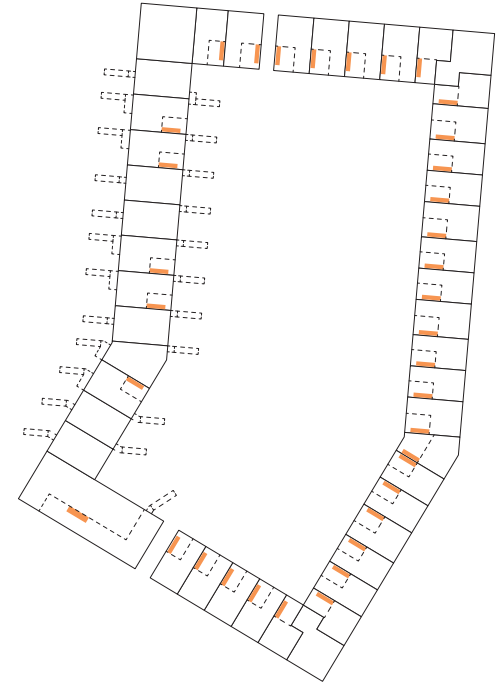

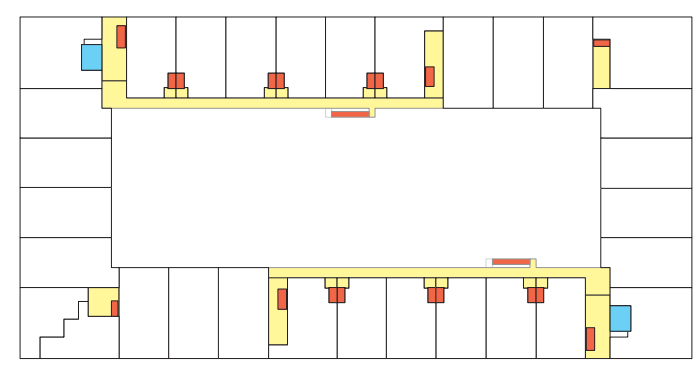

Figure $3.21 b$

Year: Floor Count: 8-12 Apartments: 214

2000 Density: $380 \mathrm{dpH}$ Site Area: $0.57 \mathrm{Ha}$

IMAGE REDACTED

(See Figure List for Source)

Figure 3.21a

14

Location: Amsterdam, The Netherlands Architect: de Architekten Cie.

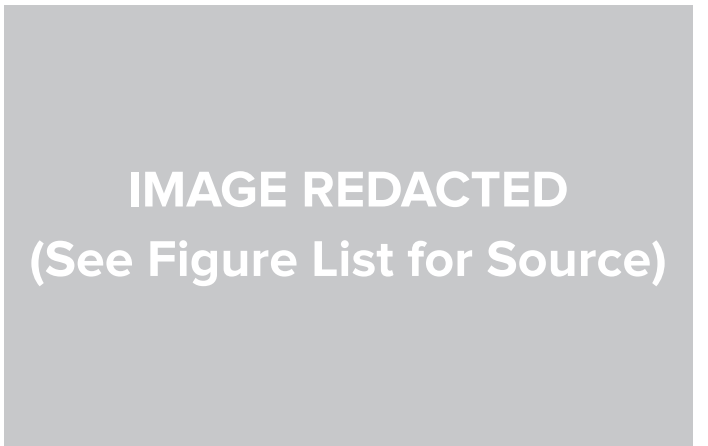

Name : 46 Social Houses

15

Location: Sevilla, Spain

Architect: Gabriel Verd Arquitectos

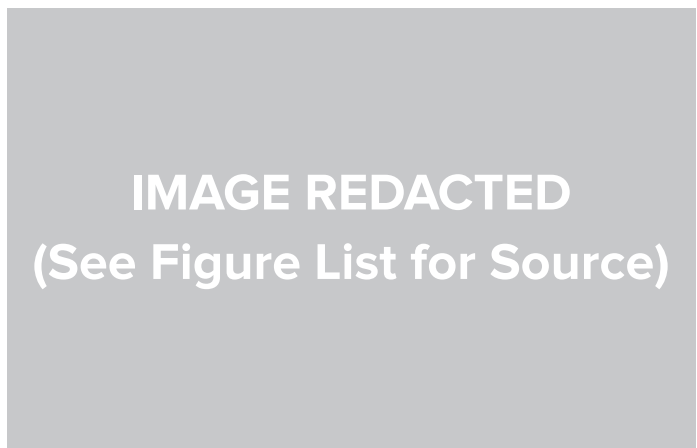

Year: Floor Count: 2-6 Apartments: 46

2011 Density: $290 \mathrm{dpH}$ Site Area: $0.16 \mathrm{Ha}$

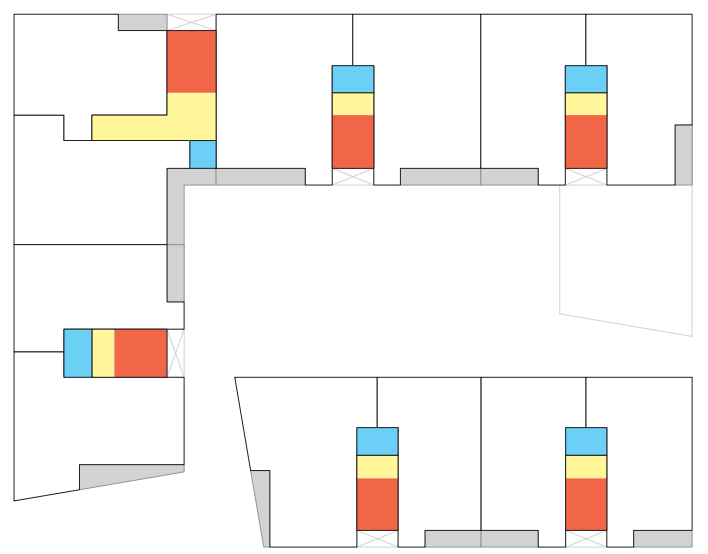

Figure $3.22 b$ 


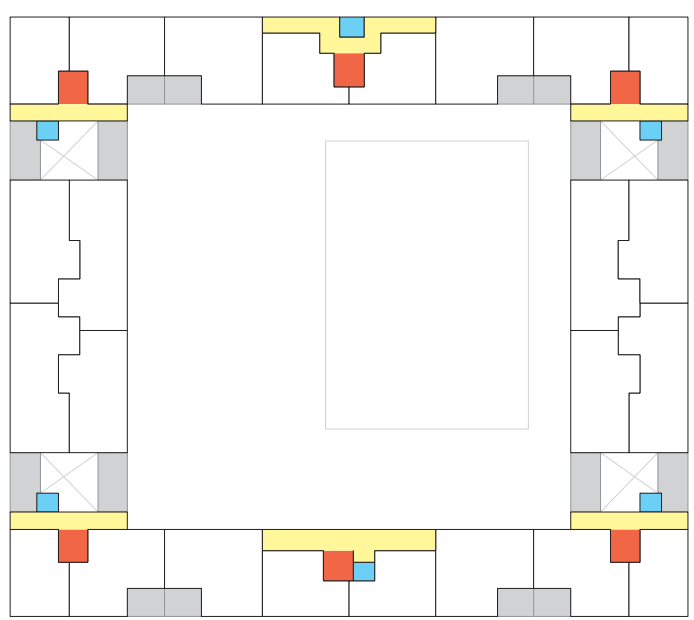

Figure $3.23 b$

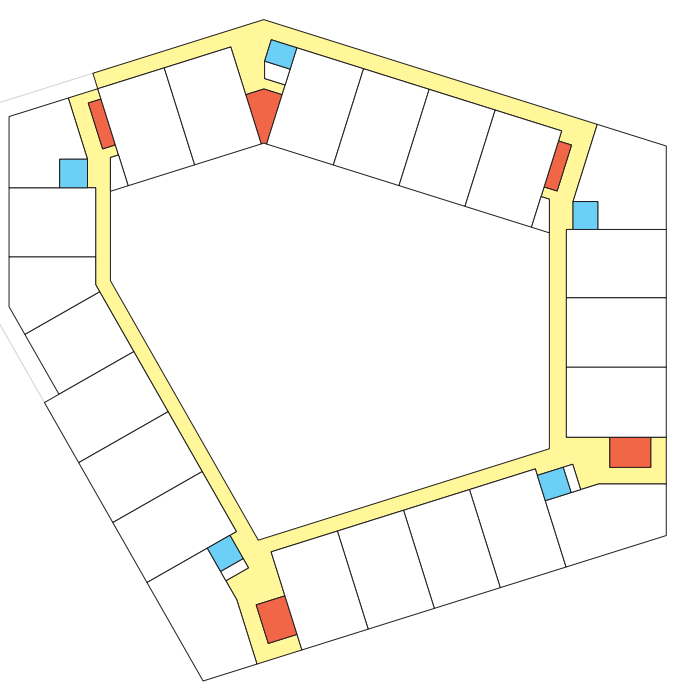

Figure $3.24 b$

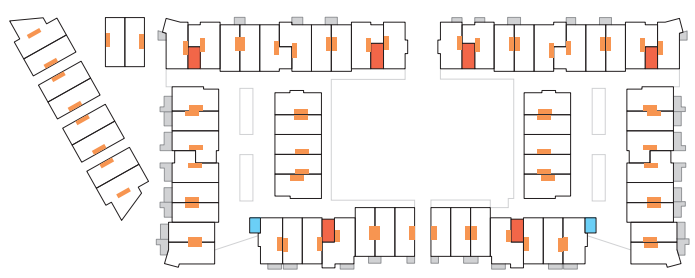

Figure $3.25 b$
16

Name : Le Bois Habité

Location: Rennes, France

Architect: Pich-Aguilera Architects

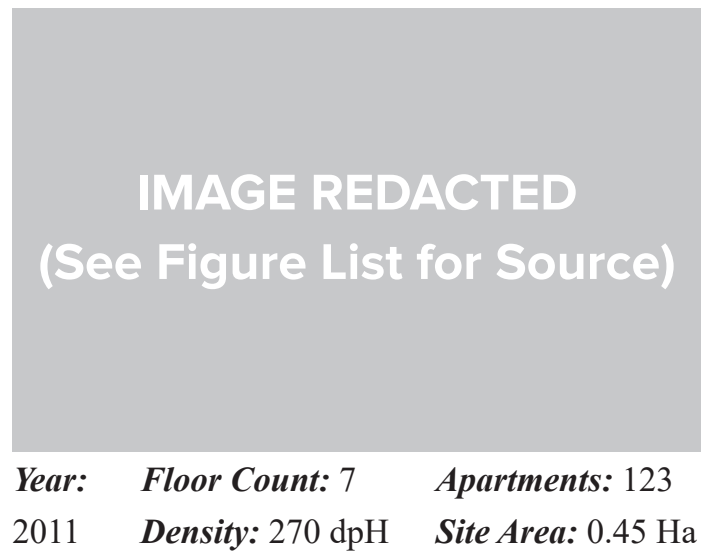

Figure $3.23 a$
Year: Floor Count: 5-14 Apartments: 200

2015 Density: $\sim 500 \mathrm{dpH}$ Site Area: $0.40 \mathrm{Ha}$

17 Location: Seoul, South Korea Architect: Frits van Dongen

IMAGE REDACTED

(See Figure List for Source)

$$
\text { Density: } \sim 500 \mathrm{dpH} \text { Site Area: } 0.40 \mathrm{Ha}
$$

Name : Armstrong Place Housing

18

Location: San Francisco, USA

Architect: David Baker \& Partners

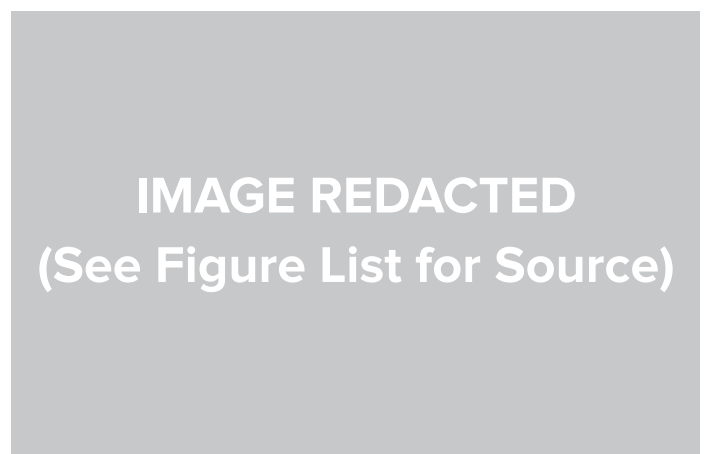

Figure $3.25 a$

Year: Floor Count: 4-5 Apartments: 124

2011 Density: $130 \mathrm{dpH}$ Site Area: $0.94 \mathrm{Ha}$ 

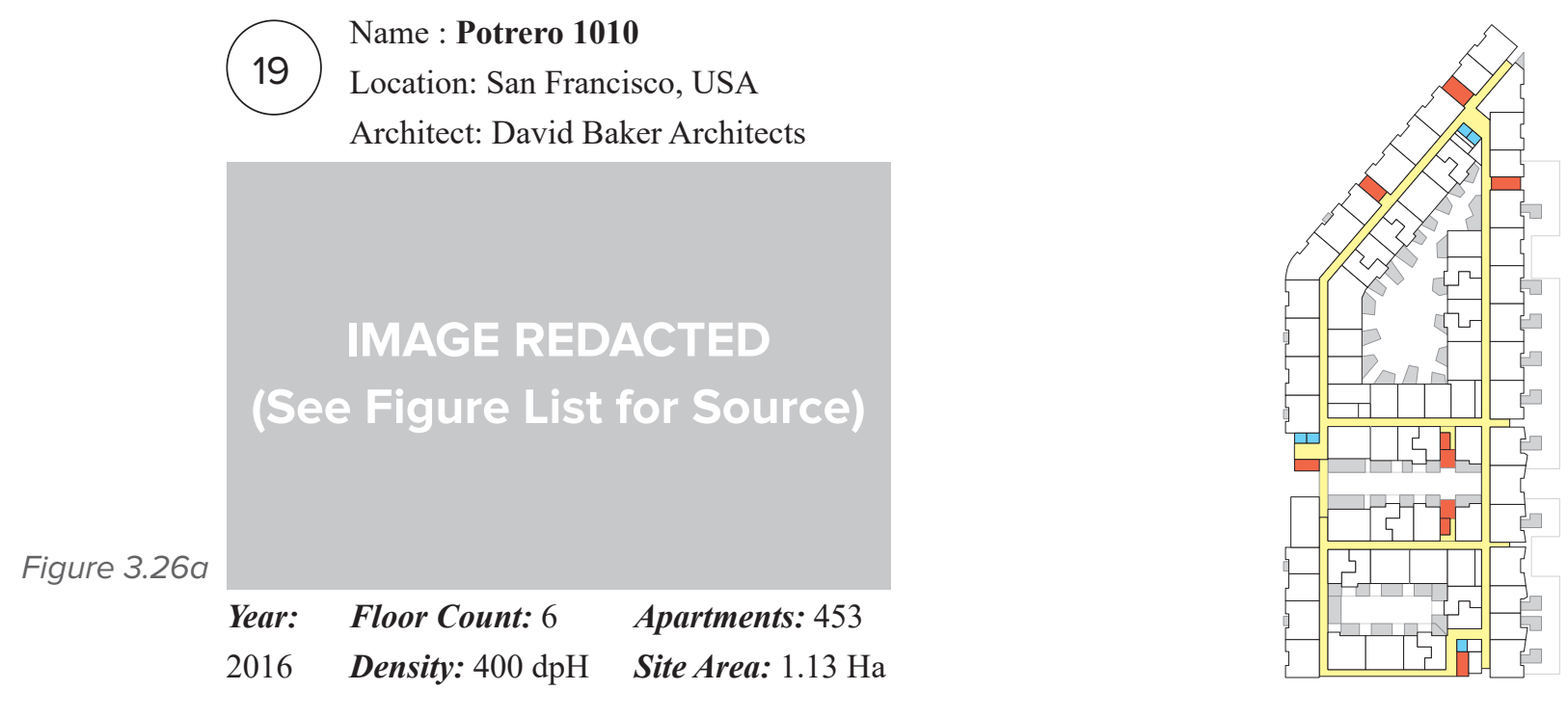

Figure $3.26 b$

(20) Lame : Carabanchel Social Housing
Location: Madrid, Spain
Architect: Coco Arquitectos

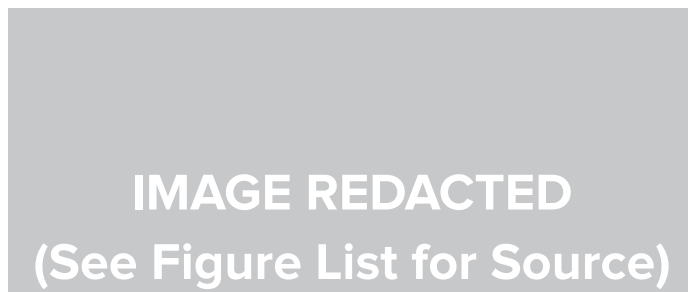

Figure 3.27a

Year: Floor Count: 7 Apartments: 168

2010 Density: $510 \mathrm{dpH}$ Site Area: $0.33 \mathrm{Ha}$

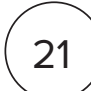

Name : Longnan Garden Social Housing

21

Location: Xuhui District China

Architect: Atelier GOM

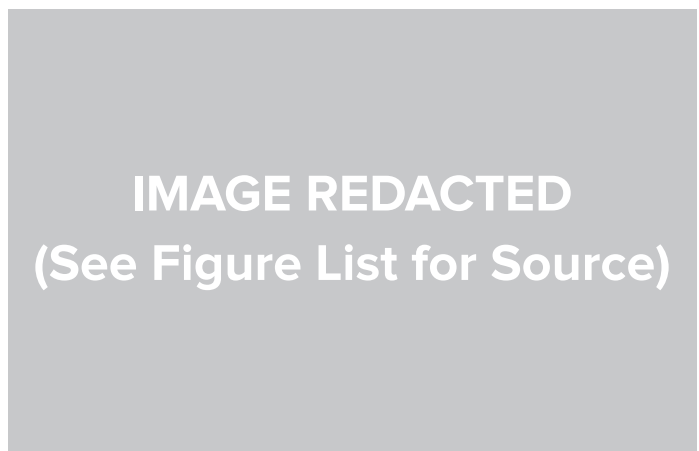

Year: Floor Count: 12 Apartments: 496

2017 Density: $1240 \mathrm{dpH}$ Site Area: $0.40 \mathrm{Ha}$

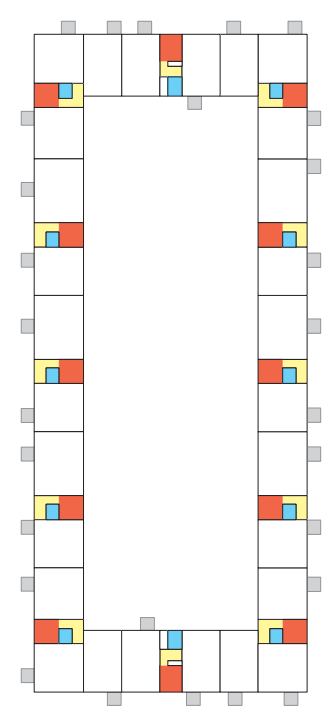

Figure $3.27 \mathrm{~b}$

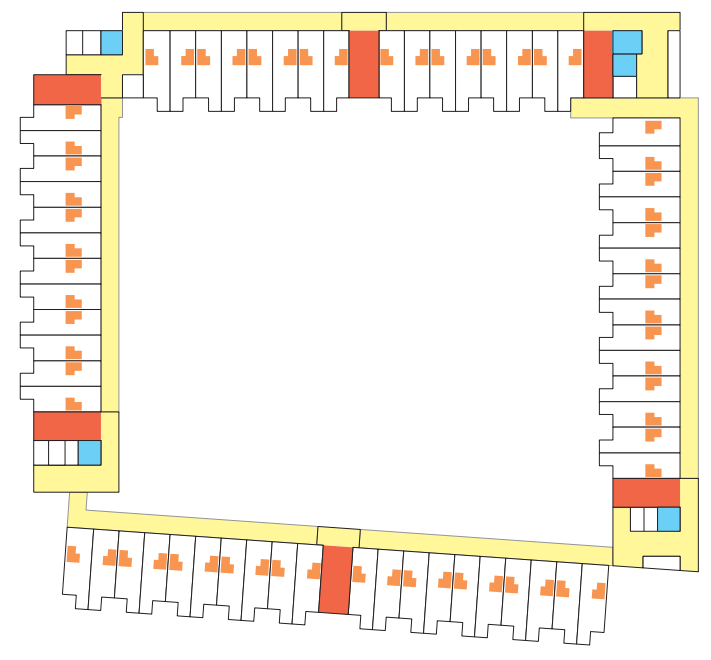

Figure $3.28 b$ 


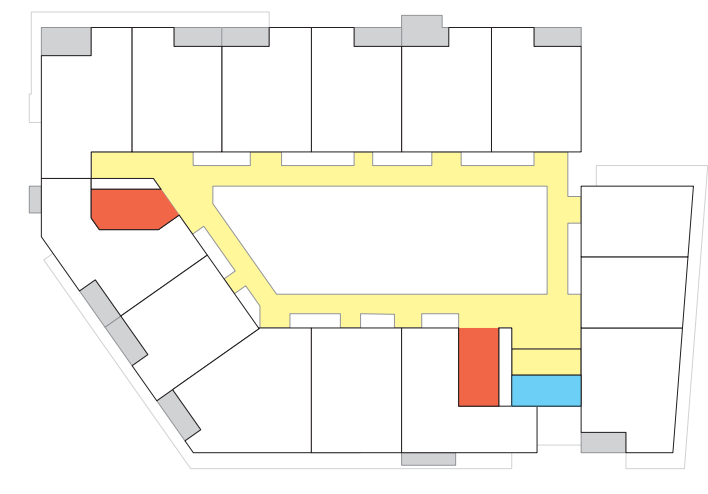

Figure $3.29 b$

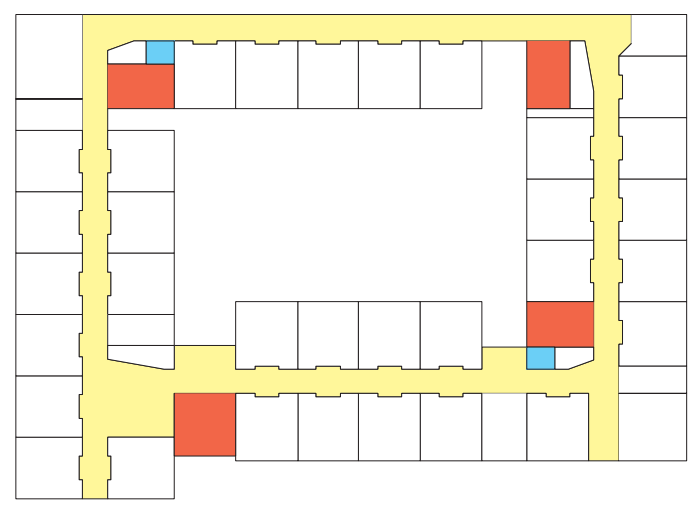

Figure $3.30 b$

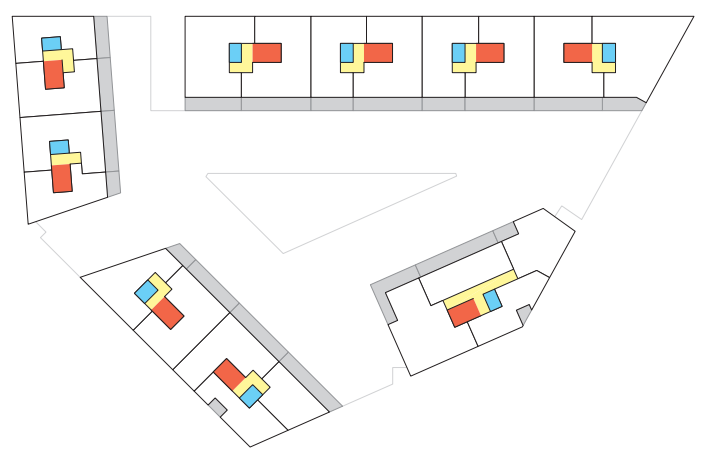

Figure 3.31b
(22) Name : Axis Building

Location: Cape Town, South Africa Architect: dhk Architects

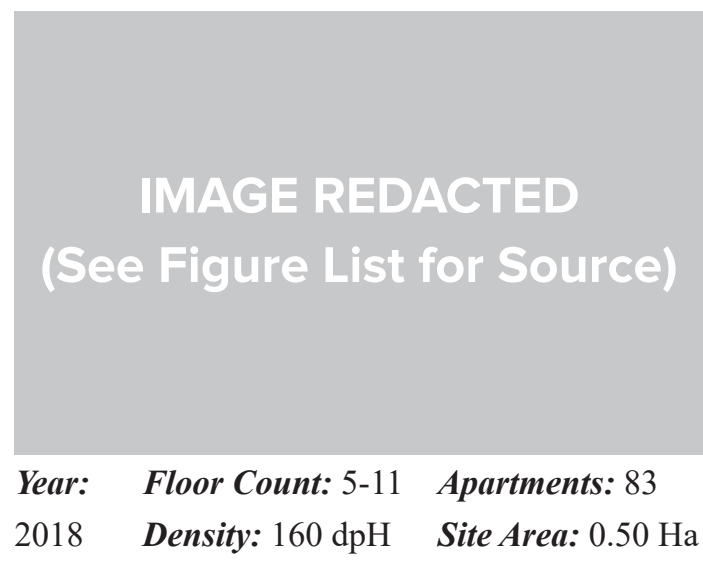

Figure $3.29 a$

2018 Density: $160 \mathrm{dpH}$ Site Area: $0.50 \mathrm{Ha}$

Name : Student Residence ULisboa

Location: Lisboa, Portugal

Architect: CVDB Arquitectos

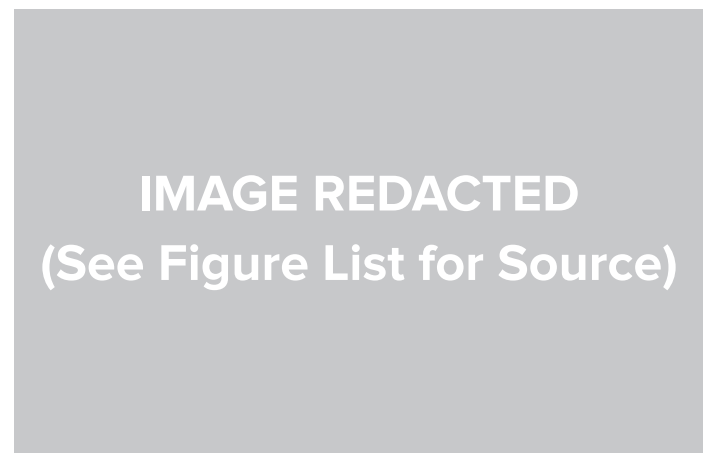

Figure $3.30 a$

Year: Floor Count: 5-6 Apartments: 180

2014 Density: $750 \mathrm{dpH}$ Site Area: $0.24 \mathrm{Ha}$

(24 Name: "Casanova" Social Housing Architect: CDM Architetti Associati

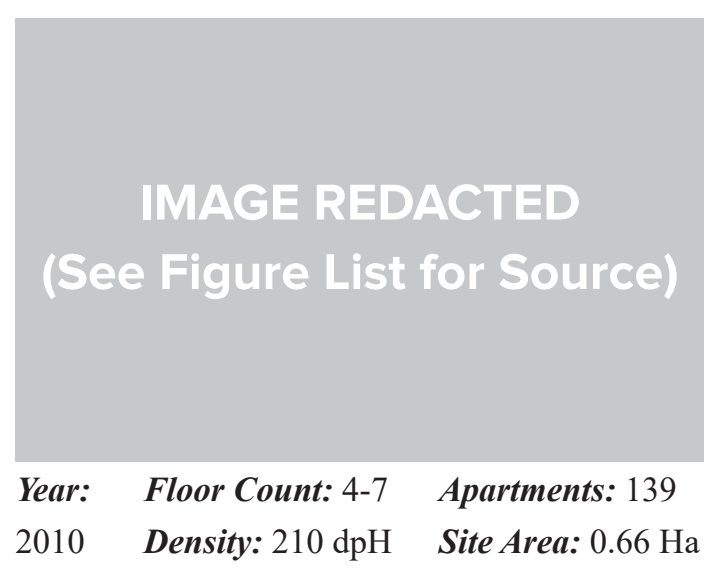


KEY SPATIAL

\section{CHARACTERISTICS}

\section{DUPLEX APARTMENTS}

Duplex apartments are helpful for

achieving double-aspect layouts.

They also reduce the extent of shared corridors or walkways, often allowing for circulation to skip floors and provide more variation on the facade. This can help to maximise the net-togross floor area ratio, resulting in less wasted space.

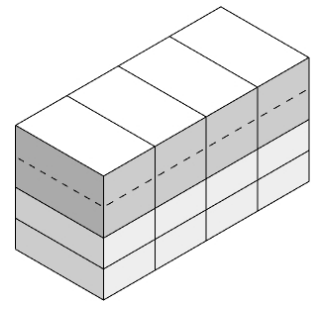

Figure 3.32

Further to this, they are good for “interlocking” efficient spatial layouts to maximise space and avoid the "shoe-box" apartment phenomenon. Unfortunately, the private internal staircase could be seen as wasted use of space especially when paired with a shared staircase to access the apartment. Also, internal staircases do not suit all occupants.

\section{VERTICAL CORES IN CORNERS}

Locating vertical circulation within the corners of the perimeter solves two problems. Firstly, staircases or lifts don't take up precious façade area, allowing for an increased number of windows. And secondly, the corner exhibits a multitude of issues regarding overlooking and outlook, so taking up some or all of this problematic space with vertical circulation is effective use of space.

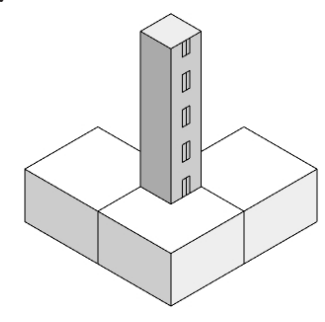

Figure 3.33

This also tends to conceal vertical circulation which can be a positive façade element and important social space within the building. There can, however, be difficulties regarding access to the corner vertical circulation, and it often only takes up a small portion of the corner, meaning that 
corner-aspect apartments are still used, but have less space.

They are, however, more versatile and can be an effective formal design

\section{SEMI-ENCLOSED BALCONY}

The private balconies on the studied examples appear to have three distinct forms. The first being more of an outdoor living room, recessed within the building envelope, sometimes with a typical apartment directly above.

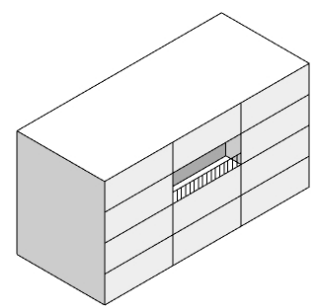

Figure 3.34

This is perfect for privacy and shelter from the elements but is unlikely to receive the best sun or views.

\section{PROTRUDING BALCONY}

The second type is the typical protruding balcony, which appears to have been tacked onto the façade. These are not particularly pleasant or safe to use, with very little privacy or shelter. component.

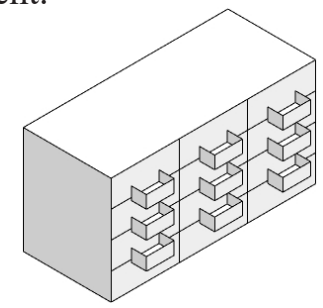

Figure 3.35

\section{STRIP BALCONY}

The final balcony form is the continuous strip balcony. In a few of the examples, this was often seen as a continuous platform wrapped around the entirety of the building at each level.

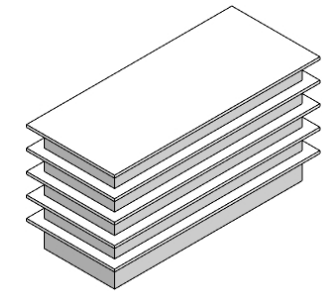

Figure 3.36

These platforms would function as walkways to access the apartments, or as private balconies divided by screens. Both options were indistinguishable from each other and their function dependent on orientation. Balconies were typically located on the side closest to the sun. 


\section{OPENING IN BLOCK PERIMETER}

A hole or opening in the perimeter of the block is common in a number of the examples, particularly in those which had public pathways through the site or had the courtyard elevated above street level.
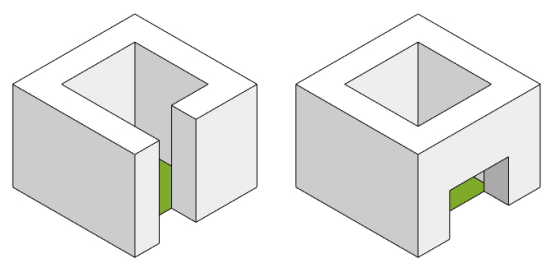

Figure 3.37

These openings can allow sunlight or fresh air to better penetrate the centre of the block, or are just necessary to allow people into the courtyard. Separation of the perimeter at the corners is also an appropriate method to provide access and also reduce overlooking and other issues that are prominent with the corner-aspect apartments.

\section{CLUSTERED APARTMENTS}

In a number of examples, the vertical circulation existed in the centre of a group of apartments. This would mean that the vertical core would not take up precious façade area and would have little-to-no corridors or walkways.

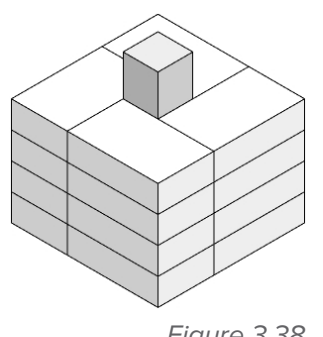

Figure 3.38

The main issue, however, was that there were typically four-to-six apartments on each floor, to each vertical core. This would mean that only the two units on the very ends would have a double-aspect layout while the rest were single-aspect.

\section{DEDICATED COMMUNAL}

\section{AREAS}

Communal areas were often provided on a dedicated section of one or two floors, in a fairly central location within the block. This space was typically celebrated via a large glazed void facing the street or by protruding from the façade into the courtyard. These areas were often used as a private gym or as a public bar, café 


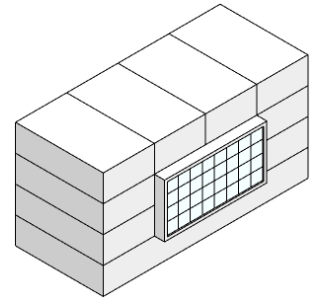

Figure 3.39

or restaurant. It was a great way to disturb any formal or spatial monotony and allows for more uses within the development.

\section{PROTRUSION INTO COURTYARD}

Protrusions into the courtyard are a good way to break up the façade and provide greater area for activities such as the communal areas mentioned above.
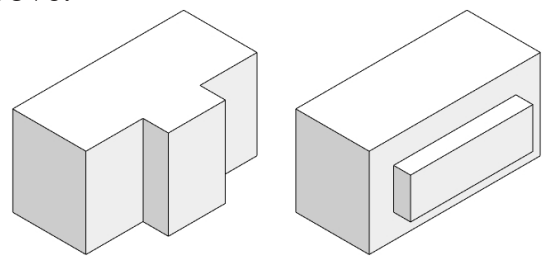

Figure 3.40

These protrusions would increase the area of building faces looking into the courtyard, allowing for more sunlight, views and ventilation on top of the increase in floor area.

\section{SUN-ORIENTED APARTMENTS}

Most of the contemporary examples opted for a sun-facing living space orientation. This improved sunlight access within these living areas, but did not often consider outlook. Other examples choose to orient the living spaces into the central courtyard.

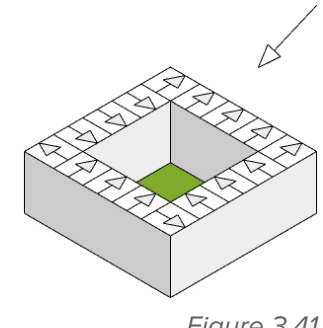

This was likely to provide a greater outlook of the landscaped courtyard, and most of the block-sides still received ample natural light. However, these developments were likely to exhibit one distinctive street-face with a different internal layout so as to direct living areas towards the sun and away from the courtyard. In the Northernhemisphere this is typically the southfacing side of the block, orienting the apartment towards the south. 


\section{KEY FORMAL}

\section{CHARACTERISTICS}

\section{SLOPED/TIERED ROOF-LINE}

A sloped or tiered roof form is a staple of contemporary EPB design and is the best way to maximise density while providing sufficient natural light and views to all apartments. The perimeter is typically lower to the south (in the northern hemisphere) to maximise sunlight penetration into the block, and therefore into the apartments.
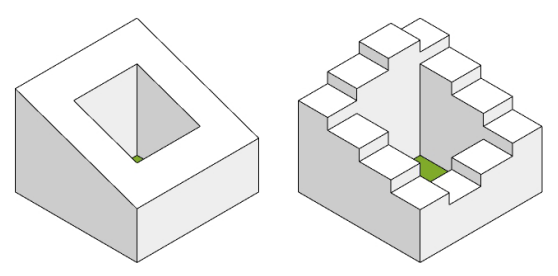

Figure 3.42

This strategy also produces building profiles that are more eventful than the traditional EPB with its typically uniform parapet. This adaptation makes the EPB better suited to standalone applications. Slope or stepping of roof is not always constant with some variation in slope or step down, sometimes fluctuating up or down.

\section{ROOFTOP TERRACES}

Rooftop terraces typically coincide with a sloped or tiered roof, taking back some of the lost space with outdoor areas to be used by adjacent apartments.

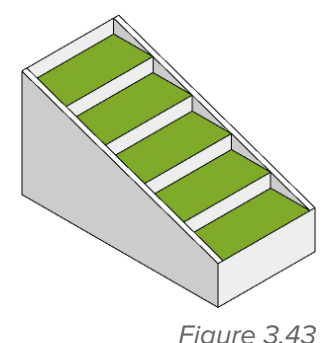

It some cases these rooftop spaces are for shared use by all the residents of the building, and are often just on the top of a building that is not tiered or sloped. It is also possible to provide a similar effect with window voids on a sloped roof plane.

\section{ELEVATED COURTYARD}

A few of the examples provided a central courtyard that was elevated above street level. The reason for this was to provide car parking and retail establishments beneath the courtyard, with direct access to the street.

Combining this characteristic with a 
gap or opening in the perimeter of the block can produce a pleasant lookout from the courtyard to the adjacent city area. However, implications for public access and landscape treatment need to be considered.

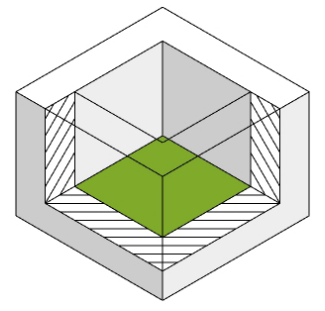

Figure 3.44

\section{SAW-TOOTH FAÇADES}

Saw-tooth façades are used when the individual apartments are oriented towards a particular view or sunlight azimuth, offset at an angle from the street axis. This is often done to maximise views or sunlight with the added benefit of an interesting façade aesthetic.

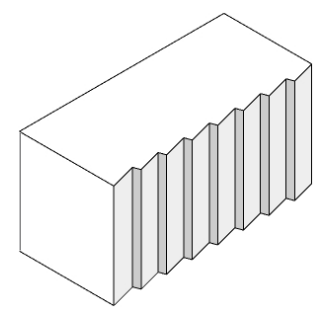

Figure 3.45
The jagged form that is produced from this also allows for each apartment to have a corner-aspect, because each single apartment face has become two meeting at a corner. This can improve cross-ventilation and provide a more varied outlook, however if the building is oriented perpendicular to the midday sun this spatial strategy can often have the opposite effect, lessening the penetration of midday sun.

\section{MODULAR PIXEL FORM}

Popular particularly with the BIG examples is a pixel-like form, comprised of hundreds of cubic modules which stack and fit together to create the overall building form.

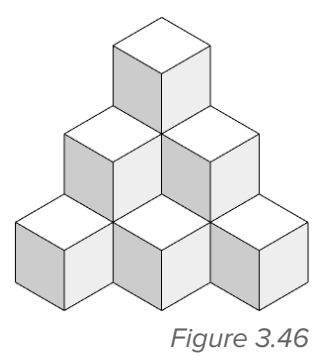

These modules are typically the size of a room and are offset from the street by $45^{\circ}$, producing a similar façade effect to the saw-tooth characteristic. 
Apartments are comprised of multiple modules (corner aspect common and important). This form is ideal for creating a tiered roof-line with private roof terraces for the top-most apartments. Like other characteristics, this is much more common with standalone developments which do not need to maintain a coherent 'street wall'.

\section{VERTICAL CORE VISUAL CHARACTER}

Vertical circulation is not always expressed externally, with some floor plans dictating an internal stair and lift core. However, a few examples do choose to identify which sections of the development use which entrances via a cladding change or varying colours.

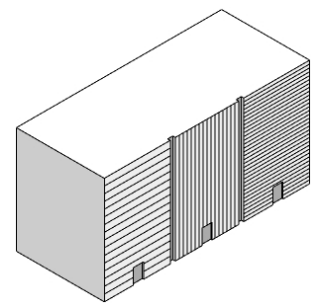

Figure 3.47

The purpose of this is not only to easily identify where to access each group of apartments, but also to provide the occupants with a greater sense of identity as opposed to simply being a small part of the greater whole.

\section{VARIED BUILDING HEIGHTS}

Varying building heights is a good alternative to stepping or sloping the roof-line because it provides voids or gaps to allow improved sunlight penetration or air circulation within the courtyard.
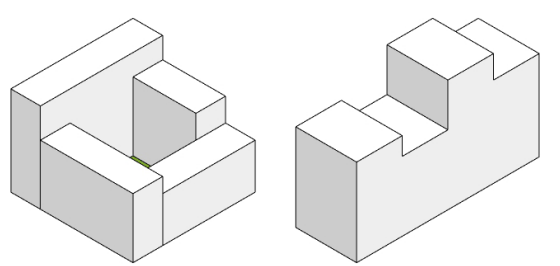

Figure 3.48

This can also increase the number of external faces for certain apartments, improving sunlight and cross ventilation if needed.

\section{UNIQUE NORTH FACE}

For most examples the north face (northern hemisphere) usually exhibited a separate identity to the 
other faces of the block due to facing away from the sun.

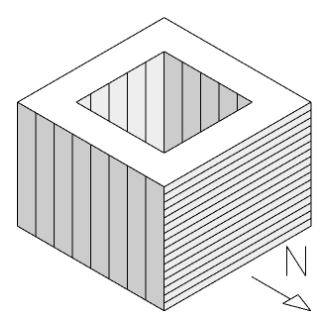

Figure 3.49

This would usually mean it had a

different orientation and therefore a different circulation to the rest of the block. The North elevation would then differ from the other street façades.

\section{INSIDE/OUTSIDE CLADDING CHANGE}

Often, different cladding was used on the inside and outside of the block.

This could be to further emphasise the division between the pubic street and the semi-private central courtyard.

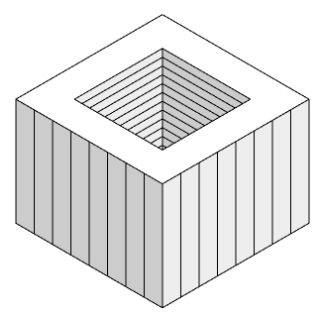

Figure 3.50
A tougher, more durable cladding may be used on the outside, while a softer, more comforting cladding may be used on the inside. This improves the intimacy and relationship between the occupants and the crucial central courtyard of the block.

\section{UNIQUE PENTHOUSE IDENTITY}

Penthouse apartments are typically given a separate treatment to the main body of the building. This can either help to celebrate the 'ideal' apartment or can be used to lessen the impact of the building's height.

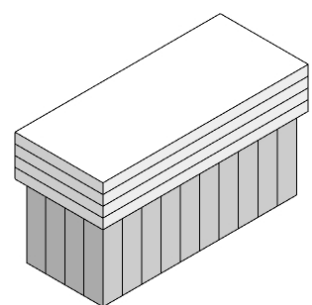

Figure 3.51

It is also important to providing an interesting overall building aesthetic and can give the penthouse owners a sense of individuality. 


\section{CONTEMPORARY DOWNSIDES}

The main problems with the

contemporary EPB's relate to

circulation, aspect and distinction

between public and private space.

Many of the examples studied adopt

a double-loaded corridor circulation

method, which produced single-aspect

apartments. This eliminates one of

the benefits of traditional EPB design;

double-aspect layout. While double-

loaded corridors are economical

in regard to minimising vertical

circulation, the quality of life within the

apartments is reduced due to a lack of

cross-ventilation and reduced sunlight.

Another troubling issue is the function

of the central courtyard. In some of

the examples, this was massively

underutilized or relegated entirely to

circulation. While the central void

is certainly beneficial in regard to

sunlight and ventilation, failure to

assign a more explicit programme

to the central open space is a wasted

opportunity. Opening up this area for public pathways through the site is also a questionable choice. While it is not always problematic (e.g. public access can help to activate the open space) it undermines the key benefits of a fully enclosed central courtyard: privacy and safety. Families want space for kids to play, close to home, without any threats or danger. Therefore, opening this space to the public compromises this objective. It allows children to wander off and permits strangers to enter what would otherwise be a private communal domain.

This courtyard is also problematic when applied to a New Zealand Context. In New Zealand there are minimal cultural traditions regarding shared spaces, particularly in a highdensity residential setting. The success of this space is unable to be accurately evaluated without a comprehensive sociological study on the relationship between New Zealanders and communal open space within highdensity residential developments. 
This thesis focuses primarily on the practical and aesthetic considerations associated with the EPB building type, of which the central courtyard is an intrinsic component. New Zealanders' acceptance of such a space is a research topic in its own right and largely outside the scope of this thesis.

\section{CONCLUSIONS}

Contemporary EPB's take a popular traditional housing model and adapt it for modern living at appropriately high densities. Each precedent exhibits a distinct form and accommodates different functions. However, all the examples include at least a few of the fundamental characteristics of the traditional EPB model.

One key trend, not particularly common in traditional EPB's, is the distinct architectural treatment of each side of the block in response to sunlight, aspect and context. This produces varying heights, materiality, circulation, and scales which results in unique designs which look good and function even better. The varied elevations also deal well with urban settings, especially in stand-alone EPB developments, which lack a closecontext of similarly scaled buildings.

Where traditional EPB's orient living spaces out towards the street, contemporary EPB's typically orient towards the sun or into the courtyard. This provides a greater outlook of the landscaped courtyard and much better sunlight into the regularly occupied living spaces. The bedrooms typically face the street with smaller windows, which in turn provides more privacy. This is especially true when the apartments are above street level.

While they do have inherent issues, as mentioned, the Contemporary EPB models can be considered a vast improvement over their traditional counterpart. The balance between traditional and contemporary characteristics offer a viable model for urban housing in a New Zealand context. 


\section{DESIGN PRINCIPLES, STRATEGIES \\ AND CRITERIA}

\section{PRINCIPLES:}

$\rightarrow \quad$ Responsive Design

$\rightarrow \quad$ Face-Specific Identity

STRATEGIES:

$\rightarrow \quad$ Duplex Apartments

$\rightarrow \quad$ Vertical Cores in Corners

$\rightarrow \quad$ Semi-Enclosed Balcony

$\rightarrow \quad$ Protruding Balcony

$\rightarrow \quad$ Strip Balcony

$\rightarrow \quad$ Opening in Block Perimeter

$\rightarrow \quad$ Clustered Apartments

$\rightarrow \quad$ Dedicated Communal Areas

$\rightarrow \quad$ Courtyard Protrusions

$\rightarrow \quad$ Sun-Oriented Apartments

$\rightarrow \quad$ Sloped/Tiered Roof-line

$\rightarrow \quad$ Rooftop Terraces

$\rightarrow \quad$ Elevated Courtyard $\rightarrow \quad$ Saw-Tooth Façade

$\rightarrow \quad$ Modular Pixel Form

$\rightarrow \quad$ Vertical Core Visual Character

$\rightarrow \quad$ Varied Building Heights

$\rightarrow \quad$ Unique North Face

$\rightarrow \quad$ Inside/Outside Cladding

\section{CRITERIA:}

$\rightarrow \quad$ High-Density with High-

Amenity

$\rightarrow \quad$ Optimised Natural light and

Outlook

$\rightarrow \quad$ Situational Circulation System

$\rightarrow \quad$ Managed Relationship

Between Public and Private

$\rightarrow \quad$ Sense of Identity and Character

$\rightarrow \quad$ Semi-Private Central Courtyard

$\rightarrow \quad$ Definition and Activation of

Public Space 
European Perimeter-Block:

SPECIFIC ATTRIBUTE STUDIES

\section{IMAGE REDACTED \\ (See Figure List for Source)}

Figure 3.53 - Potrero 1010

by David Baker Architects 


\section{ELEVATION COMPOSITION}

EPB housing in its typical form takes up an entire city block, meaning that the street walls of each block are quite uniform in character. A common issue with large developments such as these is façade monotony, typically caused by long building faces with repeating elements such as windows. This can reflect negatively on the overall building, and potentially devalue the surrounding context.

To avoid this, a brief study on the composition of building elevations has been undertaken. For this study, a single architecture practice has been chosen and its architectural portfolio analysed to provide a number of strategies for improving the visual interest of a façade and avoiding monotony.

The chosen architecture practice was David Baker Architects (DBA) from San Francisco. They were chosen based solely on my informed opinion that the majority of their architecture effectively avoids monotonous designs and produces interesting façades.

The similarities between San Francisco and New Zealand in regard to seismic design and lightweight construction is also important to a New Zealand adaptation. Since San Francisco developments are likely to follow similar construction methods and materials, the design strategies will be easily constructed with similar methods and materials in New Zealand.

Lastly, DBA was chosen based on the fact that a number of key strategies are evident in their designs. Some of these are repeated throughout their designs, and others are just unique and not often seen or used. Eight of these design strategies are identified on the next page. 
BEDROOMS PROTRUDE FROM FAÇADE

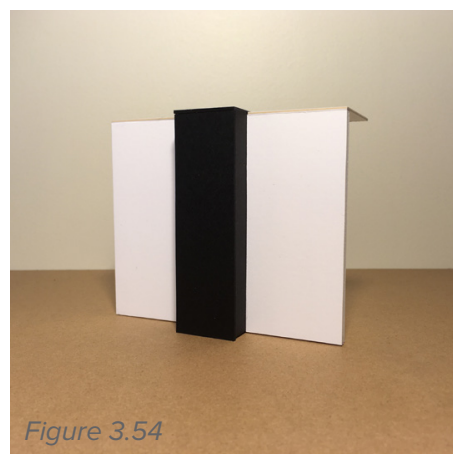

The floor plans in many of DBA's designs are identical across multiple floors. This allows chosen bedrooms to protrude from the façade, creating a unique form going up the entirety of the façade. Not only does this create more space internally, but it breaks up the façade and provides an interesting feature.

When repeated, these vertical protrusions are used to separate the living spaces of adjacent apartments, allowing for more privacy, and lessening the impact of multiple protruding balconies. Usually, a cladding change is used to emphasise recessed and protruding sections of the facade.

\section{VERTICAL CORE RECESSION}

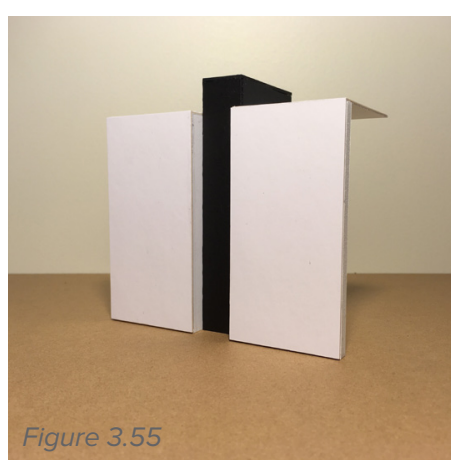

A successful technique to break up the façade is recessing the vertical core into the façade. Not only can this help to reduce monotony but in buildings with multiple cores, it can divide up the various 'clusters' of apartments which access each set of stairs/lifts. This can give the occupants within the building a greater sense of address and identity. It is also an effective way to communicate where the entrance to the building is and how to access the apartments above.

When the cores are near the corners, this can visually differentiate between the two façades on each side of the corner (See "Unique Corner identity"). Extending the top of the circulation core above the building parapet is also 
common with this technique and helps to emphasise the uses above while also providing more space for the building plant.

\section{UNIQUE GROUND FLOOR}

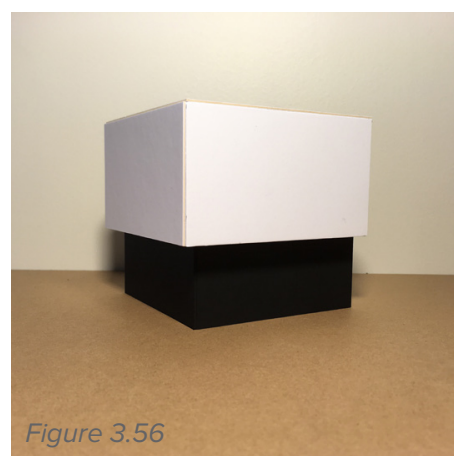

Ground floor set-back or cladding change is common in DBA's work and similarly in all forms of high-density residential dwellings. This is largely due to the ground floor being dedicated to retail or commercial establishments, or just as a main entrance into the building.

Because it has a different use, it often demands different treatments in terms of access and views in and out of these establishments. A glazed curtain wall is a popular cladding choice for this reason. Recessing the ground floor is an effective strategy for providing more foot-path space without sacrificing floor area for the apartments above. It also visually separates the private residential apartments above from the public uses below.

\section{UNIQUE CORNER IDENTITY}

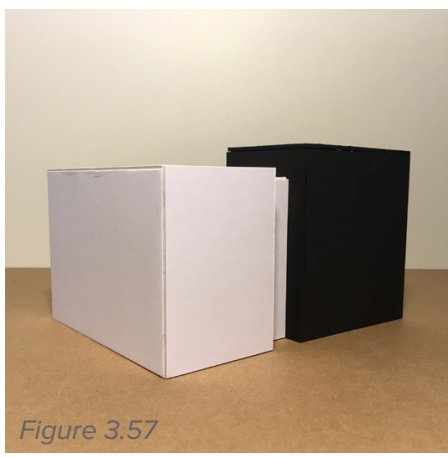

When a residential building or development is located on a street corner, the façades on each street can often differ aesthetically and sometimes functionally.

While it is not difficult for this change to occur at the intersection between the two façades, it is far more pleasant and functionally superior to wrap one façade around the corner and provide a separation between the two. This separation is typically achieved with 
a recession, such as is done with the vertical circulation cores, or by extending the corridor to the façade (see next strategy). Since apartments can often be located on these corners, the wrap-around cladding can communicate where one row of apartments differs from the apartments on the other side of the corner.

\section{CORRIDOR EXTENDED TO}

\section{FAÇADE}

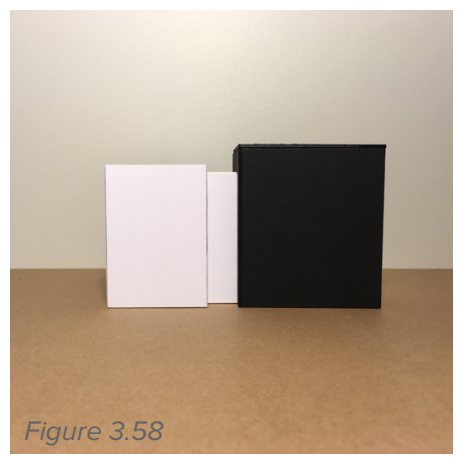

Extending internal circulation corridors to the façade can help with two things.

Firstly, it is one method to separate two façade identities, particularly at corners. And secondly, it provides natural light into what would otherwise be a fairly clinical corridor. While it is likely to be a waste of space functionally, it is likely to improve the experience of using these spaces and also improve the overall aesthetic of the façade.

\section{VOID FOR COMMUNAL AREAS}

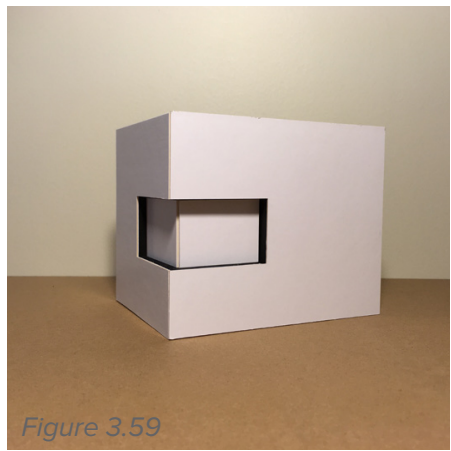

Communal areas are very common in large, higher-density residential developments. Since ground floor street-front is prime real-estate for retail or commercial establishments, the best place for the communal spaces is on the first floor. This is as close to main lobbies as possible without taking up precious ground floor space. Considering that the programme of the communal space will differ from the largely residential programme of the rest of the development, it would be no easy task to try and disguise 
it externally. Therefore, it is best to

celebrate the change in programme and simultaneously improve the outlook and sunlight penetration of this space. This can be achieved with glazed curtain-walls inset into the façade, which can be particularly effective from a functional and aesthetic viewpoint when used on corners.

\section{DISTINCTIVE SUPERIMPOSED} "SCREEN"

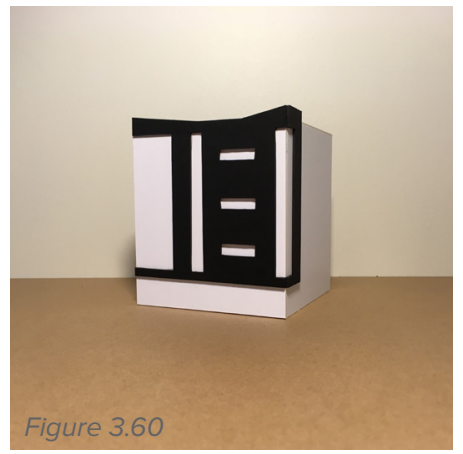

One technique to improve the interest of a building façade is by covering a section of it with what appears to be a second cladding layer. This 'layer' often has gaps and holes of various sizes and orientations to accommodate windows and further improve the interest of the façade. Wrapping this around corners is a great way to simulate unique corner identities. It is important that this feature does not take up the entire height or width of the façade, otherwise it will not appear as a 'screen' but rather just a different section of façade.

\section{MATERIAL CHANGE FOR}

\section{ALIGNED WINDOWS}

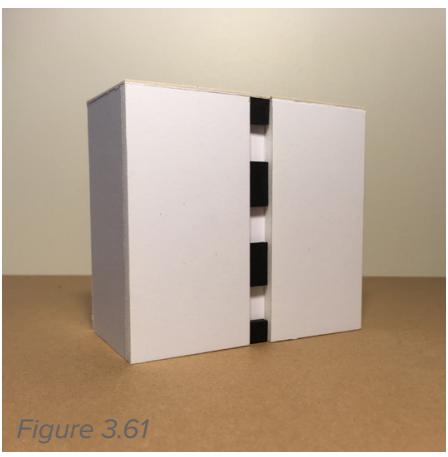

Arguably, the main contributor to monotonous façades is repeating windows. Most apartment buildings have repeating floor-plans which inturn results in repeating façades due to the apartment windows. An effective way to break up the repetition and create interesting aesthetic features is by using a "backdrop" the same width as a column of aligned windows to 
'separate' those windows from the rest of the façade. It can be used for feature windows on otherwise bare sections of façade, or amongst other windows. This strategy also potentially improves cladding installation for some cladding types.

\section{CONCLUSION}

These common strategies discovered in the work by David Baker Architects are very relevant to EPB housing design.

This may be partially due to the fact the a couple of DBS's designs are indeed contemporary perimeter-blocks, but a number of them help specifically with corners, of which an EPB has four, and long façades with multiple circulation cores.

Using all six strategies on one facade is not a particularly good idea because of clashing and over-emphatic articulation. However, combining a few selected strategies on each of the four external façades of an EPB development promises to be successful.
DESIGN PRINCIPLES, STRATEGIES AND CRITERIA

\section{PRINCIPLES:}

$\rightarrow \quad$ Avoid Facade Monotony

\section{STRATEGIES:}

$\begin{array}{ll}\rightarrow & \text { Bedrooms Protrude from } \\ & \text { Facade } \\ \rightarrow & \text { Vertical Core Recession } \\ \rightarrow & \text { Unique Ground Floor } \\ \rightarrow & \text { Unique Corner Identity } \\ \rightarrow & \text { Corridor Extended to Facade } \\ \rightarrow & \text { Void for Communal Areas } \\ & \text { Distinctive Superimposed } \\ \rightarrow & \text { "Screen" } \\ & \text { Cladding-Change for Aligned } \\ & \text { Windows }\end{array}$

\section{CRITERIA:}

$\rightarrow \quad$ Eventful Building Façades

$\rightarrow \quad$ Sense of Address / Identity

$\rightarrow \quad$ Positive Relationship to Urban

Context 


\section{STAIRCASE DESIGN}

The design strategies and criteria

discovered this far in the research

indicate that the design case study will

have multiple staircases. Some of these

serve as an aesthetic design feature

within the façade. Because of this, it is important to put some thought into the staircases' function and appearance.

Although a number of spatial strategies from the Contemporary EPB study specify hiding the staircase amongst a cluster of apartments or within the corners of the block, DBA's designs avoid this by using the vertical core as a design feature within the facade. A choice must be made between maximising occupiable facade area or improving building aesthetic.

From the perspective of developers, keeping the circulation cores within the building interior is more economical and will dedicate more facade area for apartment windows. However, expressing the core on the exterior of the building and providing the stairwell with natural light and outlook is arguably more pleasant from the perspective of the occupants.

Considering that this research is largely targeting the improvement of living conditions for the occupants of highdensity urban residential buildings, it stands to reason that the stairwells should be designed with this in mind, even at the expense of lettable area.

The following eight staircase designs were designed with various aspects of functional, aesthetic and experiential goals in mind. The aim with these designs was to experiment with as many variations as possible, with no particular orientation (courtyard or street). The common attribute for each design is maintaining a 'Lightweight' form which maximises vertical space between each staircase. This makes the space feel less cramped and allows more natural light. 


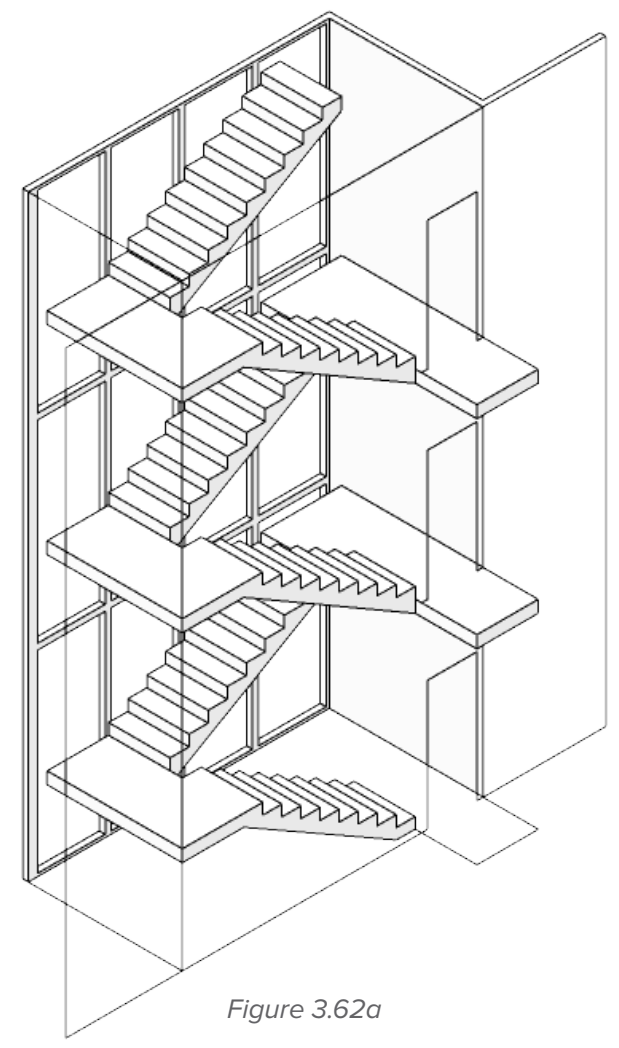

EXTERIOR ATTACHED

- Internal or external staircase

- Landing-to-landing support

- Total protrusion from facade
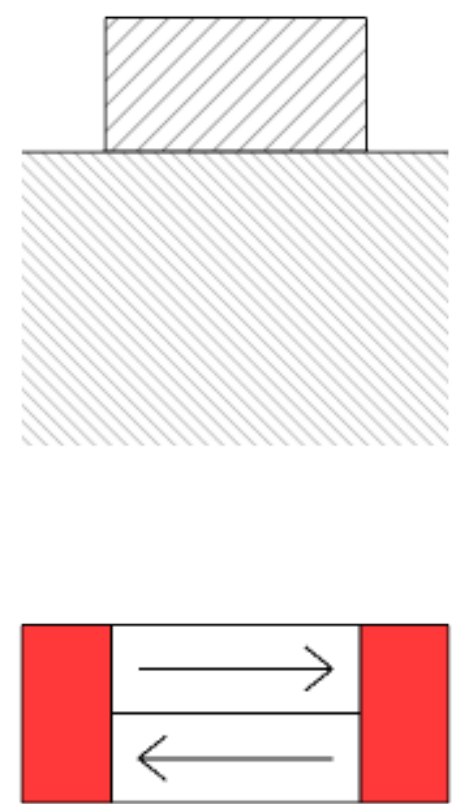

Figure $3.62 b$

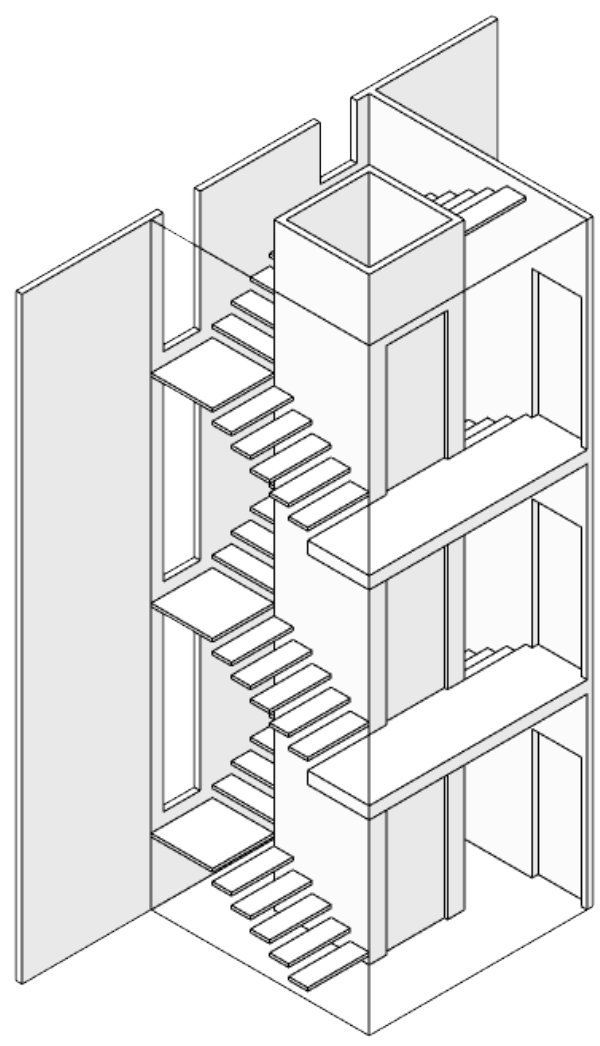

Figure $3.63 a$

WRAP-AROUND

- Internal staircase and landing

- Elevator-core stair support

- Zero protrusion from facade
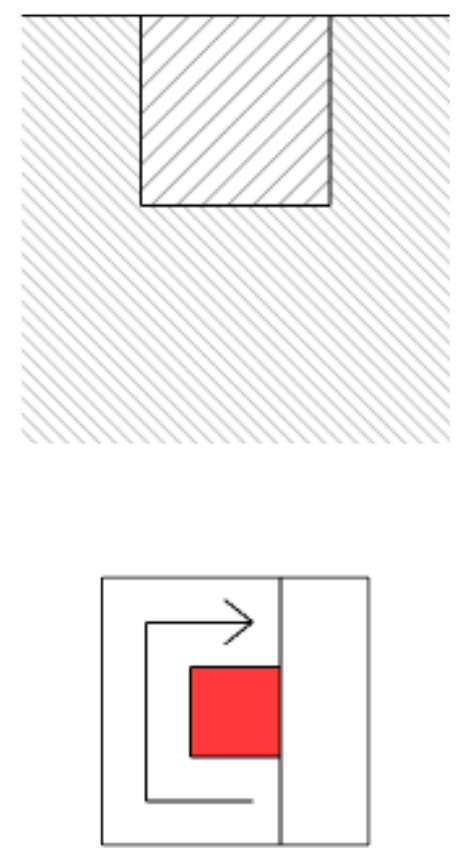

Figure $3.63 b$ 


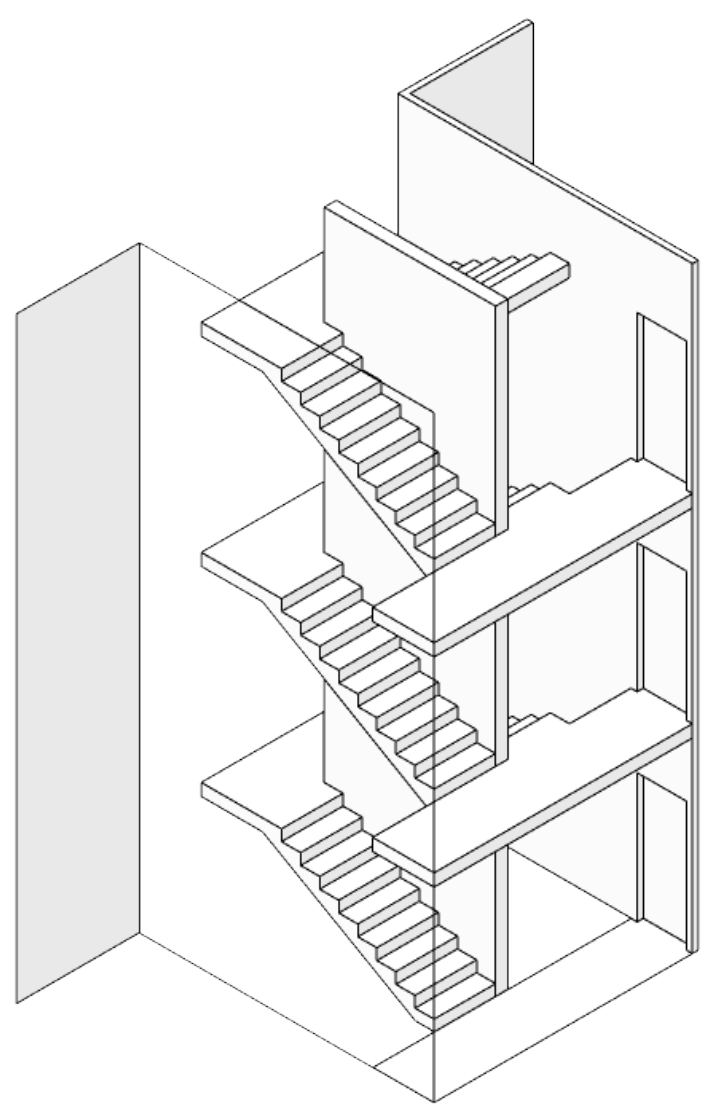

Figure $3.64 a$

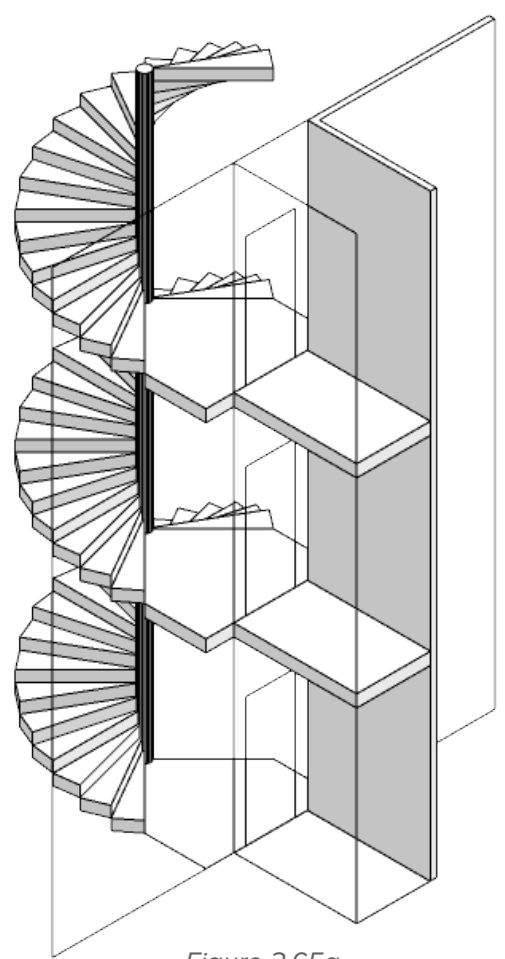

Figure $3.65 a$

\section{SPIRAL}

- External staircase and landing

- Centre-wall stair support

- Full protrusion from facade

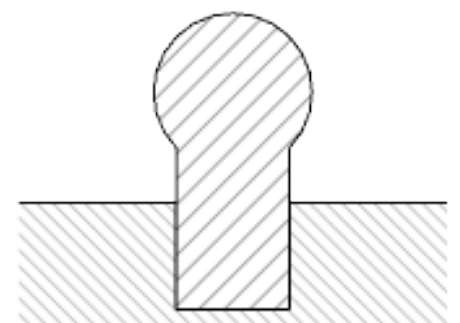

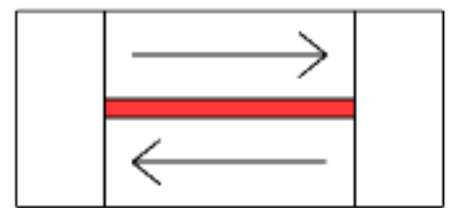

Figure $3.64 b$

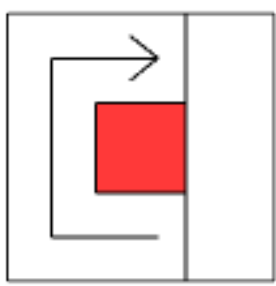

Figure $3.65 b$ 


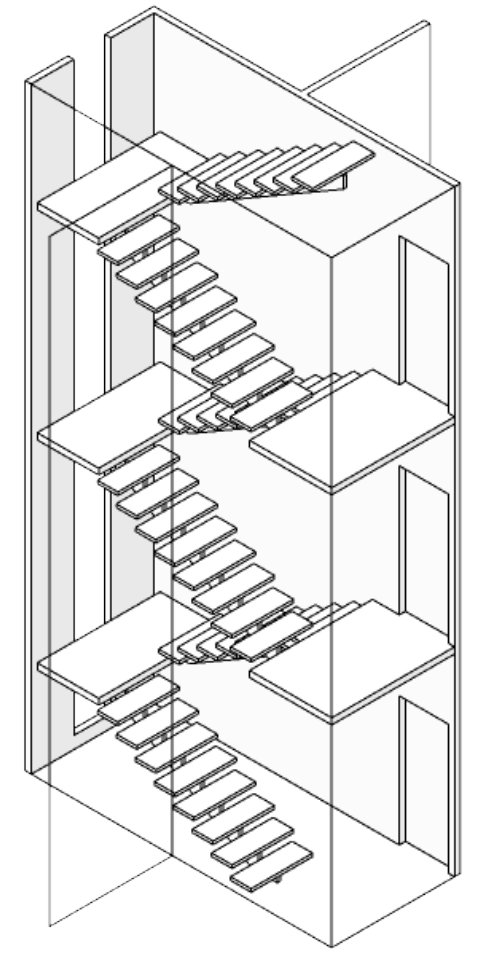

Figure $3.66 a$

\section{SLIM PROTRUSION}

- Internal staircase and landing

- Centre-stringer stair support

- Half protrusion from facade
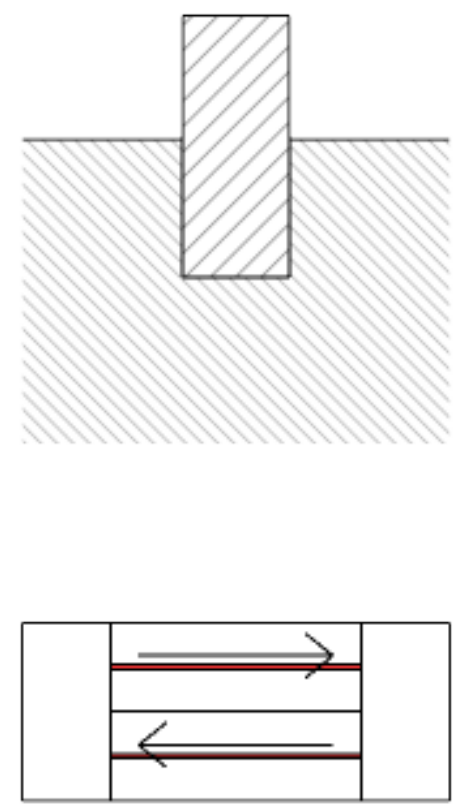

Figure $3.66 b$

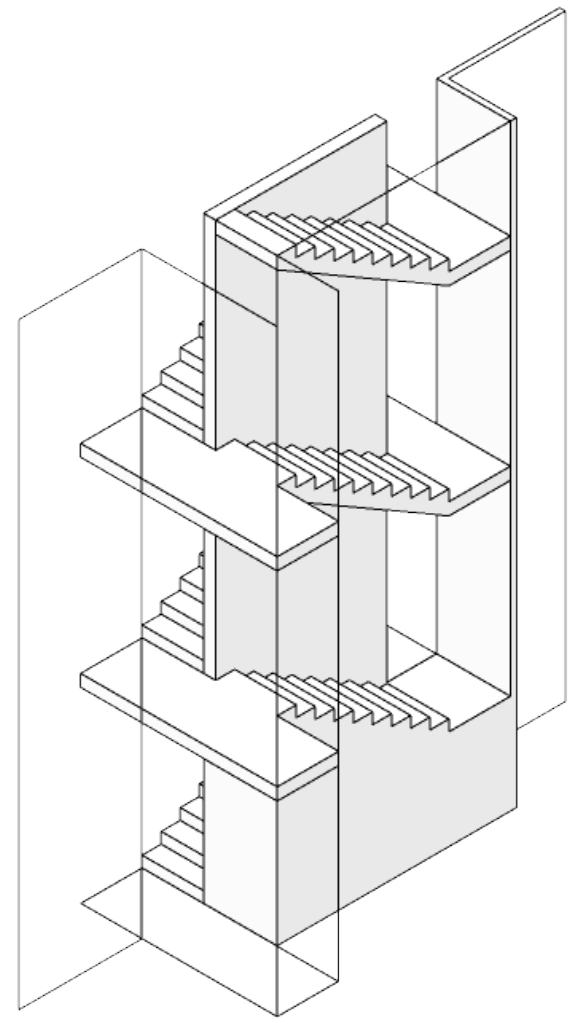

Figure $3.67 a$

IN \& OUT

- External staircase and landing

- Centre-wall stair support

- Half protrusion from facade
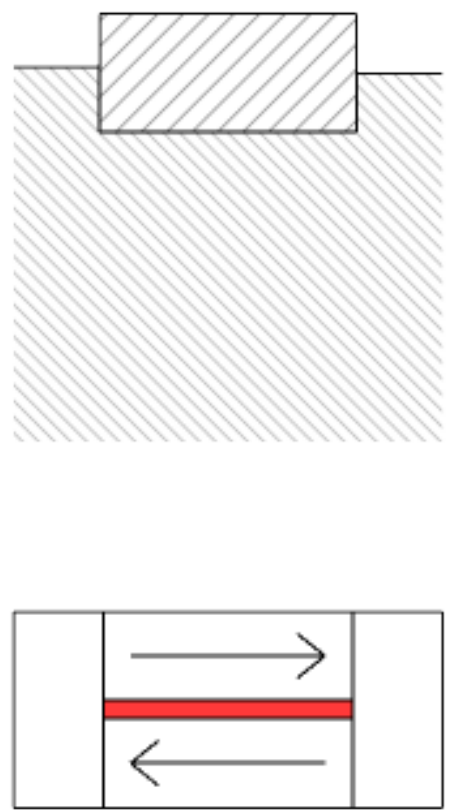

Figure $3.67 \mathrm{~b}$ 


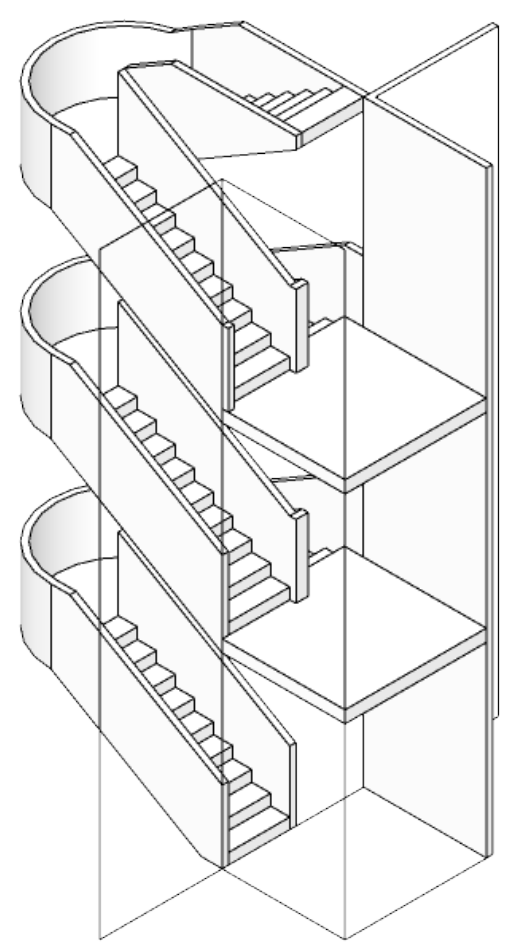

Figure $3.68 a$

\section{CANTILEVERED}

- External staircase and landing

- Cantilever handrail support

- Total protrusion from facade
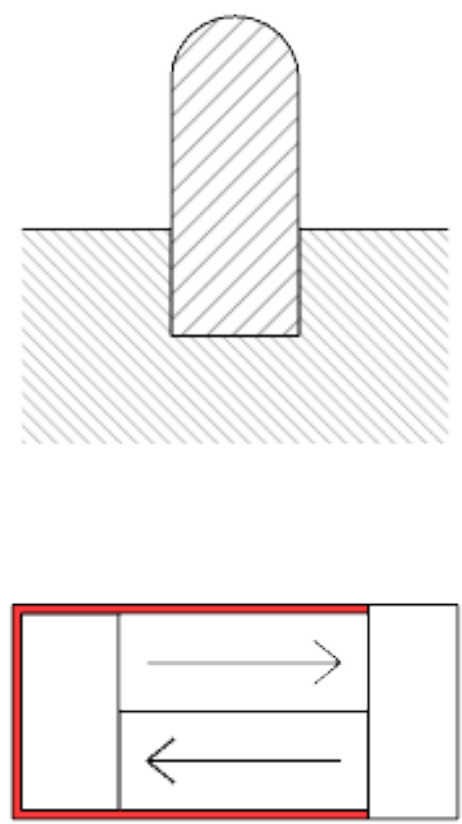

Figure $3.68 b$

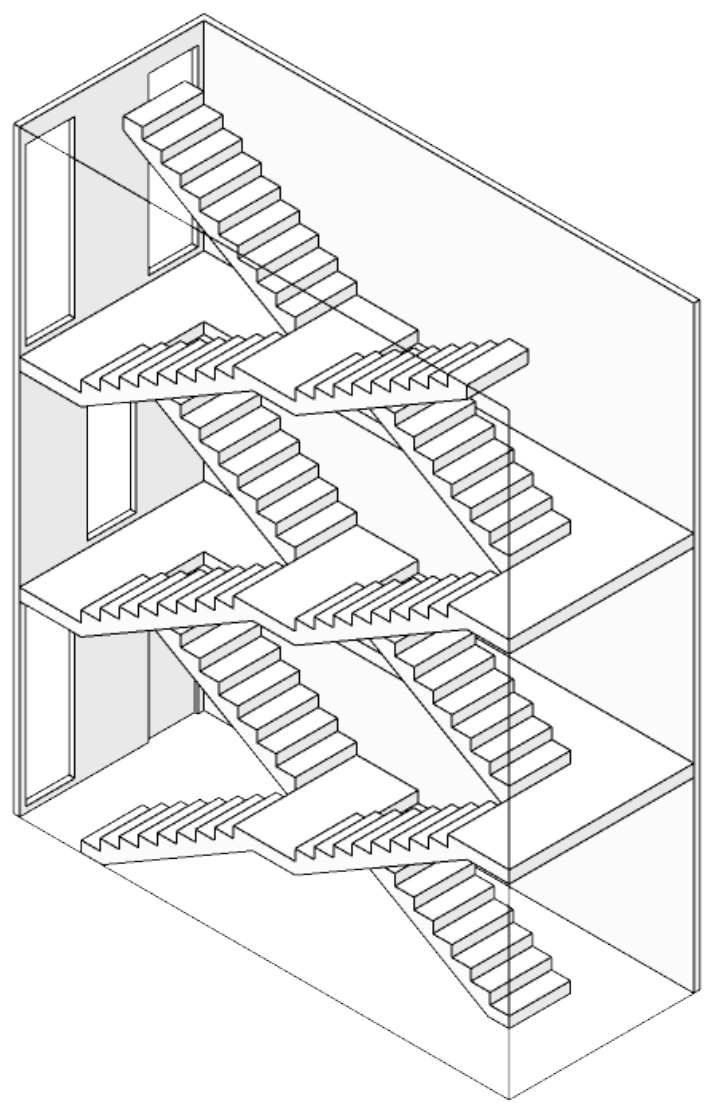

Figure $3.69 a$

\section{SCISSOR-STAIRS}

- Internal staircase and landing

- Landing-to-landing support

- Small recession into facade
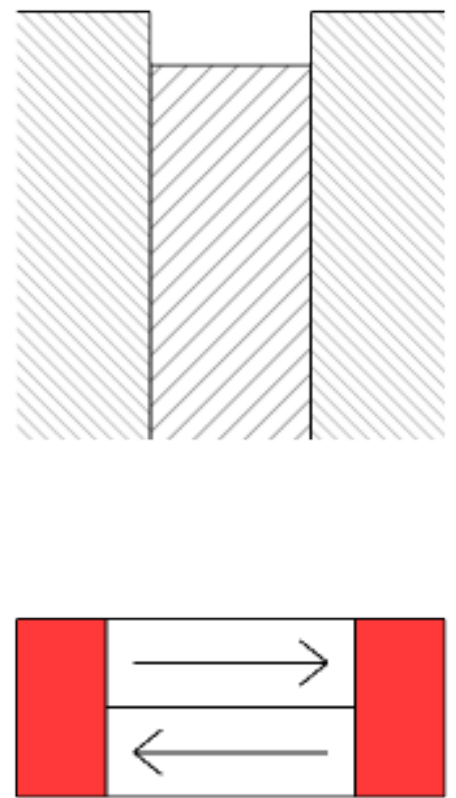

Figure $3.69 b$ 


\section{CONCLUSIONS}

Each staircase design has its own benefits and flaws based on their application, so it is difficult to discern which option or options are the best to apply to a New Zealand EPB development.

At this stage, based on the research so far, an enclosed version of the "Separated / Centre Wall" would be the best staircase option. This is largely due to the fact that while experience for occupants should definitely take priority over economy, a slimmer stairwell facade profile would mean that there is more facade space for the exterior walls of apartments. This slimmer profile also aligns with the DBA strategies and will provide a generally nicer facade feature.

From an experiential standpoint, providing windows up the entire staircase is important for allowing sufficient natural light and a pleasant outlook to the street or central courtyard.

A recess on either side of the staircase can help to produce a larger landing area while maintaining straight dividing walls between the circulation core and the adjacent apartments. The vertical core will also require an elevator, which will likely share the landing with the staircase. Therefore, extra space yielded by the recess will be much appreciated by the building occupants. This separation is also a nice unique design element, creating a 'simulated' multi-height space to improve light and ventilation.

Providing a pleasant journey from the street entrance to each apartment's front door is crucial to a successful high-density apartment building, and can greatly emphasise the tenants satisfaction with the apartments. Without this, any and all efforts to improve inner-city living are hindered. 
DESIGN PRINCIPLES, STRATEGIES AND CRITERIA

\section{PRINCIPLES:}

$\rightarrow \quad$ Pleasant journey from street to door

\section{STRATEGIES:}

$\rightarrow \quad$ Slim stairwell facade profile

$\rightarrow \quad$ Multi-level void space

$\rightarrow \quad$ Large landing area

$\rightarrow \quad$ Stairwell external windows

$\rightarrow \quad$ 'Lightweight' staircase form

\section{CRITERIA:}

$\rightarrow \quad$ Improved natural light and outlook

$\rightarrow \quad$ Perception of spaciousness

$\rightarrow \quad$ Eventful Building Façades 


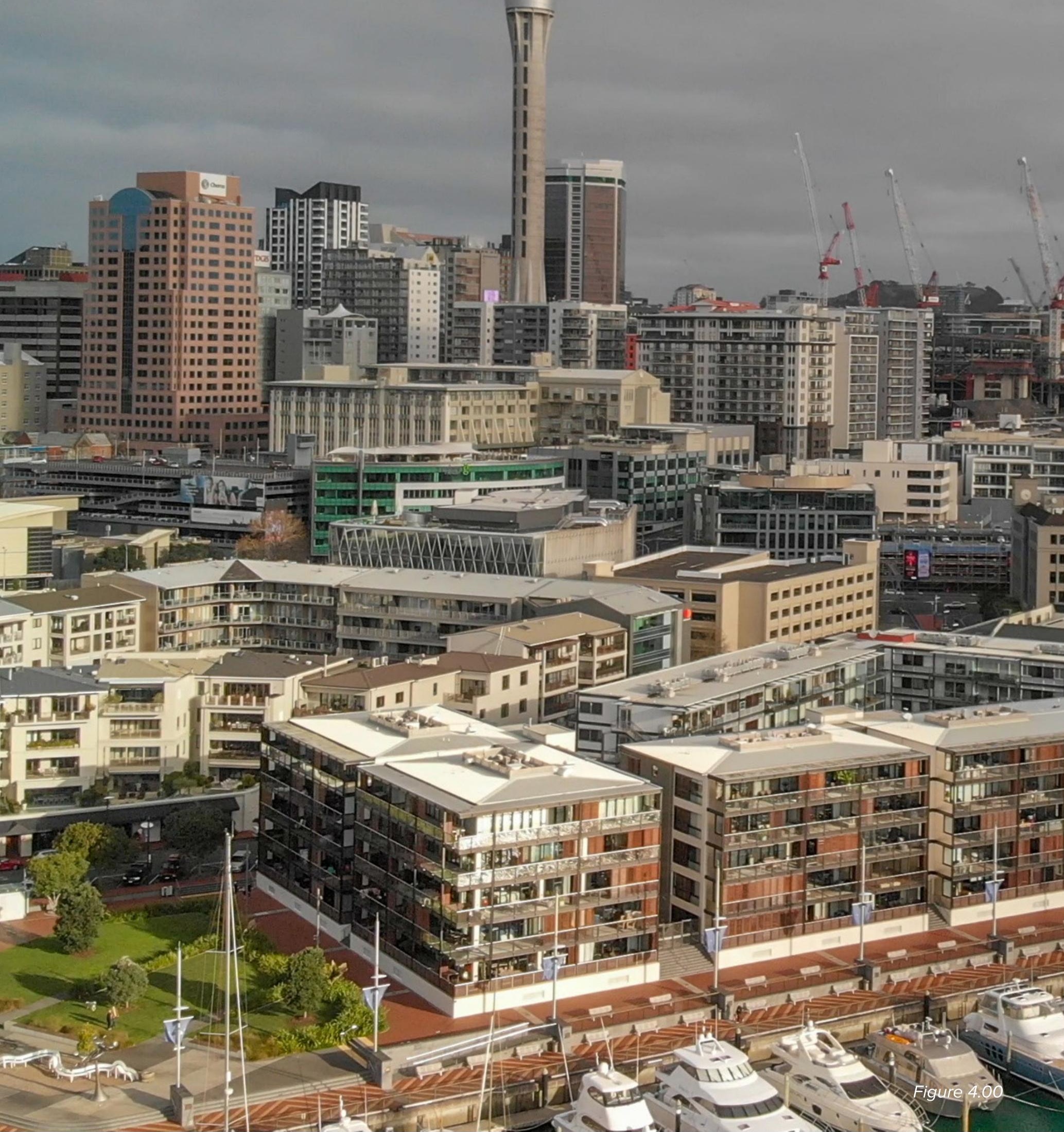




\section{CHAPTER FOUR}

Best-Practice Urban Residential Design

+ Availability of Inner-City NZ Sites 
New Zealand Urban Living:

\section{BEST-PRACTICE APARTMENT DESIGN}

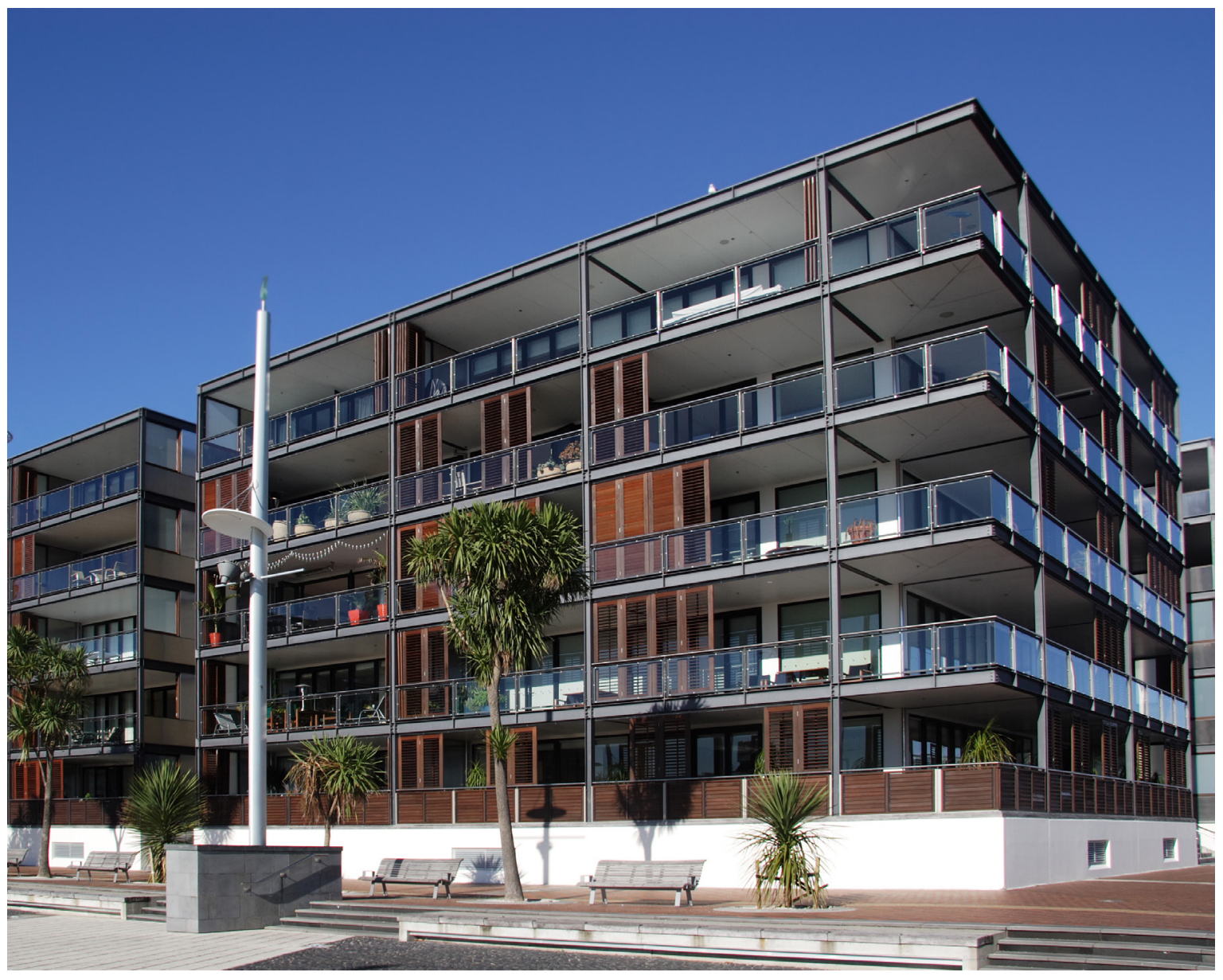

Figure 4.01 - Modern Apartment Development in Auckland City 
Up until this point, studies on the design of high-density housing have focused mostly on the formal and spatial qualities of apartment developments as a whole. There is little research on the internal layout of each individual apartment. To understand the best-practice principles for high-density urban apartments, two documents have been consulted. The first is the 2006 Good Solutions Guide for Apartments, and the other is the Auckland Design Manual. These principles will provide a list of design opportunities, constraints, and criteria to apply to the research.

\section{GOOD SOLUTIONS GUIDE}

The Good Solutions Guide for Apartments is a non-statutory 'BestPractice' design guide developed by North Shore City Council in 2006. It describes key principles for the design of high-density apartments, with six Auckland apartment developments as case-studies. The purpose of the guide is to promote good design of urban residential apartments with particular

emphasis on improving the quality of life for people living in dense urban environments.

\section{AUCKLAND DESIGN MANUAL}

The Auckland Design Manual is New Zealand's guide on urban residential design, including high-density residential apartments. It accompanies the unitary plan and is based on international best-practice standards. The Manual consults a number of successful residential case studies from around the world to provide guidance on how to design comfortable, practical and efficient residential solutions in urban New Zealand.

\section{BEST-PRACTICE PRINCIPLES}

The following urban residential design suggestions have been extracted from the two New Zealand apartment design guides. Excluded from this list are any suggestions that are already a staple of EPB design such as double-aspect apartments or outdoor space. 


\section{DIVERSE APARTMENT}

\section{SELECTION}

An apartment development must

contain a variation of apartment sizes

and types in order to appeal to a wider percentage of the market.

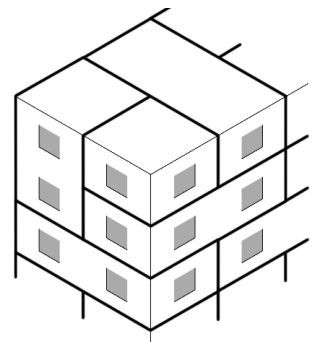

Figure 4.02

Providing apartments for a mix of households improves the diversity and stability of the development, allowing occupants to switch apartments to suit shifting needs. It is also important to provide accessible units for people with disabilities as this can be an area of the market which is often overlooked.

\section{INCREASED CEILING HEIGHT}

A particularly common issue with urban apartments is a lack of sunlight penetration and perceived spaciousness. Increasing the ceiling height for apartments not only allows sunlight to penetrate deeper into the space, but the perceived size of the space is increased. Along with living areas, this is especially useful for bedrooms which are often kept to an efficient size.

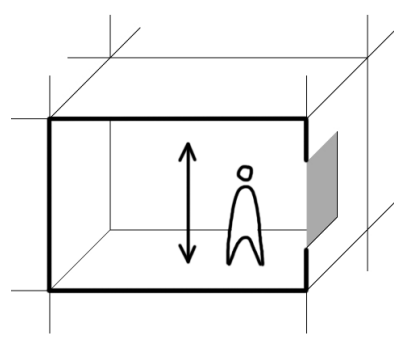

Figure 4.03

An increase in ceiling height can make the room feel bigger even when the floor-area has not changed.

\section{HABITABLE ROOMS ON EXTERNAL WALLS}

All living areas and bedrooms should be located on the external walls of the building to allow for external windows.

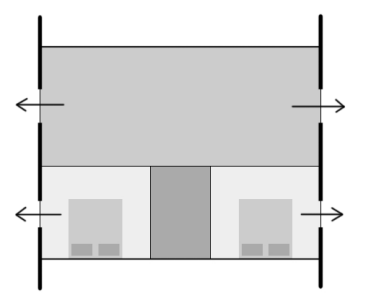

Figure 4.04

This maximises the number of rooms 
with windows, thereby improving

daylight access, natural ventilation

and outlook. Kitchens and bathrooms

should follow this principle where

possible, however mechanical

ventilation can adequately substitute

without the benefit of natural light.

\section{ACOUSTIC PRIVACY}

Where possible, apartment spaces

should be located back-to-back

with adjacent apartment spaces of

comparable noise levels.

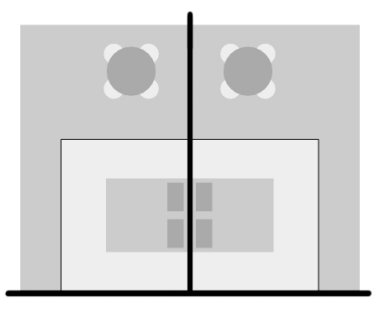

Figure 4.05

Quiet spaces such as bedrooms

should be adjacent the bedrooms of neighbouring apartments and loud spaces such as bathrooms, kitchens or living rooms should be adjacent the corresponding spaces in the neighbouring apartments. This ensures a relative acoustic transmission balance

between the neighbouring apartments. Similar methods should be applied vertically as well as horizontally.

\section{CROSS-VENTILATION}

Natural ventilation is crucial for providing a comfortable indoor environment. It removes the need for mechanical ventilation, so it is an environmentally sustainable method.

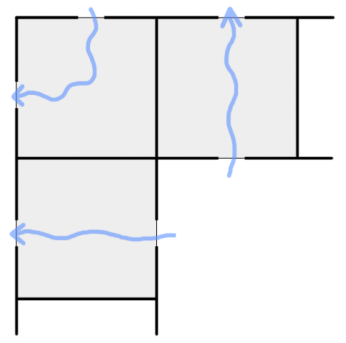

Figure 4.06

To maximise natural ventilation, each apartment should have at least two means of entry/exit for airflow. Some apartments in EPB developments are fortunate enough to have double-aspect or corner-aspect layouts which greatly facilitates cross-ventilation. Efficient ventilation occurs when openings of similar sizes are located at opposite ends of the dwelling. 


\section{SECONDARY PRIVATE}

\section{OUTDOOR SPACE}

Private outdoor spaces such as

balconies are usually essential parts

of residential apartments. However, secondary private outdoor space is often overlooked. Typically in larger apartments, providing Juliet balconies or operable walls with balustrades is important for clothes-drying, ventilation, or simply allowing a connection with outdoor space.
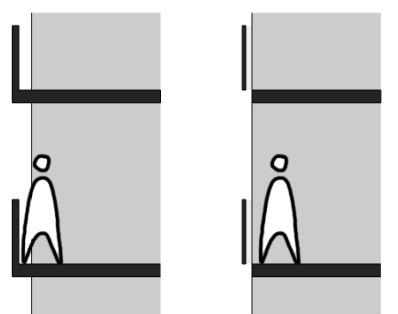

Figure 4.07

These types of balconies typically avoid the privacy issues associated with protruding balconies, and can be very effective when located adjacent to bedrooms.

\section{STORAGE}

Built-in storage is key to living large in compact urban apartments. While built- in bedroom wardrobes are common, storage for ancillary items such as vacuums or tools and recreational items like children's strollers or sporting equipment is often forgotten about. Storage for these sorts of items should be provided by a reasonably sized builtin linen-type closet. Most successful apartment buildings would also opt for an additional private storage area in the basement or car-parking area of the building. This is particularly useful for items which need somewhere to be stored but are not often required within the home. 


\section{CONCLUSIONS}

Each of these principles are easily applicable to an adapted EPB development in New Zealand, and can only improve the final outcome. However, several design principles are problematic.

The first is in regard to acoustic privacy. The nature of EPB spatial design may not allow for neighbouring spaces with comparable noise levels to be located adjacent to each other. While this can be achieved horizontally, it is much more difficult to achieve vertically, particularly with interlocking duplex apartments. This principle will certainly be considered throughout the design process, however spatial efficiency and maintaining double-aspect layouts takes priority.

Another problematic issue concerns secondary private storage. Providing an area away from the apartments for storage of private items is likely to be difficult in an EPB housing development with multiple shared semi-private circulation cores.

Basements are not a common characteristic and ground floor space is often highly sought-after for retail or commercial tenancy. While it is certainly possibly to provide this amenity in some way or another it is not a high priority. Storage within the apartments themselves is arguably more important. 


\section{DESIGN OPPORTUNITIES, CONSTRAINTS AND CRITERIA}

\section{OPPORTUNITIES:}

$\rightarrow \quad$ Opportunity for greater market appeal using apartment diversity

$\rightarrow \quad$ Opportunity to increase ceiling height in apartments

$\rightarrow \quad$ Opportunity to provide kitchens and bathrooms with external windows

$\rightarrow \quad$ Opportunity to locate spaces with similar noise levels back-to-back

$\rightarrow \quad$ Opportunity to provide secondary private outdoor space

$\rightarrow \quad$ Opportunity to provide additional private storage in basement

\section{CONSTRAINTS:}

$\rightarrow \quad$ Must provide accessible units for people with disabilities

$\rightarrow \quad$ All habitable spaces must have external opening windows

$\rightarrow \quad$ Must provide ventilation openings at opposite ends of apartments

$\rightarrow \quad$ Must provide built-in storage for ancillary household items

\section{CRITERIA:}

$\rightarrow \quad$ High density, high quality living

$\rightarrow \quad$ Provision for diverse households

$\rightarrow \quad$ Optimised natural light and ventilation

$\rightarrow \quad$ Perceived spaciousness

$\rightarrow \quad$ Spatial versatility and amenity 
New Zealand Urban Living:

AVAILABILITY OF SITES

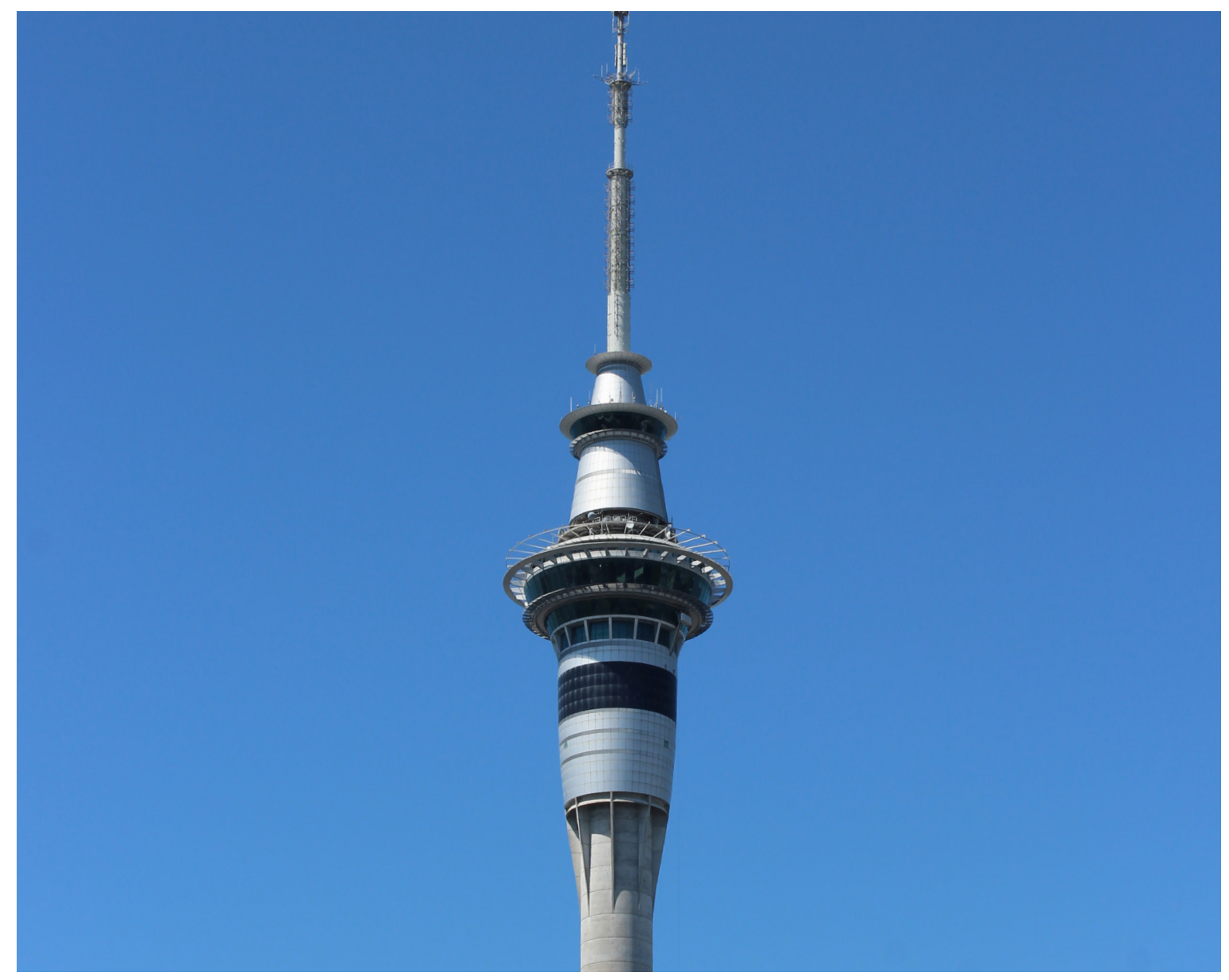

Figure 4.08 - Auckland Sky Tower 


\section{AVAILABLE NZ SITES}

EPB housing was introduced to

Europe in the early stages of large-

scale municipal urban development.

Therefore, the cities were particularly

undeveloped, with sufficient space

for new developments or extensive

renovation of existing developments.

As outlined previously, New Zealand's

cities are at a stage where new large-

scale developments can only be

constructed on the urban periphery.

This is an issue because EPB housing

becomes less useful the further it is from the urban core. Therefore, key

to the adaptation of the EPB housing model in a New Zealand context is the availability of inner-city sites.

The ideal locations for EPB housing developments are Brownfield land in close proximity to the urban core. This, however, eliminates the possibility of replicating traditional EPB housing with their beautifully consistent street frontages and orthogonal grid layout within close proximity to the urban core. Fortunately, the research on contemporary EPB examples shows that standalone EPB developments can still be successful if done well.

To best assess how a standalone EPB development might function in a New Zealand city, appropriate sites must be found that have the potential to accommodate this model. Analysis of GIS mapping from New Zealand's three major cities was conducted in order to find sites which met specific criteria.

This 'criteria for suitability' underlines the fact that in order for EPB housing to work in New Zealand, these sites must be empty, underutilised, inefficient uses of space or allocated to future development. Sites that are an inefficient use of space include: Carsales yards, petrol stations and singlestorey car-parking. While important, these site uses are very low-density and 
would be better suited within higher-

density buildings or relocated to lower-

alleyways, or just adapt the design to density urban areas.

suit having two sides up against other

buildings.

Street-definition and facade activation are crucial to the EPB housing model.

For these developments to be effective

Since EPB developments are a

medium-to-high-density housing

the site must have at least two adjacent model, they should be located within streets, road or alleyways. With this configuration, the development could areas that demand such a density. Constructing an EPB development leave space for the other two streets or outside these areas is objectionable.

\section{CRITERIA FOR SUITABILITY OF POTENTIAL SITES}

Site must be either:

$\rightarrow$ Empty (un-used or cleared for development)

$\rightarrow$ Underutilised (old/run-down or abandoned buildings)

$\rightarrow$ Inefficient use of space (Car-yards, petrol stations, parking)

$\rightarrow$ Future development (Site yet to undergo new construction)

Must be within a $2 \mathrm{~km}$ Radius of the defined "city centre"

Site is unsuitable if it contains new buildings or construction

Must have at least two adjacent streets, roads or alleyways

Must be located within a medium or high-density area 


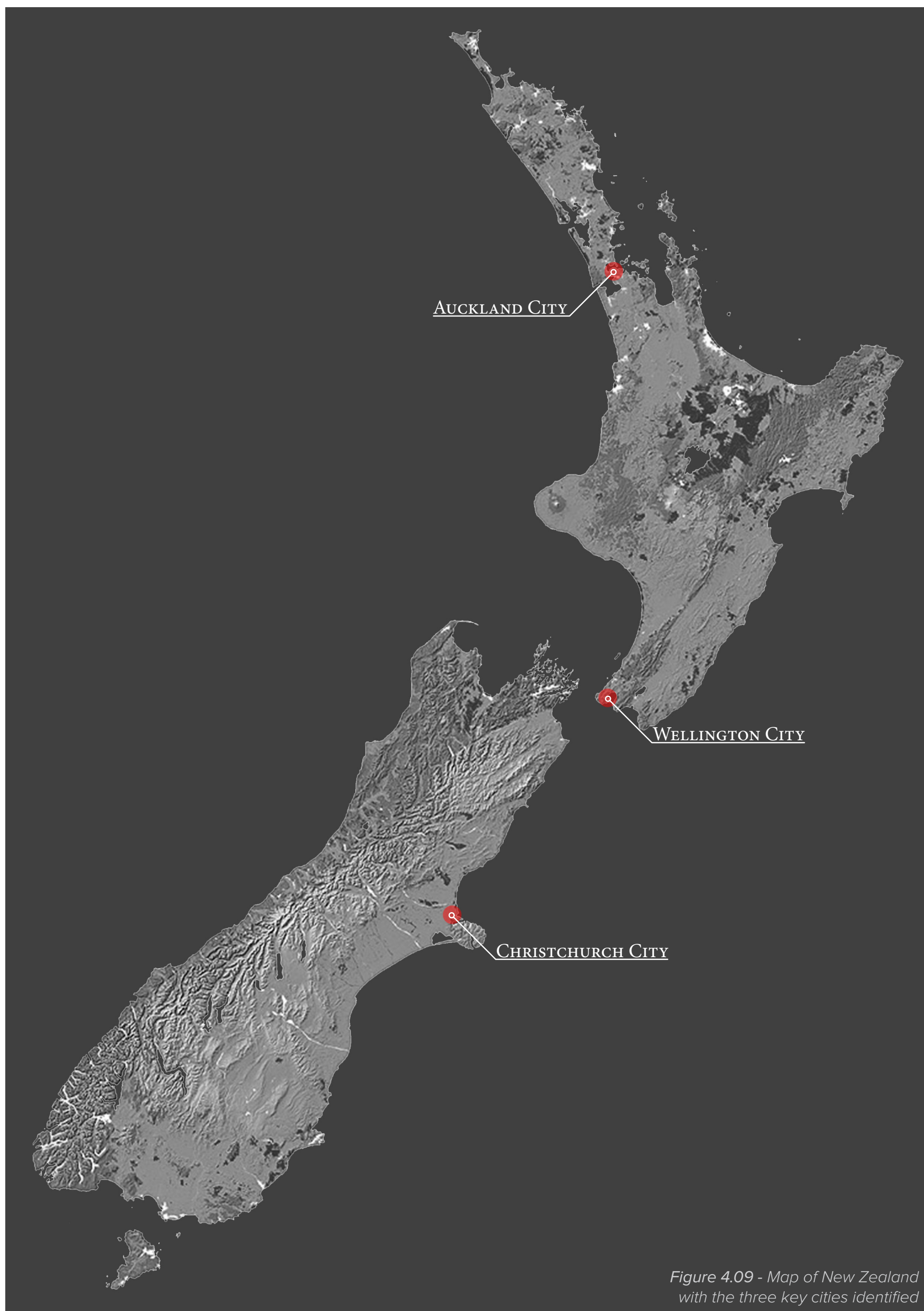




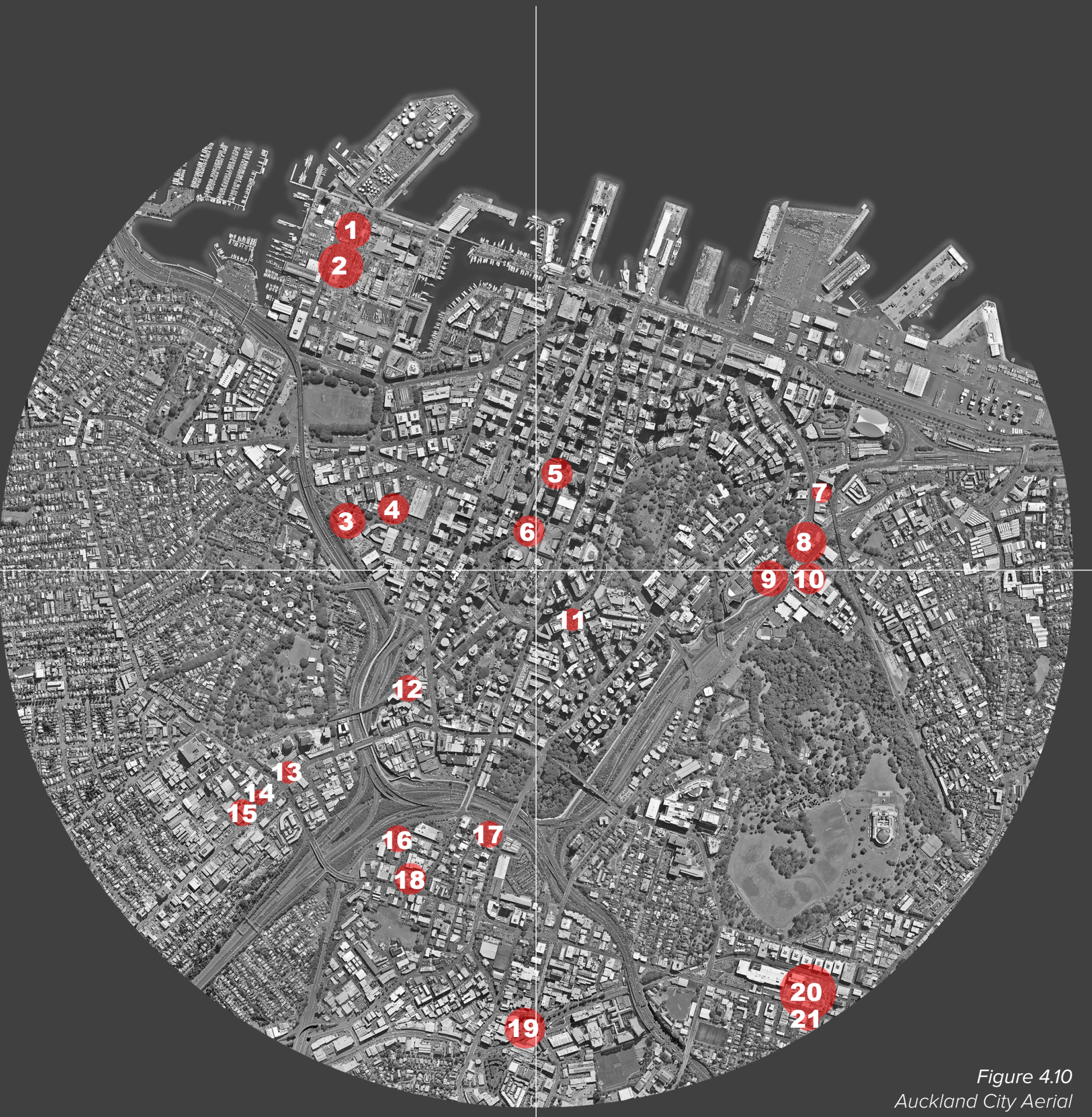


Wynyard Quarter Cleared Site

3

4

5

6

Wynyard Quarter Carpark

Placemakers - Cook Street

Les Mills Carpark - Morton St

Albert St Carpark / NDG Tower

Department of Conservation

Z Energy Ltd - Beach Road

Autohaus / Vehicle Safety Centre

Wilson Parking - Alten Road

Caltex - Stanley Street

Wilson Parking - St Paul Street

Wilson Parking - Beresford Square

Mobil - Karangahape Road

Lexus of Auckland City

John Andrew Mazda

Karaka Street Development

Wilson Parking - Alex Evans St

Z Energy Ltd - Newton Road

Wilson Parking - Boston Road

Secure Parking - Khyber Pass Rd

BP Station - Khyber Pass Rd
Site Area: $0.82 \mathrm{Ha} \quad$ Proximity to City Centre: $1.44 \mathrm{Km}$ Current Status: Car Parking Lot

Site Area: $1.14 \mathrm{Ha} \quad$ Proximity to City Centre: $1.35 \mathrm{Km}$

Current Status: Future Development

Site Area: $0.59 \mathrm{Ha} \quad$ Proximity to City Centre: $0.72 \mathrm{Km}$ Current Status: Inefficient Use of Space

Site Area: $0.54 \mathrm{Ha} \quad$ Proximity to City Centre: $0.60 \mathrm{Km}$ Current Status: Car Parking Lot

Site Area: $0.44 \mathrm{Ha} \quad$ Proximity to City Centre: $0.37 \mathrm{Km}$ Current Status: Car Parking Lot / Future Development

Site Area: $0.39 \mathrm{Ha} \quad$ Proximity to City Centre: $0.16 \mathrm{Km}$ Current Status: Car Parking Lot

Site Area: $0.20 \mathrm{Ha} \quad$ Proximity to City Centre: $1.10 \mathrm{Km}$ Current Status: Petro/ Station

Site Area: $0.85 \mathrm{Ha} \quad$ Proximity to City Centre: $1.01 \mathrm{Km}$ Current Status: Car Sales Yard

Site Area: $0.88 \mathrm{Ha} \quad$ Proximity to City Centre: $0.87 \mathrm{Km}$ Current Status: Car Parking Lot

Site Area: $0.54 \mathrm{Ha} \quad$ Proximity to City Centre: $1.01 \mathrm{Km}$ Current Status: Petrol Station

Site Area: $0.21 \mathrm{Ha} \quad$ Proximity to City Centre: $0.22 \mathrm{Km}$ Current Status: Car Parking Lot

Site Area: $0.20 \mathrm{Ha} \quad$ Proximity to City Centre: $0.64 \mathrm{Km}$ Current Status: Car Parking Lot

Site Area: $0.24 \mathrm{Ha} \quad$ Proximity to City Centre: $1.19 \mathrm{Km}$ Current Status: Petrol Station

Site Area: $0.17 \mathrm{Ha} \quad$ Proximity to City Centre: $1.33 \mathrm{Km}$ Current Status: Car Sales Yard

Site Area: $0.37 \mathrm{Ha} \quad$ Proximity to City Centre: $1.40 \mathrm{Km}$ Current Status: Car Sales Yard / Old Building

Site Area: $0.21 \mathrm{Ha} \quad$ Proximity to City Centre: $1.12 \mathrm{Km}$ Current Status: Future Development

Site Area: $0.37 \mathrm{Ha}$ Proximity to City Centre: $1.00 \mathrm{Km}$ Current Status: Car Parking Lot

Site Area: $0.54 \mathrm{Ha} \quad$ Proximity to City Centre: $1.24 \mathrm{Km}$ Current Status: Petrol Station \& Old Buildings

Site Area: $0.48 \mathrm{Ha} \quad$ Proximity to City Centre: $1.70 \mathrm{Km}$ Current Status: Car Parking Lot

Site Area: $1.85 \mathrm{Ha} \quad$ Proximity to City Centre: $1.86 \mathrm{Km}$ Current Status: Car Parking Lot

Site Area: $0.31 \mathrm{Ha} \quad$ Proximity to City Centre: $1.96 \mathrm{Km}$ Current Status: Petro/ Station 


\section{AUCKLAND SITE FOOTPRINTS}
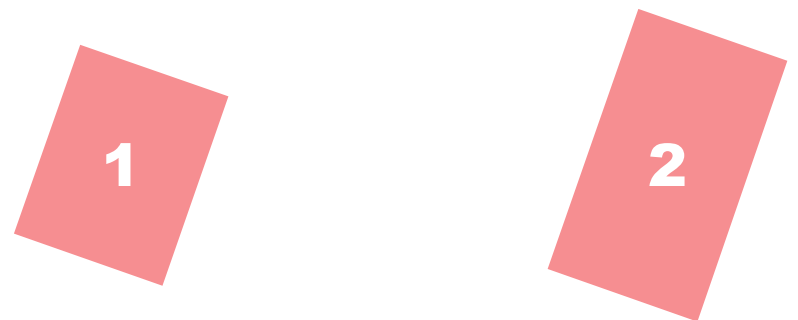

\section{3}
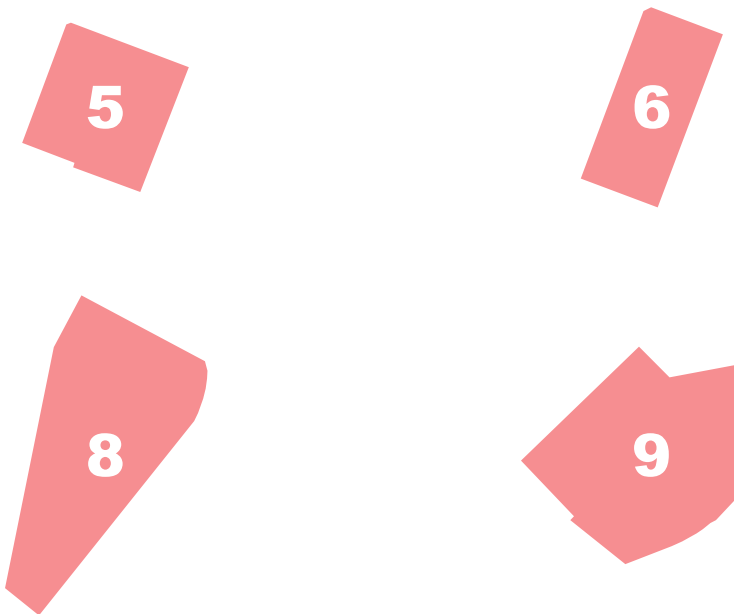

9

10
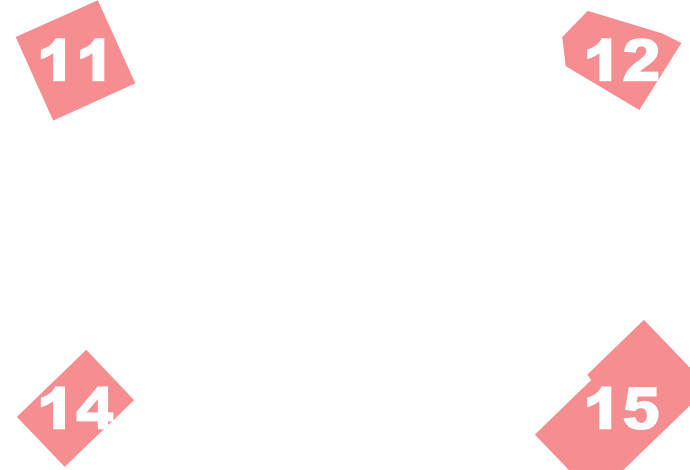

15

18

17
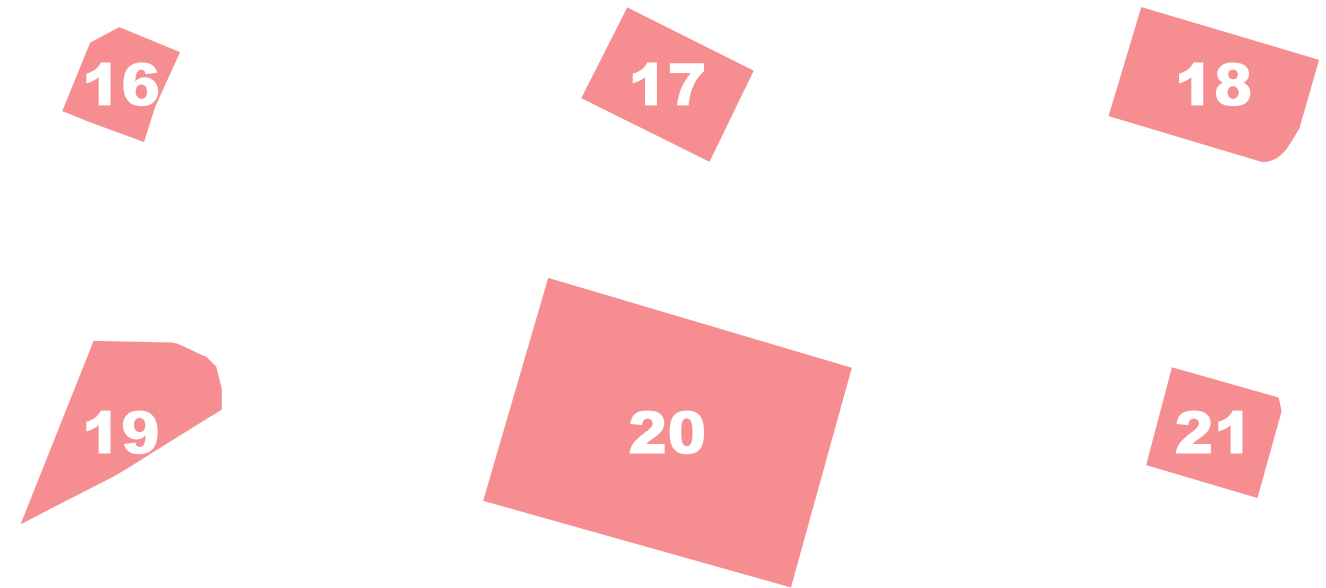
AVERAGE AUCKLAND SITE

Average Site Area: $\quad 0.54 \mathrm{Ha}$

$\left(5400 \mathrm{~m}^{2}\right)$

Average Proximity

to City Centre: $1.06 \mathrm{Km}$

Site closest to average shown:

(Caltex in Parnell)

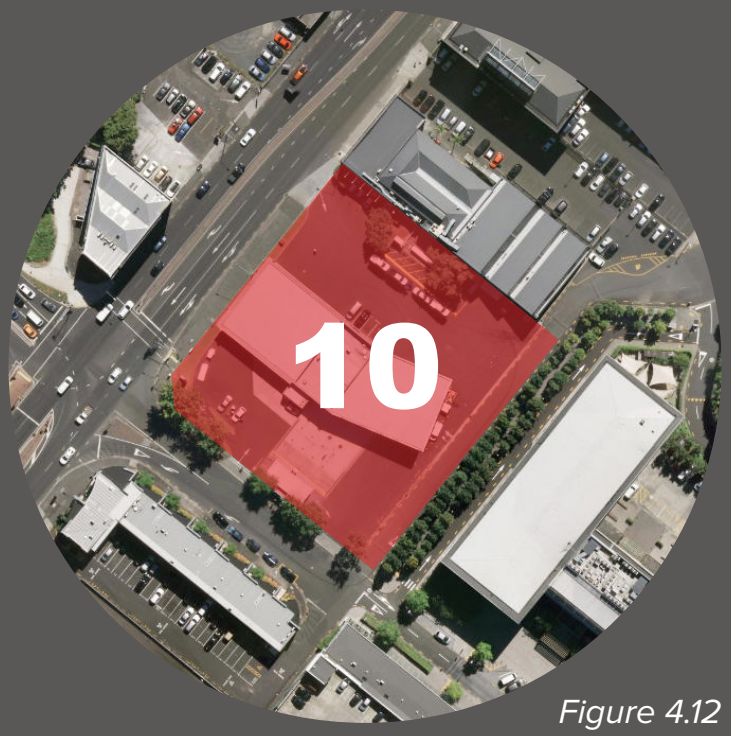




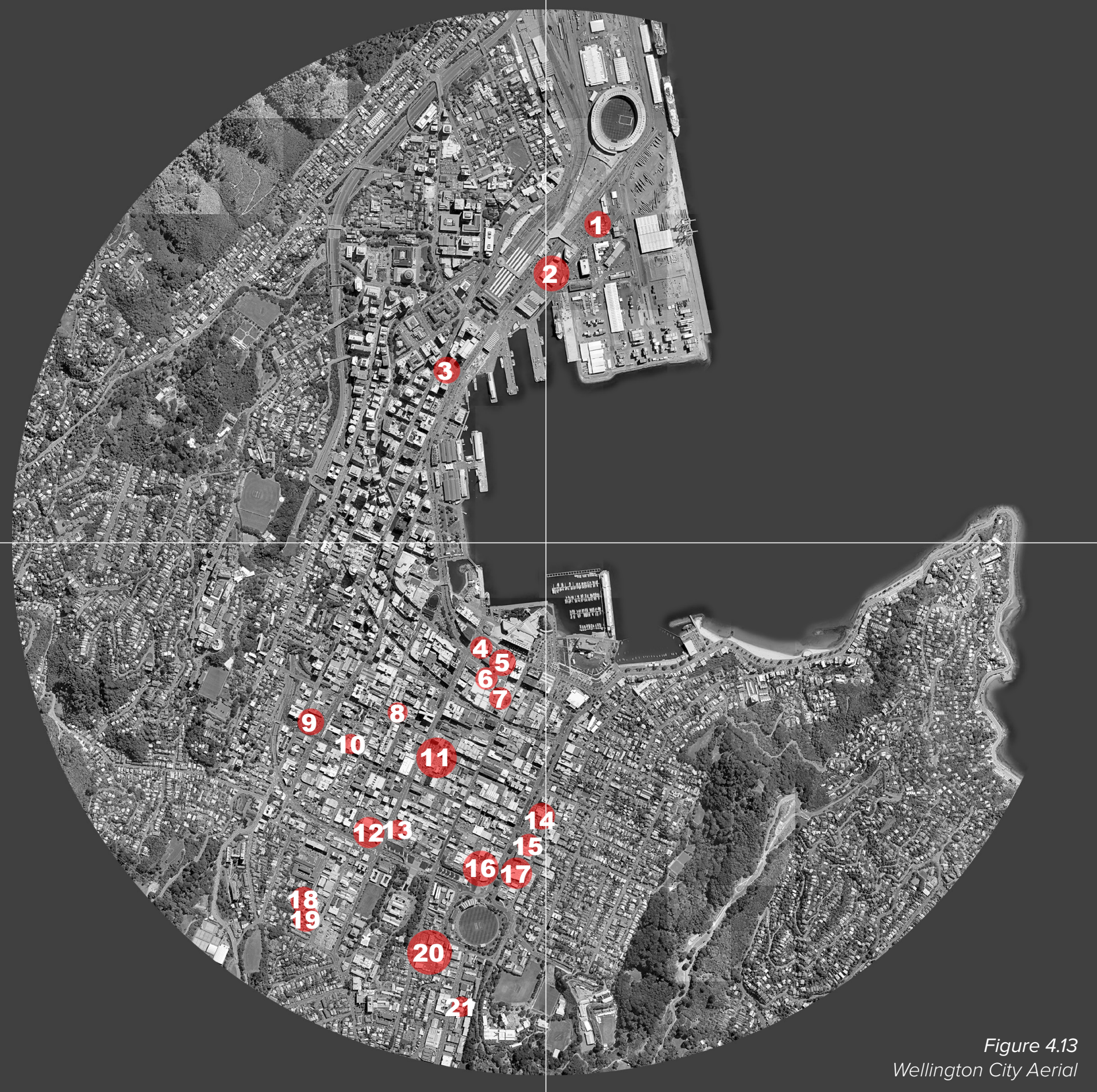


1 Central Group Forklifts and Trucks

2 Cleared Site - The Promenade

3

4

5

6

7

8

9

10

Z Energy - Harbour City

BP - Cable Street

Wilson Parking Cable Street

Cinema Parking Wakefield St

Cinema Parking Tory Street

Wilson Parking Leeds St

Wilson Parking Willis St

Z Energy - Vivian Street

Capital City Ford \& Mazda

Ebbett Cars \& Francis Holmes Ltd

Z Energy - Taranaki Street

Gazley Skoda \& VW

Rutherford \& Bond Toyota

Gazley Mitsubishi \& Mercedes

Honda Cars Wellington

Arlington St Development

Hopper St Development

Tasman St Empty Site

BP - Adelaide Road
Site Area: $0.81 \mathrm{Ha} \quad$ Proximity to City Centre: $1.24 \mathrm{Km}$ Current Status: Underutilised Site

Site Area: $0.84 \mathrm{Ha} \quad$ Proximity to City Centre: $1.04 \mathrm{Km}$ Current Status: Cleared/Empty Site

Site Area: $0.17 \mathrm{Ha} \quad$ Proximity to City Centre: $0.76 \mathrm{Km}$ Current Status: Petro/ Station

Site Area: $0.33 \mathrm{Ha} \quad$ Proximity to City Centre: $0.44 \mathrm{Km}$ Current Status: Petro/ Station

Site Area: $0.56 \mathrm{Ha} \quad$ Proximity to City Centre: $0.44 \mathrm{Km}$ Current Status: Car Parking Lot

Site Area: $0.35 \mathrm{Ha} \quad$ Proximity to City Centre: $0.54 \mathrm{Km}$ Current Status: Car Parking Lot

Site Area: $0.35 \mathrm{Ha} \quad$ Proximity to City Centre: $0.59 \mathrm{Km}$ Current Status: Car Parking Lot

Site Area: $0.14 \mathrm{Ha} \quad$ Proximity to City Centre: $0.83 \mathrm{Km}$ Current Status: Car Parking Lot

Site Area: $0.41 \mathrm{Ha} \quad$ Proximity to City Centre: $1.10 \mathrm{Km}$ Current Status: Car Parking Lot

Site Area: $0.27 \mathrm{Ha} \quad$ Proximity to City Centre: $1.03 \mathrm{Km}$ Current Status: Petro/ Station

Site Area: $0.75 \mathrm{Ha} \quad$ Proximity to City Centre: $0.89 \mathrm{Km}$ Current Status: Car Sales Yard / Future Development

Site Area: $0.34 \mathrm{Ha} \quad$ Proximity to City Centre: $1.25 \mathrm{Km}$ Current Status: Car Sales Yard / Old Building

Site Area: $0.24 \mathrm{Ha} \quad$ Proximity to City Centre: $1.19 \mathrm{Km}$ Current Status: Petro/ Station

Site Area: $0.40 \mathrm{Ha} \quad$ Proximity to City Centre: $1.00 \mathrm{Km}$ Current Status: Car Sales Yard

Site Area: $0.39 \mathrm{Ha} \quad$ Proximity to City Centre: $1.11 \mathrm{Km}$ Current Status: Car Sales Yard

Site Area: $0.60 \mathrm{Ha} \quad$ Proximity to City Centre: $1.24 \mathrm{Km}$ Current Status: Car Sales Yard

Site Area: $0.57 \mathrm{Ha} \quad$ Proximity to City Centre: $1.23 \mathrm{Km}$ Current Status: Car Sales Yard

Site Area: $0.46 \mathrm{Ha} \quad$ Proximity to City Centre: $1.60 \mathrm{Km}$ Current Status: Future Development

Site Area: $0.68 \mathrm{Ha} \quad$ Proximity to City Centre: $1.66 \mathrm{Km}$ Current Status: Future Development

Site Area: $1.35 \mathrm{Ha} \quad$ Proximity to City Centre: $1.58 \mathrm{Km}$ Current Status: Underutilised/Empty Site

Site Area: $0.25 \mathrm{Ha} \quad$ Proximity to City Centre: $1.74 \mathrm{Km}$ Current Status: Petro/ Station 
WELLINGTON SITE FOOTPRINTS
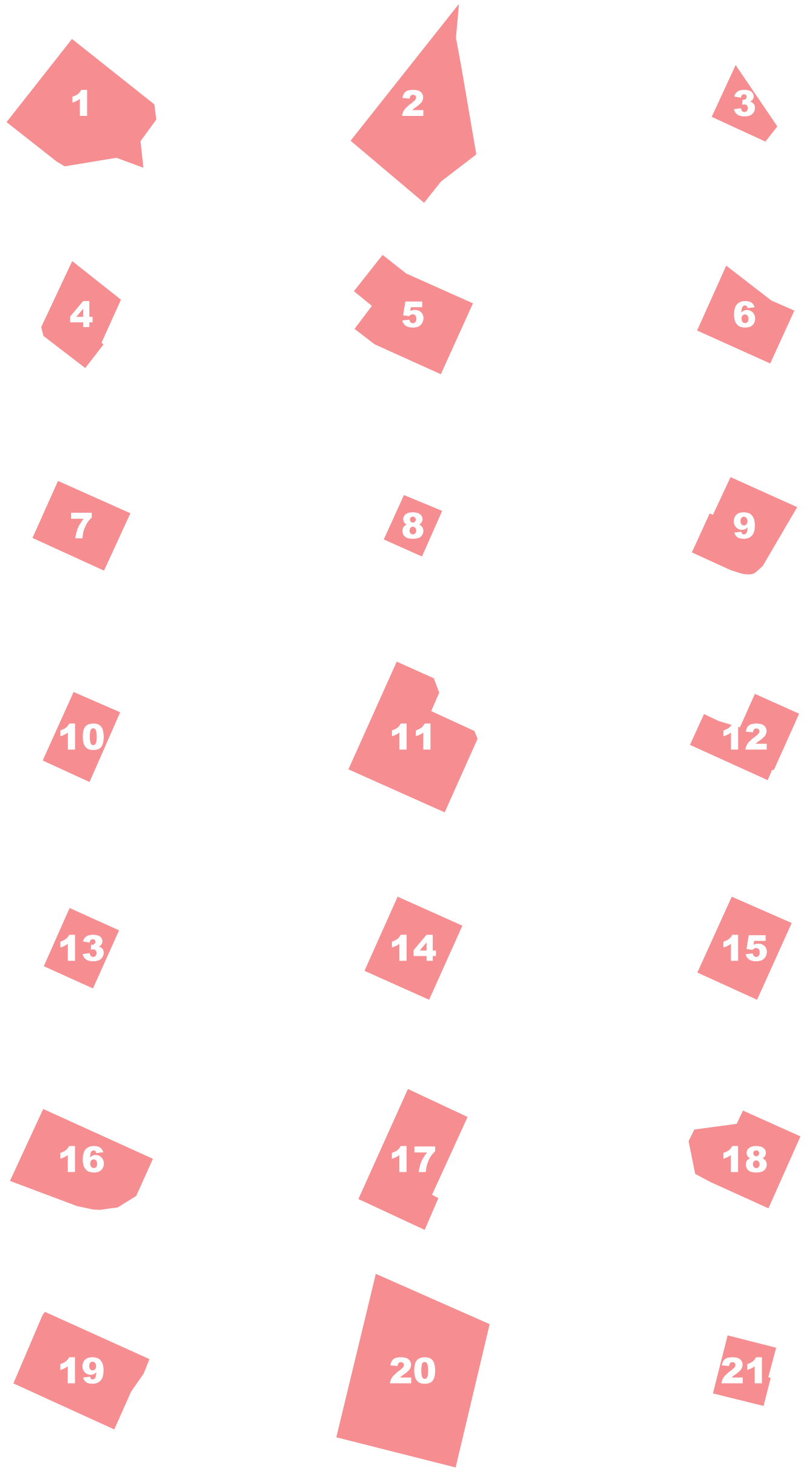
AVERAGE AUCKLAND SITE

Average Site Area: $\quad 0.54 \mathrm{Ha}$

$\left(5400 \mathrm{~m}^{2}\right)$

Average Proximity

to City Centre: $1.06 \mathrm{Km}$

Site closest to average shown:

(Caltex in Parnell)

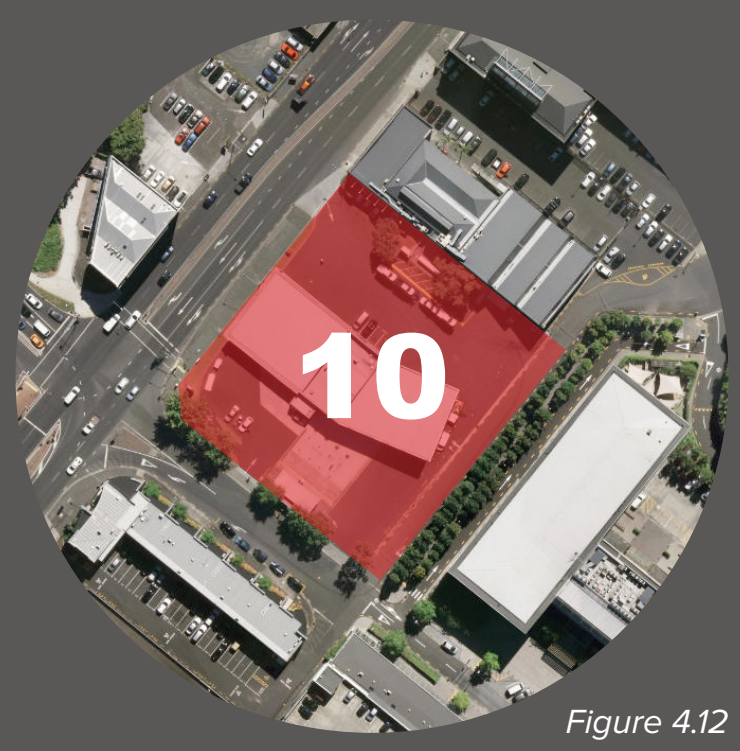

\section{AVERAGE WELLINGTON SITE}

Average Site Area: $\begin{array}{r}0.49 \mathrm{Ha} \\ \left(4900 \mathrm{~m}^{2}\right)\end{array}$

Average Proximity to City Centre:

$1.07 \mathrm{Km}$

Site closest to average shown:

(Honda Cars in Te Aro)

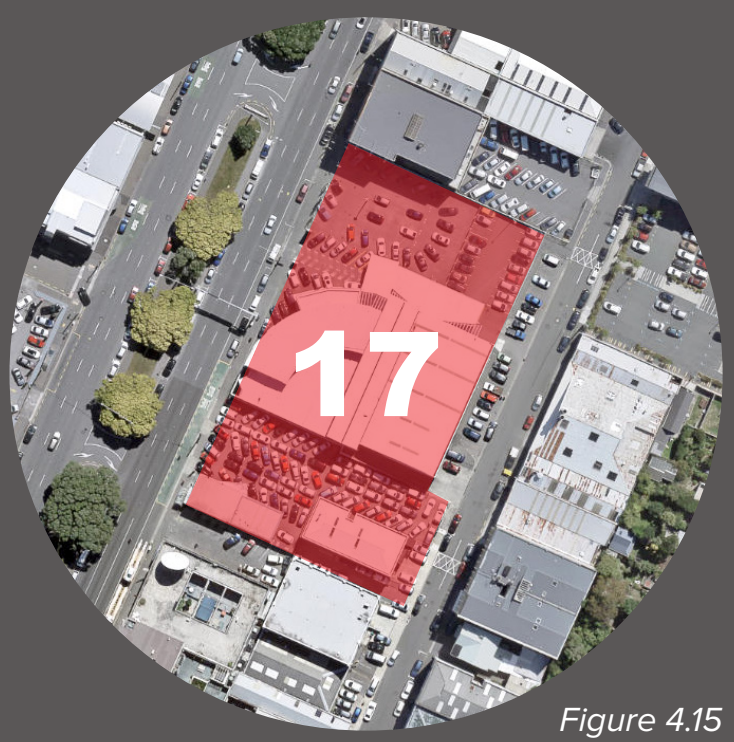




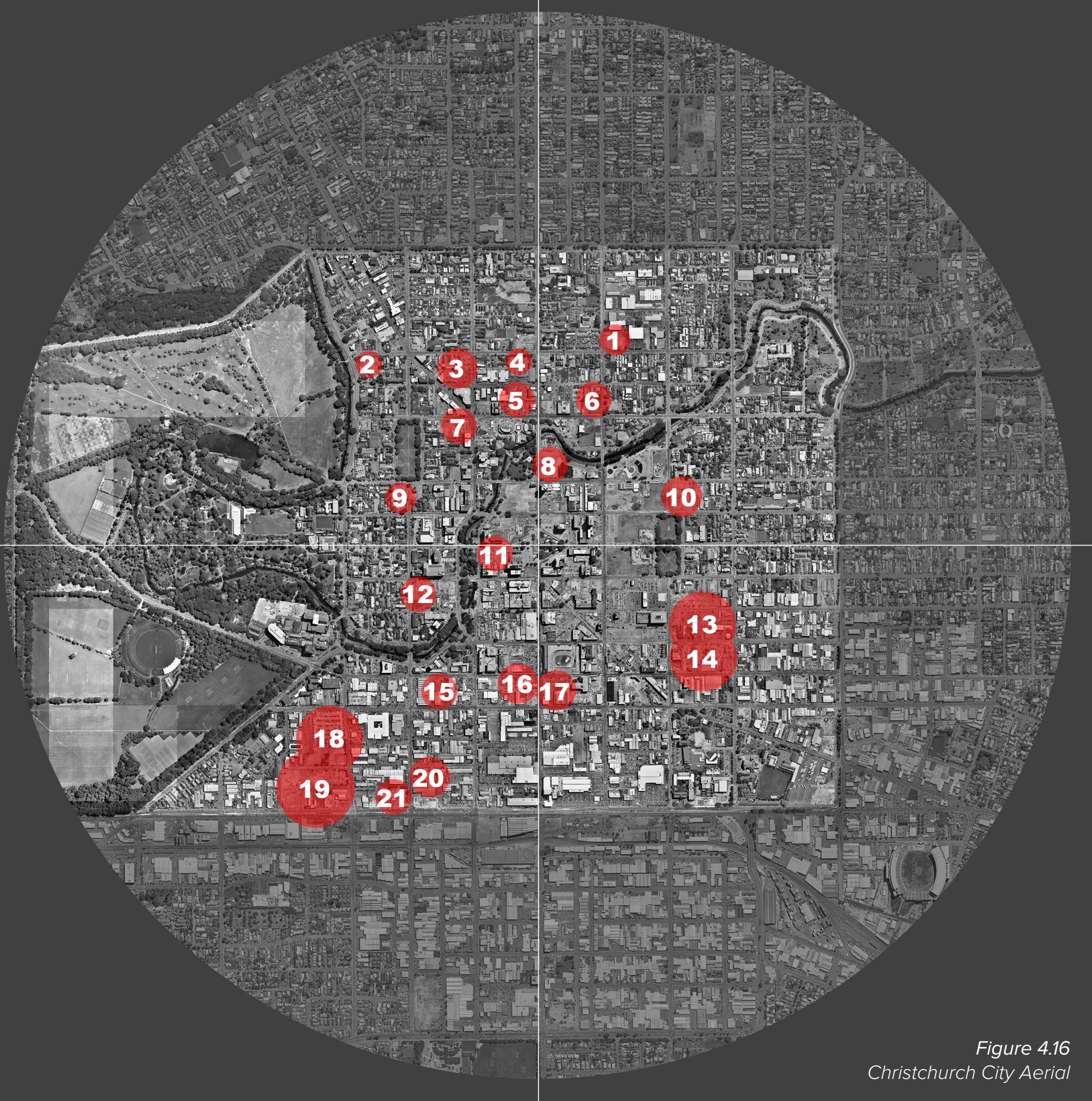




$$
\text { Manchester St + Salisbury St }
$$

Salisbury St + Park Tce

Salisbury St + Durham St North

118 Salisbury Street

\author{
Kilmore Street Parking
}

Kilmore St + Manchester St

Wilson Parking - Kilmore St

Colombo St + Oxford Terrace

Armagh St + Montreal St

Madras St + Gloucester St

Wilson Parking - Worcester St

NZ Post Box Lobby / Parking

Cashel St + Lichfield St

Lichfield St + Tuam St

Tuam St + Montreal St

Colombo St + Mollett St

Team Hutchinson Ford

St Asaph St + Antigua St

Antiqua St + Balfour St

Wilson Parking - Wilmer St

Wheeler Motor Company
Site Area: $0.54 \mathrm{Ha} \quad$ Proximity to City Centre: $0.82 \mathrm{Km}$ Current Status: Cleared Corner Site

Site Area: $0.51 \mathrm{Ha} \quad$ Proximity to City Centre: $0.93 \mathrm{Km}$ Current Status: Cleared Corner Site

Site Area: $1.02 \mathrm{Ha} \quad$ Proximity to City Centre: $0.73 \mathrm{Km}$ Current Status: Car Parking Lot / Cleared Site

Site Area: $0.40 \mathrm{Ha} \quad$ Proximity to City Centre: $0.69 \mathrm{Km}$ Current Status: Cleared / Empty Site

Site Area: $0.86 \mathrm{Ha} \quad$ Proximity to City Centre: $0.54 \mathrm{Km}$ Current Status: Car Parking Lot

Site Area: $0.62 \mathrm{Ha} \quad$ Proximity to City Centre: $0.58 \mathrm{Km}$ Current Status: Empty Site

Site Area: $0.51 \mathrm{Ha} \quad$ Proximity to City Centre: $0.54 \mathrm{Km}$ Current Status: Car Parking Lot / Empty Site

Site Area: $0.64 \mathrm{Ha} \quad$ Proximity to City Centre: $0.31 \mathrm{Km}$ Current Status: Car Parking Lot

Site Area: $0.56 \mathrm{Ha} \quad$ Proximity to City Centre: $0.55 \mathrm{Km}$ Current Status: Cleared / Empty Site

Site Area: $0.81 \mathrm{Ha} \quad$ Proximity to City Centre: $0.57 \mathrm{~km}$ Current Status: Cleared / Empty Site

Site Area: $0.51 \mathrm{Ha} \quad$ Proximity to City Centre: $0.16 \mathrm{Km}$ Current Status: Car Parking Lot

Site Area: $0.54 \mathrm{Ha} \quad$ Proximity to City Centre: $0.48 \mathrm{Km}$ Current Status: Underutilised Site / Car Parking Lot

Site Area: $2.25 \mathrm{Ha} \quad$ Proximity to City Centre: $0.68 \mathrm{Km}$ Current Status: Cleared / Empty Block

Site Area: $2.24 \mathrm{Ha} \quad$ Proximity to City Centre: $0.75 \mathrm{Km}$ Current Status: Cleared / Empty Block

Site Area: $0.92 \mathrm{Ha} \quad$ Proximity to City Centre: $0.67 \mathrm{Km}$ Current Status: Car Parking Lot / Cleared Site

Site Area: $0.61 \mathrm{Ha} \quad$ Proximity to City Centre: $0.52 \mathrm{Km}$ Current Status: Car Parking Lot / Cleared Site

Site Area: $1.03 \mathrm{Ha} \quad$ Proximity to City Centre: $0.55 \mathrm{Km}$ Current Status: Car Sales Yard

Site Area: $2.79 \mathrm{Ha} \quad$ Proximity to City Centre: $1.07 \mathrm{Km}$ Current Status: Cleared Site / Future Development

Site Area: $3.45 \mathrm{Ha} \quad$ Proximity to City Centre: $1.24 \mathrm{Km}$ Current Status: Cleared Site / Future Development

Site Area: $0.53 \mathrm{Ha} \quad$ Proximity to City Centre: $0.96 \mathrm{Km}$ Current Status: Car Parking Lot

Site Area: $0.81 \mathrm{Ha} \quad$ Proximity to City Centre: $1.09 \mathrm{Km}$ Current Status: Car Parking Lot / Car Sales Yard 
CHRISTCHURCH SITE FOOTPRINTS
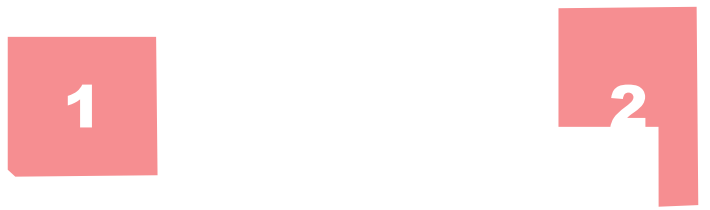

3

\section{4}

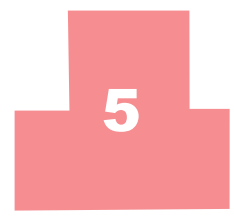

6

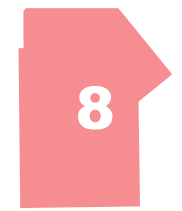

9

7

10

11

12

14

15

13
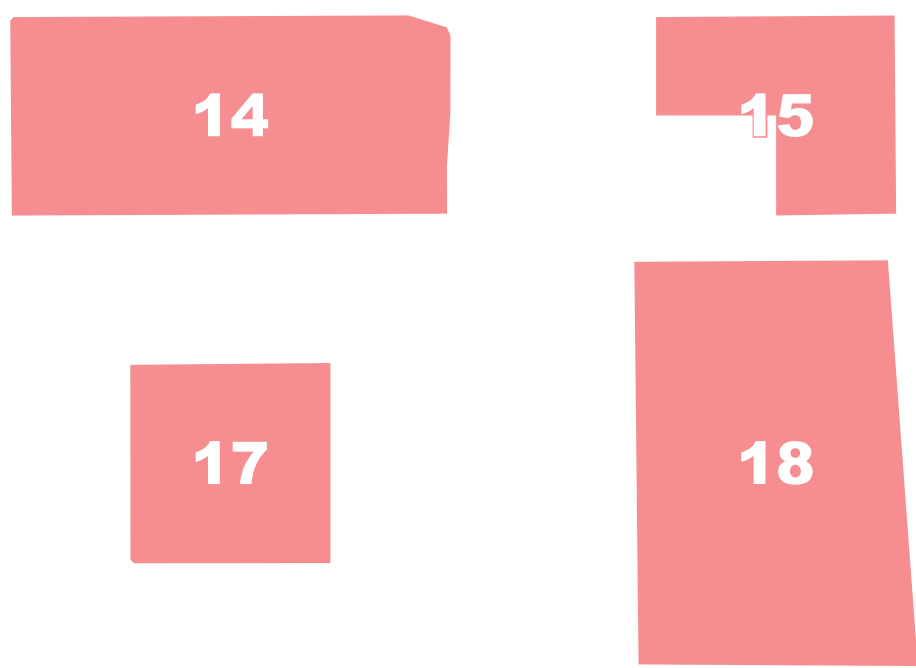

17

21 


\section{AVERAGE AUCKLAND SITE}

Average Site Area:

$0.54 \mathrm{Ha}$

$\left(5400 \mathrm{~m}^{2}\right)$

Average Proximity

to City Centre:

$1.06 \mathrm{Km}$

Site closest to average shown:

(Caltex in Parnell)

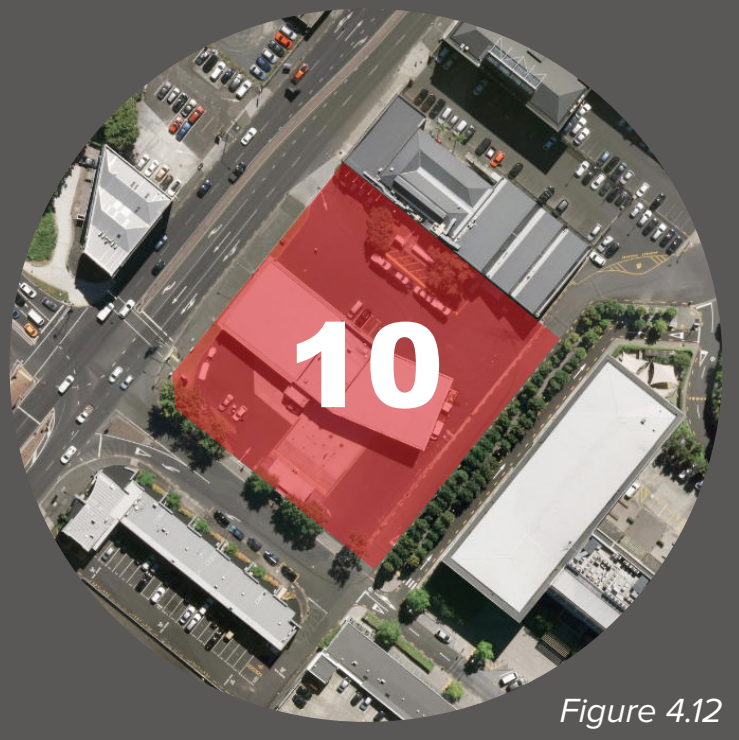

Figure 4.12

\section{AVERAGE WELLINGTON SITE}

Average Site Area:

$0.49 \mathrm{Ha}$

$\left(4900 \mathrm{~m}^{2}\right)$

Average Proximity

to City Centre:

$1.07 \mathrm{Km}$

Site closest to average shown:

(Honda Cars in Te Aro)

\section{AVERAGE CHRISTCHURCH SITE}

Average Site Area: $\quad 1.05 \mathrm{Ha}$ $\left(10500 \mathrm{~m}^{2}\right)$

Average Proximity to City Centre:

$0.69 \mathrm{Km}$

Site closest to average shown: (Parking lot, Salisbury St)

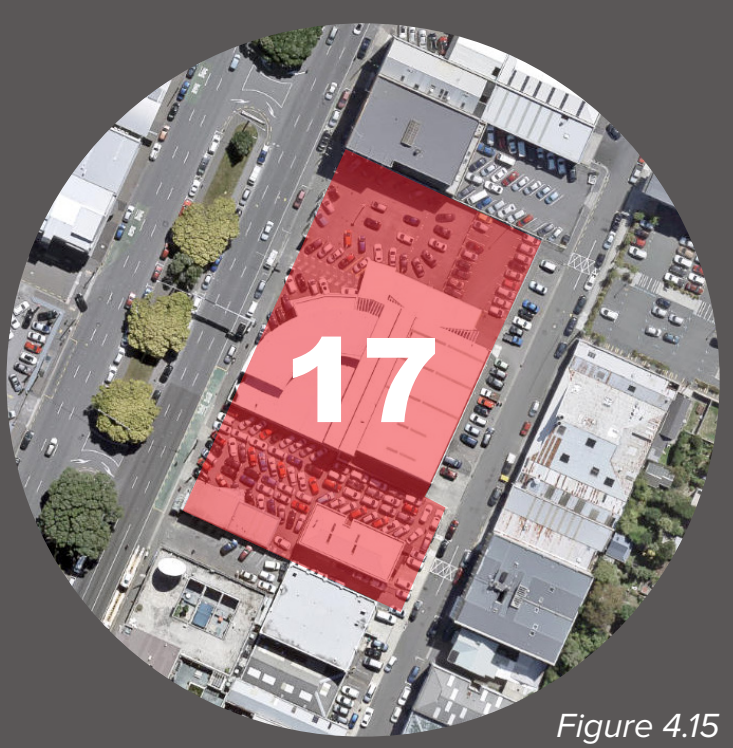

Figure 4.15

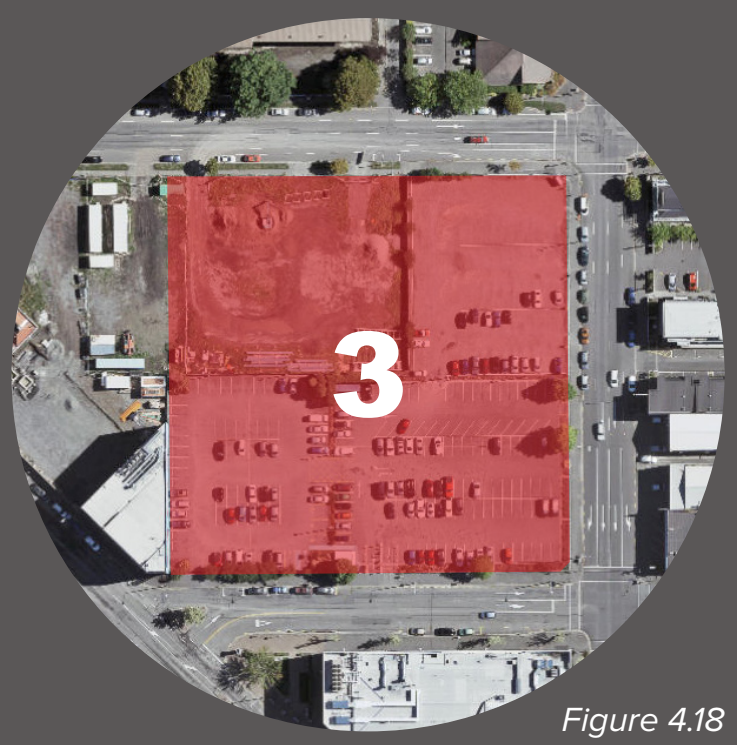




\section{SITE CONCLUSIONS}

The survey of available sites uncovered a generous number of available sites across the three cities. This is a promising finding and certainly improves the viability of adapting EPB housing for use in New Zealand.

Christchurch had the largest sites, and potentially the most, however this is largely due to the 2011 earthquake disaster which damaged thousands of buildings in and around the city. While this would be the perfect place for large-scale development of EPB housing, Christchurch lacks an established demand for higher density living. This distinguishes the city from Auckland and Wellington where apartment living is well established.

Auckland and Wellington both had a similar number of available sites beyond what is shown, and the average size and proximity of sites was almost identical. While a suitable case-study site could be found in Wellington City, an Auckland site was selected because

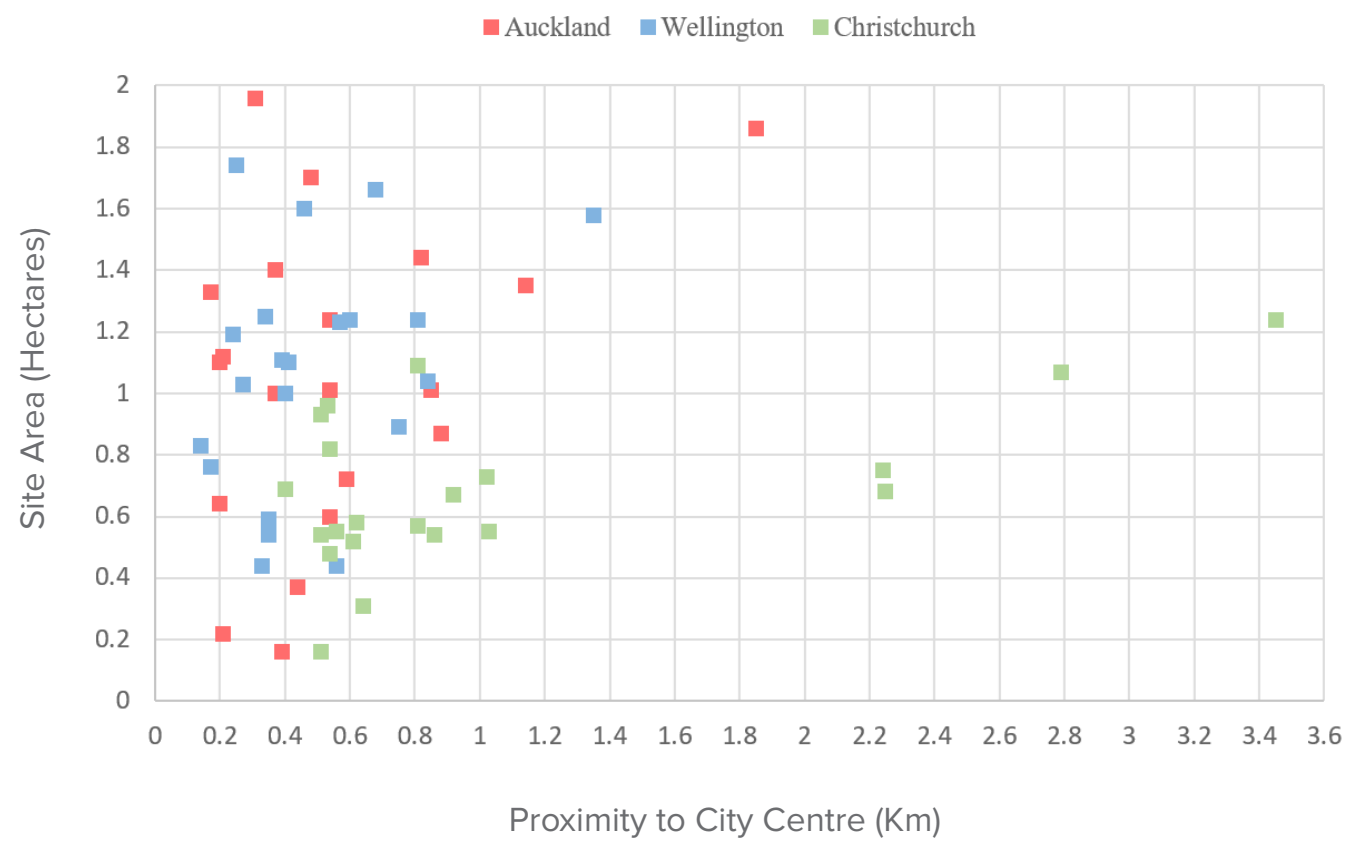

Figure 4.19 
this city is in urgent need of a new

model which promises to deliver both

high-density and high-amenity.

Therefore, the chosen site is in

Auckland City. It has a site area close to the site average for Auckland and

Wellington. This size ensures that other comparable sites can be found in both cities, so the research findings are therefore widely applicable. Like much of urban New Zealand, Auckland is hilly. Consequently, a sloping site provides a useful setting with broad application to other New Zealand settings.

The selected site for the design case study is showcased in the next chapter.

\section{DESIGN OPPORTUNITIES,} CONSTRAINTS AND CRITERIA

\section{OPPORTUNITIES:}

$\rightarrow \quad$ Opportunity for more than two adjacent streets

$\rightarrow \quad$ Opportunity to be a part of an existing community

\section{CONSTRAINTS:}

$\rightarrow \quad$ EPB development must function as a standalone building in context

$\rightarrow \quad$ EPB development must function on a sloping site

\section{CRITERIA:}

$\rightarrow \quad$ Versatile Design

$\rightarrow \quad$ Street edge definition

$\rightarrow \quad$ Facade activation 

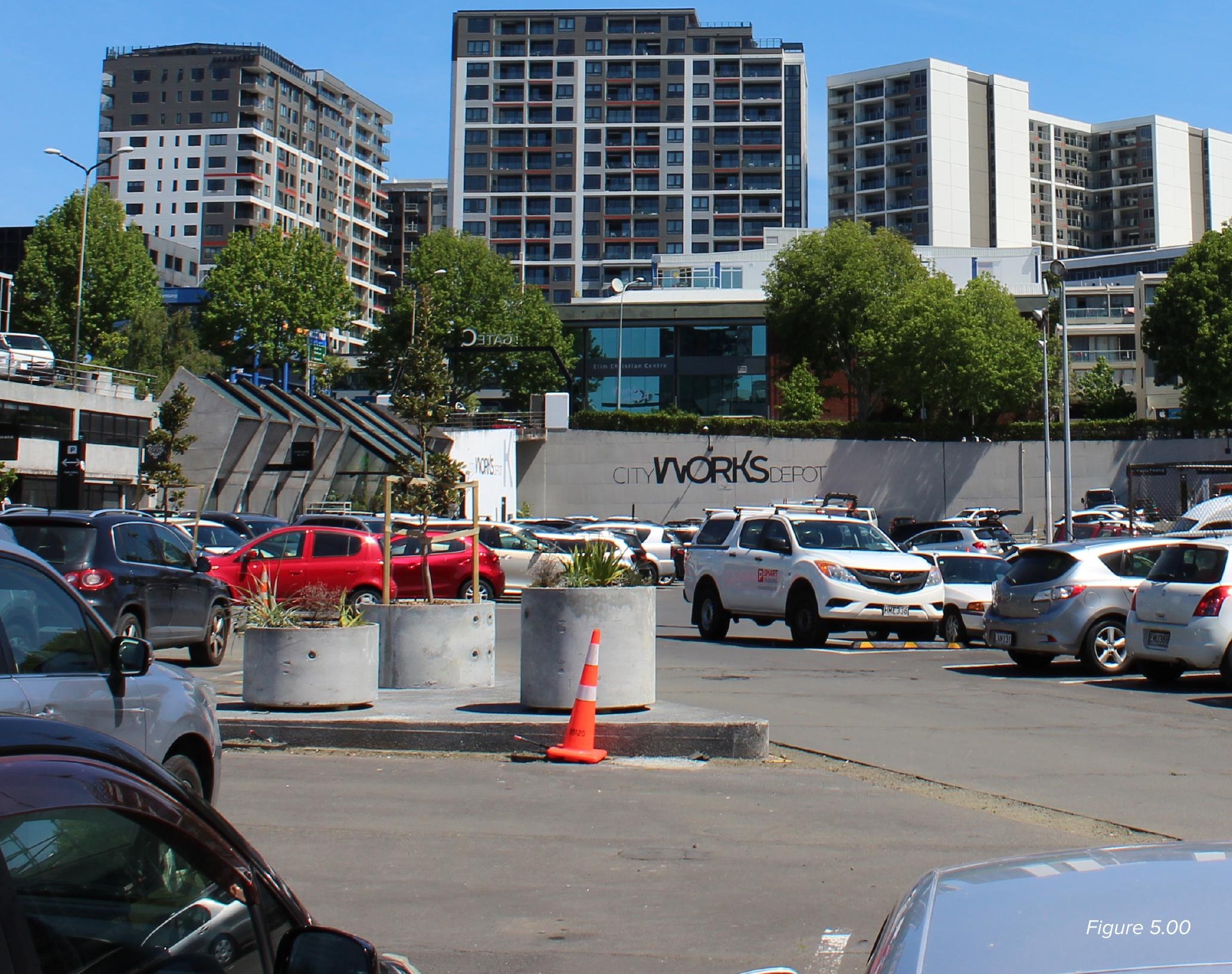


\section{CHAPTER FIVE}

Adapted Design Strategies and Criteria

+ Chosen Site Showcase 
New Zealand EPB Development:

\section{ADAPTED DESIGN STRATEGIES \& CRITERIA}

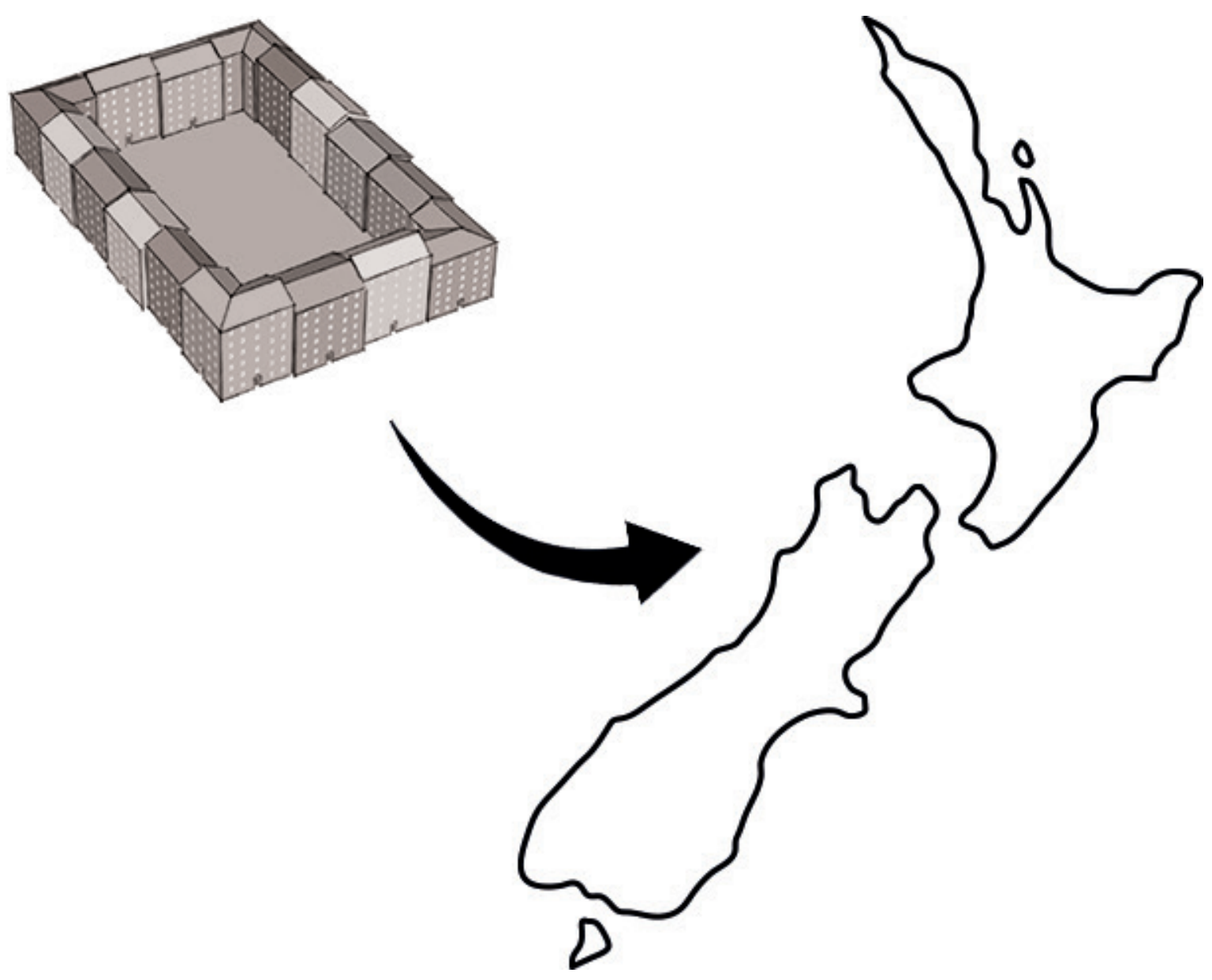

Figure 5.01 - Image illustrating the adaptation of EPB housing for NZ 


\section{RESEARCH FINDINGS}

\section{UNSUITABLE STRATEGIES}

The findings from each study or section of research undertaken in this thesis has uncovered a list of Design Principles, Strategies and Criteria (EPB research) or a list of Design Opportunities, Constraints and Criteria (NZ context research). The purpose of these is to inform the design of EPB housing in New Zealand. However, in order to apply the research findings to the design case-study, they must first be collated into a single collection of adapted design strategies and criteria.

These adapted design strategies will inform the formal and spatial design of the EPB development, and the criteria will be used to assess the success of the design through each iteration and provide the basis for evaluating the final design. The concluding outcome of this thesis is a final set of design criteria and a repertoire of strategies that usefully inform EPB housing development in New Zealand.

Of all the strategies collected so far, it appears that there are some conflicting outcomes. A number of strategies were "overruled" or contradicted by subsequent studies. Therefore, the list of adapted design strategies has removed, combined or edited some strategies to ensure the list is concise and cohesive. The reasons for some of these are as follows:

\section{BALCONIES}

Three strategies for balconies were discovered in the contemporary EPB research. The strip balcony which typically wraps around the entirety of the building, creating a 'banding' aesthetic will not easily collaborate with the other facade strategies so has been removed from the list. It is also likely to provide facade monotony, which a number of strategies are aiming to avoid, and without a substantial overhang, does not produce very deep private outdoor space. 


\section{BLOCK OPENING}

Providing an opening in the block perimeter is a common strategy in the contemporary examples, however, since the research indicates that New Zealand families would prefer a fully enclosed courtyard, gaps or holes in the perimeter will only compromise this. The main use for this strategy is when paired with an elevated courtyard for an urban outlook, however this strategy has been removed as well.

\section{ELEVATED COURTYARD}

An elevated courtyard works well when lower-level apartments are designed to directly interact with the courtyard, and when there are only a couple of main access points to the courtyard. However, this strategy makes it more difficult for the courtyard to be accessed by multiple circulation cores and makes it even more difficult to use the courtyard as a thoroughfare to access opposite sides of the block. Because of this, an elevated courtyard is not a successful strategy to use.

\section{SAW-TOOTH FACADE AND MODULAR PIXEL FORM}

Two strategies that are particularly similar and appear to be predominantly from BIG examples are the saw-tooth facade and modular pixel form. While these two strategies are undoubtedly useful, they pose an issue when combined with other strategies which may ultimately reduce the effectiveness or success of the design. They are also unlikely to suit current NZ urban contexts and are not efficient methods for maximising plot ratio because the constructed building will not effectively meet the site boundary.

\section{CORRIDOR EXTENDED TO FACADE}

David Baker's strategy of extending the corridor to the facade is one that would typically not be possible in a modern EPB development. This is mostly due to the clustered or efficient circulation systems which can not afford to take up precious facade area. Therefore this strategy was also removed. 


\section{ADDED STRATEGIES}

A number of opportunities and constraints supplied by the studies of New Zealand urban living provided the final four design strategies as well as contributing to the adapted design criteria. These strategies are more specific to the design of the individual apartments, and aim to improve living conditions within these spaces.

\section{ADAPTED DESIGN STRATEGIES}

The list below has compiled all the design strategies from each section of the research so far and removed those that are unsuitable or contradictory. This list of adapted design strategies provide the 'toolbox' for the design case-study.

- Linked perimeter of buildings

- Communal central courtyard

- Double-Aspect Apartments

- Multi-core access to units

- Semi-private shared staircases

- Ground-floor retail

- Duplex Apartments

- Vertical Cores in Corners

- Semi-Enclosed Protruding Balcony

- Clustered Apartments

- Dedicated Communal Areas

- Courtyard Protrusions

- Sun-Oriented Apartments

- Sloped/Tiered Roof-line

- Rooftop Terraces

- Vertical Core Visual Character

- Varied Building Heights
- Unique North Face

- Unique Inside/Outside Cladding

- Vertical Protrusions from Facade

- Vertical Core Recession

- Unique Ground Floor

- Unique Corner Identity

- Distinctive Superimposed "Screen"

- Cladding-Change for Aligned Windows

- Slim stairwell facade profile

- Multi-level void space

- Large landing area

- Stairwell external windows

- 'Lightweight'staircase form

- Increased ceiling height

- External windows to habitable spaces

- Secondary private outdoor space

- Locate similar spaces back-to-back 


\section{ADAPTED DESIGN CRITERIA}

Below is a refined list of all the design criteria discovered and established from each section of the research. Each of the 10 adapted design criteria are an amalgamation of repeating or related criteria brought up in the various studies throughout the research. The criteria from each study are shown on the next page and are labelled relative to the adapted criteria in which they contributed to or inspired. The adapted design criteria is a concise list used to inform the design case-study and evaluate the success of the final design.

01. High-Density with High-Amenity

02. Definition and Activation of the Public Street Edge

03. Optimised Natural Light, Ventilation and Outlook

04. Semi-Private Central Courtyard

05. Managed Relationship between Public, Private \& Semi-Private Space

06. Situational Circulation System

07. Design Versatility and Diversity

08. Coherent Form with Positive Impact on Urban Context

09. Eventful Building Façades with Sense of Identity and Character

10. Perception of Safety and Spaciousness 


\section{TRADITIONAL EPB STUDY}

01. Low-Rise High-Density

05. Explicit Distinction between Public and Private

04. Semi-Private Green Space Amenity

07. Variable design and function

03. Abundant sunlight and ventilation

02. Defined, active street edge

08. Coherent urban form

08. Conforms to contextual parameters

\section{NZ URBAN HOUSING STUDY}

01. High level of amenity provision

06. Efficient circulation system

07. Diverse provision of apartments

05. Public, private and semi-private separation

10. Improved perception of safety and spaciousness

\section{APARTMENT BEST-PRACTICE STUDY}

01. High density, high quality living

07. Provision for diverse households

03. Optimised natural light and ventilation

10. Perceived spaciousness

07. Spatial versatility and amenity

\section{CONTEMPORARY EPB STUDY}

01. High-Density with High-Amenity

03. Optimised Natural light and Outlook

06. Situational Circulation System

05. Managed Relationship Between Public and Private

09. Sense of Identity and Character

04. Semi-Private Central Courtyard

02. Definition and Activation of Public Space

\section{STAIRCASE STUDY}

03. Improved natural light and outlook

10. Perception of spaciousness

09. Eventful Building Façades

\section{ELEVATION STUDY}

09. Eventful Building Façades

09. Sense of Address / Identity

08. Positive Relationship to Urban Context

\section{AVAILABLE SITES STUDY}

07. Versatile Design

02. Street edge definition

02. Facade activation 


\section{ADAPTED CRITERIA}

The adapted design criteria carefully

and specifically combines all the design criteria from the various studies or pieces of research throughout the thesis. The purpose of this design criteria is to assess the success of the design case-study using a concise, interrelated list of key principles which should be present in the design.

The purpose of each is as follows:

\section{HIGH-DENSITY WITH HIGH-}

\section{AMENITY}

- Is the design an appropriate density

for its inner-city context while still

providing high-quality easily-accessible

amenities for the building occupants?

\section{DEFINITION AND}

\section{ACTIVATION OF THE PUBLIC} STREET EDGE

- Does the design clearly define the public street edge around the development and provide an active facade with shops, cafés, businesses, and community facilities to be used by the general public?

\section{OPTIMISED NATURAL LIGHT, VENTILATION AND OUTLOOK}

- Are design elements considered and implemented in a way that maximises natural light and ventilation within the various spaces of the development, while also providing a pleasant or interesting outlook from the apartments?

\section{SEMI-PRIVATE CENTRAL COURTYARD}

- Does the design incorporate a shared central courtyard for use by the building occupants that is perceived to be safe and private while providing pleasant, usable outdoor space?

\section{MANAGED RELATIONSHIP BETWEEN PUBLIC, PRIVATE \& SEMI-PRIVATE SPACE}

- Does the design clearly distinguish between public, private and semi- 
private space while also managing the relationship between these spaces to improve the experience of crossing the public/private threshold?

\section{VARIABLE CIRCULATION SYSTEM + APARTMENT LAYOUT}

- Does the circulation system of the design respond to the location and orientation within the block development to improve outlook and aspect for the apartments?

\section{DESIGN VERSATILITY AND DIVERSITY}

- Is the design easily adaptable and widely applicable to other urban New Zealand sites? Does it include a broad provision of apartment types and sizes, including accessible apartments for people with disabilities and spatial versatility for the living spaces?

\section{COHERENT FORM WITH} POSITIVE IMPACT ON URBAN CONTEXT

- Does the design appear to fit within

the context it is situated and improve the public's perception of neighbouring buildings and spaces? Do the dimensions of the design conform to the contextual parameters?

\section{EVENTFUL BUILDING FAÇADES WITH SENSE OF IDENTITY AND CHARACTER}

- Are the façades of the design architecturally eventful and therefore interesting to look at? Is the building seen as a single entity while also providing a sense of identity and character for the occupants and their apartments?

10. GREATER PERCEPTION OF SAFETY AND SPACIOUSNESS

- Does the design exhibit an improved perception of safety and spaciousness for all private and semi-private spaces within the development? This includes the semi-private courtyard, circulation spaces, private apartments and private outdoor space. 
New Zealand EPB Development:

SITE SELECTION

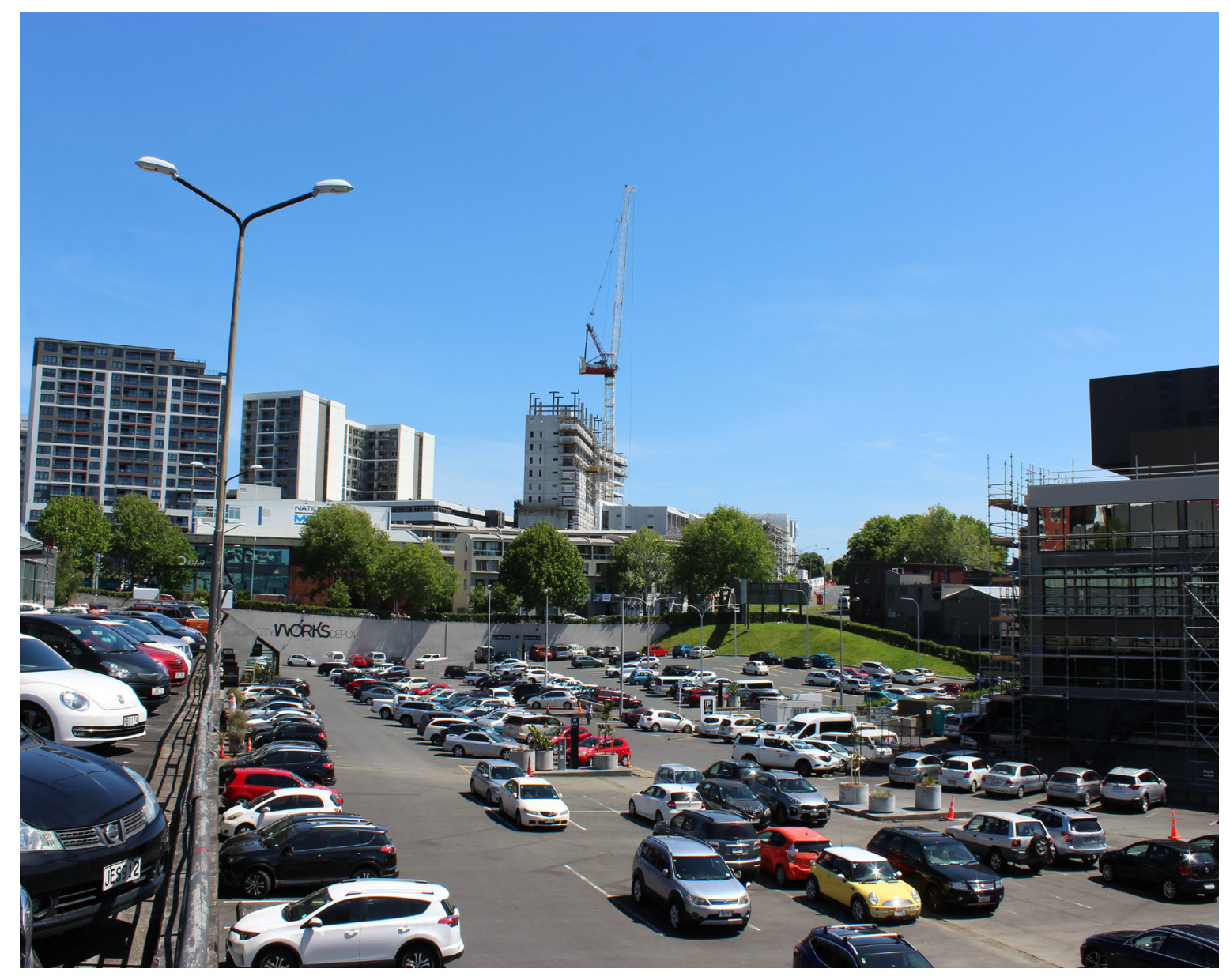

Figure 5.02 - Selected site Photograph by Author 


\section{SELECTED SITE}

The selected site to take forward to the design case study is the Les Mills car-park on the corner of Cook Street and Morton Street. The current use of the site is car-parking for a gym on an adjacent city block. This is an inefficient use of space in an everexpanding city, particularly when more space-efficient options exist. Therefore, the site urgently requires and will benefit from a new high-density development.

This site was chosen because it has a site area close to the site average for Auckland and Wellington. This size ensures that other comparable sites can be found in both cities, so the research findings are therefore widely applicable. The site also exhibits a fairly generous slope across the site and an irregular shape. These three factors provide a suitable basis for broad application of the design case-study to other New Zealand urban settings.
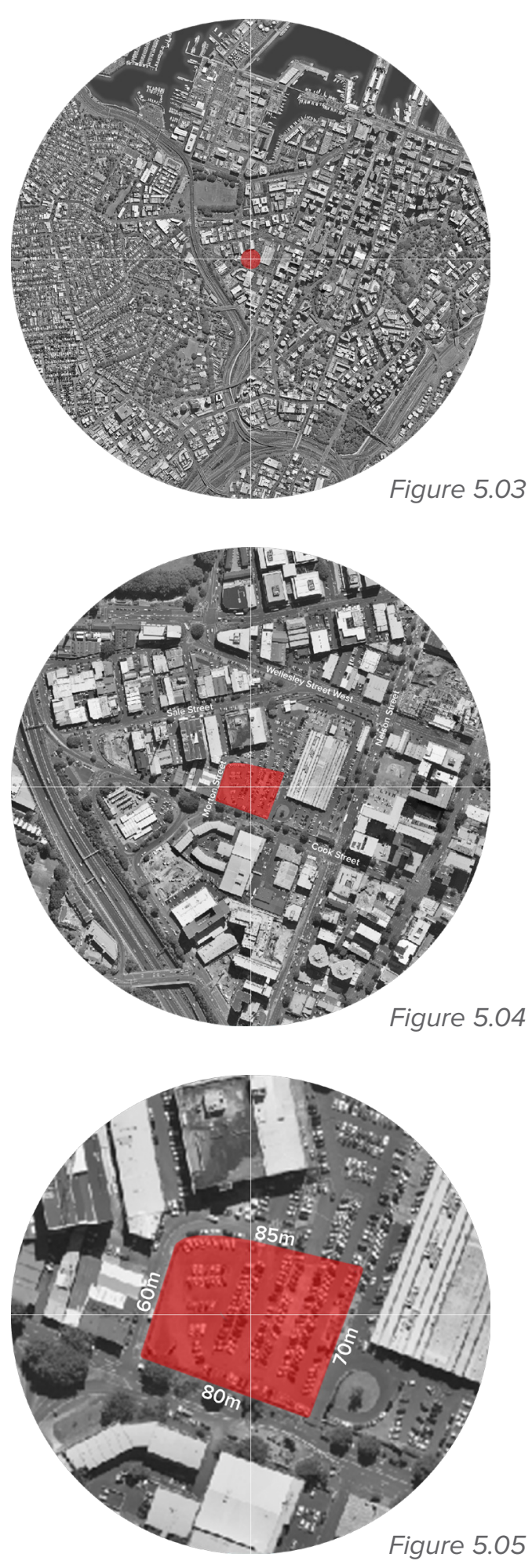
SITE ANALYSIS

$\sim 480 \mathrm{~m}$ radius
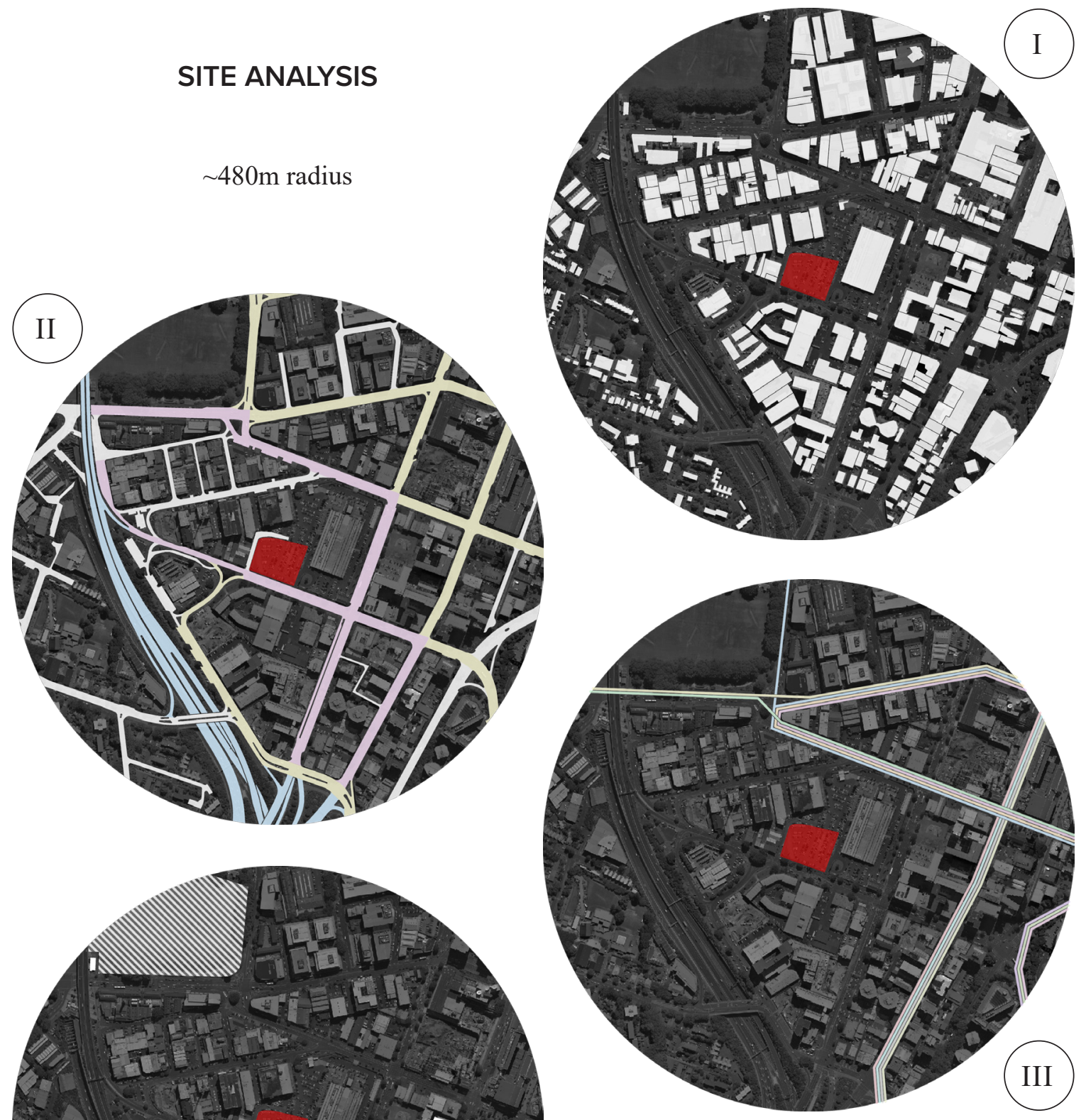

FIGURES:

I. Figure 5.06 - Built Form (Footprints)

II. Figure 5.07 - Infrastructure (Roads)

III. Figure 5.08 - Bus transport Routes

IV. Figure 5.09 - Education + Open Space 
I. The built form surrounding the site is irregular with no distinct pattern. Buildings are loosely packed together with varying sizes and shapes. This suggests that there is certainly room for higher-density buildings and the area is likely to undergo extensive redevelopment.

II. The roads surrounding the selected site feature a hierarchy of transportation controls. Regional arterial roads (purple) border three sides of the urban block. Of which two carry traffic from the motorway (blue) off-ramps. These roads are heavily populated with people and traffic, which will help to activate the street edges of the block.

III. A number of major inner-city bus routes are within easy walking-distance from the site. Some even go directly past the Northern edge of the current urban block, which also has a bus-stop. This could provide a viable argument for removing car-parking from the design case-study. Especially when the public transport network is constantly improving and the new underground railway system is nearing completion.

IV. Open green-space is lacking in the vicinity of the selected site. With only two provisions within a half-kilometre radius, of which one is for the private use of a nearby Primary School. Victoria Park to the North is a large area of green space and fairly close-by. However, the means to get there are not particularly safe for children due to busy roads. More provision of open green-space would be very useful for the occupants of a new development. The public would also benefit from a public provision of open green space.

Also shown on the map is a number of educational establishments.

Accompanying the park to the west is the Primary school and the buildings near the site are preschool centres. These are very useful for the families who will occupy the new development. 
SITE ANALYSIS

$\sim 240 \mathrm{~m}$ radius

(VI)
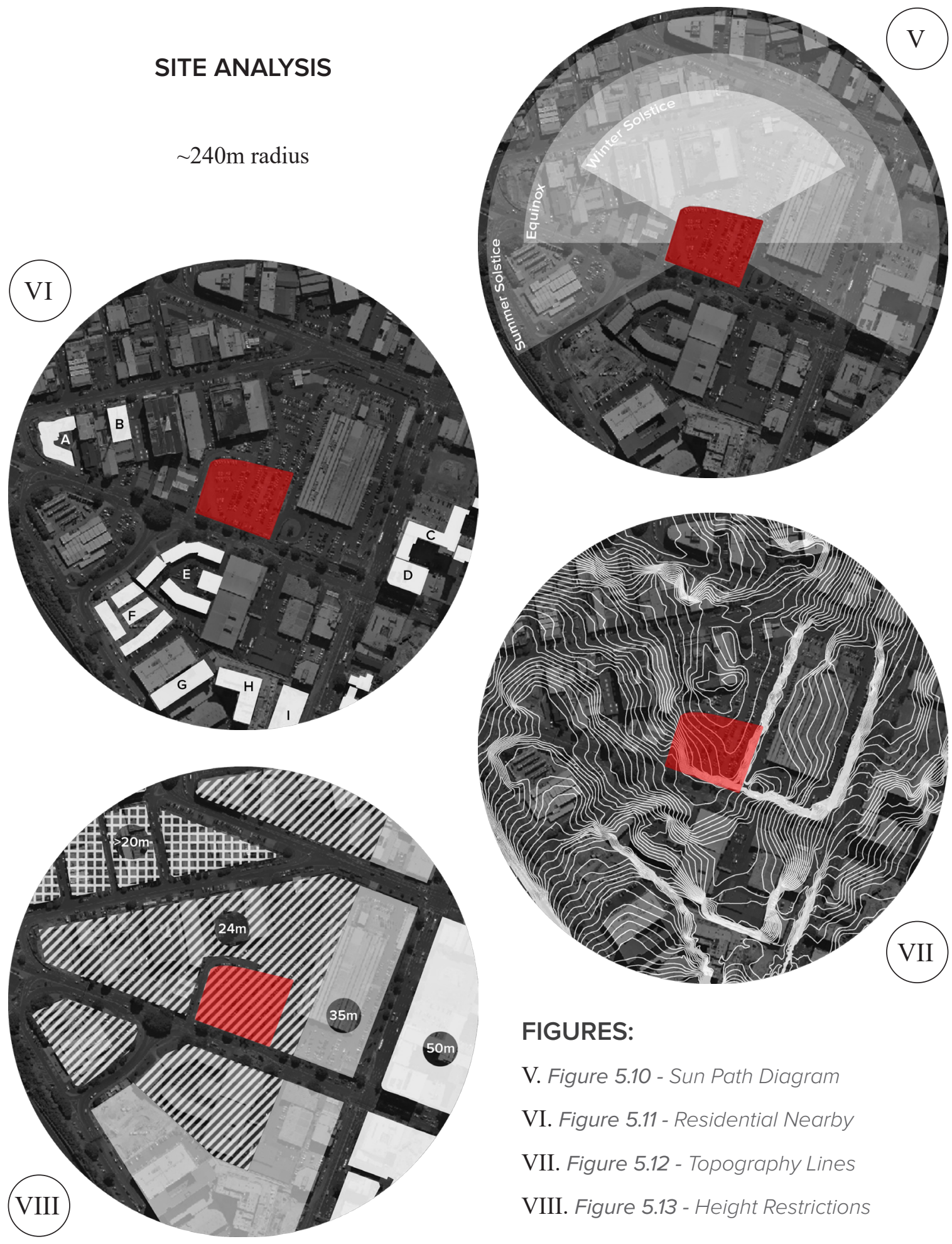

\section{FIGURES:}

V. Figure 5.10 - Sun Path Diagram

VI. Figure 5.11 - Residential Nearby

VII. Figure 5.12 - Topography Lines

VIII. Figure 5.13 - Height Restrictions 
V. As expected, and emphasised by the diagram, the southern side of the site will receive zero sunlight in the winter months and very little during the rest of the year. As with many of the EPB examples, this will require a special treatment for the southern face of the EPB development. Due to the slight rotation of the site, the Northern and Western sides of the development will receive the most sunlight.

VI. There are a number of residential buildings within a quarter-kilometre radius of the site. These range in age, size and density. The approximate densities of each are as follows:
A. Grace VQ Apts. 700dpH
B. Sale St Apts. 250dpH
C. Zest Apts. 1300dpH
D. Aura Apts. $1100 \mathrm{dpH}$
E. Cook St Apts. 100dpH
F. Union Green $\quad 400 \mathrm{dpH}$
G. Sugartree Prima 900dpH
H. Sugartree Centro 600dpH
I. Sugartree Altro $1000 \mathrm{dpH}$

The EPB housing design will need to compete with these current developments in order to be a relevant urban housing alternative.

VII. The topography of the site, like the rest of Auckland city, is hilly. There is a significant step-down from the Southern and Eastern sides of the site. Two sides of the site will need to be sloped for all sides to be accessible.

VIII. The Auckland Unitary plan imposes various height restrictions across the city. These height restrictions around the site vary from $50 \mathrm{~m}$ to as little as $16 \mathrm{~m}$. The height restriction for the selected site is $24 \mathrm{~m}$, which is particularly low for high-density development. An argument could be made towards increasing this height due to the probable redevelopment of the area and consequent density increase. Alternatively, a gradual reduction in building height across the site would provide an option that honours the unitary intentions. 


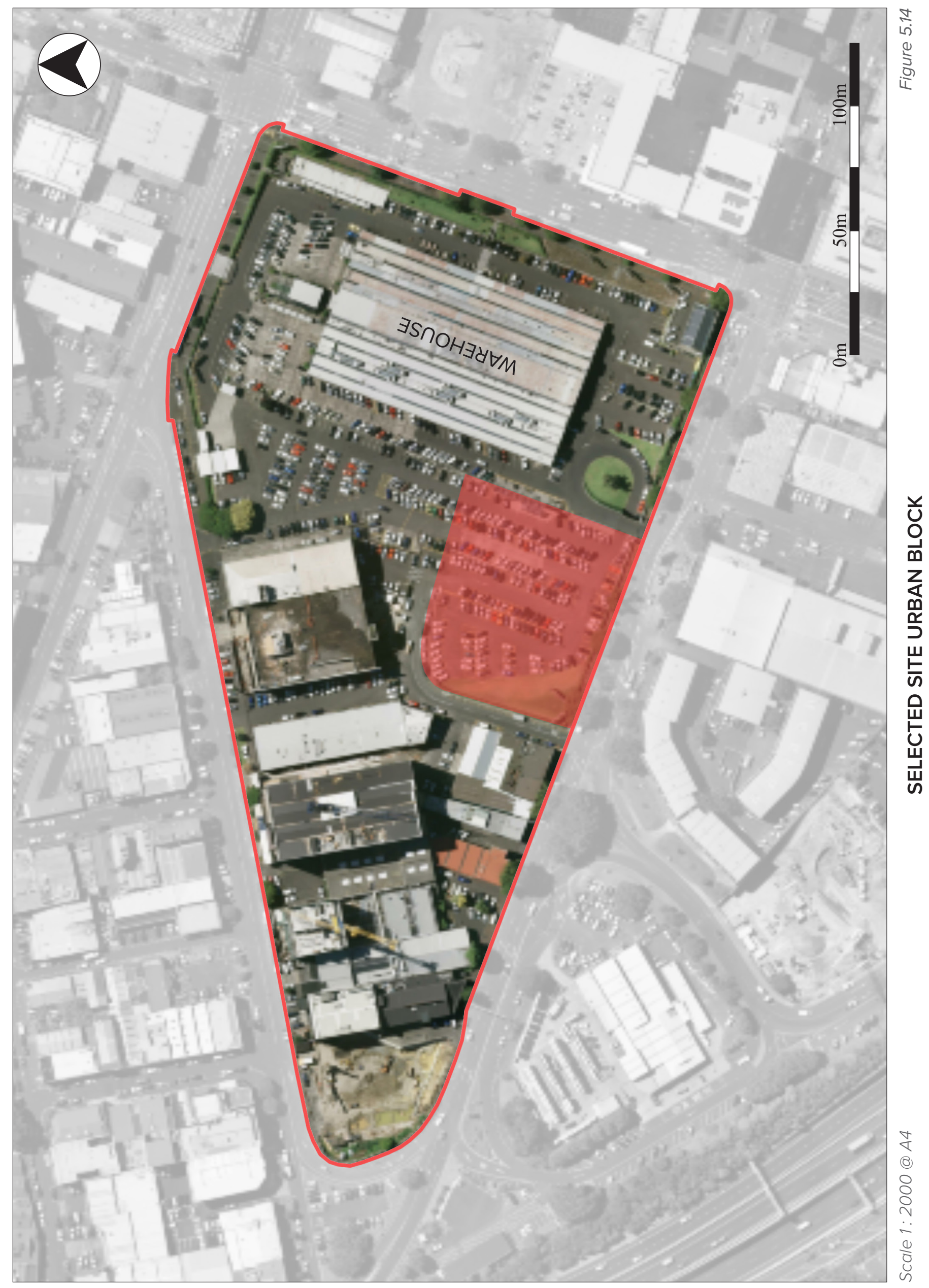



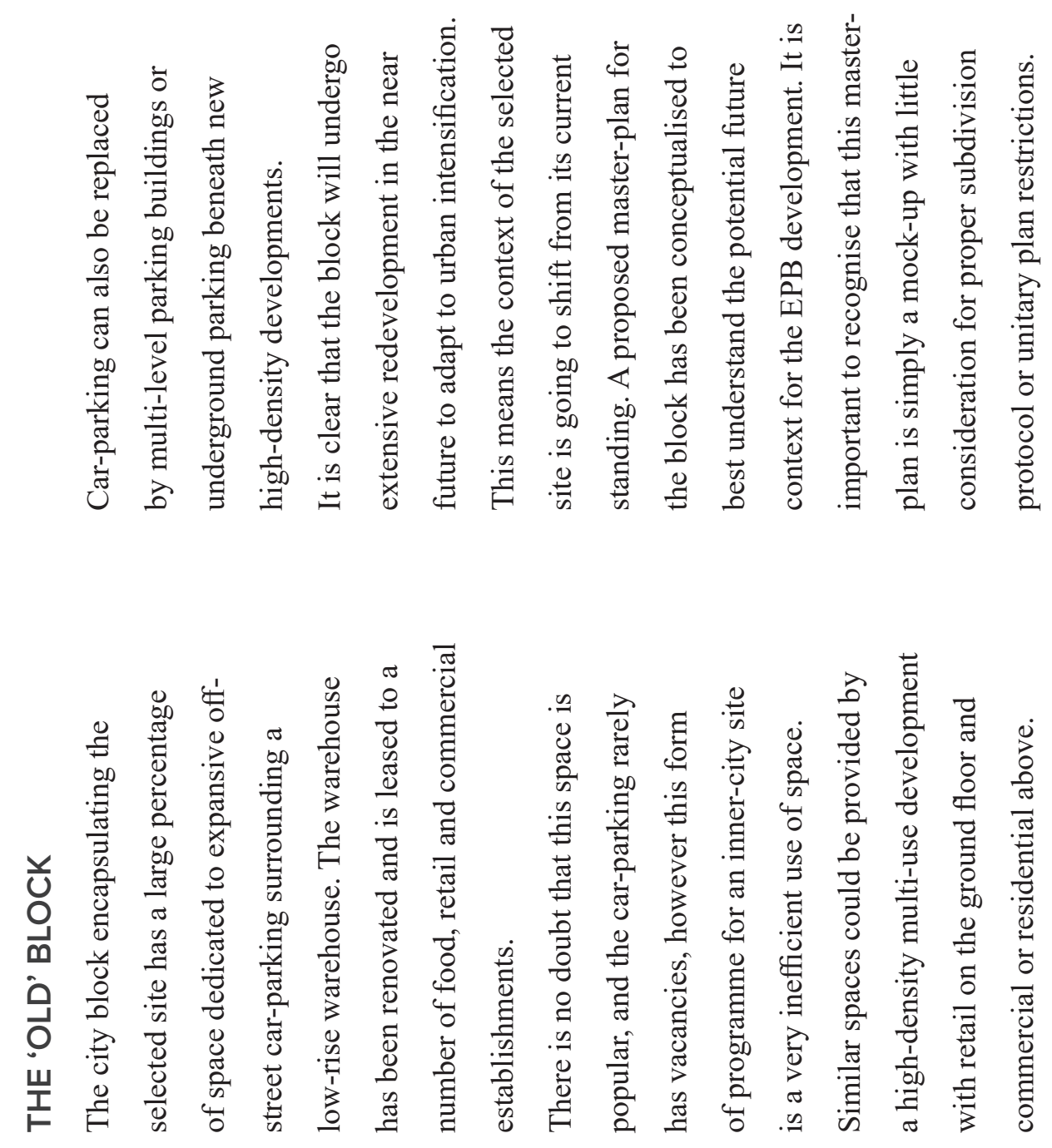


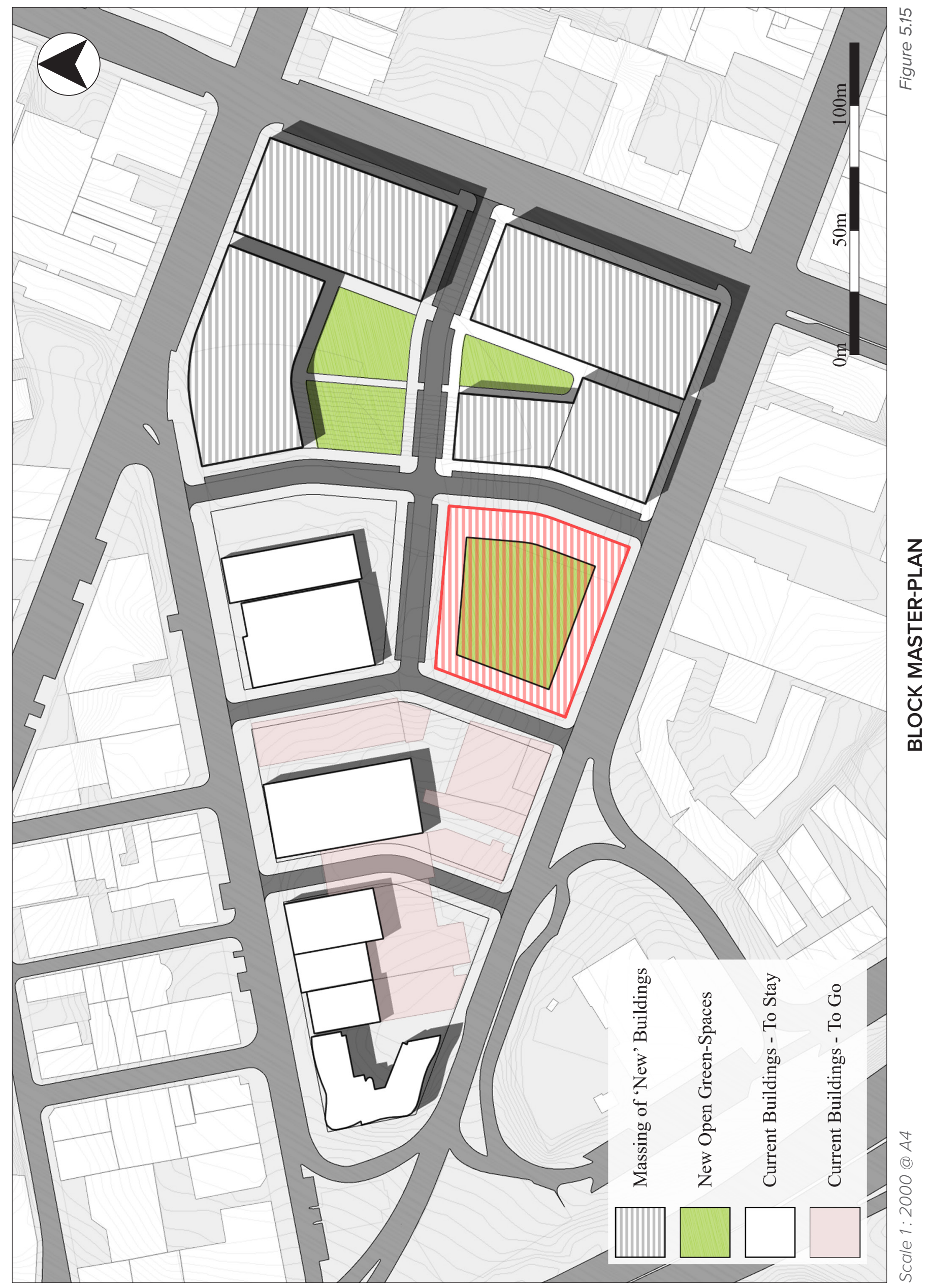



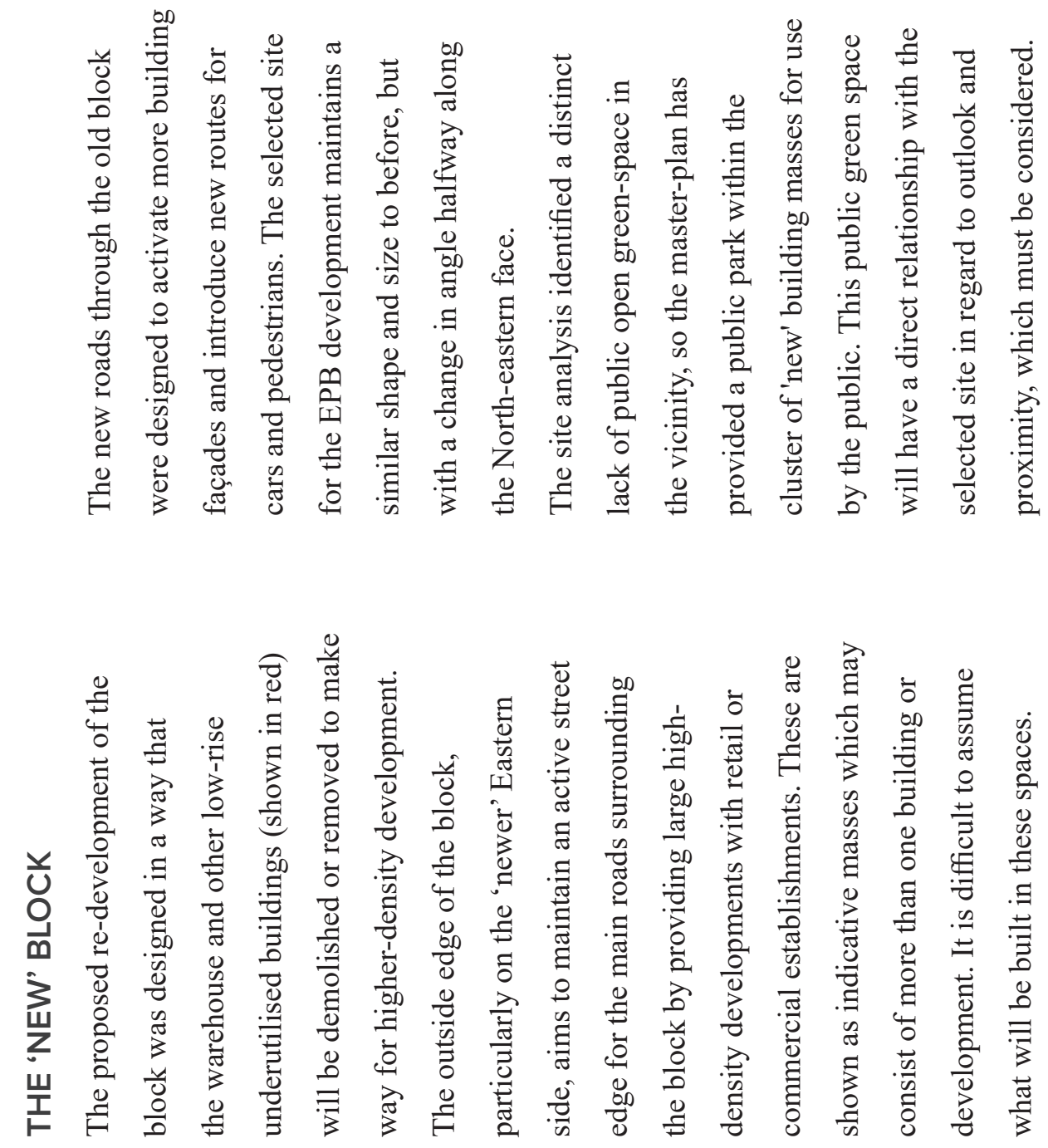


\section{SITE CONCLUSIONS}

The selected site is very suitable for the research because it does not exhibit a distinct identity or cohesive urban context. The size of the selected site is also close in area to the average of the available sites in Auckland and Wellington city. Pairing this with a simple but irregular shape and a generous slope across the site means that the final design on this site will be widely applicable to other New Zealand urban settings.

The proposed master-plan of the block surrounding the site introduces a new immediate urban context to the site, in response to the current under-utilisation of the block. This conceptualisation of potential redevelopment provides greater definition of the street edge surrounding the selected site as well as improving the activation of the street edge along the Eastern side of the urban block.
The adapted EPB development on this site will need to function as a standalone entity, with sloping streets on at least two sides. The design casestudy will need to consider the impact of the new development on the site in its current state and after it undergoes extensive redevelopment. This will ensure that the design has a positive impact on its urban context throughout its lifetime and will not appear out of place.

While the unitary plan defines the height limit of the site as 24 metres, a gradient from $35 \mathrm{~m}$ to $24 \mathrm{~m}$, East to West would provide a suitable alternative, and an arguably more pleasant change in urban scale. The design might consider providing additional childcare facilities, as there are only a few within the vicinity and the familydominant occupancy of the design will benefit greatly from this provision. 


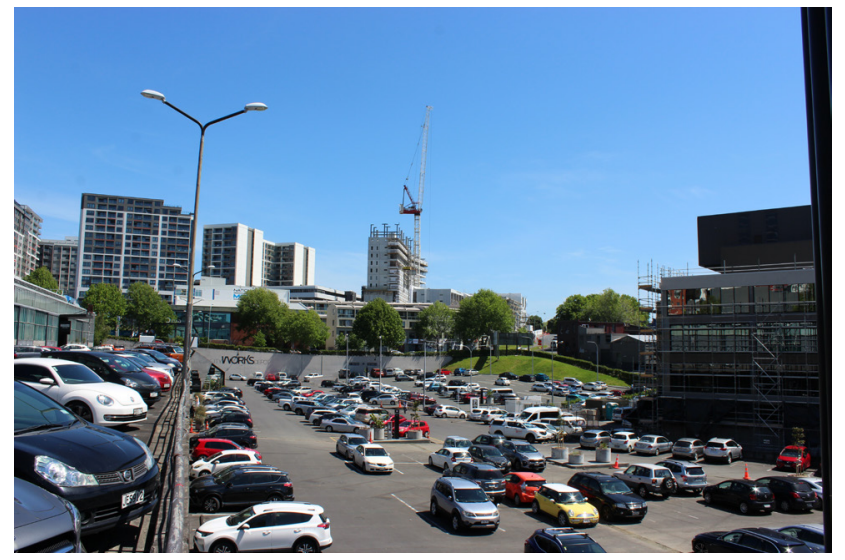

Figure 5.16

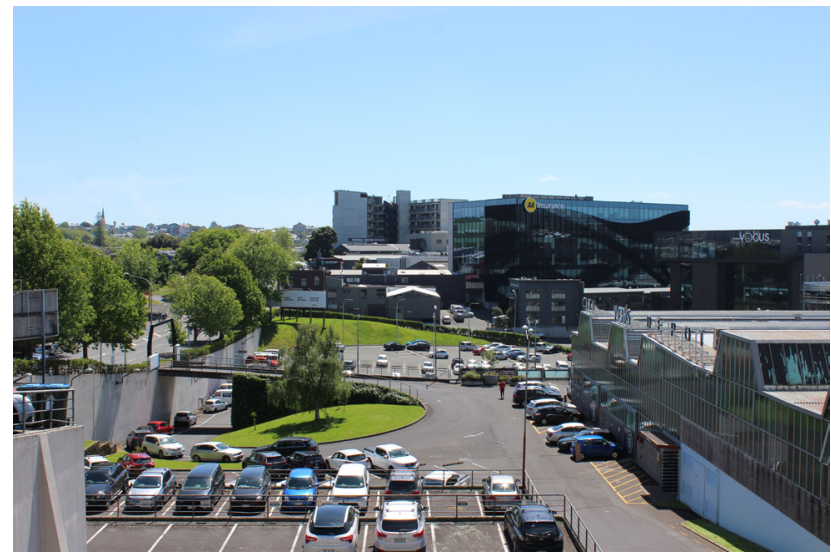

Figure 5.17

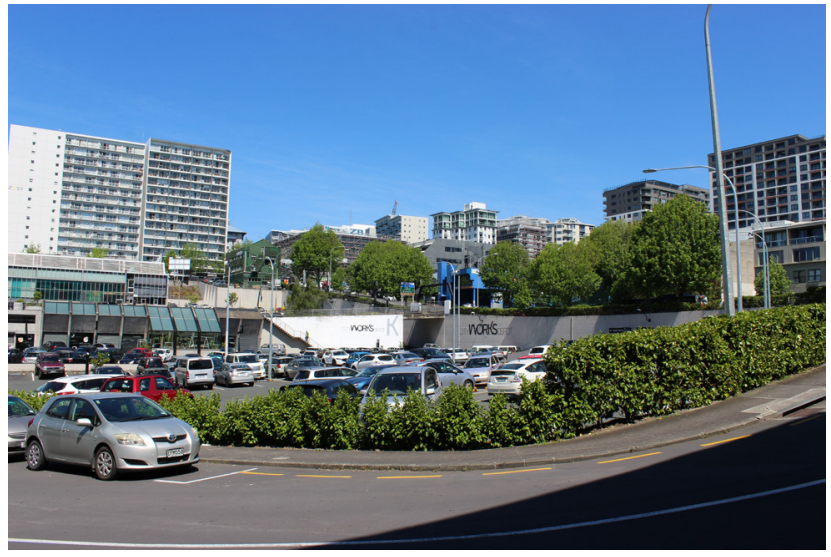

Figure 5.18 
15

\section{$\frac{3}{3}=$

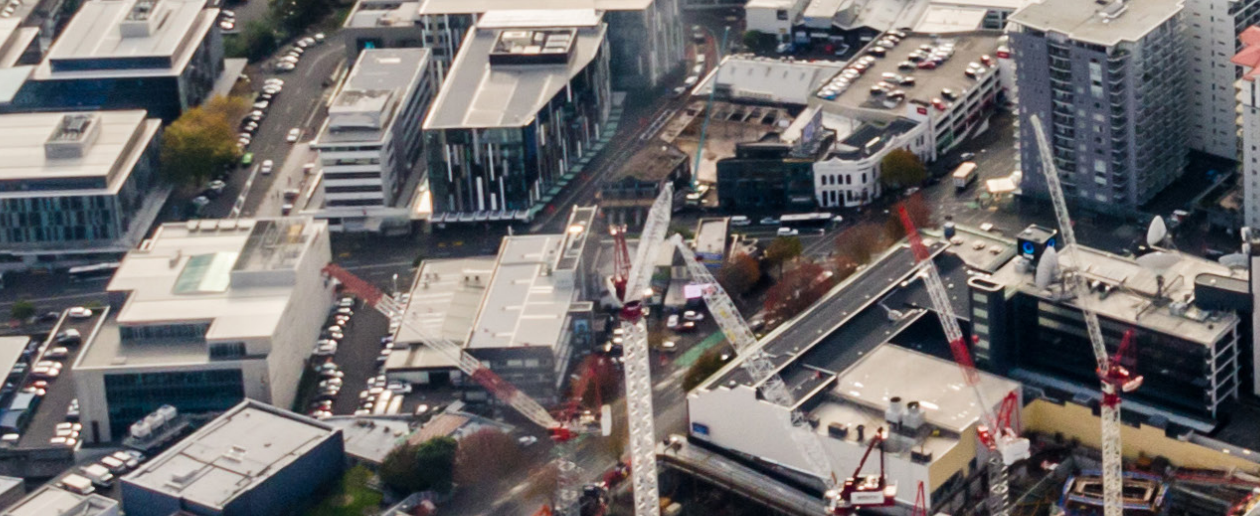
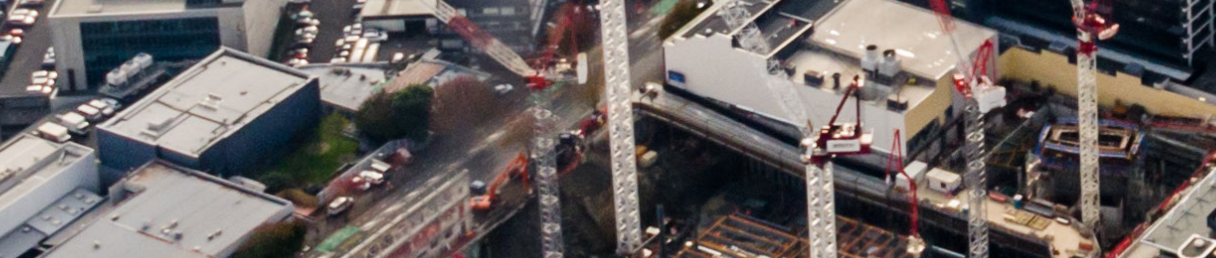

The
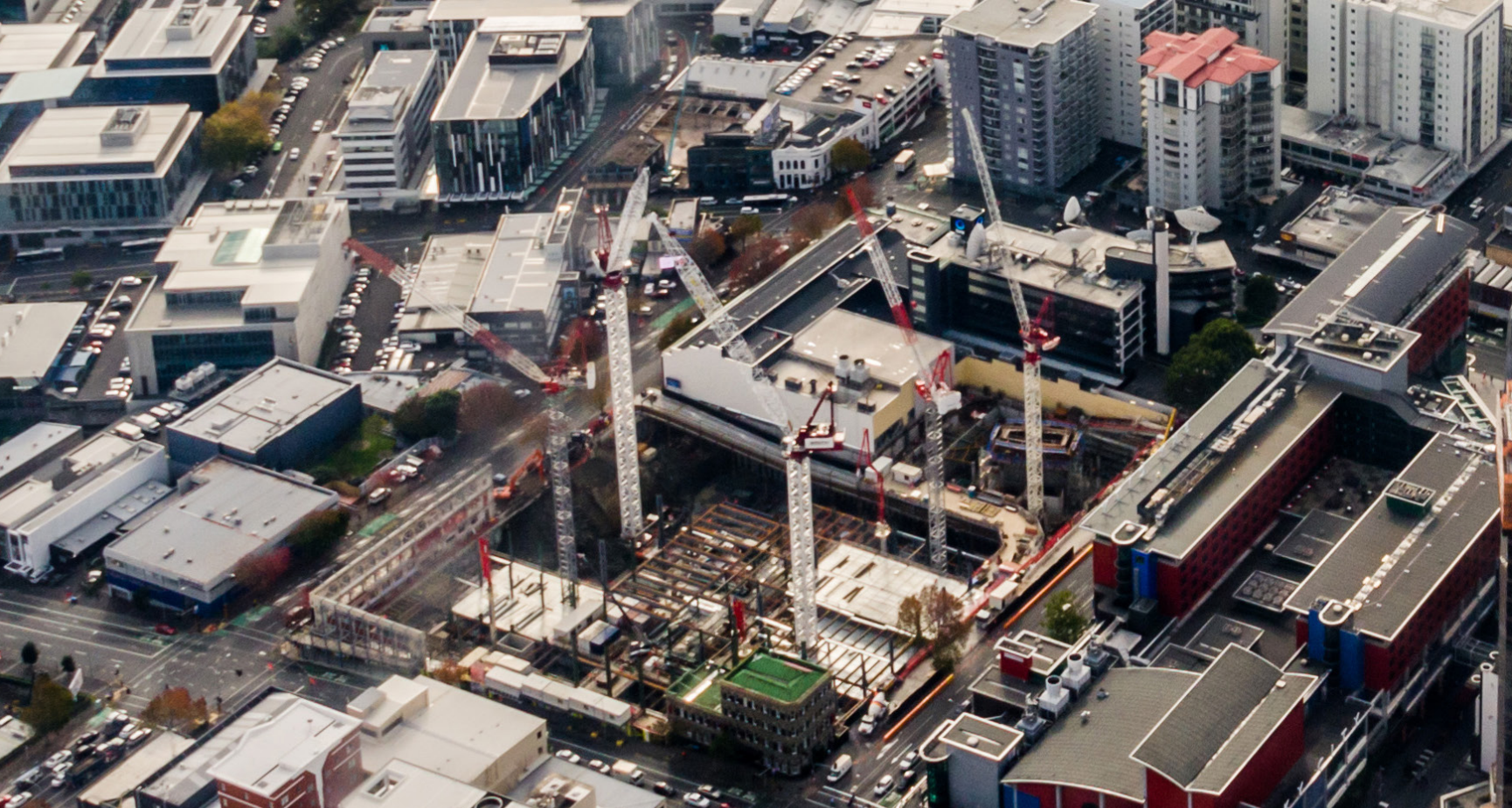

\section{l.

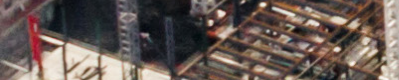

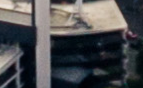




\title{
CHAPTER SIX
}

\author{
Design Case Study + \\ Evaluation of Final Design
}


New Zealand EPB Development: DESIGN CASE-STUDY

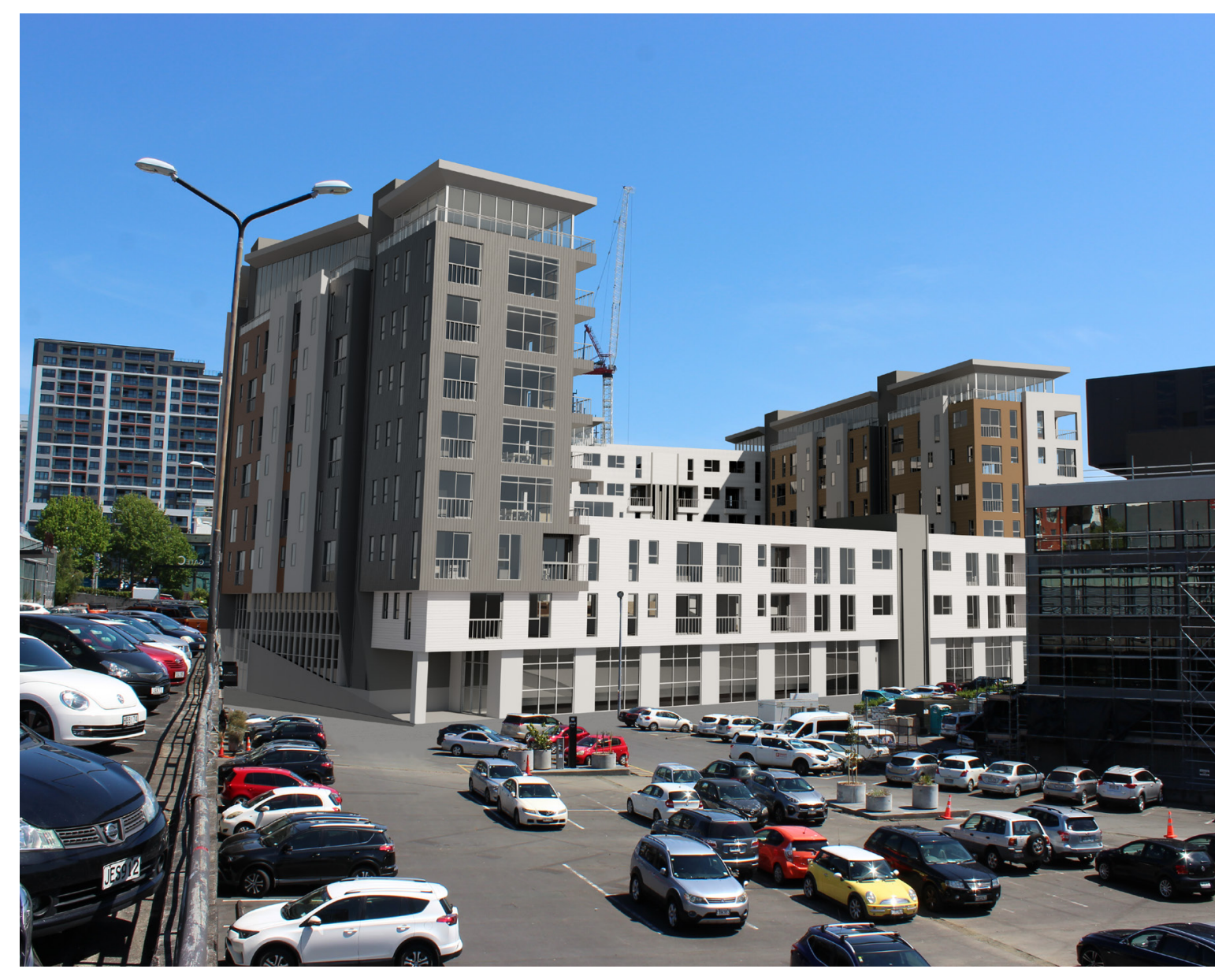

Figure 6.01 - Final design superimposed onto selected site 


\section{DESIGN PROCESS}

The aim of the design case-study is to test the adapted design strategies and criteria on an attractive EPB housing development located on the selected site in Auckland City.

The design process was iterative with each iteration critiqued and evaluated against the strategies and criteria.

Continuous reflection governed the development of one design iteration to the next.
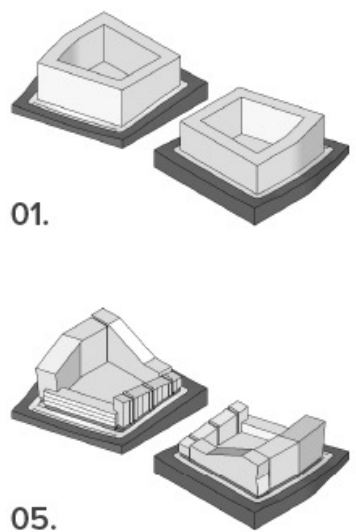

05.
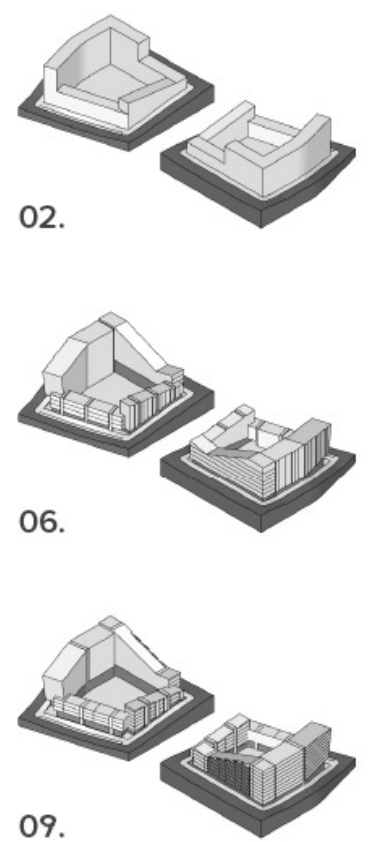

Building form and spatial layout were developed simultaneously, with the failure of one dictating an alteration to the other. The spatial layout was the main driving factor of the design due to the importance of the apartments.

This chapter will focus on showcasing the result of the design case-study in the form of a final design for EPB housing in New Zealand. Reflection and evaluation of the final design using the design criteria is in the next chapter.

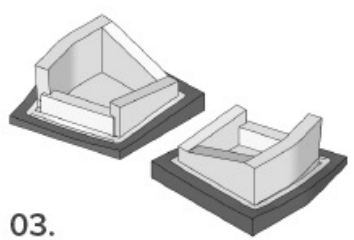

04.
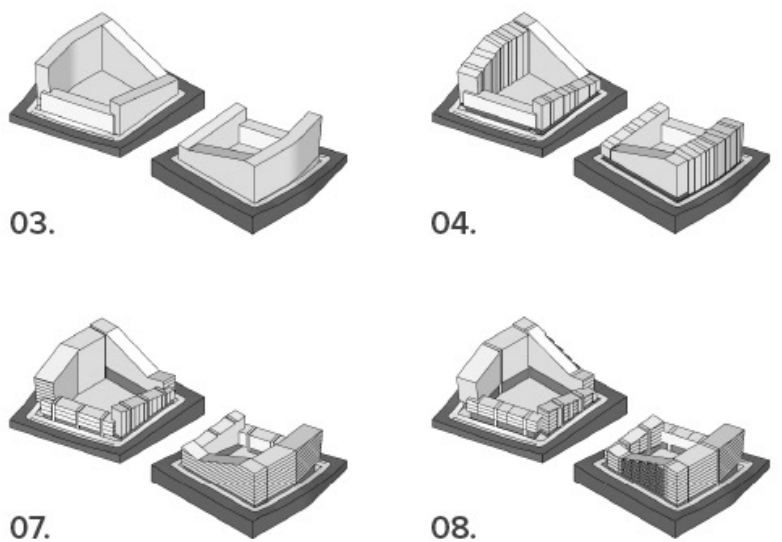

10.

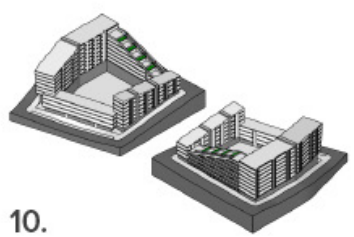

Figure 6.02 - Summary of design iterations and development 


\section{FINAL DESIGN}

The design exhibits the fundamental characteristics of the traditional EPB housing model, including the linked perimeter of building(s), defining the street edge and surrounding a central courtyard. Multiple circulation cores are located around the entirety of the building, with entrances at street-level providing access into the courtyard and to the apartments above. Ground floor retail or commercial spaces activate the street edge and allow for at least onestorey between the apartments and the courtyard.

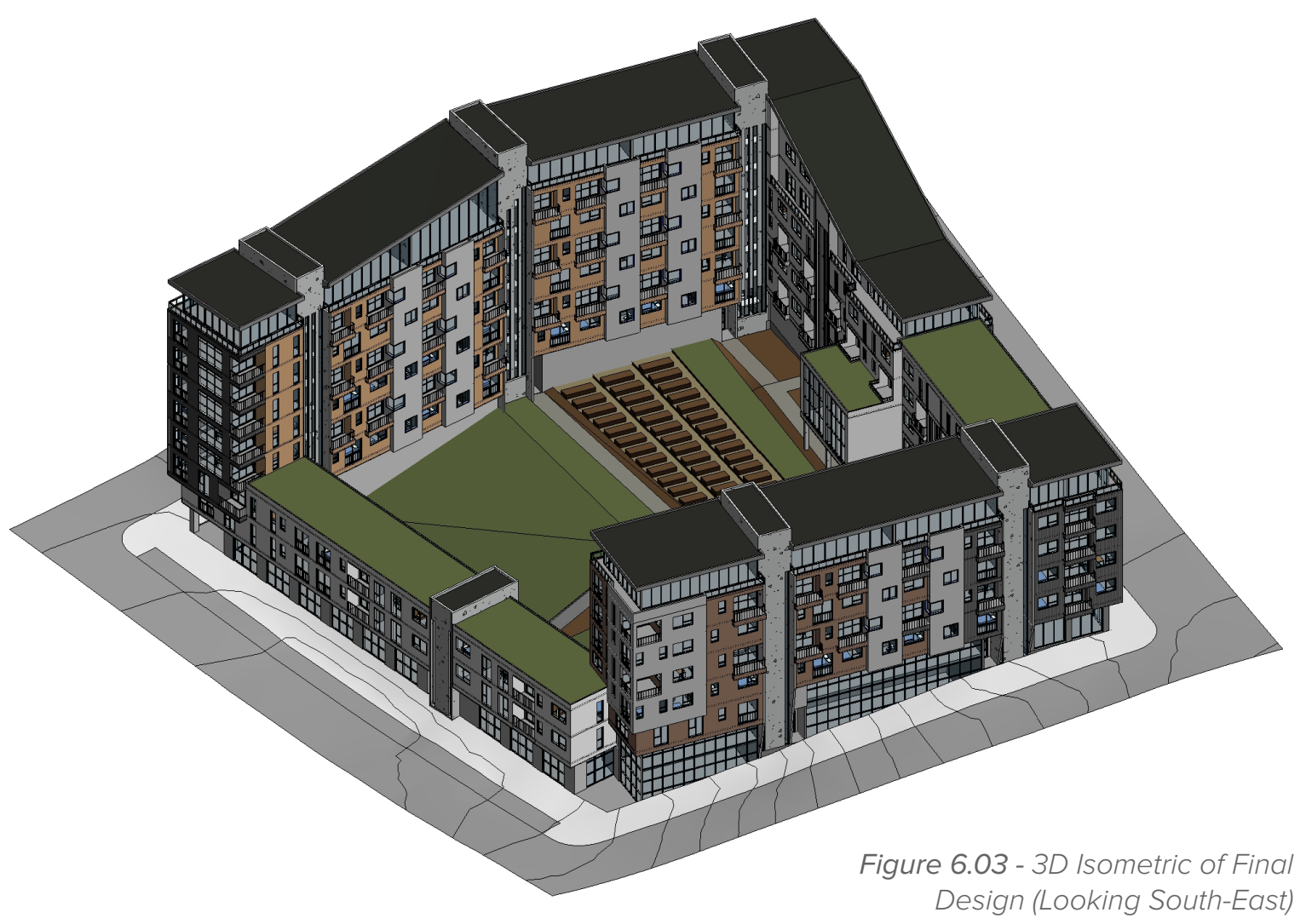




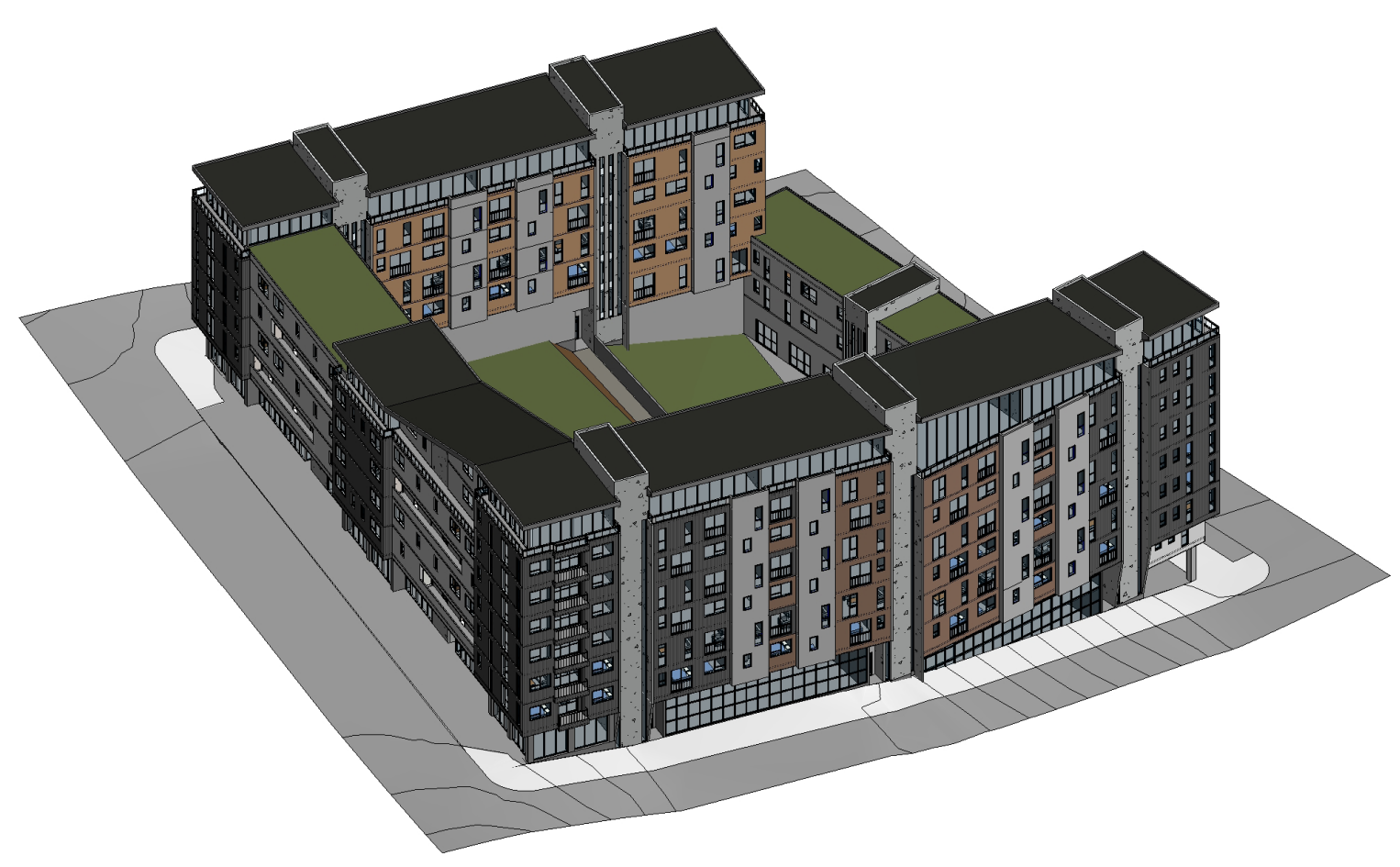

Figure 6.04 - 3D Isometric of Final Design (Looking North-West)

The majority of the apartments are designed to have double-aspect living spaces looking both into the courtyard and out to the street. Most of these are two levels (duplex apartments) to best incorporate this feature. The apartments are oriented towards the sun to maximise natural light within each apartment. This means some apartments primarily face the street as opposed to the more-pleasant verdant courtyard. A selection of apartment types and sizes are available throughout the development. 


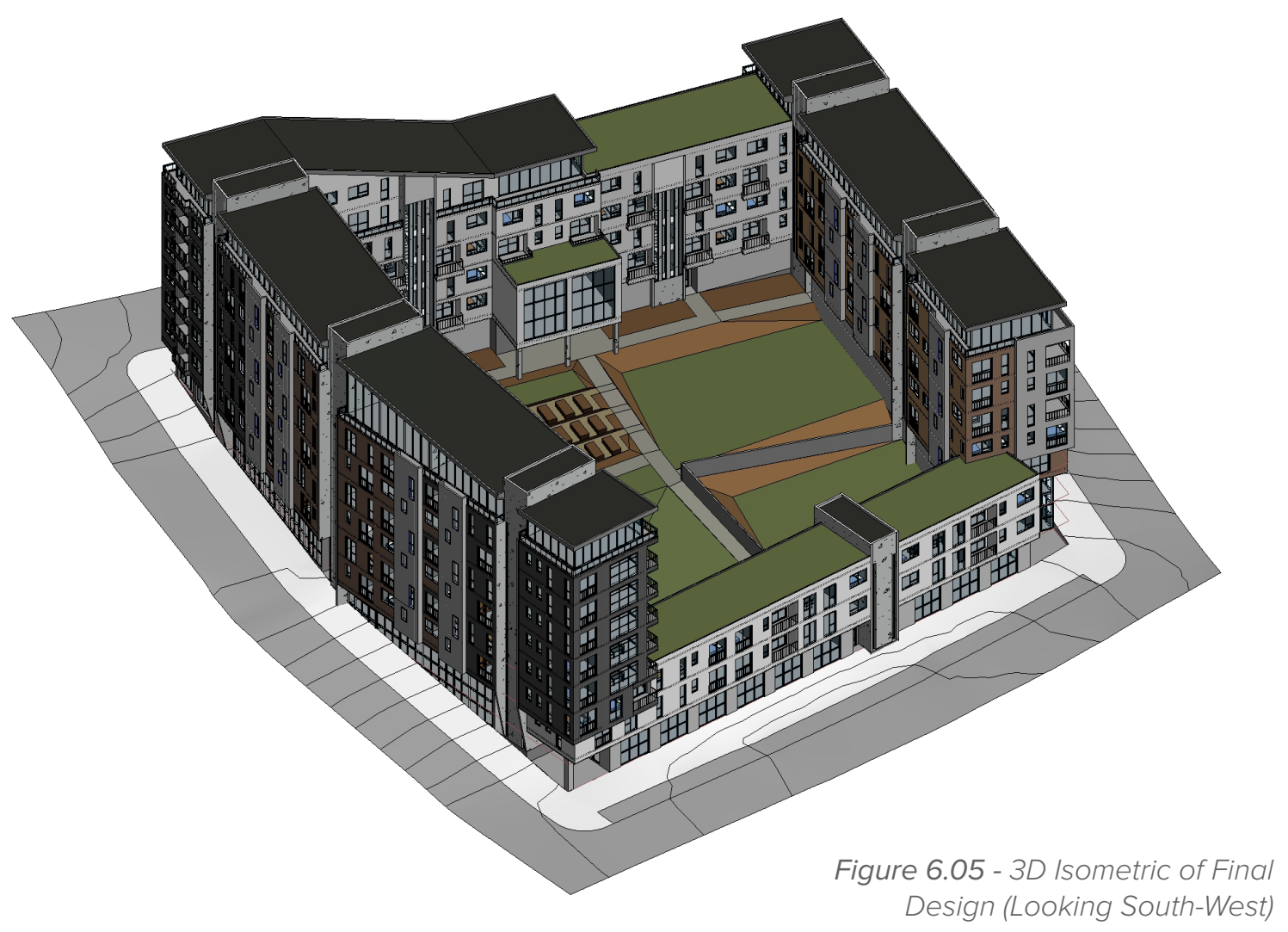

The building aesthetic and materiality focuses primarily on differentiating between the different identities within the development. This refers to the identities of the different sides of the block, the different identities of the inside and outside of the block, and also identifying the relationship between the apartments and the vertical circulation core which serves them. The circulation cores are a crucial element of the design so these are expressed on the inner and outer façades of the building. 
The building height was adjusted

around the development to improve

the penetration of sunlight into the

courtyard and the apartments facing into the courtyard. Since most

apartments are oriented towards the

North/North-West, the North and
West sides of the building have been

lowered to accommodate this. This has

also been done due to unitary height restrictions. Fully-glazed penthouse apartments on the upper levels also aim to lower the impact of the buildings' height on the surrounding context.

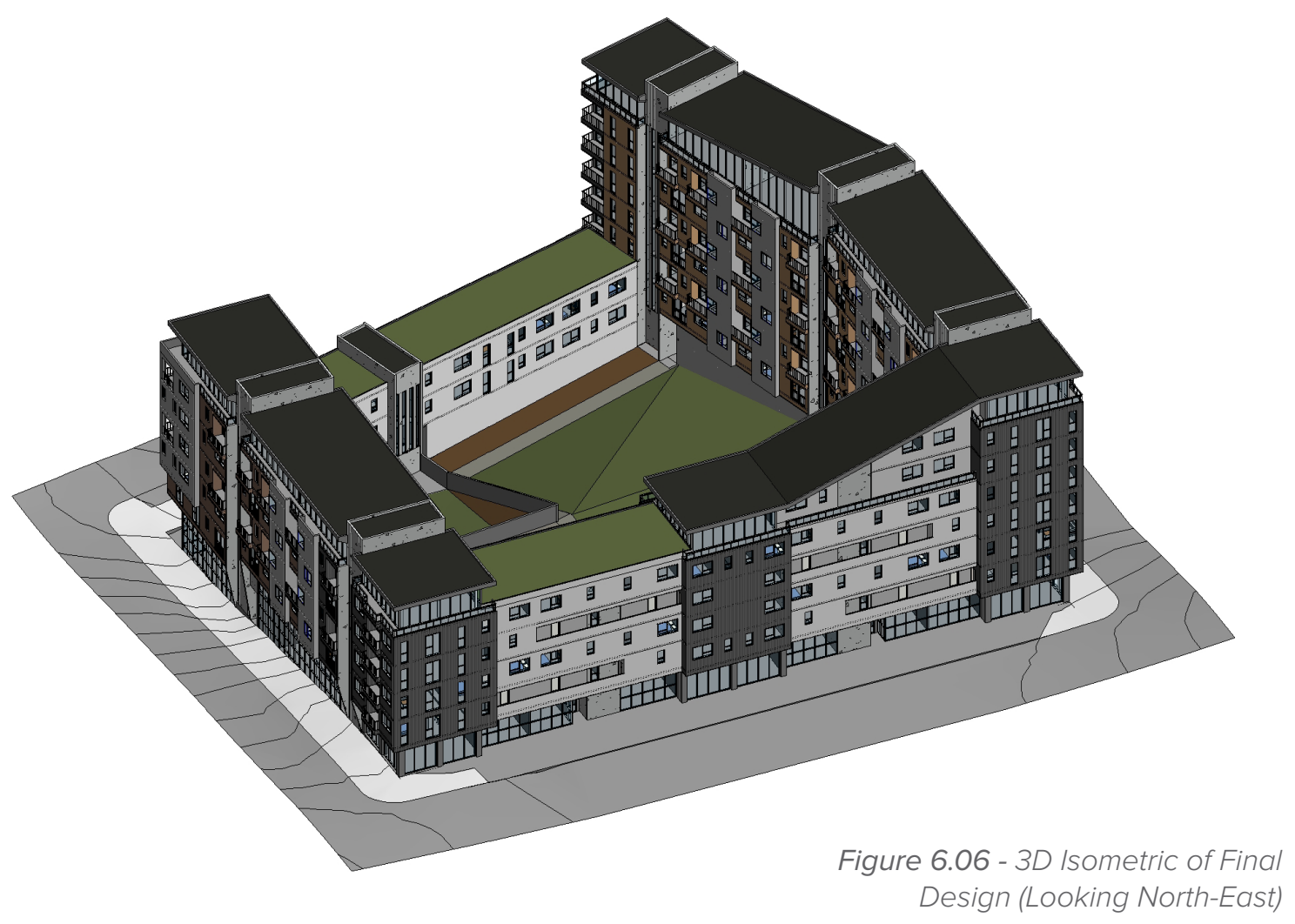




\section{FORM COMPOSITION}

01. Footprint of building with central green space. Circulation cores located around building perimeter.

02. Multiple circulation cores formally identified and extended to building height.

03. Building perimeter established between circulation cores, fully surrounding central courtyard.

04. Height of perimeter adjusted to increase solar penetration into apartments and courtyard.
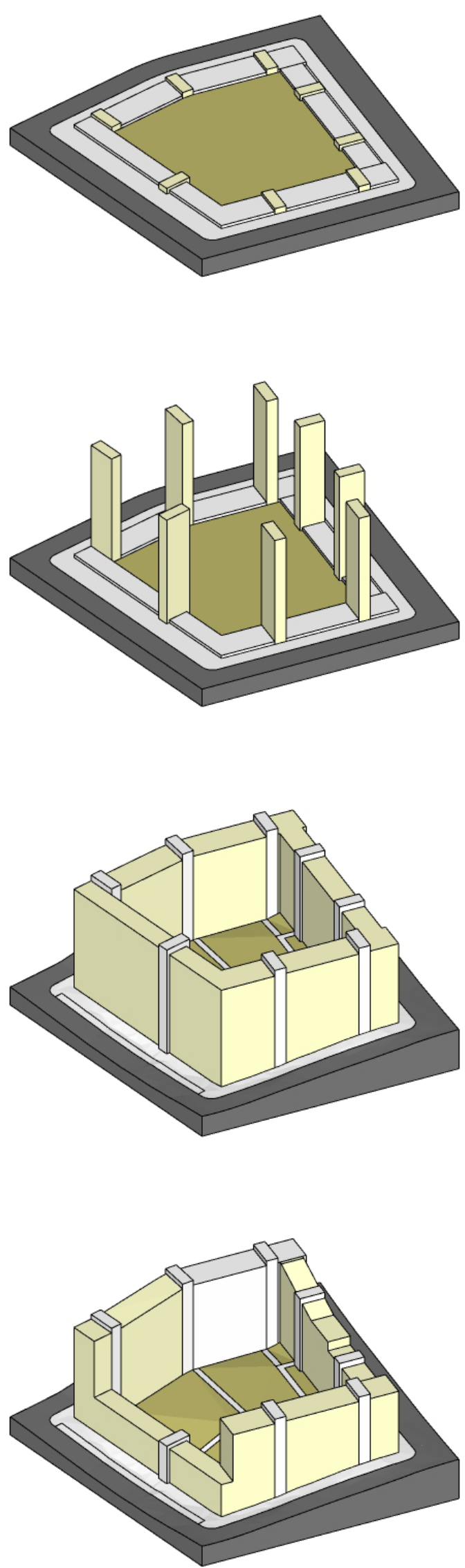

Figure 6.07 - Diagrams illustrating composition of the building form 
05. Apartments extruded from main building form to recess circulation cores and define the ground floor retail.

06. Alterations made to the building form to best express key aesthetic components.

07. Slim roof added to the top of the penthouse apartments.

08. Facade protrusions added to apartments and communal area extended into courtyard.
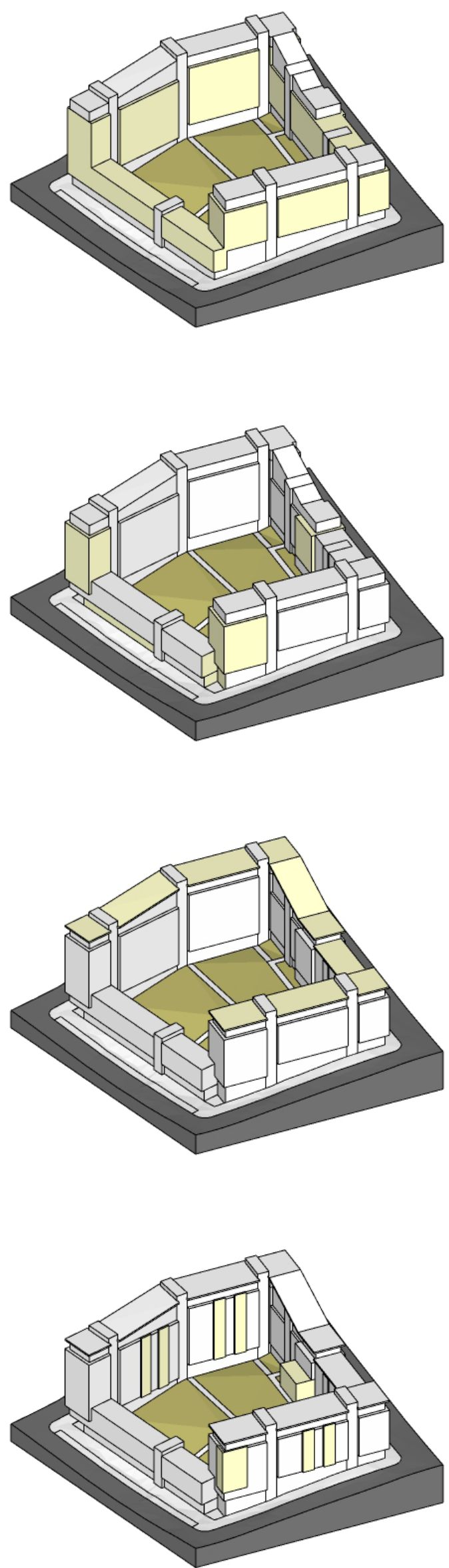

Figure 6.08 - Diagrams illustrating composition of the building form 


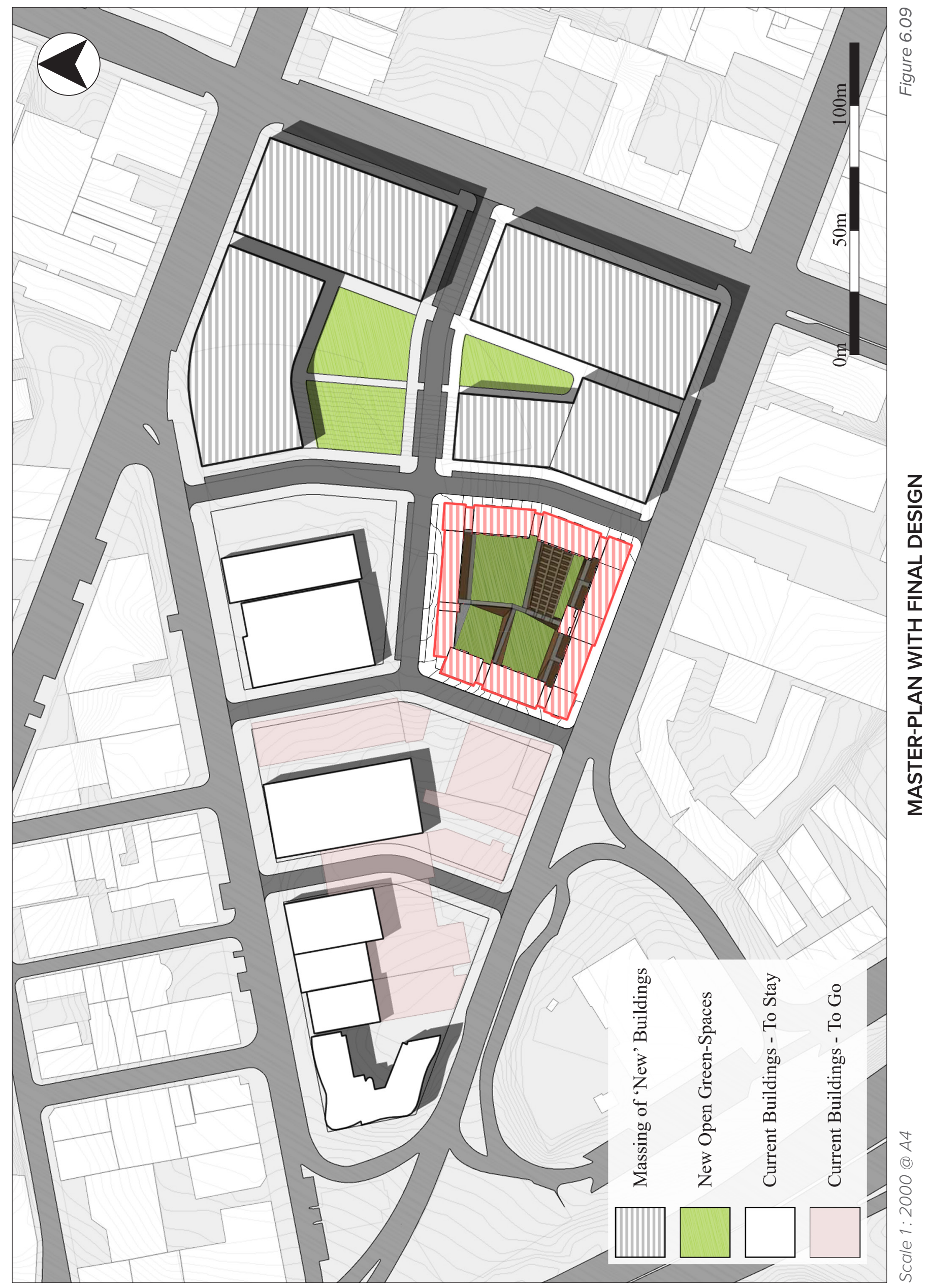




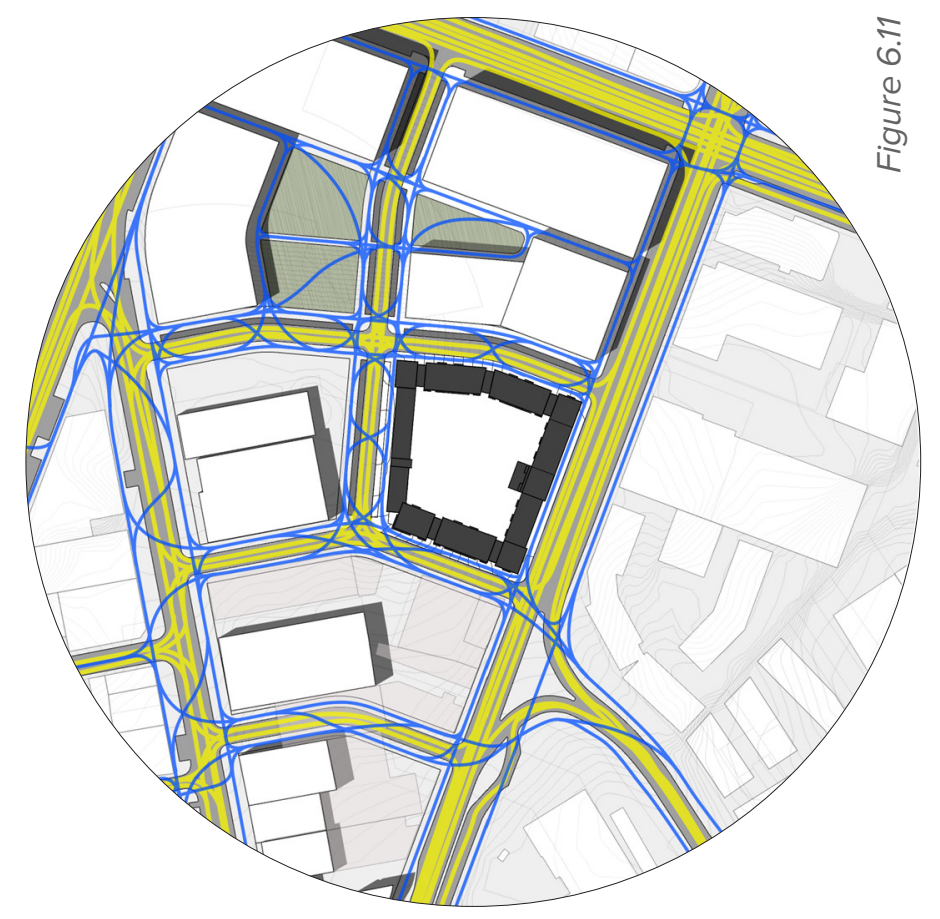

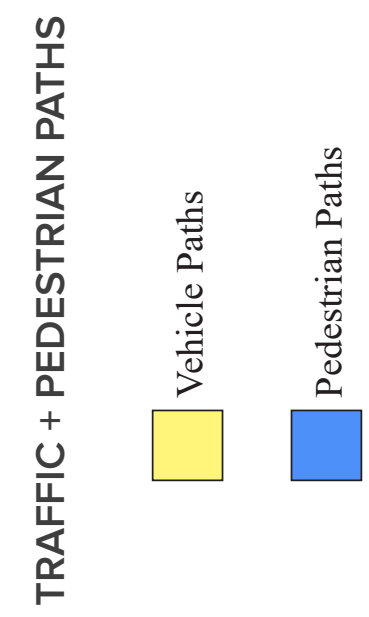

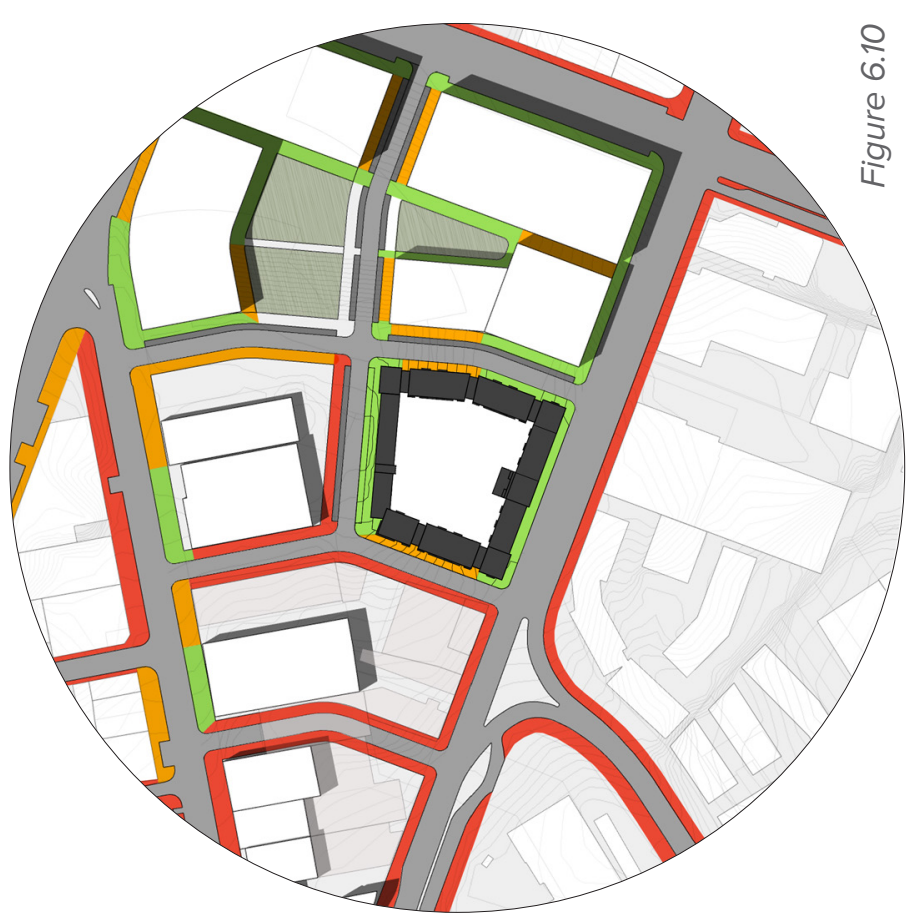

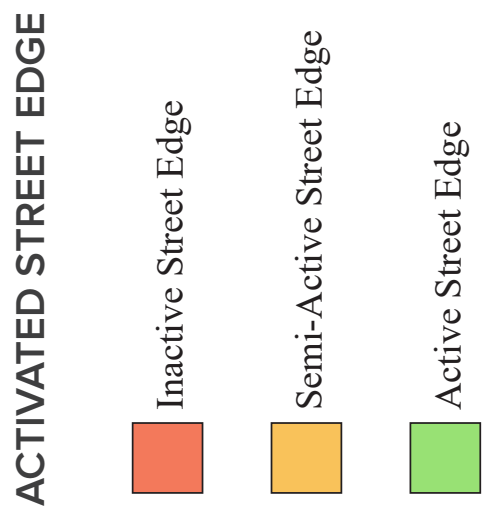




\section{THE CENTRAL COURTYARD}

The central courtyard is one of the key aspects of any European Perimeter-Block, with no exception in the Design Case-Study. However, it has been repeatedly acknowledged that there is no way to ascertain how New Zealanders would prefer to use this space, and its success is indiscernible without further in-depth sociological research.

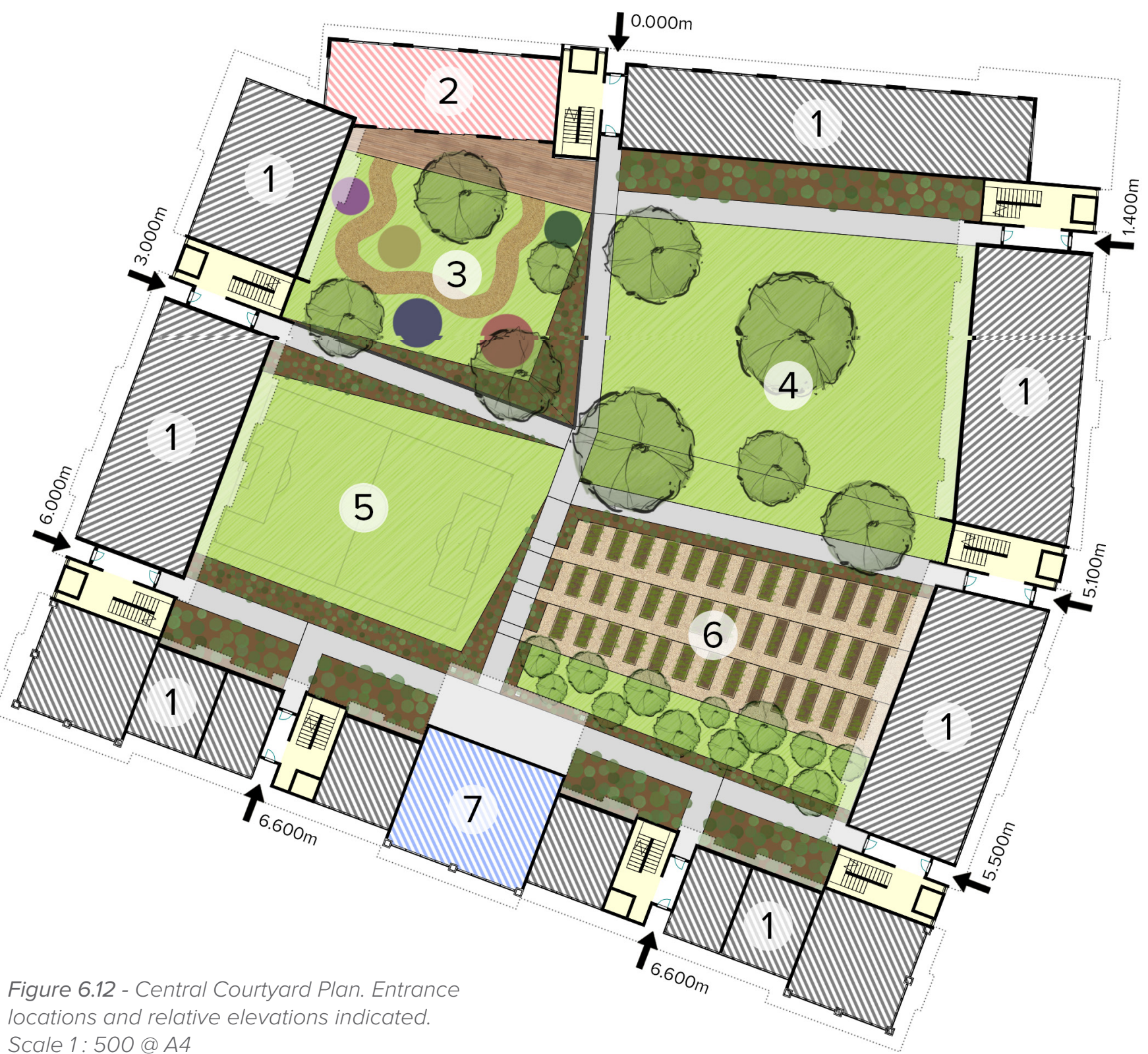


Therefore, the design has presented a number of different uses within the central courtyard:

1. Retail or commercial spaces at ground level.

(Spatial fit-out beyond the scope of the research).

2. Indoor area of the on-site childcare centre.

(Spatial fit-out beyond the scope of the research).

(3.) Fenced outdoor area of the on-site childcare centre.

Play activity areas indicated by the coloured circles.

4. Sloped grass area with large trees for shade. Area for miscellaneous use such as picnics or children's play. Might include communal BBQ's, seating areas and/or a children's playground for use by the building occupants.

5. Flat grass area for sports activities and other active recreation.

6. Community garden for use by the building occupants. Includes planting boxes for herbs/vegetables and a large section dedicated to fruit trees.

7. On-site cafe or bar with access to the central courtyard, for use only by the occupants of the building. 


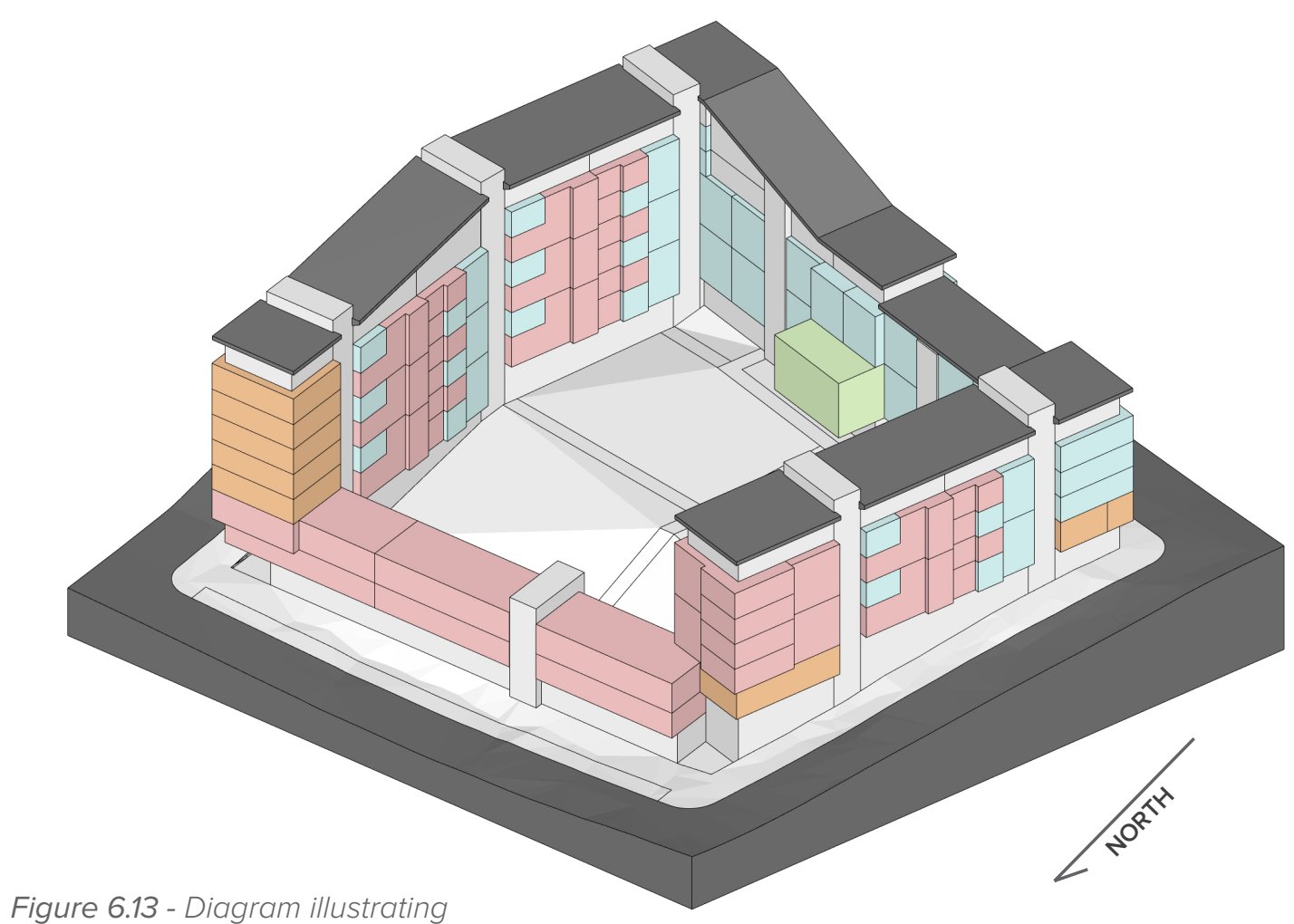

Figure 6.13 - Diagram illustrating

apartment assembly, looking South-East

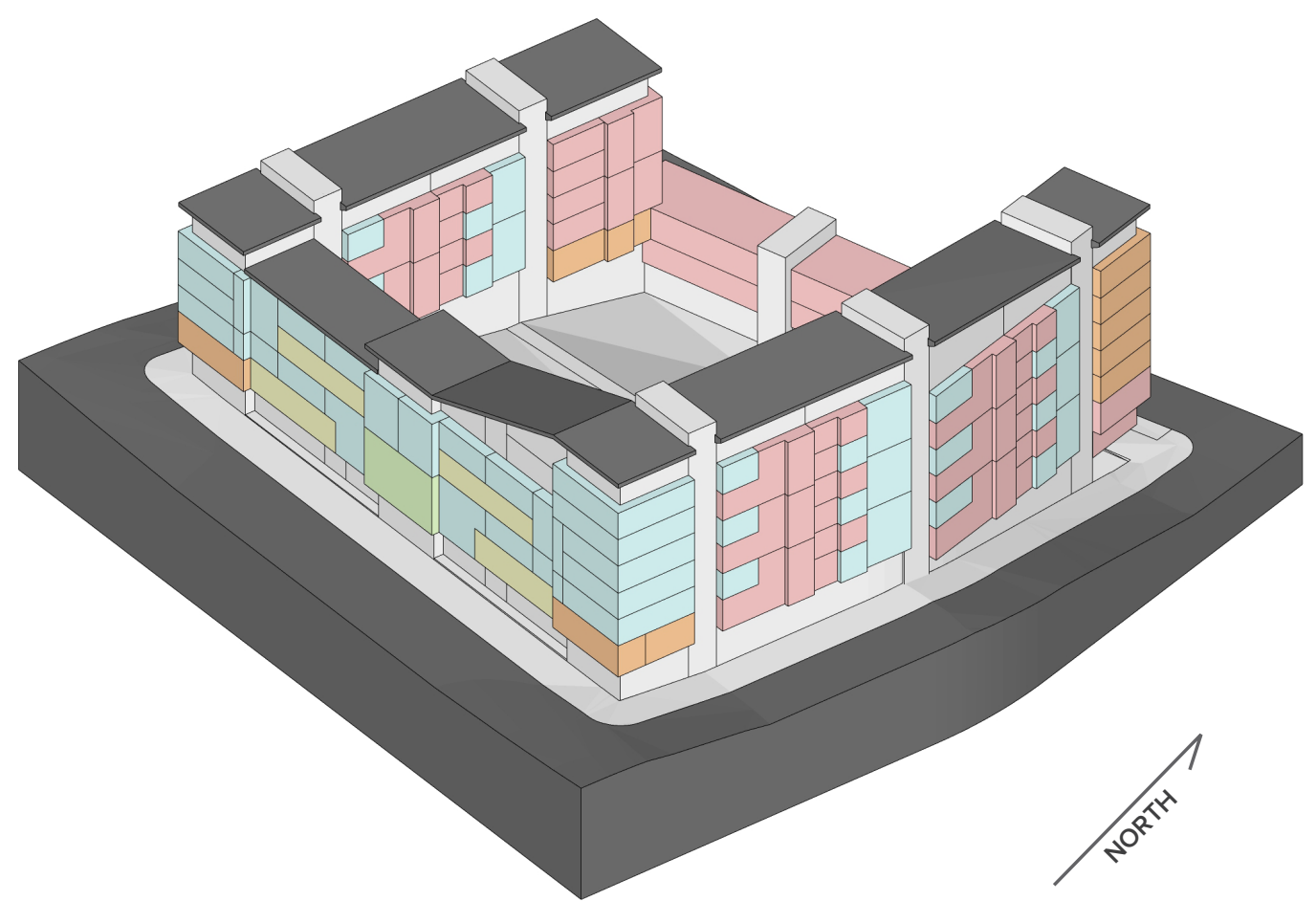

Figure 6.14 - Diagram illustrating

apartment assembly, looking North-West 


\section{APARTMENT ASSEMBLY}

The design provides a variety of different apartment types and sizes to suit different families and situations:

THREE BEDROOM APARTMENTS:

- 26 Apartments total

- Duplex apartments on east and west

- Single-level apartments for disabled occupants to the north

\section{ONE BEDROOM /} STUDIO APARTMENTS:

- 11 Apartments total

- Located in the residual areas of the block development

- All single-level with the main 5 apartments to the north having 3 external faces

\section{TWO BEDROOM} APARTMENTS:

- 38 Apartments total

- Duplex apartments on east, west and southern sides of the block

- Single-level in southern corners

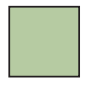

\section{COMMUNAL ACTIVITY} AREA:

- Dedicated area to be used as a communal centre for the occupants

- Is currently proposed as a gym

- It is important to note that the spatial design of this space is outside the research scope, so has been left blank

The design also features 12 penthouse apartments on the upper levels of the design. These are beyond the scope of the research and considered to be primarily formal or aesthetic additions to the EPB development for the purpose of this research.

\section{DENSITY OF THE DESIGN}

Given the site area of $4576 \mathrm{~m}^{2}$ and a total apartment number of 87 , the density of the EPB development is calculated to be: 190 dwellings-per-hectare. 
Figure 6.15 - Level 0 Apartments Floor Plan (With retail and commercial spaces cropped out) Scale1:500@A4

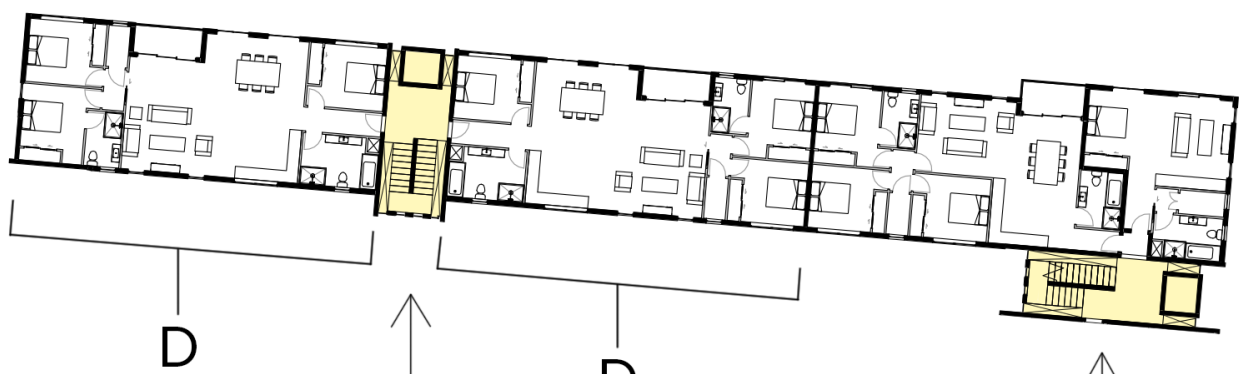

D

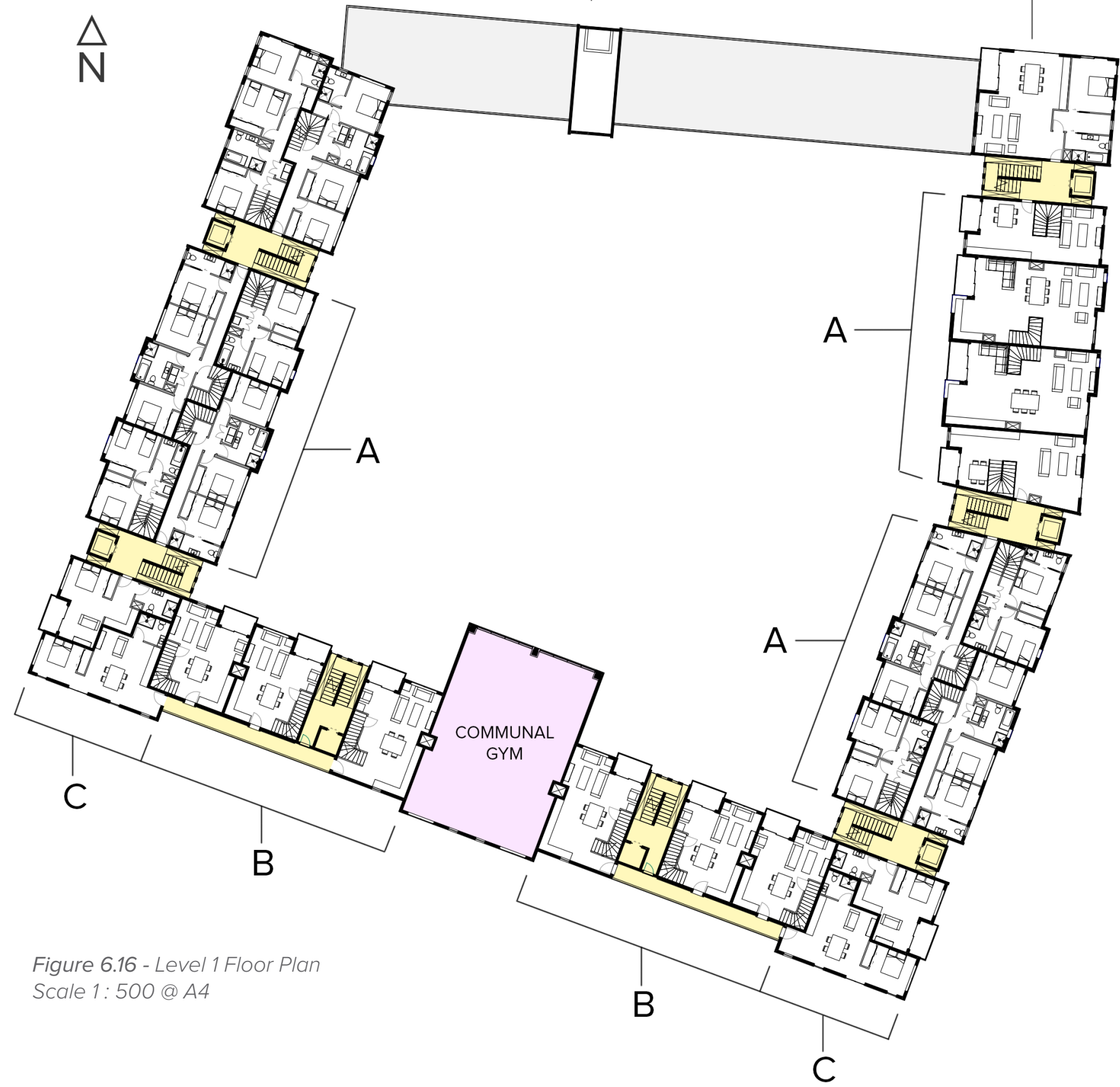




\section{APARTMENT FLOOR PLANS}

Below are the first two levels of apartments. For the most part, these two floor levels are repeated for the apartments above (or below in the case of level 0 ), so only these plans are shown.

The design features four different apartment clusters that are repeated at least once per level and exhibit different features or aspects due to their location in the block. These are indicated by the labels and are showcased on the subsequent pages.

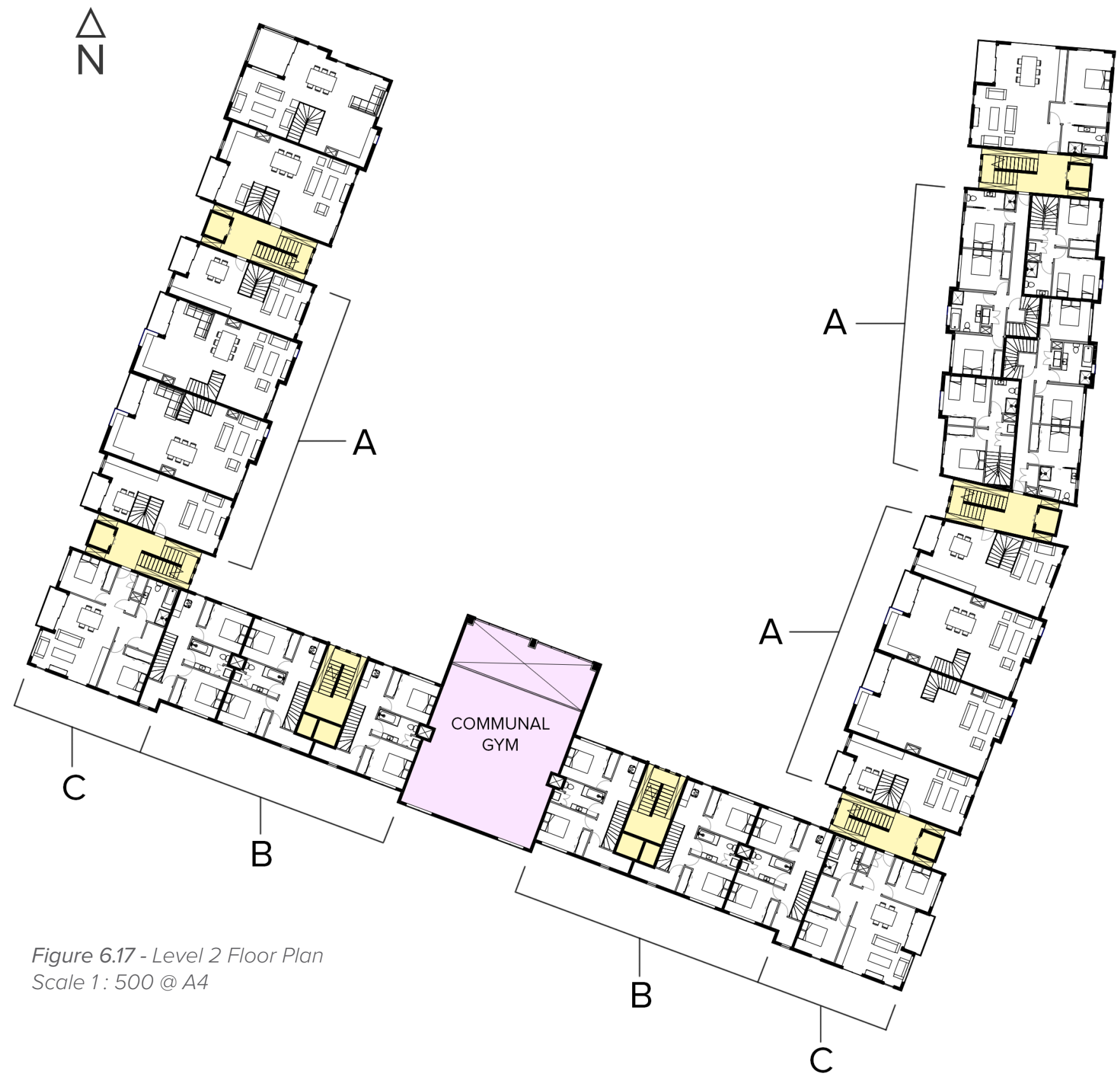


APARTMENT CLUSTER 'TYPE A'

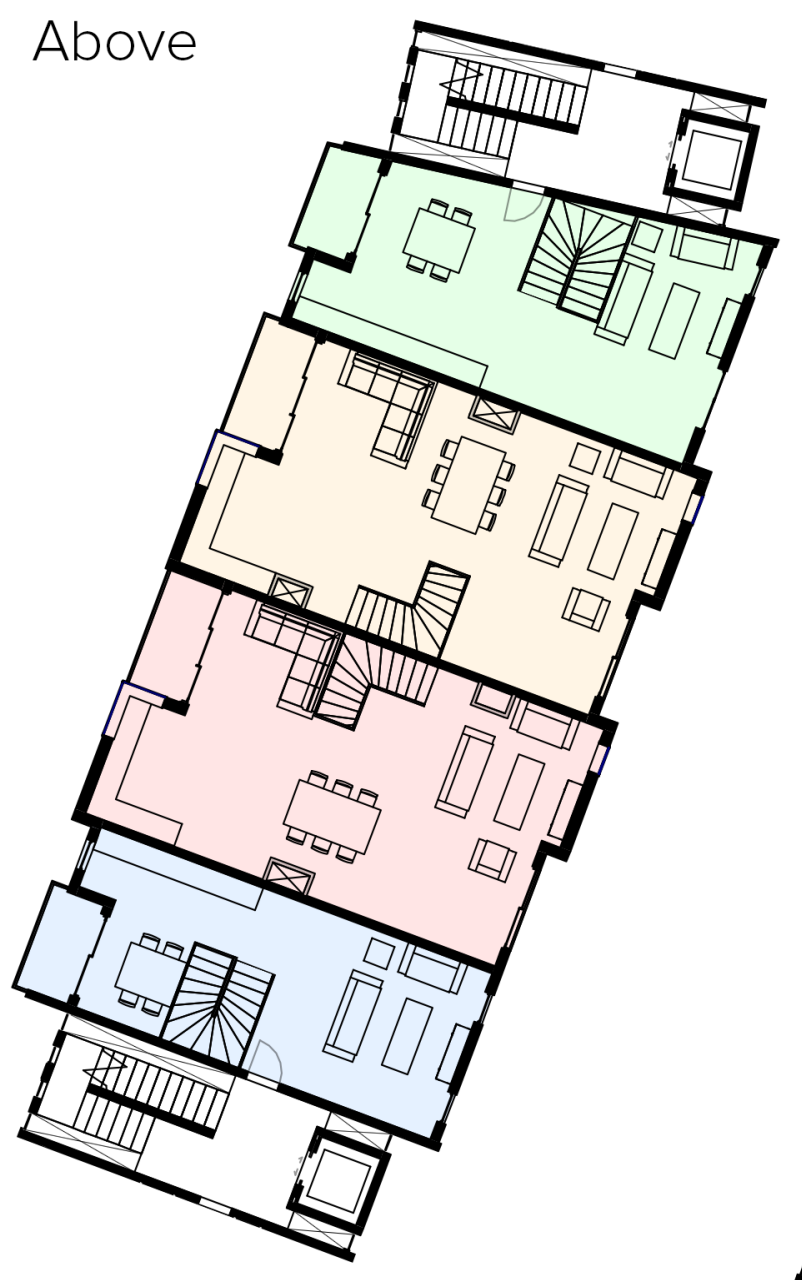

Figure 6.18 - Apartment Cluster type A Bedroom level and living level.

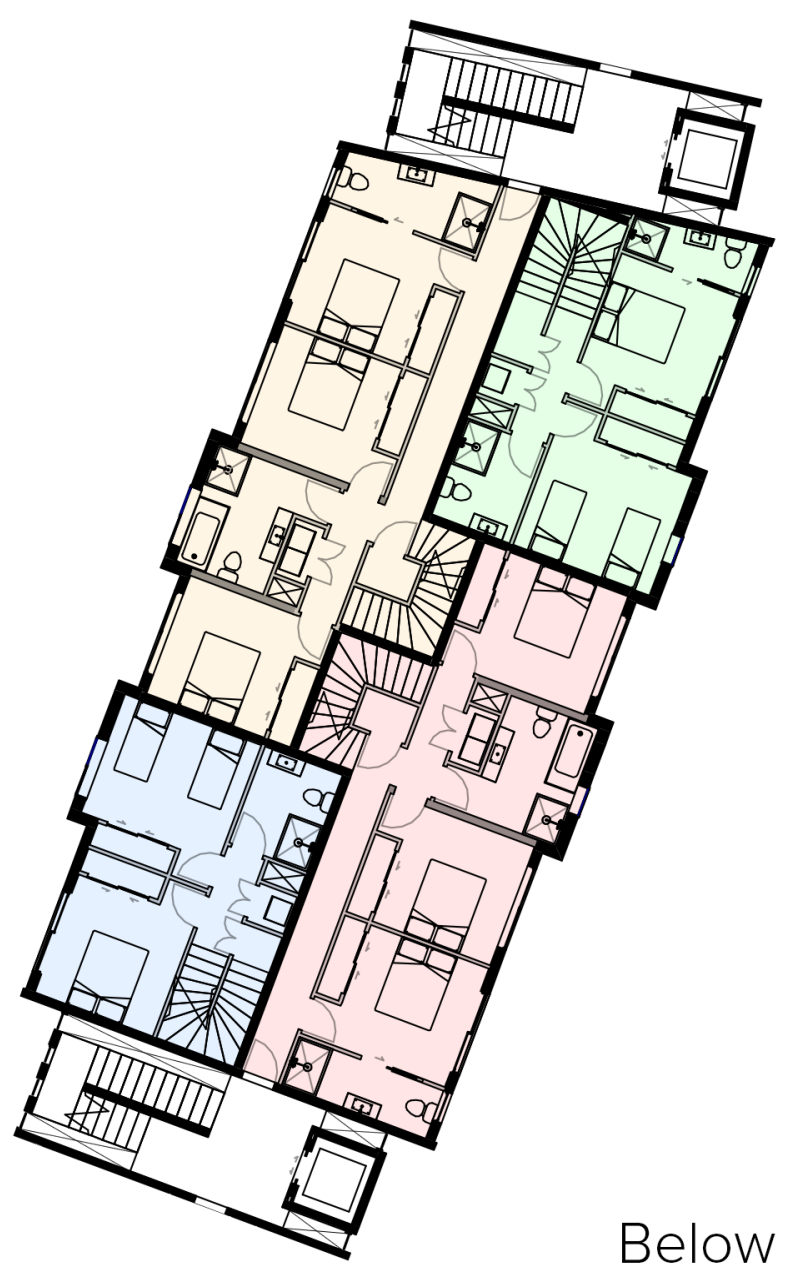
Scale 1: $250 @$ A4 
The apartments shown in cluster type A are the most prevalent in the design. Each of the three cluster A's features two 2-bedroom and two 3-bedrooms apartments every two levels. The 3-bedrooms apartments are accessed via the lower levels, and the 2-bedrooms by the upper levels.

Each apartment is duplex, with double-aspect living areas above, and single-aspect bedrooms/bathrooms below. Balconies are located on the side with the most northfacing outlook to maximise sunlight. The outlook of the lower levels alternates sides to provide each bedroom with an external window.

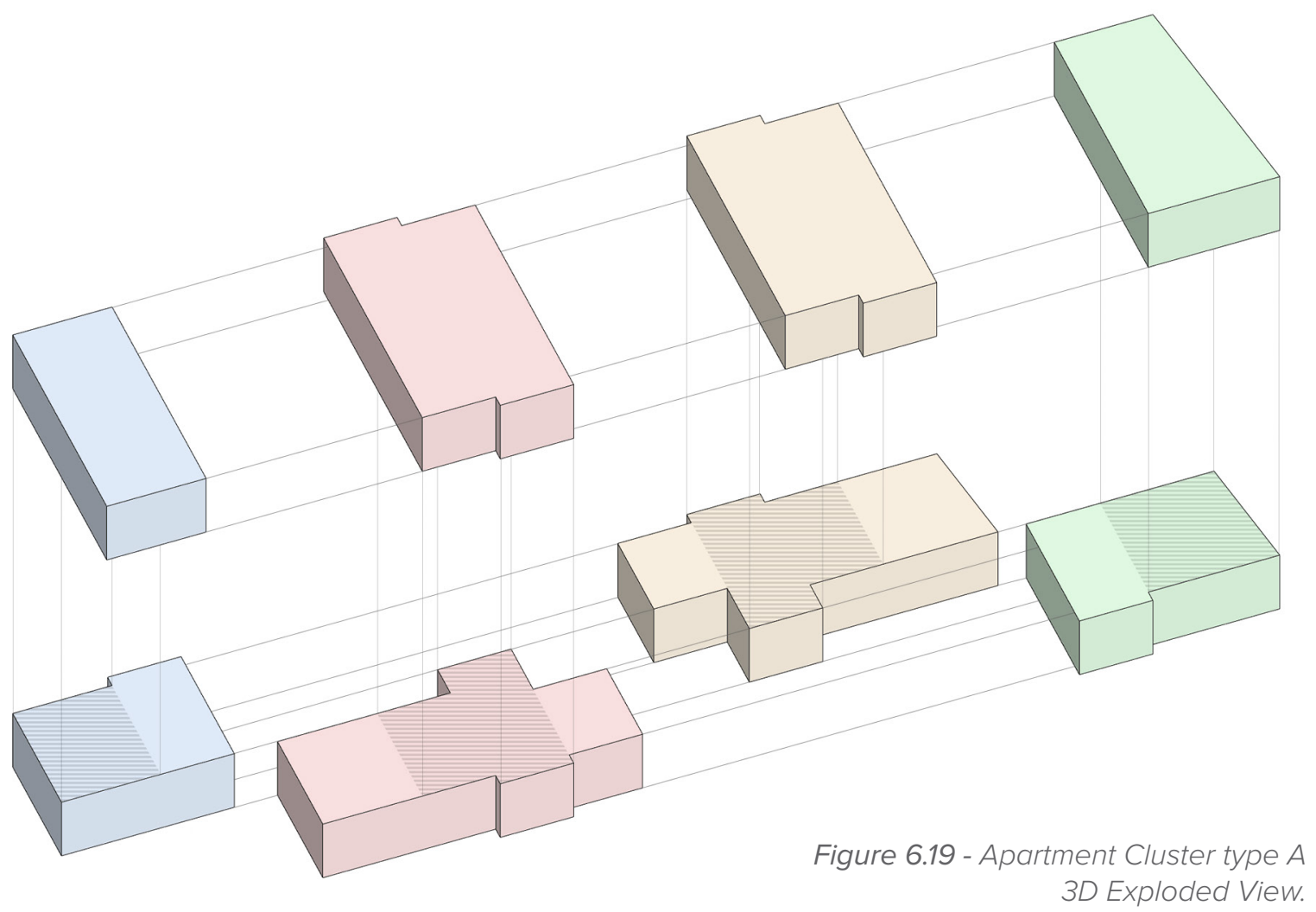


APARTMENT CLUSTER 'TYPE B'

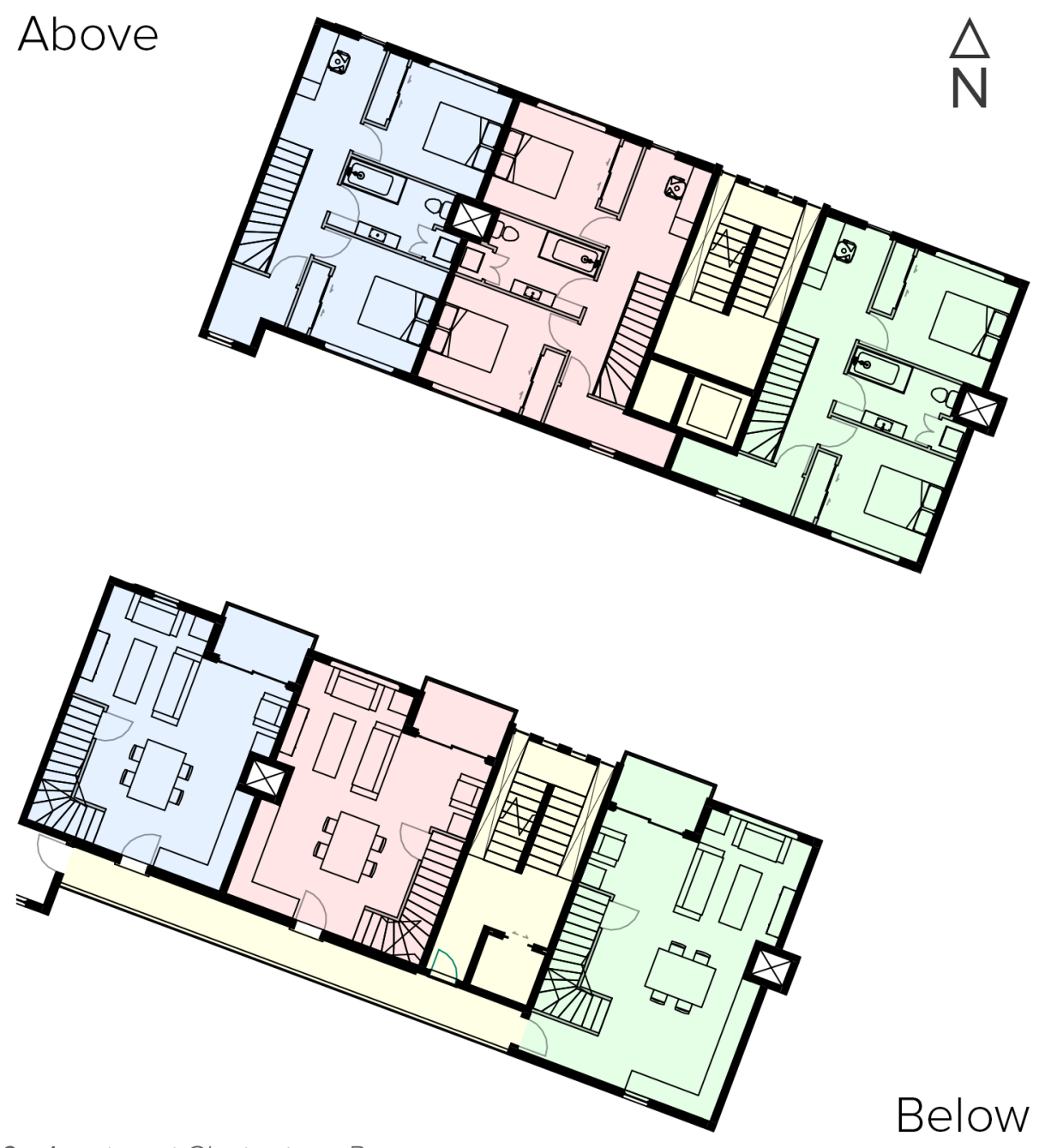

Figure 6.20 - Apartment Cluster type B Bedroom level and living level.

Scale 1:250@A4 
The apartments shown in cluster type B are located only on the southern side of the development. Each of the two cluster B's feature three 2-bedroom apartments every two levels which are mirrored to the other side of the block. Each apartment is accessed from the lower level via an external walkway.

Each apartment is duplex, with double-aspect bedrooms/bathrooms above and semi-double-aspect living areas below, with two of the apartments backing onto the walkway. Balconies are located on the northern side, with the outlook of the bedrooms facing both sides to provide each bedroom with an external window.

Figure 6.21 - Apartment Cluster type $B$ 3D Exploded View

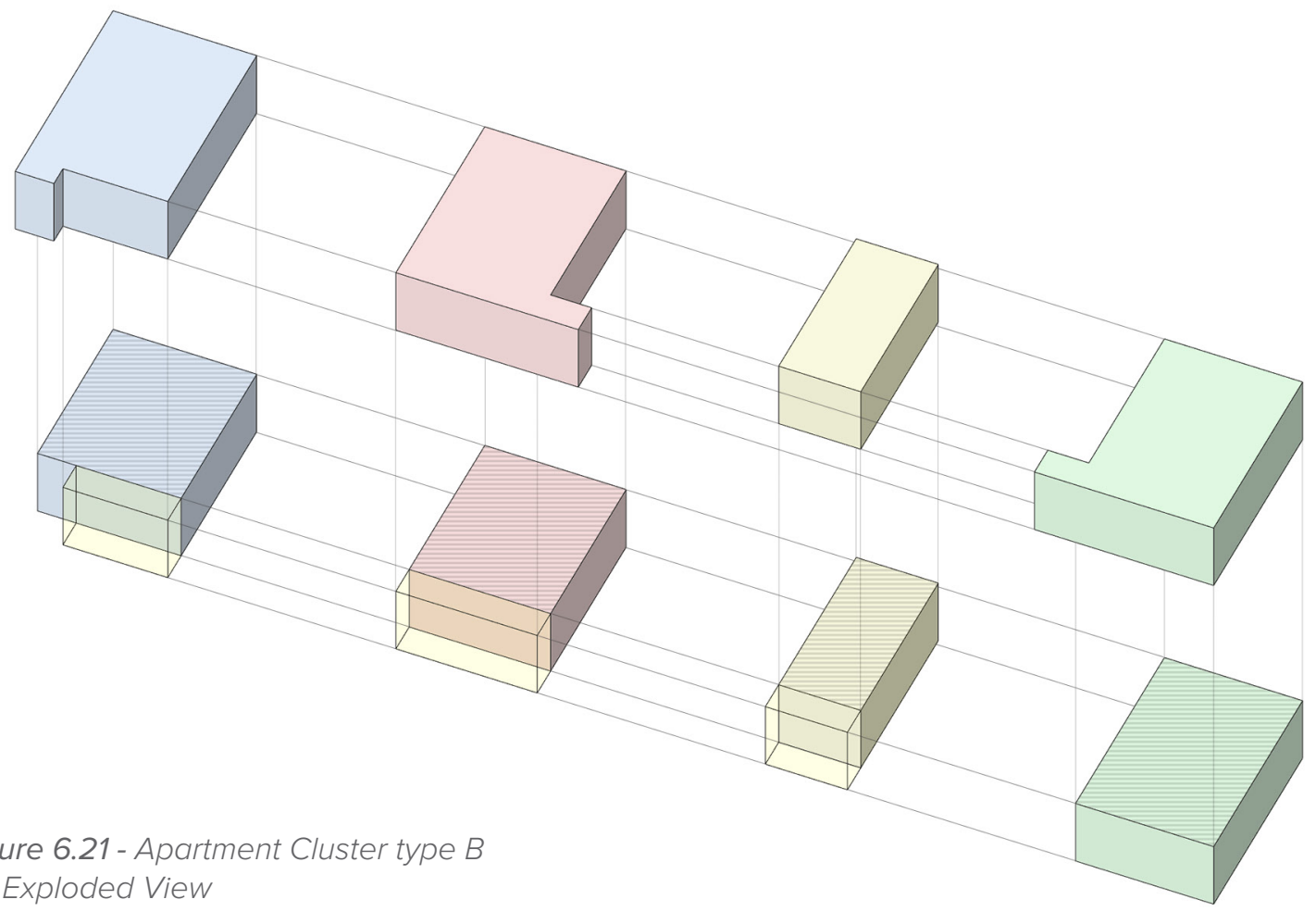


APARTMENT CLUSTER 'TYPE C'

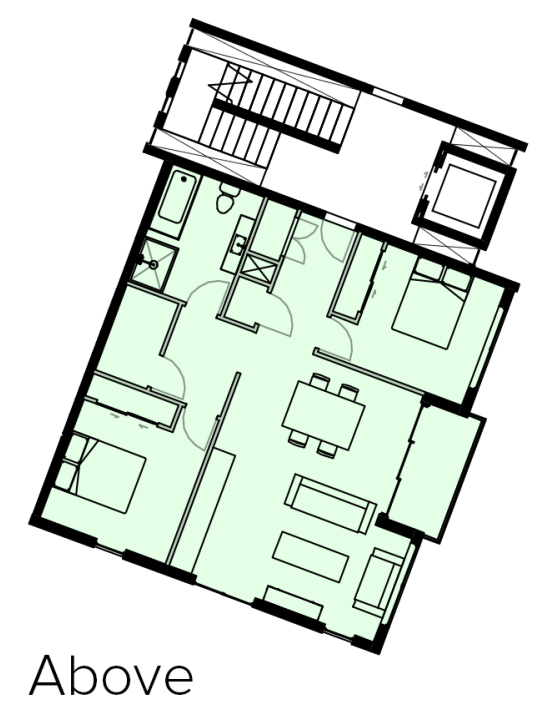

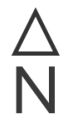

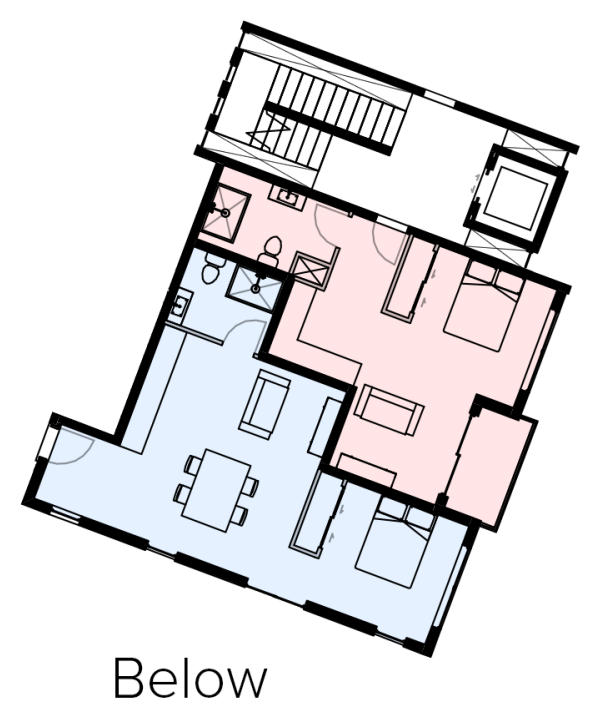

Figure 6.22 - Apartment Cluster type C 1-Bedrooms below, 2-Bedroom Above Scale1:250@A4 
The apartments shown in cluster type $\mathrm{C}$ are located only on the two southern corners of the development. Each of the two cluster C's feature two interlocking studio apartments on level one, with 2-bedroom apartments for every level above. The cluster is mirrored on the other side of the building.

Each apartment is a single level, with the 2-bedroom units having corner-aspect outlook. Balconies are located on the East or West side, depending on the apartment's location.

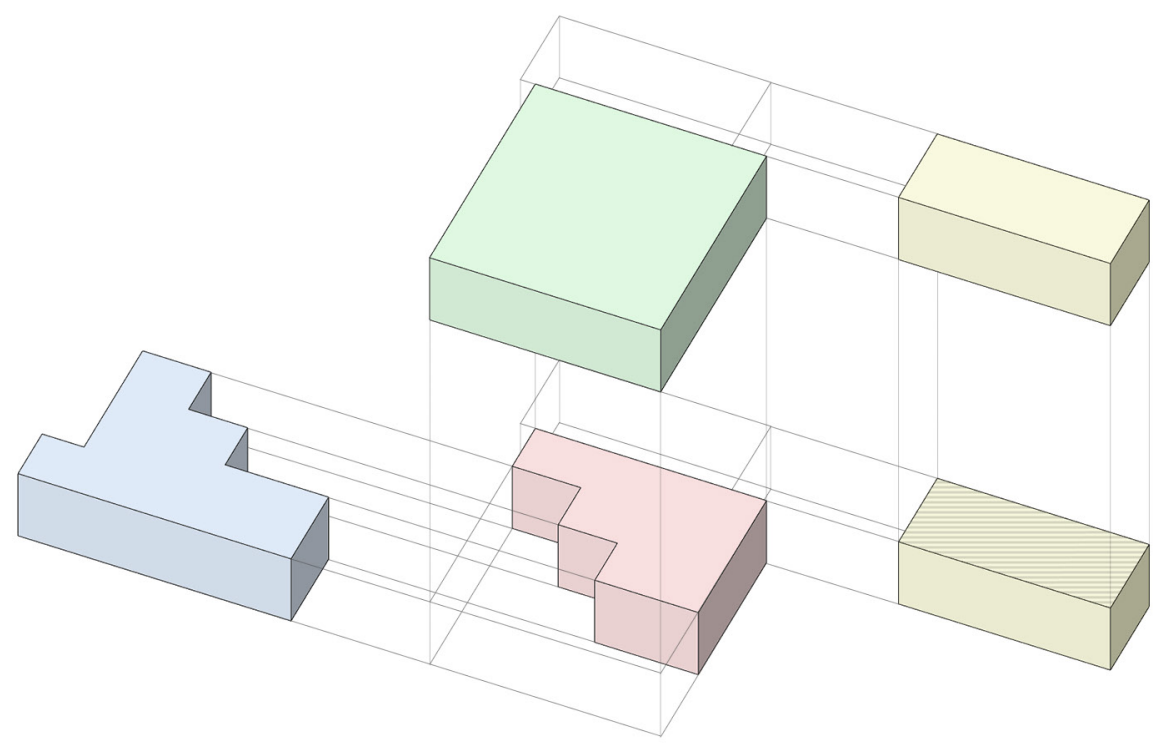

Figure 6.23 - Apartment Cluster type C 3D Exploded View 


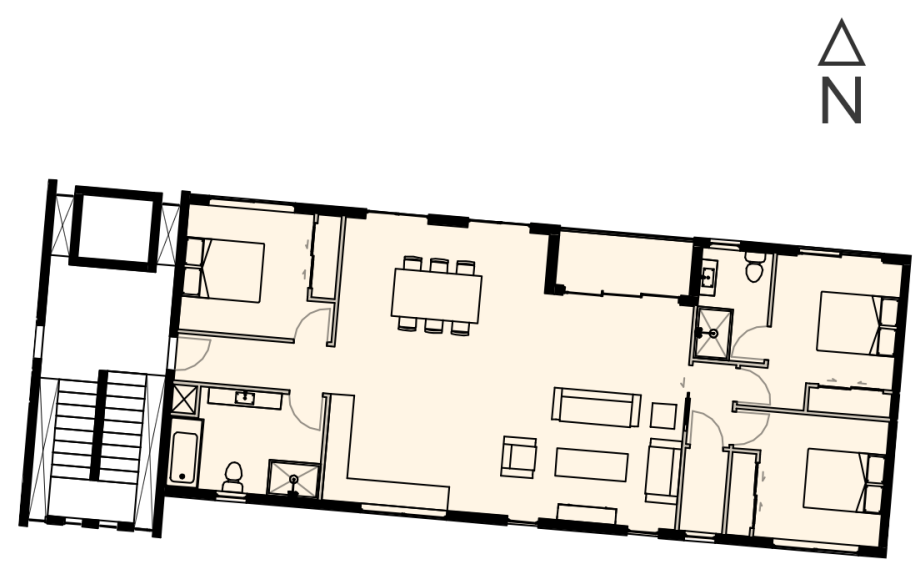

Figure 6.24 - Apartment Cluster type D Scale 1:250@A4

The apartments shown in cluster type D are located only on the Northern side of the development. Each of the apartments are 3 bedroom, single-level with easy access from the street, making them suitable for disabled occupants. Balconies are located on the northern side, with the outlook of the bedrooms facing both sides to provide each bedroom with an external window.

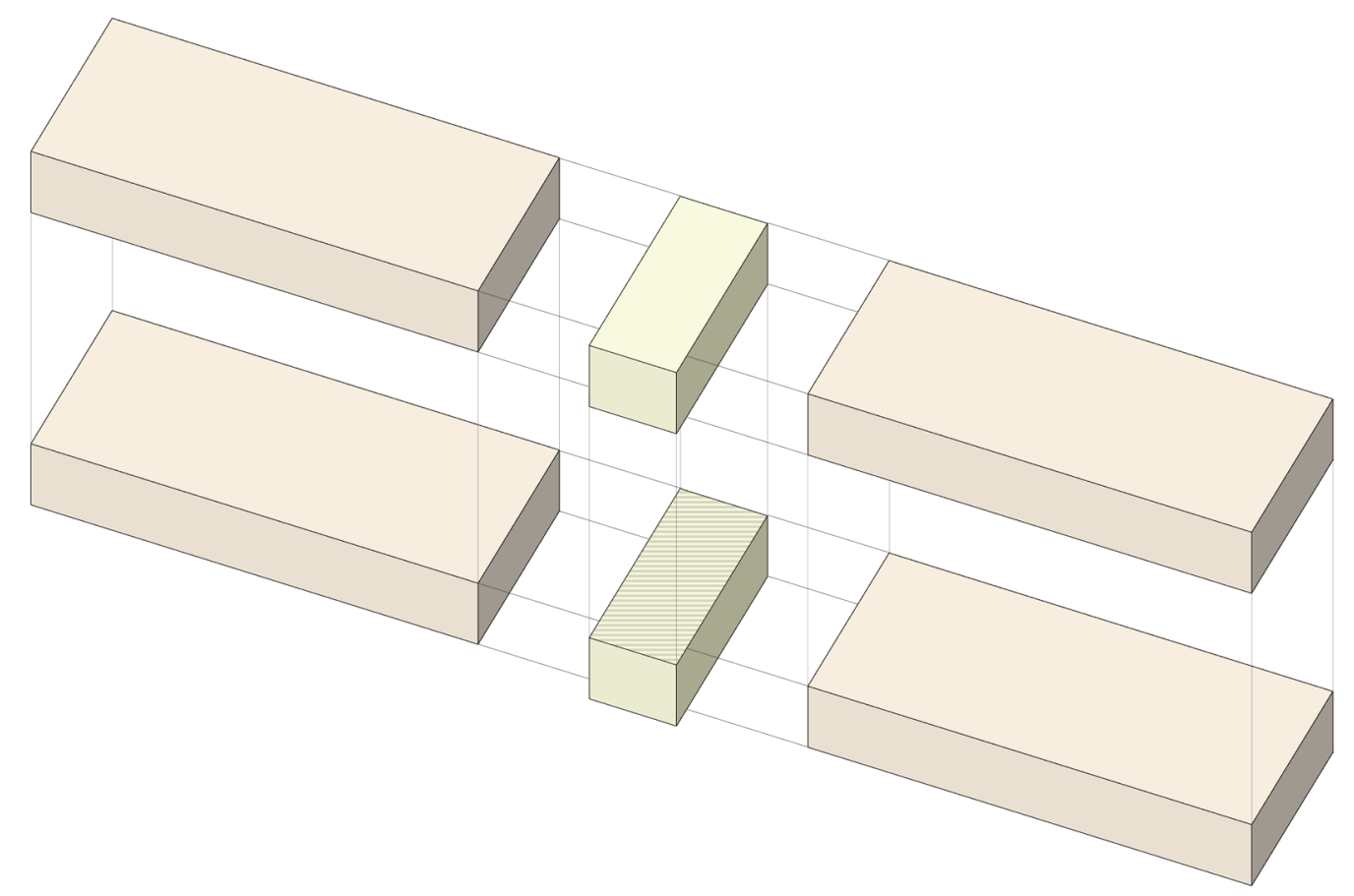

Figure 6.25 - Apartment Cluster type D 


\section{LEVELS OF PRIVACY}

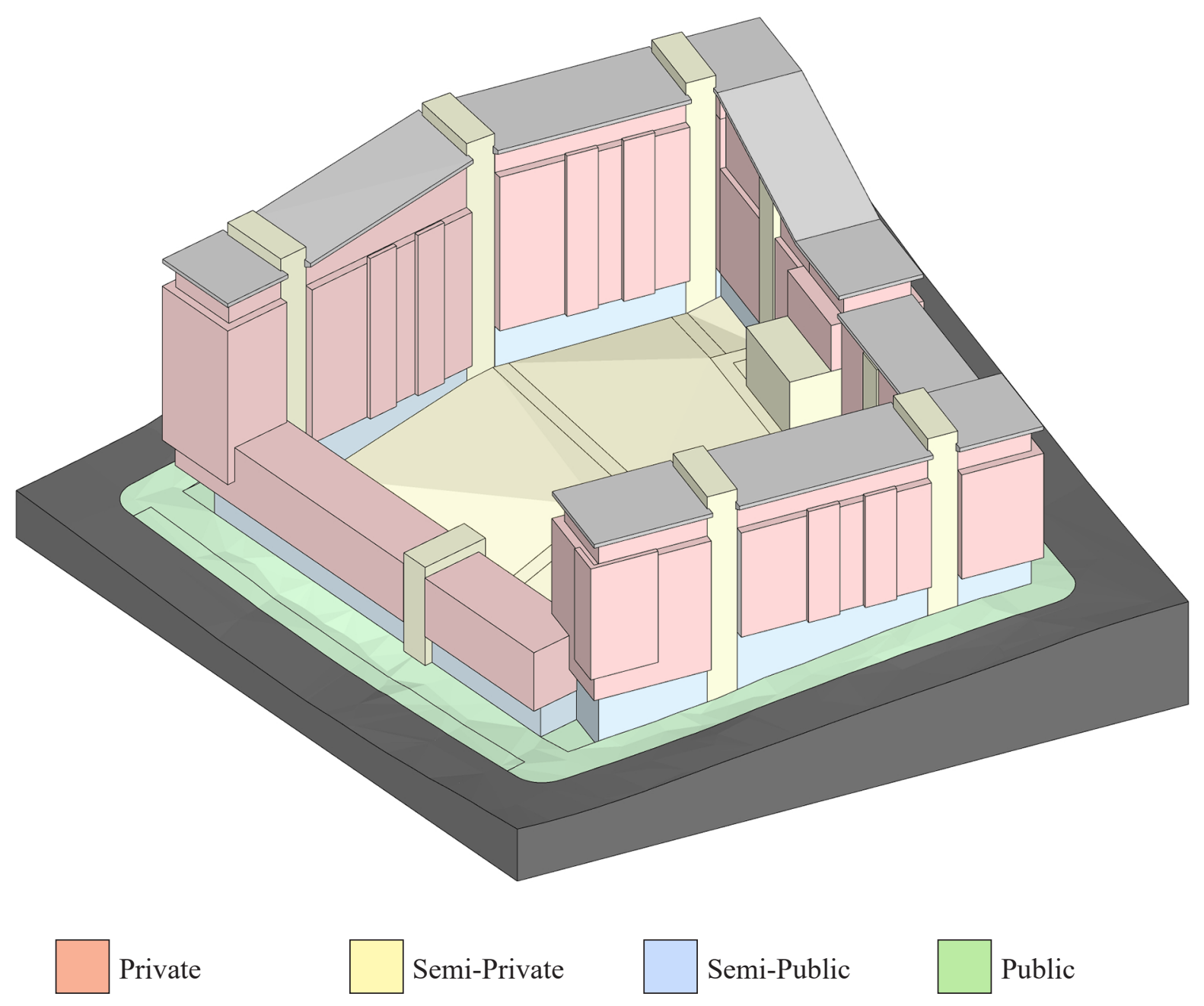

Figure 6.26 - 3D diagram illustrating the varying levels of privacy throughout the developments 


\section{DEVELOPMENT ELEVATIONS}

Each of the four external building elevations of the development are shown below.

The different facade identities are indicated by the two colours, each of which corresponding to the relative entrance and vertical core.

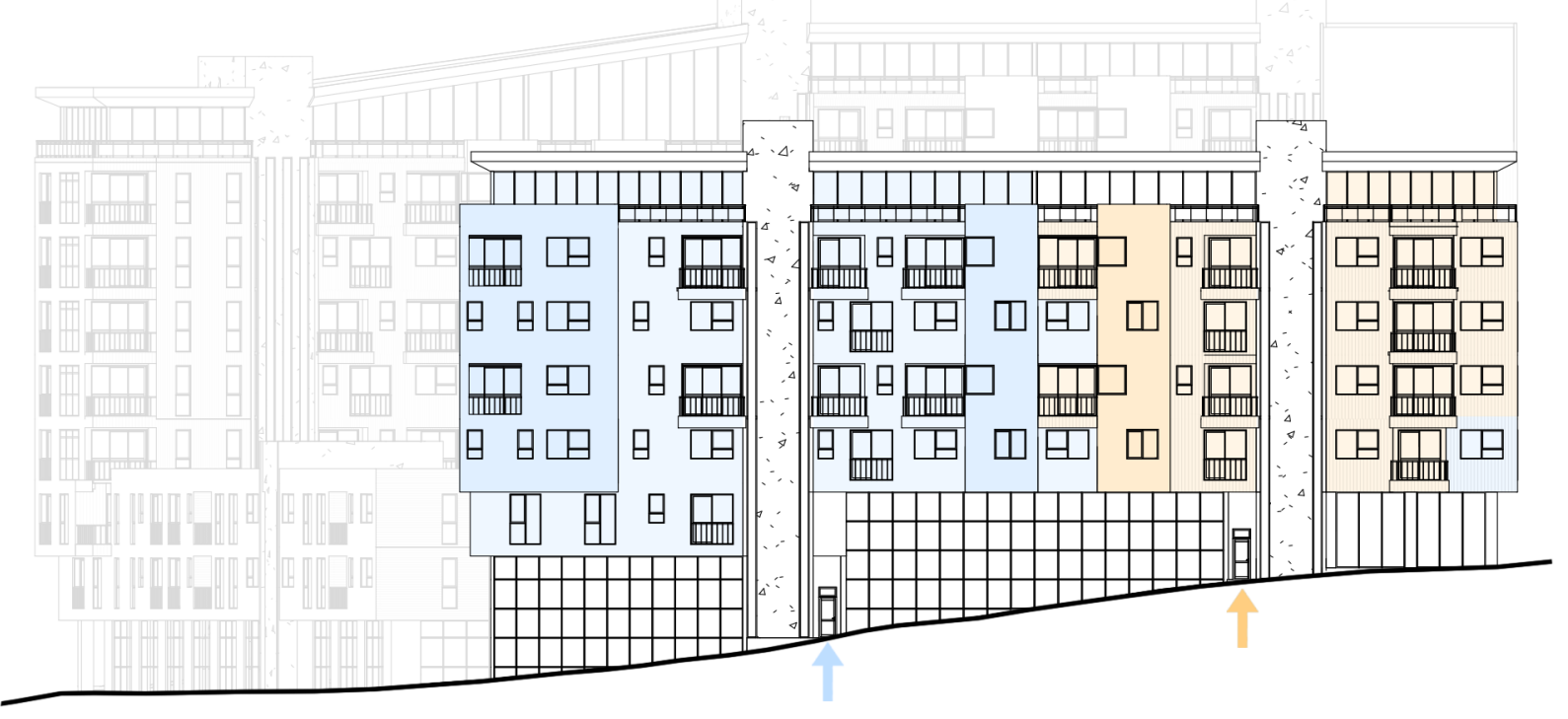

Figure 6.27 - West Elevation

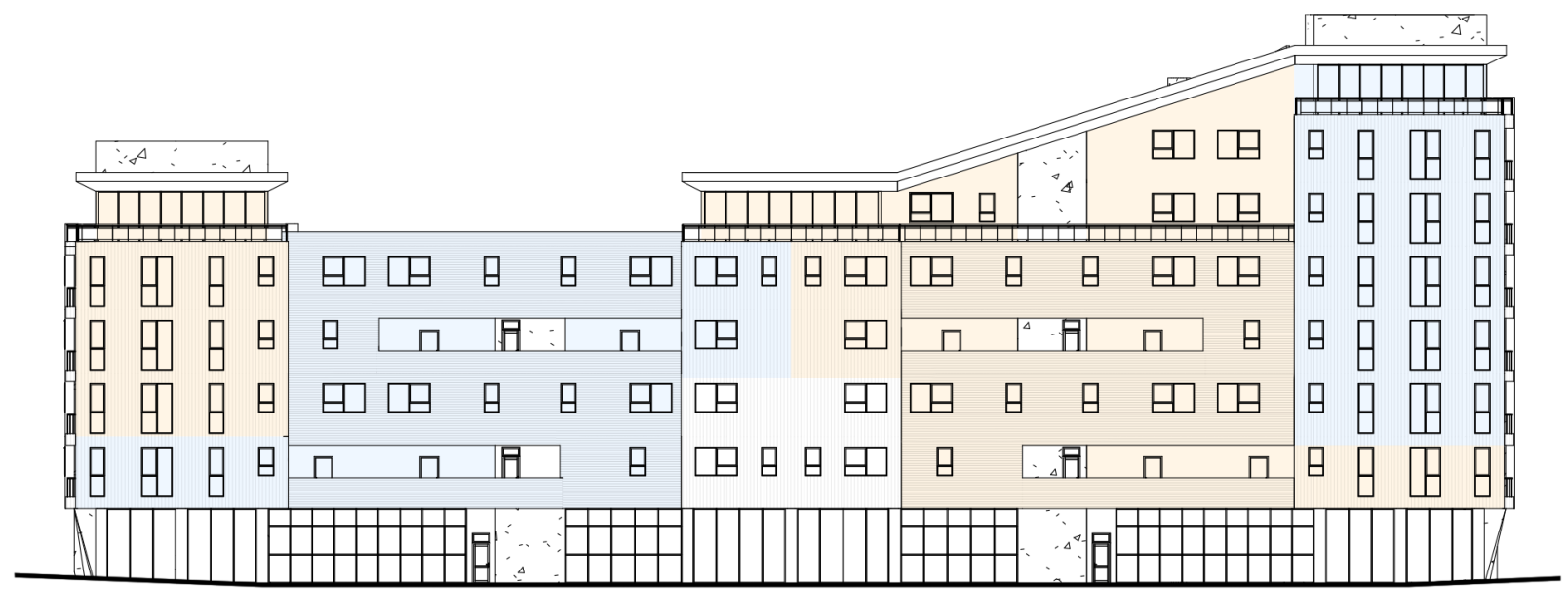

Figure 6.28 - South Elevation 
The arrows indicate the entrances to the apartments, and are shown in the colour of the apartments that use these entrances.

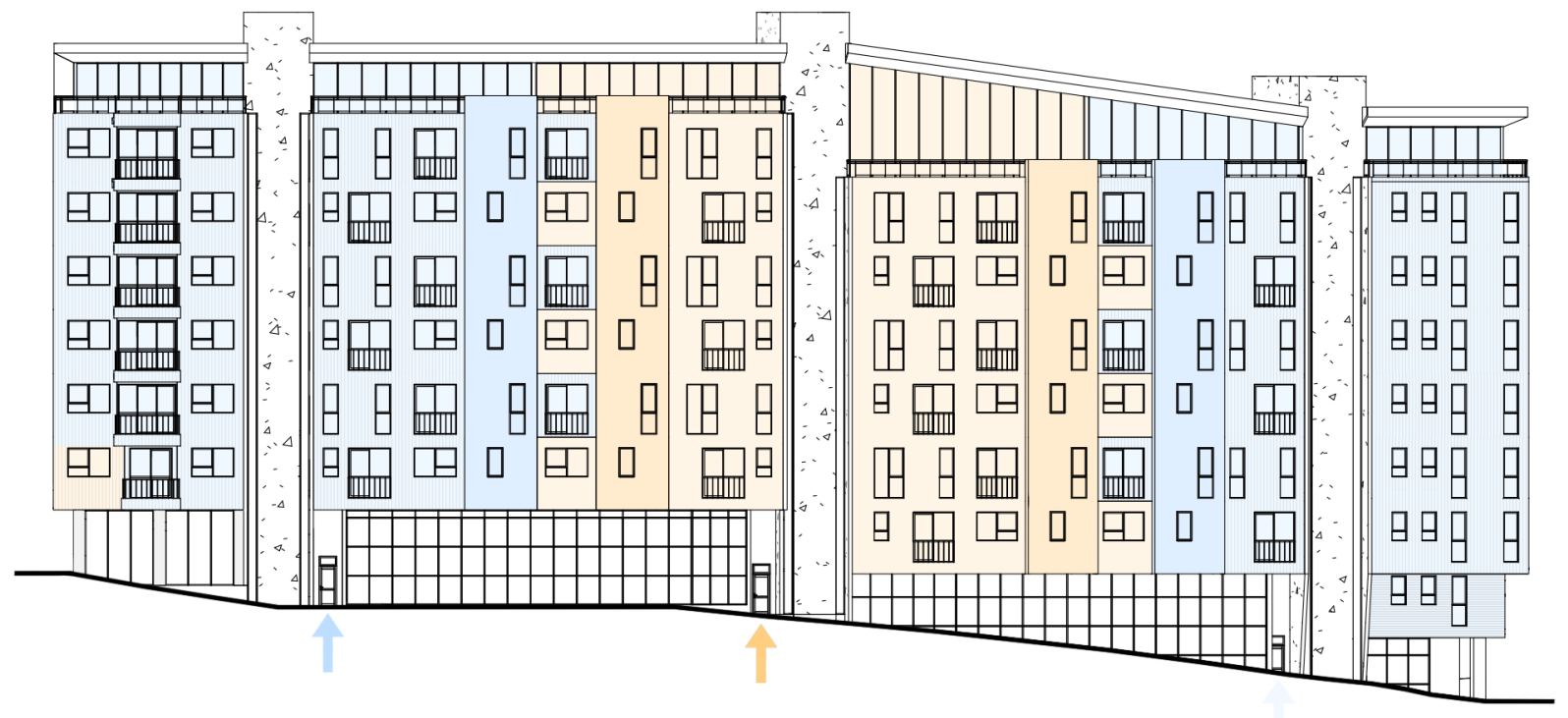

Figure 6.29 - East Elevation

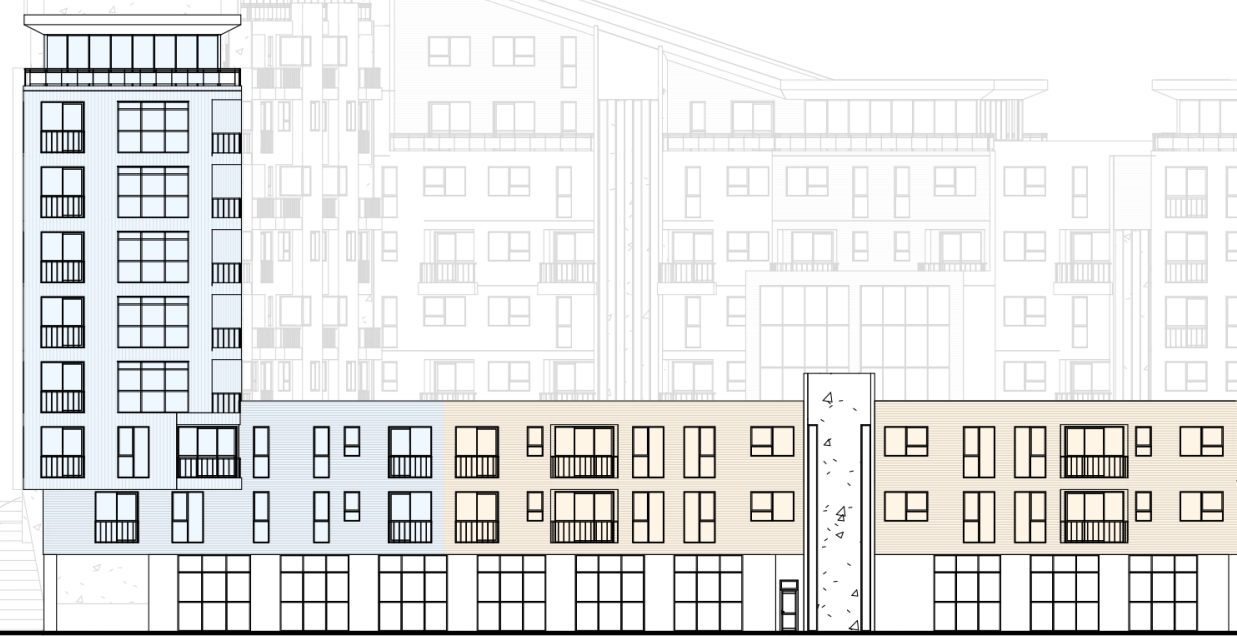

Figure 6.30 - North Elevation 

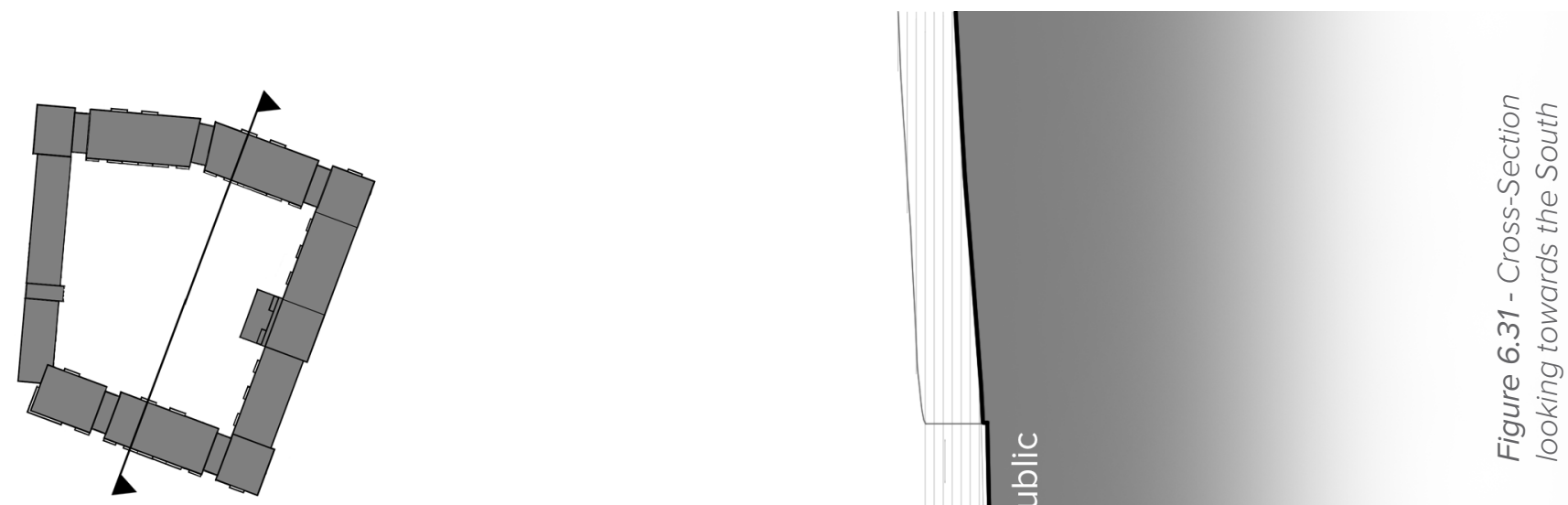

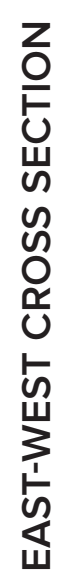

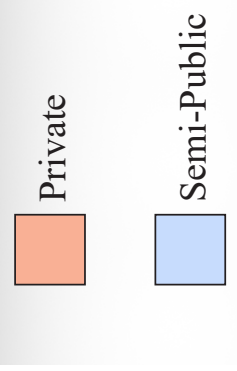




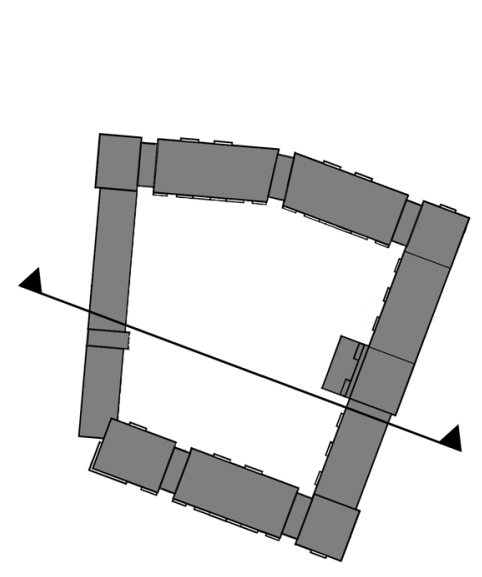

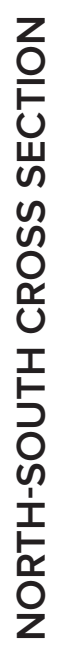

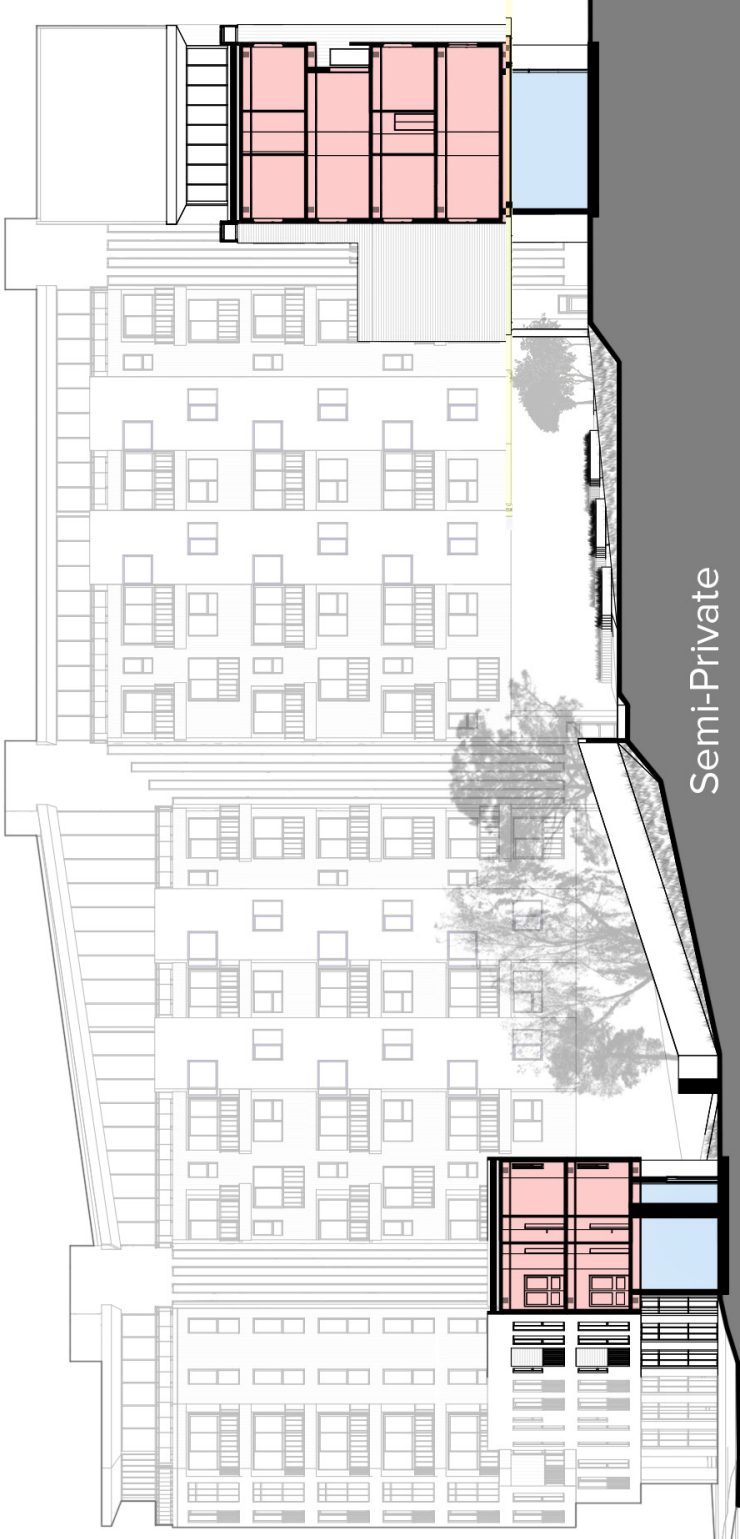



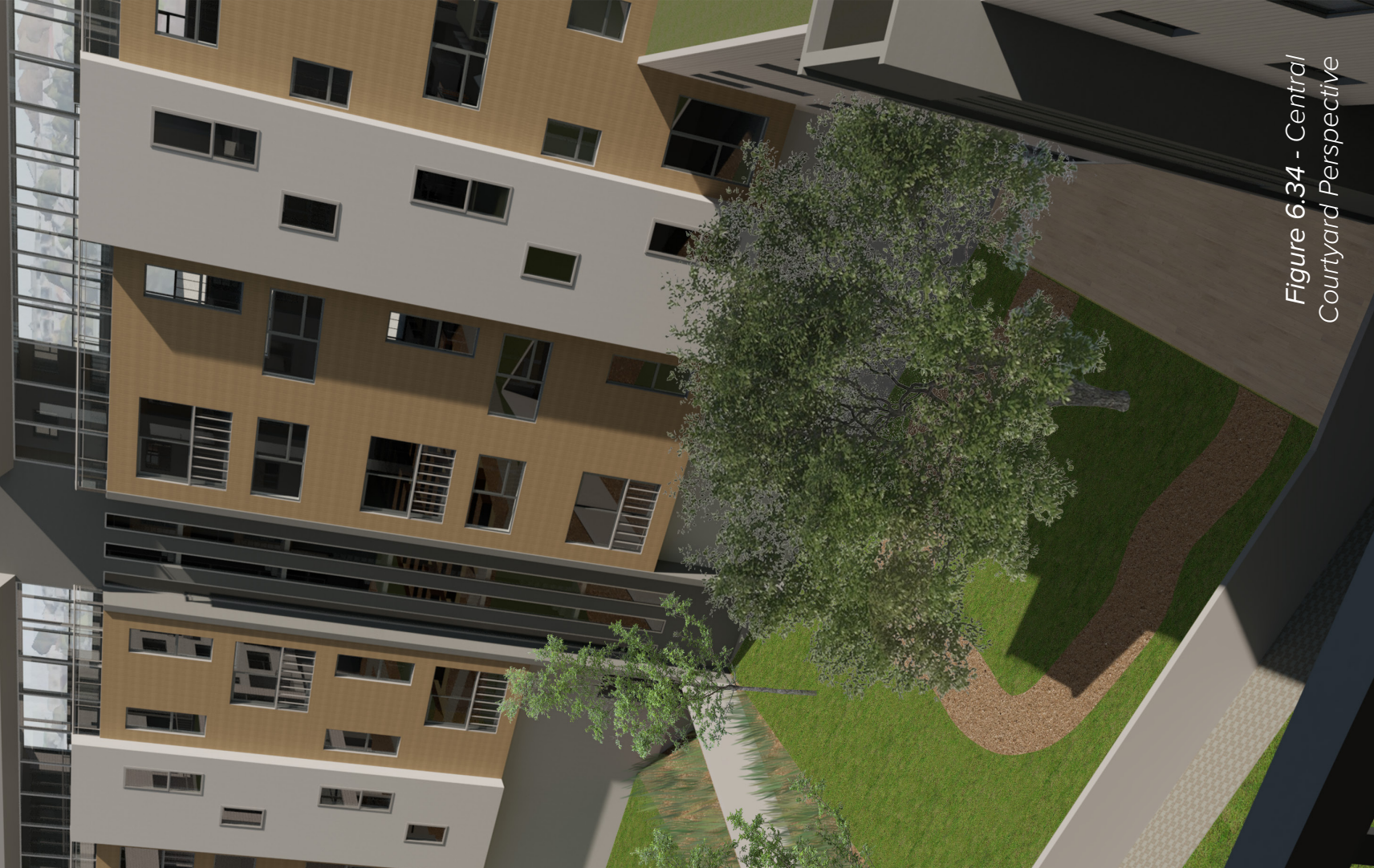

들 $-2=-$

率

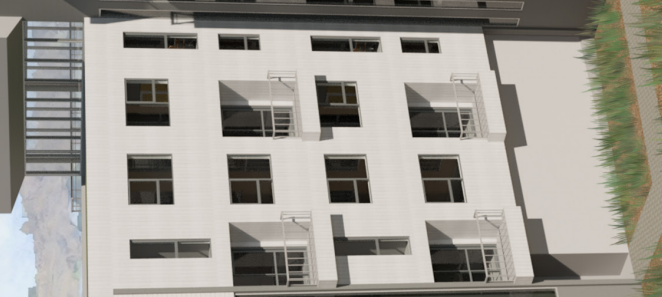

- 드민

4. 다 진

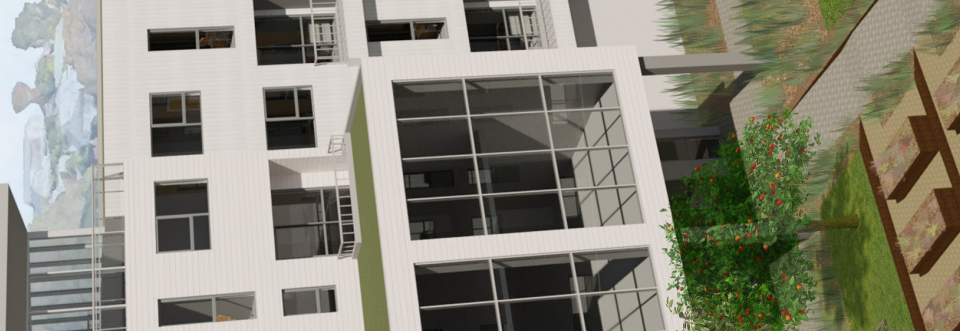

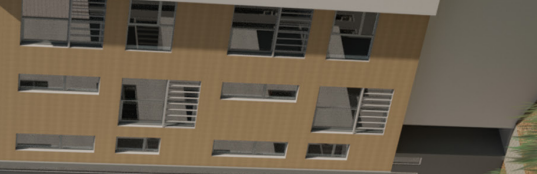




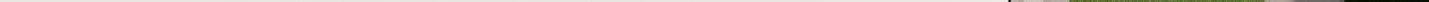





\section{New Zealand EPB Development: DESIGN EVALUATION}

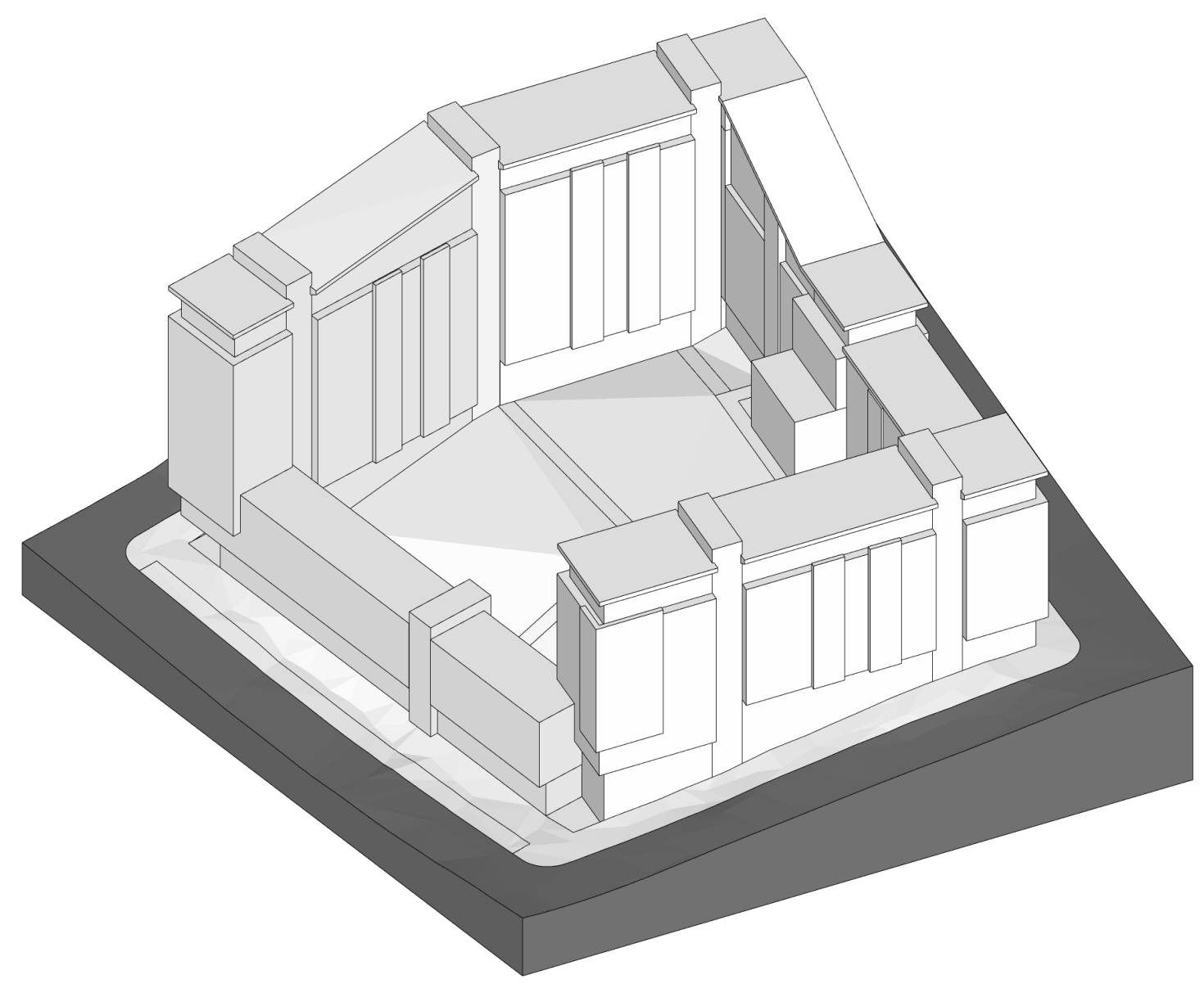

Figure 6.37 - Simplified 3D model of final case-study design 


\section{DESIGN EVALUATION}

The aim of the design case-study was to apply a European inner-city housing model to a New Zealand context to improve the appeal of higher-density urban housing. The target market for these developments is New Zealand families because they make up $70 \%$ of national households and are also the most demanding occupants of high-density housing options. A refined set of design criteria and repertoire of design strategies were collected from various research exercises and studies all pertaining to the EPB housing model or the New Zealand context. The final design applied these strategies and criteria to an EPB housing development on a selected site in Auckland City. The design exhibits the fundamental characteristics of the traditional EPB housing model and improves on its shortcomings using lessons learnt from contemporary EPB examples, best-practice New Zealand apartment design, and a successful San Francisco architecture firm. This development certainly provides an attractive housing model for New Zealand families. However there are a few inherent issues and uncertainties still to be resolved. The design is evaluated using the following adapted design criteria to ascertain its success and key findings:

01. High-Density with High-Amenity

02. Definition and Activation of the Public Street Edge

03. Optimised Natural Light, Ventilation and Outlook

04. Semi-Private Central Courtyard

05. Managed Relationship between Public, Private \& Semi-Private Space

06. Situational Circulation System

07. Design Versatility and Diversity

08. Coherent Form with Positive Impact on Urban Context

09. Eventful Building Façades with Sense of Identity and Character

10. Perception of Safety and Spaciousness 


\section{HIGH-DENSITY WITH HIGH-}

\section{AMENITY}

The design case-study aimed to balance an acceptable inner-city housing density with the provision of and access to important residential amenities. The final density of the EPB housing development was approximately 190 dwellings per hectare. This is not particularly competitive when compared to the residential apartment buildings in the vicinity. The average density of the surrounding nine apartment buildings is just over $700 \mathrm{dpH}$, which is significantly higher than the EPB development.

There are two possible explanations for this; firstly, the target market for the development requires apartments with two or three bedrooms. This is compared to apartment developments with presumably only studio and single-bedroom apartments with the occasional two-bedroom. The 'dwellingsper-hectare' measurement does not account for the number of people a building can occupy, just the number of apartments. Going forward, a more accurate assessment of density could have been achieved using the "habitable rooms per hectare" measurement. This is likely to provide a more realistic comparison and reveal the case-study design to be a more plausible density.

The second explanation is simply that the density of the development is not as high as the local buildings because it has a high level of access to amenity provided by the design case-study. The central courtyard with communal garden, childcare centre and green-space, central-city location close to shops or schools, and the provision of a communal gym on-site are just a few examples of the amenities provided by the final design. There is an argument to be made about the value of these spaces in providing high-density housing that is not only more pleasant to live in than other inner-city housing models, but also has a greater appeal, so attracts more potential tenants.

In short, the design provides a high level of amenity with a density that is undoubtedly high but requires reaffirmation to ensure competitive inner-city housing provision. 


\section{DEFINITION AND ACTIVATION OF THE PUBLIC STREET EDGE}

Since the final design is simply a contemporary adaptation of the traditional EPB housing model, strong streetedge definition is achieved. The EPB development covers the entirety of the block perimeter with a ground floor dedicated to retail or commercial establishments. These establishments are set-back from the rest of the façade to emphasise a program change and improve the level of intimacy and enclosure for the street-front. This activates the street-edge in a very positive manner.

The key issue with this, however, occurs on the sloping sides of the site. The particularly aggressive grade prevents the delivery of consistent shop-fronts or seamless curtain walls. A stepped design was also not possible due to the inter-locking apartment design above which must be at the same level. While these retail and commercial establishments were still provided on the sloped sections of the ground-floor, they were not as easily accessible or interpreted as the street-fronts on the two flat sides of the development. Future adaptations might consider a variable height ground floor or an integrated footpath or walkway which dropsdown or rises-up to meet the store-front.

Nevertheless, the final design provides the opportunity for successful definition and activation of the public street edge with only minor tweaks to execution.

\section{OPTIMISED NATURAL LIGHT, VENTILATION AND OUTLOOK}

A fundamental benefit of the EPB housing model as a result of double-aspect apartment layout, is the improved sunlight, ventilation and outlook for each apartment. The design case-study took this a step further by implementing strategies to further improve sunlight penetration, cross-ventilation, and provide a pleasant, verdant outlook into the central courtyard. Higher ceilings paired with tall windows will improve the sunlight penetration into each apartment, and opening windows on each façade of the doubleaspect apartments promotes passive crossventilation.

Height variations are popular, particularly 
with the contemporary examples. The final design implements this strategy by lowering the block height significantly on the northern side of the building and moderately on the western side. This ensures that each apartment is not constantly shaded by the building segment on another side of the block.

One particular issue with this aspect of the design is that it is harder to predict which apartments will be shaded. A more in-depth study using simulation software would be required to accurately ascertain the success of the varied design height. Regardless of this, the aim of such a design decision is to provide each apartment with more sunlight, and if it is assumed that it does, then it is a great success and should be applied to future EPB developments.

\section{SEMI-PRIVATE CENTRAL COURTYARD}

The central courtyard is a necessary provision for any form of EPB development. There was a lot of deliberation early in the research as to whether this central space should be exclusively used by the occupants of the development or, like some contemporary examples, used as a public pathway through the site. The design casestudy opted for the former option, choosing to prioritise safety and a greater sense of privacy within the semi-private space.

From the outset of the study, it has been acknowledged that comprehensive assessment of the success of this space goes beyond the scope of this research. Determining success would require a sociological study that examines the relationship between New Zealanders and communal open space within high-density residential developments. Nevertheless, some design strategies were used to minimise the risk of the central area failing socially. In the design case-study, providing multiple useful programmes within this space allows a versatility that increases the probability of success. This multiplicity and flexibility appears to be a sound way to approach the design of a new type of urban space. Lessons can be learned from how the space is used when the completed development is occupied. 
However, to further the research of this

Thesis, behavioural studies with input from a sociologist would prove beneficial to the development of a central courtyard within New Zealand EPB housing.

\section{MANAGED RELATIONSHIP BETWEEN PUBLIC, PRIVATE \& SEMI- PRIVATE SPACE}

Like typical EPB housing developments, the design case-study provides various levels of public, private and semi-private space. Public space is clearly defined by the street edge with public access to the various retail and commercial establishments.

Private space is defined by the apartments themselves, and semi-private space refers to the communal areas of the development including circulation spaces. EPB developments have no difficulty providing a distinction between these three types of spaces because of the continuous perimeter around the block. However, managing the relationship between these spaces is more challenging.

In the case of the final design, intermediary space was provided between the public realm, private apartments and semiprivate courtyard in the form of multiple vertical-circulation cores with ground-floor lobbies. These semi-private spaces are very successful at dissolving the harsh public/ private thresholds which can often exist in high-density residential developments.

Unlike other high-density housing models with a single vertical core, the provision of multiple cores around the block adds a degree of intimacy, creating a more pleasant experience for the occupants of the building and a more exclusive journey from the street to their front door. Connecting these spaces using pathways through the semi-private courtyard further emphasises this journey or experience, and demonstrates the successful relationship between the spaces.

\section{VARIABLE CIRCULATION SYSTEM AND APARTMENT LAYOUT}

In order to maintain an acceptable level of natural light access for each apartment in an EPB development, changes must be made to the circulation system and orientation of apartments. Contemporary examples, 
including the design case-study typically achieve this by changing the primary orientations of the apartments within the block. Primary orientation is defined as the main apartment outlook, typically with a private outdoor balcony, and is either facing the courtyard or facing the street. In the design case-study, the primary orientations were directed towards the side receiving the most sun. The North and West sections of the block have street-facing primary orientations, whereas the South and East sections are facing into the courtyard. This is an effective way to ensure maximum sunlight into the main living spaces. However, since sunlight is prioritised, the pleasant outlook into the courtyard is compromised for half the block. This may not be an issue for most families, as some may actually prefer an urban outlook over the central courtyard. The double-aspect apartments still allow some form of outlook into both spaces, regardless of the primary orientation.

In the case of circulation, the south side of the block exhibits a different form of circulation than the rest of the building.
This is also common with contemporary examples, and is used because the façade facing away from the sun is the least desirable due to minimal natural light and arguably the least pleasant urban outlook. The design case-study used external walkways on the southern street façade to provide a more efficient circulation while maintain the provision of external windows. Using duplex apartments allows this walkway to skip floors, reducing the impact they will have on the building aesthetic and maintaining the desirable double-aspect layout for the living spaces of these apartments. These walkways produce horizontal voids in the southern façade which is an interesting and unique façade aesthetic while also being economical.

\section{DESIGN VERSATILITY AND DIVERSITY}

The design case-study produced an EPB development with a high level of versatility and diversity. The selected site for the design case study was chosen on the basis that it represented an average of the available sites within New Zealand cities. The size, 
shape and grade of the chosen site were all fairly neutral, which ensures a high level of versatility. Therefore, the research findings from an EPB development designed for this site would be widely applicable to other urban sites in New Zealand. This is reinforced by the nature of all EPB developments, which allow for dimensional changes without drastically altering the experience for the occupants.

In regard to diversity, the design-case study considered families of various sizes, living requirements and financial situations. Two and three bedroom apartments dominate the development with a smaller provision of one-bedroom and studio units. There are varied offerings of the multi-bedroom units, with the inclusion of accessible apartments for people with disabilities. Penthouse apartments are also available to those who prefer to live a life of innercity luxury. So there is little doubt that the EPB development caters for a variety of households. One critique of the way this has been handled by the design case-study is that there is not enough diversity of apartment location within the block. Specific apartments are dedicated to certain areas, which provides little option for outlook.

Diversity is also provided at the apartment scale, with open-plan living areas allowing various furniture layouts. Also, for two sides of the block, half of the apartments have bedrooms facing the courtyard and half face the street. While this is largely a consequence of the efficient apartment layout, an argument could be made regarding preference diversity for occupants.

\section{COHERENT FORM WITH POSITIVE IMPACT ON URBAN CONTEXT}

The case-study development exhibited a coherent urban form, with the entire block interpreted as one entity. Despite the different identities on alternating streetfacades, coherence is maintained using aesthetic design strategies. These strategies ensure that the block can exhibit different identities in response to orientation or circulation changes, without alluding to the development being separate buildings. The 
same can be said for identity-shifts for the ground-floor retail establishments and the penthouse apartments, which arguably help to reduce the impact of the developments' size on the immediate context.

Having a positive impact on the urban context is difficult to measure. This is especially true for the selected site which is located on a very underdeveloped city block. The block is likely to undergo future development, which will provide a shift in the identity and character of the urban context. While it is hard to predict how this might occur, a segment of this Thesis was dedicated to providing a potential masterplan for the block. This ensures that the design case-study is positively impacting its current context as well as the potential future context which has been speculated.

In an effort to have a positive impact on the current context, which will consequently benefit the future context, the design conforms to contextual restrictions such as overall building height, minimum ground floor height, and being less intrusive on the surrounding buildings. The South-west corner of the block is lowered to reduce shading on the current residential complex to the south of the design, thereby having a positive impact on the urban context.

\section{EVENTFUL BUILDING FAÇADES WITH SENSE OF IDENTITY AND CHARACTER}

As with the developments' impact on the urban context, the success of architectural aesthetic is very difficult to determine. Since it is highly subjective, there is no quantitative measurement for success. Therefore, rather than aiming to achieve something with no definitive outcome, the design case-study aimed to actively avoid an unsuccessful building aesthetic synonymous with traditional EPB housing; façade monotony.
Monotonous facades produce buildings that are uninteresting and fatiguing due to repeating elements. Design strategies from a specific study on successful residential building facades were used to inform the EPB development design to avoid façade 
monotony. This, paired with careful

consideration of façade materiality has

provided a design with building facades that

are undoubtedly interesting and eventful.

Another downfall of EPB developments

and other high-density residential buildings

is that the building occupants can feel that

their apartments lose the sense of identity or

character that would often be experienced

with a suburban housing alternative.

Strategies were applied to the design casestudy in an attempt to visually divide the building into different sections. The building occupants can then identify with these smaller sections and feel a greater sense of address within the development. The outcome of this was particularly successful, using façade materiality to further identify the different apartment 'clusters'. This could be improved with a more formal relationship between the vertical cores and the apartments they serve. However, for the most part the building façades are eventful, interesting and exhibit distinct identities for the various apartment clusters throughout the block.

\section{GREATER PERCEPTION OF SAFETY AND SPACIOUSNESS}

The research identified that New Zealand families perceive current high-density options to lack safety and spaciousness. Since perception is attached to the opinion of individuals, it is highly subjective and therefore not possible to measure quantifiably. Judgements could only be made using a comprehensive survey of occupant's opinions on existing spaces. This said, integration of specific strategies can provide a suitable basis for evaluation. Increased ceiling height, open-plan living spaces and large circulation landings are a few examples of strategies used in the design case-study that have proven to be successful methods for improving the perception of spaciousness in other designs. This, combined with larger-than-average apartment sizes deems the design casestudy to have successfully improved the perception of spaciousness within the private and semi-private spaces of the development.

A relatively high-level of safety would be perceived in the semi-private spaces of 
the design-case study due to the success of the public/private relationship. The use of multiple circulation cores means that each core is used by less people and is not accessible to the public. The central courtyard also has a high-level of safety when compared to public open space. This is because it is only used by the building occupants, with no public access, and is passively monitored by the many apartments looking into the courtyard. An area where the perception of safety may be lacking is regarding private outdoor space. A lack of safety for private outdoor balconies was an identified concern in the research but was not actively pursued. The inset balconies of the final design may provide a greater perception of safety, however there is no certainty on this. Further research or analysis will be required to properly ascertain the perception of safety for the private outdoor spaces of the design.

\section{LIMITATIONS}

Limitations have already been acknowledged regarding the use of the central courtyard and the specific form of the EPB roof-line to reduce shading of apartments. Other limitations include financial feasibility, corner apartments and consideration of the unitary plan.

\section{FINANCIAL FEASIBILITY}

Since focus was primarily on providing an attractive housing alternative to dissolve the distaste associated with high-density innercity housing, financial feasibility was briefly considered but not actively pursued. Highdensity urban housing appeal was considered from the perspective of improving living conditions for the occupants and having a positive impact on its context, as these areas are where current practice faltered. However, it is important to recognise that regardless of the research outcome, families will not be drawn to inner-city housing if it exceeds the cost of low-density suburban alternatives. Furthering this research with particular emphasis on the approximate cost 
of such a development and the appropriate market value of each apartment will play a pivotal role in determining the success of New Zealand EPB housing.

\section{CORNER APARTMENTS}

Corner apartments still remain an issue in the design case-study, despite acknowledging similar issues with traditional EPB developments. This issue applies more specifically to the two southern corners of the block. The larger apartments provided in these areas are a good size, with corner-aspect and cross ventilation, however there is zero connection with the central courtyard, and they are only exposed to the morning or evening sun depending on the apartment's location (South-East or South-West corner). The single bedroom and studio apartments in these corners are less pleasant, however these are intended to be cheaper, less-premium inner-city housing options. While strategies for potentially solving these corner issues were discovered in the research, these were overruled by more important factors. It appears that this is simply a consistent issue with EPB developments, and must be accepted as a consequence of the housing model. Despite the fact that the living conditions within these corner apartments are not as good as those throughout the rest of the EPB development, they are arguably still better than in alternative high-density housing models.

\section{UNITARY REGULATIONS}

While the design case-study aimed to produce a positive impact on the urban context, the research did not conduct a comprehensive review of the Auckland Unitary plan and apply this to the design case-study. This is because the purpose of the study was to introduce a new housing model to New Zealand, avoiding the mistakes made by current urban housing models. In this context, developing new rules and standards is just as legitimate as conforming to existing ones. Improved living conditions and increased desire for high-density living would provide a convincing argument for revising regulations. This said, the design case-study has produced a development with relatively 
low site coverage and density (measured by plot ratio) as well as overall building height comparable with neighbouring structures. In this sense, the design offers a plausible testcase for EPB housing in central Auckland.

\section{PRIVATE CAR-PARKING}

While not a limitation of the design or research, it is important to acknowledge and justify the decision not to include private car-parking in the final design. While the design of underground parking goes beyond the scope of the research and is not a pertinent aspect of the design, an argument can also be made against its necessity. The site analysis identified that a strong publictransport network exists within Auckland city, with several bus routes going directly past the Northern edge of the urban block, which also has a bus-stop. Those routes not passing the block have bus-stops within just a few blocks walk from the development. This ever-improving bus network, along with the new railway system nearing completion, provides a suitable alternative to private vehicle transport. 


\section{EVALUATION CONCLUSION}

The outcome of the design case-study is a high-density inner-city residential development that offers an attractive housing option to New Zealand families, yet also has a few limitations. A set of design criteria were used to inform and evaluate the design-case study. These criteria performed well within the research, and allowed the successes, drawbacks and limitations of the design to be readily identified. These criteria also provided a solid framework for the adaptation and development of an EPB housing model suited to New Zealand cities. The criteria are concise, coherent and appropriately interrelated; each criterion constructively improved the design outcome. As a result, the design criteria do not require further adaptation or adjustment, i.e. they provide a clear set of research outcomes for informing and assessing EPB development in New Zealand.

The final design was developed using a repertoire of formal and spatial design strategies. These strategies were compiled throughout the research and were used to inform each design decision to meet the requirements of the design criteria. The overall success of the final design suggest that these strategies performed well. They facilitated the development of an attractive housing design in New Zealand cities. A small selection of design strategies were either under-used or not used at all in the design case study. This is not an indictment of the strategies themselves, but rather illustrates the limited scope for application within a single design case-study.

Nevertheless, this limitation in scope means that some strategies have not been tested.

These include:

- Vertical Cores in Corners

- Rooftop Terraces

- Dedicated Communal Areas

- Courtyard Protrusions

- Cladding-Change for Aligned Windows

Further research could be undertaken to test these strategies in a design application. For now, these untested strategies remain in the EPB 'toolbox'. 
CHAPTER SEVEN

\author{
Research Conclusions \\ + Works Cited and Figure List
}




\section{RESEARCH CONCLUSIONS}

The research set out to discover whether a housing model prevalent in Europe's biggest cities could be adapted and applied to a New Zealand context to provide an attractive housing choice within New Zealand cities. With a specific focus on provision for families, a European Perimeter-Block housing development was designed for a selected site in Auckland City, informed by a research-developed set of design strategies and criteria. The evaluation of the final design indicated that EPB housing can certainly be adapted and applied to a New Zealand context to successfully provide an attractive inner-city housing alternative. The main findings of this design-led research come in the form of a concise set of design criteria and a repertoire of design strategies which provide a framework for the successful design of EPB housing in New Zealand. The design criteria were used to inform and evaluate the outcome of the design case-study, and performed admirably within the scope of the research. The successes, flaws and limitations of the design were readily identified, with an overall successful design outcome. The final set of design criteria remains unchanged after the design-case study due to its success. This set can be regarded as the primary outcome of the thesis, promoting the design of attractive EPB housing developments in New Zealand that appeal to family lifestyles. 


\section{FINAL DESIGN CRITERIA}

01. High-Density with High-Amenity

02. Definition and Activation of the Public Street Edge

03. Optimised Natural Light, Ventilation and Outlook

04. Semi-Private Central Courtyard

05. Managed Relationship between Public, Private \& Semi-Private Space

06. Situational Circulation System

07. Design Versatility and Diversity

08. Coherent Form with Positive Impact on Urban Context

09. Eventful Building Façades with Sense of Identity and Character

10. Perception of Safety and Spaciousness 
In addition to the criteria, a repertoire of design strategies provided the means for developing the final design. These strategies informed each design decision to meet the requirements of the design criteria. Considering the success of the final design, as evaluated by the design criteria, the design strategies can be considered to have performed well within the scope of the research. Like the criteria, the final list of design strategies remains unchanged after the design-case study. Despite the acknowledgement of a small list of unused or underutilised strategies, these cannot be ruled out simply because they were not needed in the final design. The final list is a broad, widely-applicable collection of formal and spatial design strategies to usefully inform the design of EPB housing in New Zealand. (Shown on the right)

This broad applicability of the research outcomes would be particularly useful for inner-city housing developers and unitary authorities in New Zealand. The final set of design strategies and criteria can increase the appeal of higher-density housing, particularly for families, which make up most of New Zealand households. This is beneficial for developers, who can use the research findings to attract potential buyers and improve sales, which might encourage others to follow suit. Unitary authorities can also use the research to inform the design of potential government-funded housing projects, in an effort to resolve the current national housing shortage and improve urban growth management.

While it has been concluded that the EPB housing model provides an attractive inner-city housing model for families, little was considered regarding the financial feasibility of these developments. It is to be assumed that housing choice for New Zealand families is largely informed by financial stability, so the appeal of a new attractive housing development could be undone due to a high price tag. A study on the approximate cost of each apartment within the EPB developments would have been beneficial to discerning the success of the final design. Further research into this avenue using the findings of this thesis 


\section{FINAL DESIGN STRATEGIES}

- Linked perimeter of buildings

- Communal central courtyard

- Double-Aspect Apartments

- Multi-core access to units

- Semi-private shared staircases

- Ground-floor retail

- Duplex Apartments

- Vertical Cores in Corners

- Semi-Enclosed Protruding Balcony

- Clustered Apartments

- Dedicated Communal Areas

- Courtyard Protrusions

- Sun-Oriented Apartments

- Sloped/Tiered Roof-line

- Rooftop Terraces

- Vertical Core Visual Character

- Varied Building Heights
- Unique North Face

- Unique Inside/Outside Cladding

- Vertical Protrusions from Facade

- Vertical Core Recession

- Unique Ground Floor

- Unique Corner Identity

- Distinctive Superimposed "Screen"

- Cladding-Change for Aligned Windows

- Slim stairwell facade profile

- Multi-level void space

- Large landing area

- Stairwell external windows

- 'Lightweight'staircase form

- Increased ceiling height

- External windows to habitable spaces

- Secondary private outdoor space

- Locate similar spaces back-to-back 
will be key to confirming the plausibility of an adapted EPB housing model in New Zealand. Further studies could also be conducted using all of the design strategies or a different combination of strategies in a different New Zealand context. This would be a useful way to test the applicability of the research findings in different contextual scenarios.

Along with the above suggestions, a number of limitations were identified in the evaluation of the design case-study which provide opportunities to further the research and reinforce the key findings. These limitations include the success of the central courtyard, sunlight penetration, and perception of safety, to name just a few. To conclusively discern the success of these design aspects, further research will be required using comprehensive studies with input from specialists. For example, a behavioural study of the relationship between New Zealanders and communal open space, with input from a sociologist, would prove beneficial to the design of the central courtyard in a New Zealand context.
The final list of design criteria and repertoire of strategies indicate that there is no definitive model for successful EPB development in New Zealand. The research has shown how various EPB housing examples can achieve similar results using a different selection or combination of design strategies. The selected site for the designcase study was specifically chosen so that the design would have broad applicability to other inner-city New Zealand sites, using similar strategies. The primary function of the design criteria and strategies is to provide a set of guidelines for achieving successful design without being anchored to one particular design or site. 


\section{WORKS CITED}

Ashworth, M. (2018). Where the Heck Do I Put the Barbeque? High-Rise Housing for New Zealanders. Victoria University of Wellington.

Auckland City Council. (n.d.). Auckland Design Manual. Retrieved from http://www. aucklanddesignmanual.co.nz/

Bentley, I. (1985). Responsive environments: A manual for designers. Amsterdam: Elsevier.

Bryson, K. (2017). The New Zealand Housing Preferences Survey: Attitudes towards medium-density housing. New Zealand: BRANZ Ltd.

Carroll, P., Witten, K., \& Kearns, R. (2011). Housing Intensification in Auckland, New Zealand: Implications for Children and Families. Housing Studies, 26(3), 353-367.

Diehl, S. (1981). Perimeter planning: An old design approach for a new urban housing design : with special reference to Central European housing. Retrieved from http:// digitool.library.mcgill.ca/R?func=dbin-jump-full\&object_id=62666

Edwards (2006) Courtyard Housing, Past, Present, Future. Retrieved from https://www. academia.edu/12290858/Edwards_2006_Courtyard_Housing_Past_Present_Future

Gropius, W. (1956). Scope of total architecture. London; Allen \& Unwin.

Heath, T., Oc, T., \& Tiesdell, S. (2010). Public places - urban spaces : The dimensions of urban design. Retrieved from https://ebookcentral-proquest-com.helicon.vuw.ac.nz 
Kiwibank. (2019). Property Insights: New Zealand's housing shortage is getting worse, not better. Retrieved from https://inner.kiwi/commentary/property-insights-newzealands-housing-shortage-getting-worse-not-better/

Leupen, B. (2011). Housing design: A manual / Bernard Leupen \& Harald Mooij ; with contributions by Rudy Uytenhaak ... [et al] ; [drawings, Mohamad Ali Sedighi, Alexander van Zweeden ; translation, Pierre Bouvier, Laura Vroomen]. (2nd rev. English language ed..). Rotterdam: NAi Publishers.

Lewis, S. (2005). Front to back : A design agenda for urban housing. Retrieved from https://ebookcentral-proquest-com.helicon.vuw.ac.nz

North Shore City Council. (2006). Good Solutions Guide for Apartments. Retrieved from https://www.dropbox.com/s/ukzouyfhkkdtimi/ApartGuide_HiRes.pdf?dl=0

Sonne, W. (2009). Dwelling in the metropolis: Reformed urban blocks $1890-1940$ as a model for the sustainable compact city. Progress in Planning, 72(2), 53-149. https://doi. org/10.1016/j.progress.2009.06.001

The New Zealand Government. (2018). A Stocktake of New Zealand's Housing. Retrieved from https://www.beehive.govt.nz/sites/default/files/2018-02/A\%20 Stocktake\%20Of\%20New\%20Zealand\%27s\%20Housing.pdf

Witten, K., \& Carroll, P. (2011). Intensification, housing affordability and families: learning from the Auckland CBD. Growth misconduct Wellington, New Zealand: NZ Centre for Sustainable Cities, University of Otago. 


\section{FIGURE LIST}

\section{CHAPTER 1 - THESIS INTRODUCTION, METHODOLOGY, AND FEASIBILITY OF RESEARCH QUESTION}

Figure 1.00 Aerial image of Munich from helicopter.

Royalty free standard licence by Adobe Stock.

Author: Wolfgang Hauke / stock.adobe.com. File \#: 232762964

Figure 1.01 Research Methodology Diagram

Image by Author.

Figure 1.02 Aerial Images of NZ buildings that resemble EPB's

Image by Author.

Image adapted from Google Maps.

Figure 1.03 Aerial Images of NZ buildings that resemble EPB's

Image by Author.

Image adapted from Google Maps.

\section{CHAPTER 2 - BACKGROUND INFORMATION ON PERIMETER-BLOCKS AND NEW ZEALAND URBAN LIVING}

Figure 2.00 A view of Copenhagen (København) city center as seen from The Church of Our Saviour (Vor Frelsers Kirke).

Royalty free standard licence by Adobe Stock.

Author: Anders Haukland / stock.adobe.com. File \#: 329384814

Figure 2.01 Indicative isometric of tenement-style EPB housing. Image by Author.

Figure 2.02 Indicative section through EPB tenement housing Image by Author.

Figure 2.03 Access to apartments via semi-private shared stairwell Image by Author.

Figure 2.04 Indicative access to and from apartments (Plan view) Image by Author.

Figure 2.05 High density apartment housing in Auckland NZ Image by Author.

Figure 2.06 BRANZ survey data on "Willingness to live in housing types 
in the future".

Image from Bryson, K. (2017). The New Zealand Housing Preferences

Survey: Attitudes towards medium-density housing (p. 19). New

Zealand: BRANZ Ltd.

\section{CHAPTER 3 - CONTEMPORARY EPB BODY OF WORK STUDY + APARTMENT ATTRIBUTE STUDIES}

Figure 3.00 Beautiful view of the 8 Tallet building captured in

Copenhagen, Denmark.

Royalty free standard licence by Adobe Stock.

Author: Wirestock / stock.adobe.com. File \#: 306385601

Figure 3.01 Photograph of contemporary EPB development, 79\&Park

by Bjarke Ingels Group.

Retrieved from https://big.dk/wp-content/uploads/2018/11/BIG

ST7_79th-and-Park_Image-by-Laurian-Ghinitoiu_01-1351x900.jpg

Figure 3.02a 3D isometric of 8-House by Bjarke Ingels Group.

Image by Author.

Adapted from https://big.dk/wp-content/uploads/2018/09/8h-diagram-

by-big-13.jpg

Figure 3.02b Floor plan of 8-House by Bjarke Ingels Group. Scale 1:500@ A4.

Image by Author.

Adapted from https://architizer- prod.imgix.net/mediadata/

projects/372010/5d658994.jpg

Figure 3.03a 3D isometric of VIA 57 West by Bjarke Ingels Group.

Image by Author.

Adapted from https://big.dk/wp-content/uploads/2018/09/VIA_

Diagram20by20BIG20-20Bjarke20Ingels20Group_13.jpg

Figure 3.03b Floor plan of VIA 57 West by Bjarke Ingels Group. Scale 1:300 @ A4.

Image by Author.

Adapted from https://averyreview.com/content/3-issues/21-20/4-how-

to-judge-an-icon/kubey-plan.jpg 
Figure 3.04a 3D isometric of Sluishuis (Lock House) by Bjarke Ingels Group.

Image by Author.

Adapted from https://big.dk/wp-content/uploads/2018/09/sluis___ 4

diagrams_page_4-1600x900.jpg

Figure 3.04b Floor plan of Sluishuis (Lock House) by Bjarke Ingels Group.

Scale1:300@A4.

Image by Author.

Adapted from https://sluishuis.nl/en/house-finder

Figure 3.05a 3D isometric of Aarhus by Bjarke Ingels Group.

Image by Author.

Adapted from https://big.dk/wp-content/uploads/2018/09/aar-big-

bjarke-ingels-group9-1200x900.jpg

Figure 3.05b Floor plan of Aarhus by Bjarke Ingels Group. Scale 1:300@ A4.

Image by Author.

Adapted from http://aarhusiaarhus.dk/plantegning.asp?posid= [9-248]

Figure 3.06a 3D isometric of 79\&Park by Bjarke Ingels Group.

Image by Author.

Adapted from https://big.dk/wp-content/uploads/2018/11/05_ST7_

Diagram-by-BIG-Bjarke-Ingels-Group-1440x900.jpg

Figure 3.06b Floor plan of 79\&Park by Bjarke Ingels Group. Scale 1:300 @ A4.

Image by Author.

Adapted from https://images.adsttc.com/media/images/5be4/906c/08a5/

e549/e300/04cf/large_jpg/BIG_ST7_79andPark_3rd-Floor-Plan_

Drawing-by-BIG-Bjarke-Ingels-Group.jpg?1541705737

Figure 3.07a 3D isometric of King Toronto by Bjarke Ingels Group.

Image by Author.

Adapted from https://big.dk/wp-content/uploads/2016/02/180906

KING_DIAGRAMS_Page_4-1200x900.jpg

Figure 3.07b Floor plan of King Toronto by Bjarke Ingels Group. Scale 1:300 @ A4.

Image by Author.

Adapted from http://kingtoronto.com/static/flp/pdfs

Figure 3.08a Photograph of Sluseholmen.

Retrieved from https://images.adsttc.com/media/images/5118/decb/ 
b3fc/4bc2/d000/0024/large_jpg/Sluseholmen-2686_red_AST.

jpg?1414516103

Figure 3.08b Floor plan of Sluseholmen. Not to scale.

Image by Author.

Adapted from https://images.adsttc.com/media/images/5118/de5a/

b3fc/4b40/e400/001f/large_jpg/Captura_de_pantalla_2013-02-11_a_

la(s)_8.44.46.jpg?1414516212

Figure 3.09a Photograph of Vivazz, Mieres Social Housing.

Retrieved from https://images.adsttc.com/media/images/51c8/92fb/

b3fc/4bf9/e400/0140/large_jpg/R.HALBE_mieres_social_housing_02_

ZZA.jpg?1372099310

Figure 3.09b Floor plan of Vivazz, Mieres Social Housing. Not to scale.

Image by Author.

Adapted from https://s3images.coroflot.com/user_files/individual_files/

large_604013_sanmu0_0jpwxc2uwmtnpag9uw.jpg

Figure 3.10a Photograph of Tietgen Dormitory.

Retrieved from https://images.adsttc.com/media/images/52f3/041d/

e8e4/4eb1/2300/006a/large_jpg/PORTADA.jpg?1391657969

Figure 3.10b Floor plan of Tietgen Dormitory. Not to scale.

Image by Author.

Adapted from https://images.adsttc.com/media/images/52f3/04d2/

e8e4/4ea3/c500/0073/large_jpg/FLOOR_PLAN.jpg?1391658186

Figure 3.11a Photograph of Harjunkulma Housing Block.

Retrieved from https://images.adsttc.com/media/images/5547/fec9/

e58e/ce50/2900/062b/large_jpg/view_from_V\%C3\%91in\%C3\%

AEnkatu_and_Harjukatu_crossraod_-_Tuomas_Uusheimo.

jpg?1430781604

Figure 3.11b Floor plan of Harjunkulma Housing Block. Not to scale.

Image by Author.

Adapted from https://images.adsttc.com/media/images/5547/ffbe/e58e/

ce50/2900/0631/large_jpg/floor_(3).jpg?1430781851

Figure 3.12a Photograph of De Kameleon.

Retrieved from https://images.adsttc.com/media/images/5031/ 
ad8b/28ba/0d18/3000/0cc5/large_jpg/stringio.jpg?1414252636

Figure 3.12b Floor plan of De Kameleon. Not to scale.

Image by Author.

Adapted from http://www.nlarchitects.nl/slideshow/152?slide=19

Figure 3.13a Photograph of Bayonne Marinadour.

Retrieved from https://images.adsttc.com/media/images/563a/d551/

e58e/ce91/0300/009e/large_jpg/_MG_9783.jpg?1446696260

Figure 3.13b Floor plan of Bayonne Marinadour. Not to scale.

Image by Author.

Adapted from https://images.adsttc.com/media/images/592f/0ed4/

e58e/ce98/ac00/03dc/large_jpg/MAP_100_200_PLANTAS_C

OMUNICACION_03-BAYONNE-1A-202.jpg?1496256206

Figure 3.14a Photograph of Heliopolis Social Housing.

Retrieved from https://images.adsttc.com/media/images/53e8/3d02/

c07a/8038/8e00/00b8/large_jpg/Conjunto_Habitacional_Heliopolis_-_

Foto_23_-_Nelson_Kon_m.jpg?1407728882

Figure 3.14b Floor plan of Heliopolis Social Housing. Not to scale.

Image by Author.

Adapted from https://images.adsttc.com/media/images/53e8/3c75/

c07a/8038/8e00/00b5/large_jpg/PConjunto_Habitacional_Heliopolis_-_

Plantas_acesso_conjuntos_A_e_B_copy.jpg?1407728737

Figure 3.15a Photograph of Block 64.

Retrieved from https://images.adsttc.com/media/images/5017/

c048/28ba/0d49/f500/04c2/large_jpg/stringio.jpg?1421731974

Figure 3.15b Floor plan of Block 64. Not to scale.

Image by Author.

Adapted from https://images.adsttc.com/media/images/5017/

c061/28ba/0d49/f500/04cb/large_jpg/stringio.jpg?1421732024

Figure 3.16a Photograph of Sorenga Block 6.

Retrieved from https://images.adsttc.com/media/images/5821/8e3c/

e58e/cef0/5700/013b/large_jpg/2.jpg?1478594083

Figure 3.16b Floor plan of Sorenga Block 6. Not to scale.

Image by Author. 
Adapted from https://images.adsttc.com/media/images/5821/901a/e58e/ cef0/5700/0140/large_jpg/Plan_S\%C3\%B8renga_Mad_ark. jpg?1478594558

Figure 3.17a Photograph of The "Anker Gardens".

Retrieved from https://images.adsttc.com/media/images/594a/5abc/ b22e/3898/a700/0154/large_jpg/kresing_anker_1705170073.

jpg? 1498045056

Figure 3.17b Floor plan of The "Anker Gardens". Not to scale.

Image by Author.

Adapted from https://images.adsttc.com/media/images/594a/5fb8/

b22e/3898/a700/0161/large_jpg/floor_plan_second_floor.

jpg?1498046370

Figure 3.18a Photograph of The Architect (De Bouwmeester).

Retrieved from https://images.adsttc.com/media/images/5449/cbeb/

e58e/cebb/8100/0286/large_jpg/LEVS_Bouwmeester01.

jpg? 1414122460

Figure 3.18b Floor plan of The Architect (De Bouwmeester). Not to scale.

Image by Author.

Adapted from https://images.adsttc.com/media/images/5449/cf19/e58e/

ce99/9700/0286/large_jpg/LEVS_Bouwmeester-1st_floor.

jpg?1414123278

Figure 3.19a Photograph of Rosteriet.

Retrieved from https://images.adsttc.com/media/images/5a0b/933c/

b22e/3847/6300/045f/large_jpg/Rosteriet_Kod_Arkitekter_02_Photo_

Mans_Berg.jpg?1510708008

Figure 3.19b Floor plan of Rosteriet. Not to scale.

Image by Author.

Adapted from https://images.adsttc.com/media/images/5a0b/9304/

b22e/3847/6300/045e/large_jpg/Kod_Arkitekter_Rosteriet_Floor_

plan_5th_floor.jpg?1510707941

Figure 3.20a Photograph of Lange Eng Collective Living.

Retrieved from https://architizer-prod.imgix.net/

media/1431681446296DMA-LS_LangeEng_0103_H._Cop.jpg 
Figure 3.20b Floor plan of Lange Eng Collective Living. Not to scale.

Image by Author.

Adapted from http://www.nabofellesskap.no/wp-content/

uploads/2017/11/Lange-Eng_PollenNo2.pdf

Figure 3.21a Photograph of The Whale.

Retrieved from https://cie.nl/image/2018/6/8/9532_whale_001.

jpg\%28mediaclass-large.3682f12c8a25e7ddf527c764f460f59b88c

7c810\%29.jpg

Figure 3.21b Floor plan of The Whale. Not to scale.

Image by Author.

Adapted from https://architizer-prod.imgix.net/mediadata/

projects/452011/ffd567ca.jpg

Figure 3.22a Photograph of 46 Social Houses.

Retrieved from https://images.adsttc.com/media/images/5164/c5fa/

b3fc/4b92/fe00/003d/large_jpg/11_gabriel_verd_mairena.

jpg?1365558775

Figure 3.22b Floor plan of 46 Social Houses. Not to scale.

Image by Author.

Adapted from https://images.adsttc.com/media/images/5168/06cd/

b3fc/4bf5/7e00/008c/large_jpg/04_gabriel_verd_PLANTA_TIPO_2. jpg?1365771978

Figure 3.23a Photograph of Le Bois Habite.

Retrieved from https://images.adsttc.com/media/images/5369/8dc1/

c07a/806b/9b00/010a/large_jpg/031E9457-\%EF\%BF\%BDphoto_S_

Chalmeau_non_libre_de_droits.jpg?1399426478

Figure 3.23b Floor plan of Le Bois Habite. Not to scale.

Image by Author.

Adapted from https://images.adsttc.com/media/images/5369/8e48/

c07a/8029/2e00/012d/large_jpg/floor.jpg?1399426619

Figure 3.24a Photograph of Tower Block Hybrid.

Retrieved from https://images.adsttc.com/media/images/577c/f02b/

e58e/ce5d/3100/0121/large_jpg/Myoung_Sik_Kim_005.

jpg?1467805727 
Figure 3.24b Floor plan of Tower Block Hybrid. Not to scale.

Image by Author.

Adapted from https://images.adsttc.com/media/images/577c/f06a/e58e/ ce5d/3100/0123/large_jpg/24KO_A3_BLOCK_D.jpg?1467805788

Figure 3.25a Photograph of Armstrong Place Housing.

Retrieved from https://images.adsttc.com/media/images/5014/

ff71/28ba/0d58/2800/10ce/large_jpg/stringio.jpg?1414043303

Figure 3.25b Floor plan of Armstrong Place Housing. Not to scale.

Image by Author.

Adapted from https://images.adsttc.com/media/images/5014/

ff54/28ba/0d58/2800/10c9/large_jpg/stringio.jpg?1414043353

Figure 3.26a Photograph of Potrero 1010.

Retrieved from https://architizer-prod.imgix.net/media/mediadata/ uploads/150843966679020311_Potrero1010_BruceDamonte_31.jpg

Figure 3.26b Floor plan of Potrero 1010. Not to scale.

Image by Author.

Adapted from https://architizer-prod.imgix.net/media/mediadata/ uploads/150844148643920311-daggett-level-2-plan-hq.jpg

Figure 3.27a Photograph of Carabanchel Social Housing.

Retrieved from https://images.adsttc.com/media/

images/5007/150b/28ba/0d41/4800/0eb8/large_jpg/stringio.

jpg?1414028421

Figure 3.27b Floor plan of Carabanchel Social Housing. Not to scale.

Image by Author.

Adapted from https://images.adsttc.com/media/

images/5007/14ef/28ba/0d41/4800/0eb3/large_jpg/stringio.

jpg?1414028449

Figure 3.28a Photograph of Longnan Garden Social Housing.

Retrieved from https://images.adsttc.com/media/images/5953/bb47/

b22e/38a8/8b00/01c4/large_jpg/38.jpg?1498659639

Figure 3.28b Floor plan of Longnan Garden Social Housing. Not to scale.

Image by Author.

Adapted from https://images.adsttc.com/media/images/5953/b958/ 
b22e/38f6/7d00/026d/large_jpg/47.jpg?1498659147

Figure 3.29a Photograph of Axis Building.

Retrieved from https://images.adsttc.com/media/

images/5cd1/9e81/284d/d17d/3100/02b3/large_jpg/01_dhk_Axis_

DaveSouthwood.jpg?1557241436

Figure 3.29b Floor plan of Axis Building. Not to scale.

Image by Author.

Adapted from https://images.adsttc.com/media/images/5cd1/9c7b/284d/

d17d/3100/02ab/large_jpg/06_dhk_Axis_plans_level_3.

jpg?1557240920

Figure 3.30a Photograph of Student Residence ULisboa.

Retrieved from https://images.adsttc.com/media/images/5486/

f128/e58e/cef0/ed00/00f5/large_jpg/CVDB-Residencia-Estudantes-ULImg02.jpg?1418129699

Figure 3.30b Floor plan of Student Residence ULisboa. Not to scale.

Image by Author.

Adapted from http://www.cvdbarquitectos.com/new-gallery-87/

hgi3jpce7ov82fj16r1sc9b7rmimd8

Figure 3.31a Photograph of "Casanova" Social Housing.

Retrieved from https://images.adsttc.com/media/images/51c3/2637/

b3fc/4bc6/cb00/0086/large_jpg/3.jpg?1371743793

Figure 3.31b Floor plan of "Casanova" Social Housing. Not to scale.

Image by Author.

Adapted from http://premiobaffarivolta.ordinearchitetti.mi.it/wp-

content/uploads/2013/07/02_PIANTA-PIANO-TIPO-1-200.jpg

Figure 3.32 Diagram illustrating "Duplex Apartments" design strategy.

Image by Author.

Figure 3.33 Diagram illustrating "Vertical Cores in Corners" design strategy.

Image by Author.

Figure 3.34 Diagram illustrating "Semi-Enclosed Balcony" design strategy.

Image by Author.

Figure 3.35 Diagram illustrating "Protruding Balcony" design strategy.

Image by Author. 
Figure 3.36 Diagram illustrating "Strip Balcony" design strategy.

Image by Author.

Figure 3.37 Diagrams illustrating "Opening in Block Perimeter" design strategy.

Image by Author.

Figure 3.38 Diagram illustrating "Clustered Apartments" design strategy.

Image by Author.

Figure 3.39 Diagram illustrating "Dedicated Communal Areas" design strategy. Image by Author.

Figure 3.40 Diagrams illustrating "Protrusion into Courtyard" design strategy. Image by Author.

Figure 3.41 Diagram illustrating "Sun-Oriented Apartments" design strategy. Image by Author.

Figure 3.42 Diagrams illustrating "Sloped/Tiered Roof-Line" design strategy. Image by Author.

Figure 3.43 Diagram illustrating "Rooftop Terraces" design strategy. Image by Author.

Figure 3.44 Diagram illustrating "Elevated Courtyard" design strategy. Image by Author.

Figure 3.45 Diagram illustrating "Saw-tooth Facades" design strategy. Image by Author.

Figure 3.46 Diagram illustrating "Modular Pixel Form" design strategy. Image by Author.

Figure 3.47 Diagram illustrating "Vertical Core Visual Character" design strategy. Image by Author.

Figure 3.48 Diagrams illustrating "Varied Building Heights" design strategy. Image by Author.

Figure 3.49 Diagram illustrating "Unique North Face" design strategy. Image by Author.

Figure 3.50 Diagram illustrating "Inside/Outside Cladding Change" design strategy. Image by Author.

Figure 3.51 Diagram illustrating "Unique Penthouse Identity" design strategy. Image by Author.

Figure 3.53 Photograph of Potrero 1010 elevation by David Baker Architects. 
Retrieved from https://architizer-prod.imgix.net/media/mediadata/

uploads/150843931138920311_Potrero1010_BruceDamonte_17.jpg

Figure 3.54 Physical model illustrating "Bedrooms Protrude from Façade" Design

Strategy.

Image by Author.

Figure 3.55 Physical model illustrating "Vertical Core Recession" Design Strategy. Image by Author.

Figure 3.56 Physical model illustrating "Unique Ground Floor” Design Strategy. Image by Author.

Figure 3.57 Physical model illustrating "Unique Corner Identity” Design Strategy. Image by Author.

Figure 3.58 Physical model illustrating "Corridor Extended to Facade" Design Strategy.

Image by Author.

Figure 3.59 Physical model illustrating "Void for Communal Areas" Design

Strategy.

Image by Author.

Figure 3.60 Physical model illustrating "Distinctive Superimposed Screen" Design Strategy.

Image by Author.

Figure 3.61 Physical model illustrating "Material Change for Aligned Windows"

Design Strategy.

Image by Author.

Figure 3.62a 3D diagram of "Exterior Attached" staircase design test.

Image by Author.

Figure 3.62b Plan-view diagram illustrating the connection of the "Exterior

Attached" staircase to the building, and the form of structural support.

Image by Author.

Figure 3.63a 3D diagram of "Wrap-Around" staircase design test.

Image by Author.

Figure 3.63b Plan-view diagram illustrating the connection of the "Wrap-Around" staircase to the building, and the form of structural support.

Image by Author. 
Figure 3.64a 3D diagram of "Separated / Centre Wall" staircase design test.

Image by Author.

Figure 3.64b Plan-view diagram illustrating the connection of the "Separated / Centre Wall" staircase to the building, and the form of structural support.

Image by Author.

Figure 3.65a 3D diagram of "Spiral" staircase design test.

Image by Author.

Figure 3.65b Plan-view diagram illustrating the connection of the "Spiral" staircase to the building, and the form of structural support.

Image by Author.

Figure 3.66a 3D diagram of "Slim Protrusion" staircase design test.

Image by Author.

Figure 3.66b Plan-view diagram illustrating the connection of the "Slim Protrusion" staircase to the building, and the form of structural support.

Image by Author.

Figure 3.67a 3D diagram of "In \& Out" staircase design test.

Image by Author.

Figure 3.67b Plan-view diagram illustrating the connection of the "In \& Out"

staircase to the building, and the form of structural support.

Image by Author.

Figure 3.68a 3D diagram of "Cantilevered" staircase design test.

Image by Author.

Figure 3.68b Plan-view diagram illustrating the connection of the "Cantilevered" staircase to the building, and the form of structural support.

Image by Author.

Figure 3.69a 3D diagram of "Scissor-Stairs" staircase design test.

Image by Author.

Figure $3.69 \mathrm{~b}$ Plan-view diagram illustrating the connection of the "Scissor-Stairs" staircase to the building, and the form of structural support.

Image by Author. 
CHAPTER 4 - BEST-PRACTICE URBAN RESIDENTIAL DESIGN + AVAILABILITY OF INNER-CITY NZ SITES

Figure 4.00 Auckland, New Zealand - August 26, 2018: Aerial view of cityscape at sunset.

Royalty free standard licence by Adobe Stock.

Author: jovannig / stock.adobe.com. File \#: 225464110

Figure 4.01 Waterfront apartments in Auckland.

Royalty free standard licence by Adobe Stock.

Author: CJPhoto / stock.adobe.com. File \#: 3740269

Figure 4.02 Diagram illustrating "Diverse Apartment Selection" best-practice apartment design principle.

Image by Author.

Figure 4.03 Diagram illustrating "Increased Ceiling Height" best-practice apartment design principle.

Image by Author.

Figure 4.04 Diagram illustrating "Habitable Rooms on External Walls" best-practice design principle.

Image by Author.

Figure 4.05 Diagram illustrating "Acoustic Privacy" best-practice design principle. Image by Author.

Figure 4.06 Diagram illustrating "Cross-Ventilation" best-practice design principle. Image by Author.

Figure 4.07 Diagram illustrating "Secondary Private Outdoor Space" best-practice design principle.

Image by Author.

Figure 4.08 Photograph of Auckland Sky Tower.

Image by Author.

Figure 4.09 Map of New Zealand with the three key cities identified.

Image by Author.

Adapted from https://www.virtualoceania.net/newzealand/maps/reliefbig.jpg

Figure 4.10 Aerial photography of Auckland City with potential sites identified. 
Image by Author.

Adapted from Auckland Council GeoMaps mapping service.

Figure 4.11 Auckland City potential site footprints. Scale 1:5000@ A4.

Image by Author.

Figure 4.12 Aerial photography of average Auckland site with site footprint.

Image by Author.

Adapted from Auckland Council GeoMaps mapping service.

Figure 4.13 Aerial photography of Wellington City with potential sites identified.

Image by Author.

Adapted from Wellington City Council LocalMaps mapping service.

Figure 4.14 Wellington City potential site footprints. Scale 1:5000@ A4.

Image by Author.

Figure 4.15 Aerial photography of average Wellington site with site footprint.

Image by Author.

Adapted from Wellington City Council LocalMaps mapping service.

Figure 4.16 Aerial photography of Christchurch City with potential sites identified.

Image by Author.

Adapted from Christchurch City CanterburyMaps map viewer.

Figure 4.17 Christchurch City potential site footprints. Scale 1:5000@ A4.

Image by Author.

Figure 4.18 Aerial photography of average Christchurch site with site footprint.

Image by Author.

Adapted from Christchurch City CanterburyMaps map viewer.

Figure 4.19 Graph of potential site areas versus proximity to city centre.'

Image by Author.

\section{CHAPTER 5 - ADAPTED DESIGN STRATEGIES AND CRITERIA + CHOSEN SITE SHOWCASE}

Figure 5.00 Photograph of selected site with new apartment developments in the background.

Image by Author.

Figure 5.01 Image illustrating the adaption of EPB housing for New Zealand. 
Image by Author.

Adapted from New Zealand map of black contour curves of vector illustration.

Royalty free standard licence by Adobe Stock.

Author: elenvd / stock.adobe.com. File \#: 168436946

Figure 5.02 Photograph of selected site.

Image by Author.

Figure 5.03 Zoomed-out aerial photograph identifying location of selected site within Central Auckland City.

Image by Author.

Adapted from Auckland Council GeoMaps mapping service.

Figure 5.04 Aerial photograph identifying location of selected site within surrounding context.

Image by Author.

Adapted from Auckland Council GeoMaps mapping service.

Figure 5.05 Zoomed-in aerial photograph identifying footprint and dimensions of selected site.

Image by Author.

Adapted from Auckland Council GeoMaps mapping service.

Figure 5.06 Aerial site analysis of built form around the selected site.

Image by Author.

Adapted from Auckland Council GeoMaps mapping service.

Figure 5.07 Aerial site analysis of infrastructure (roads) around the selected site.

Image by Author.

Adapted from Auckland Council GeoMaps mapping service.

Figure 5.08 Aerial site analysis of Bus Transport Routes around the selected site.

Image by Author.

Adapted from Auckland Council GeoMaps mapping service.

Figure 5.09 Aerial site analysis locating educational establishments and public open space around the selected site.

Image by Author.

Adapted from Auckland Council GeoMaps mapping service.

Figure 5.10 Aerial site analysis of sun paths at different times of the year on the 
selected site.

Image by Author.

Adapted from Auckland Council GeoMaps mapping service.

Figure 5.11 Aerial site analysis locating residential buildings around the selected site.

Image by Author.

Adapted from Auckland Council GeoMaps mapping service.

Figure 5.12 Aerial site analysis of land topography on and around the selected site. Image by Author.

Adapted from Auckland Council GeoMaps mapping service.

Figure 5.13 Aerial site analysis of Unitary Height Restrictions around the selected site.

Image by Author.

Adapted from Auckland Council GeoMaps mapping service.

Figure 5.14 Aerial site photography indicating the perimeter of the urban block in which the selected site is situated. Scale1:2000@A4.

Image by Author.

Adapted from Auckland Council GeoMaps mapping service.

Figure 5.15 Proposed Master-Plan for the future redevelopment of the urban block in which the selected site is located.

Image by Author.

Adapted from Auckland Council GeoMaps mapping service.

Figure 5.16 Photograph of selected site.

Image by Author.

Figure 5.17 Photograph of selected site.

Image by Author.

Figure 5.18 Photograph of selected site.

Image by Author.

CHAPTER 6 - DESIGN CASE-STUDY + EVALUATION OF FINAL DESIGN

Figure 6.00 Auckland, New Zealand - May 24, 2017: Panoramic aerial view of the Auckland city downtown. 
Royalty free standard licence by Adobe Stock.

Author: Natalia / stock.adobe.com. File \#: 163729187

Figure 6.01 Final design superimposed onto selected site.

Image by Author.

Figure 6.02 Summary of design iterations and development.

Image by Author.

Figure 6.03 3D Isometric of Final design (Looking South-East).

Image by Author.

Figure 6.04 3D Isometric of Final design (Looking North-West).

Image by Author.

Figure 6.05 3D Isometric of Final design (Looking South-West).

Image by Author.

Figure 6.06 3D Isometric of Final design (Looking North-East).

Image by Author.

Figure 6.07 Diagrams illustrating composition of the building form.

Image by Author

Figure 6.08 Diagrams illustrating composition of the building form.

Image by Author.

Figure 6.09 Proposed Master-Plan for the future redevelopment of the urban block in which the selected site is located, including the final design.

Image by Author.

Figure 6.10 Analysis of active street edges around the final design.

Image by Author.

Figure 6.11 Analysis of traffic and pedestrian paths around the final design.

Image by Author.

Figure 6.12 Plan of the central courtyard for the final design. Relative entrance

locations and elevations indicated.

Image by Author.

Figure 6.13 Diagram illustrating apartment assembly for the final design, looking

South-East.

Image by Author.

Figure 6.14 Diagram illustrating apartment assembly for the final design, looking North-West. 
Image by Author.

Figure 6.15 Level 0 Apartments Floor Plan. (With retail and commercial spaces cropped out)

Scale $1: 500 @$ A4

Image by Author.

Figure 6.16 Level 1 Floor Plan. Scale 1 :500@ A4.

Image by Author.

Figure 6.17 Level 2 Floor Plan. Scale 1:500@ A4.

Image by Author.

Figure 6.18 Apartment Cluster type A. Bedroom level and Living level.

Scale1:250@A4.

Image by Author.

Figure 6.19 Apartment Cluster type A 3D exploded view.

Image by Author.

Figure 6.20 Apartment Cluster type B. Bedroom level and living level.

Scale1:250@A4.

Image by Author.

Figure 6.21 Apartment Cluster type B 3D exploded view.

Image by Author.

Figure 6.22 Apartment Cluster type C. 1-Bedrooms below, 2-bedrooms above.

Scale1:250@A4.

Image by Author.

Figure 6.23 Apartment Cluster type C 3D exploded view.

Image by Author.

Figure 6.24 Apartment Cluster type D. Scale 1:250@ A4.

Image by Author.

Figure 6.25 Apartment Cluster type D 3D exploded view.

Image by Author.

Figure 6.26 3D diagram illustrating the varying levels of privacy throughout the development.

Image by Author.

Figure 6.27 West elevation of EPB development.

Image by Author. 
Figure 6.28 South elevation of EPB development.

Image by Author.

Figure 6.29 East elevation of EPB development.

Image by Author.

Figure 6.30 North elevation of EPB development.

Image by Author.

Figure 6.31 Cross-Section of the EPB development, looking South.

Image by Author.

Figure 6.32 Cross-Section of the EPB development, looking East.

Image by Author.

Figure 6.33 Aerial perspective of EPB development in current context of selected site.

Image by Author.

Figure 6.34 Central courtyard perspective from apartment balcony.

Image by Author.

Figure 6.35 View of EPB development in potential future context, looking South-West.

Image by Author.

Figure 6.36 View of EPB development in potential future context, looking South-East.

Image by Author.

Figure 6.37 Simplified 3D model of final case-study design.

Image by Author. 
